\title{
LOS ESTADIOS LARVARIOS DE LOS CRISÓPIDOS IBÉRICOS (INSECTA, NEUROPTERA, CHRYSOPIDAE), NUEVOS ELEMENTOS SOBRE LA MORFOLOGÍA LARVARIA APLICABLES A LA SISTEMÁTICA DE LA FAMILIA
}

\author{
V. J. Monserrat* \& L. M. Díaz-Aranda**
}

\section{RESUMEN}

V. J. Monserrat \& L. M. Díaz-Aranda. 2012. Los estadios larvarios de los Crisópidos ibéricos (Insecta, Neuroptera, Chrysopidae), nuevos elementos sobre la morfología larvaria aplicables a la sistemática de la familia. Grael/sia, 68(1): 31-158.

Tras una breve introducción sobre la evolución en el conocimiento de las fases juveniles de la familia Chrysopidae, sobre su biología, comportamiento y características morfológicas más interesantes, se realiza una revisión de los estadios preimaginales de las especies ibéricas (38 de las 49 especies, pertenecientes a los 13 géneros ibéricos), tanto en base a la información existente en la bibliografía, como en las descripciones realizadas por los autores tras la recolección de hembras grávidas, obtención de las puestas y cultivo de sus larvas. Se ofrece nueva información sobre la biología, comportamiento, aspecto, pigmentación y quetotaxia detallada de la larva neonata y de la larva madura de estas 38 especies, y se describen por primera vez los estadios preimaginales de Chrysopa dorsalis, Nineta guadarramensis, Suarius iberiensis e Italochrysa stigmatica. Se proponen una serie de caracteres morfológicos especialmente válidos para la diferenciación de las larvas ibéricas a nivel de subfamilia, tribu, género y especie. A nivel de subfamilia: morfología de la antena y número de sensilas del último segmento del palpo labial. A nivel de género: quetotaxia cefálica, presencia o ausencia de una hilera transversal de setas en el mesonoto, número de tubérculos dorsales y laterodorsales en el abdomen, morfología y desarrollo de los tubérculos laterales del tórax y morfología de las setas. Y a nivel de especie: pigmentación cefálica, morfología de la uña, forma del espiráculo mesotorácico, del esclerito laterodorsal protoráci$\mathrm{co}$, número y longitud de las setas de los tubérculos laterales y laterodorsales del abdomen, número de setas de la hilera posteroventral del segmento abdominal $\mathbf{X}$ y coloración tegumentaria. En base a estos caracteres, se ofrece una clave de subfamilias, géneros y especies ibéricas que posibilitan su identificación.

Comprobamos que el empleo de caracteres morfológicos larvarios apoya, de forma general, la actual clasificación basada en los imagos, aunque el estudio de la morfología larvaria de todas estas especies, nos ha permitido detectar una serie de anomalías que cuestionan la validez o la identidad taxonómica de lo que hasta ahora entendíamos sobre algunas especies ibéricas (Pseudomallada prasinus, Chrysopa nigricostata, Chrysopa phyllochroma y Chrysopa viridana). A nivel global, el desconocimiento general sobre la morfología larvaria de muchos géneros de esta familia limita, por ahora, la utilización de caracteres morfológicos larvarios en estudios taxonómicos y sistemáticos generales, haciéndose necesaria la realización de descripciones más detalladas y completas en un mayor número de especies de un mayor número de géneros/tribus/subfamilias a nivel mundial.

* Dept. de Zoología y Antropología Física, Universidad Complutense, E-28040 Madrid. E-mail: artmad@bio.ucm.es ** Dept. de Biología Animal, Universidad de Alcalá de Henares, E-28014 Madrid. E-mail: luisam.diaz@uah.es 
Como complemento a este estudio, y tras más de treinta años de toma de nuevos datos, se recopila y actualiza la información existente sobre la biología, preferencia de sustrato vegetal, distribución geográfica, altitudinal y fenológica de las especies de crisopas ibéricas.

Palabras clave: Insecta; Neuroptera; Chrysopidae; Estadios juveniles; Huevo; Larva; Península Ibérica; Faunística; Morfología.

\section{ABSTRACT}

V. J. Monserrat \& L. M. Díaz-Aranda. 2012. Larval stages of the Iberian green-lacewings (Insecta, Neuroptera, Chrysopidae), new data on larval morphology applicable to the family systematics. Grael/sia, 68(1): 31-158 (in Spanish).

After a brief historical introduction to the knowledge of chrysopid immature stages, their biology, behaviour, and especially interesting morphological features, we review the preimaginal stages of the lberian species (38 of the 49 lberian species, belonging to the $13 \mathrm{lberian}$ genera). Our presentation includes information from the literature and new descriptions by the authors after collecting gravid females, obtaining eggs and rearing larvae. Specifically, it provides new information on the biology, behavior, appearance, pigmentation and detailed chaetotaxy of the neonate and mature larvae of these 38 species, and describes for the first time the preimaginal stages of Chrysopa dorsalis, Nineta guadarramensis, Suarius iberiensis and Italochrysa stigmatica. We propose a series of morphological characters that differentiate the Iberian larvae at subfamilial, tribal, generic, and species levels. At the subfamilial level: morphology of the antenna and sensilla number of the last segment of labial palp. At the generic level: cephalic chaetotaxy, presence or absence of a transverse row of setae on the mesonotum, number of dorsal and laterodorsal tubercles on the abdomen, morphology and size of the lateral tubercles of the thorax, and morphology of the setae. And at the species level: cephalic pigmentation, morphology of the claw, shape of the mesothoracic spiracle, shape of the prothoracic laterodorsal sclerite, number and length of the setae on lateral and laterodorsal abdominal tubercles, number of setae of the posteroventral row on the tenth abdominal segment, and integumentary coloration. Based on these characters, the article offers a key that enables the identification of subfamilies, genera and lberian species of Chrysopidae.

We found that the use of larval morphological characters supports, in general, the current classification based on imagoes, but the study of the larval morphology of these species, has allowed us to detect a number of anomalies that question the validity or the taxonomic identity of what, until now, we understood about some Iberian species (Pseudomallada prasinus, Chrysopa nigricostata, Chrysopa phyllochroma, and Chrysopa viridana). Globally, general ignorance of the larval morphology of many genera in this family limits, for now, the used of larval morphological characters in general taxonomic and systematic studies. Thus we recommend more detailed and complete larval descriptions of a larger number of species in a greater number and broader range of genera, tribes, and subfamilies worldwide.

In addition to the morphological information, this study provides more than thirty years of new biological data on the lberian green-lacewings. In presenting these data, it compiles the existing and new information on the biology, plant substrate preference,and geographic, altitudinal and phenological distributions of Iberian species.

Key Words: Insecta; Neuroptera; Chrysopidae; Preimaginal States; Egg; Larva; Iberian Peninsula; Faunistics; Morphology.

\section{Introducción}

La familia Chrysopidae, Schneider, 1851, presenta una distribución prácticamente cosmopolita, e incluye unas 1200 especies agrupadas en 86 géneros (Brooks \& Barnard, 1990), cifras que han venido incrementándose desde entonces. No sólo se trata de una de las familias del orden Neuroptera más extensas en cuanto al número de especies, sino también de una de las más importantes por su reconocido interés aplicado/económico, pues muchas especies de esta familia son utilizadas en programas de control biológico contra plagas de fitófagos, especialmente áfidos, cóccidos y aleyródidos, ya que sus estadios larvarios, y también algunos de sus imagos, depredan activamente sobre estos insectos, 
y por su labor como agentes espontáneos de control o por su empleo y cultivo por el hombre con el fin de combatir estas plagas, es una familia sobradamente conocida, y esto queda reflejado en la abundante bibliografía existente sobre de su cultivo en masa, resistencia a pesticidas, elaboración de dietas artificiales para adultos y larvas, técnicas de cultivo, manipulación y distribución en el campo del material biológico, aplicación en los cultivos de atrayentes artificiales para imagos, aplicación y resultados en distintos tipos de cultivo, etc. Información sobre estos temas ha sido recopilada en Bigler (1984); Tulisalo (1984); Principi (1984); New (1989, 1999), etc., y especialmente por Canard et al. (1984) o McEwen et al. (2001).

La actual clasificación de la familia está basada, exclusivamente, en caracteres de coloración tegumentaria, venación y genitalia de los imagos (Tjeder, 1966; New, 1984, 1989, 2001a, b; Schlüter, 1984; Barnard, 1984; Brooks \& Barnard, 1990; Tauber et al., 2006a, 2008b, etc.). En base a estos caracteres, tres grandes subfamilias son comúnmente reconocidas: Nothochrysinae Navás, 1910 (9 géneros), Apochrysinae Handlirsch, 1908 (11 géneros) y Chrysopinae Schneider, 1851. Esta última subfamilia es la más extensa de todas y está dividida, a su vez, en 4 tribus: Ankylopterygini Navás, 1910 (5 géneros), Belonopterygini Navás, 1913 (15 géneros), Chrysopini Schneider, 1851 (más de 30 géneros) y Leucochrysini Adams, 1978 (7 géneros). Según New $(1984,2001$ b) la clasificación de esta familia es todavía confusa y resalta la necesidad de una revisión que aclare los numerosos problemas taxonómicos y sistemáticos del grupo, anotando la importancia de la realización de estudios complementarios a los efectuados exclusivamente sobre la morfología de los adultos, y sus fases larvarias aportarían mucha información al respecto. A pesar de ello, son relativamente escasos los trabajos que han abordado, como método complementario, el estudio de la morfología de los estadios preimaginales (Hirai, 1957; Tauber, 1969, 1974, 1975; Tauber \& Tauber, 1973; Tauber et al., 1992; Tsukaguchi, 1978; New, 1981, 1983, 1986a, b; Boros, 1984; Gepp, 1983, 1984a, b, 1989; Díaz-Aranda \& Monserrat, 1995; Monserrat et al., 2001; DíazAranda et al., 2001; Aspöck, 1992, 2002; Aspöck \& Aspöck, 2010; Aspöck et al., 2011; Mantoanelli et al., 2011, etc.), obras que ayudan en esta cuestión junto a otros estudios como el análisis de cariotipos, estudios comportamentales, sobre hibridaciones, electroforesis de enzimas, o más recientemente genético-moleculares, de los que hay abundante bibliografía y que resultan de gran utilidad como complemento en los estudios taxonómicos y sistemáticos, contribuyendo a esclarecer la actual clasificación y las relaciones filogenéticas de la familia.

Centrándonos en la morfología de los estadios preimaginales de la familia Chrysopidae, tema objeto del presente estudio, nos encontramos con el problema de que la información existente al respecto es escasa, fragmentaria y dispersa, ya que la atención prestada a estas fases de desarrollo radica, mayoritariamente, en los estudios realizados sobre control biológico (New, 2001b), en particular en especies de los géneros Chrysopa Leach, 1815 y Chrysoperla Steinmann, 1964, y más concretamente Chrysoperla carnea (s.l.) (Stephens, 1836), que últimamente ha despertado un interesante y novedoso debate sobre la compleja y enigmática diversidad taxonómica que encierra.

En relación con el tema que tratamos, la descripción de los estadios larvarios en esta familia tiene un largo historial (Aspöck \& Aspöck, 2007). El primer trabajo en el que se describen los estadios preimaginales de especies de crisópidos fue el realizado por Brauer (1850). Posteriormente, Pariser (1917); Withycombe (1923, 1925); Lacroix (19211925) y Smith $(1921,1922,1924,1929)$ describen los estadios preimaginales de algunas especies de la fauna centroeuropea, inglesa, francesa y norteamericana respectivamente. Más tarde, Killington $(1936,1937)$ publica su monografía sobre los Neurópteros de Inglaterra, realizando la descripción sobre los estadios inmaduros de las especies inglesas. Normalmente estos trabajos, y otros posteriormente realizados, estaban fundamentalmente basados en caracteres de coloración y aportaban escasos datos sobre quetotaxia u otros caracteres morfológicos larvarios en detalle, y hoy resultan francamente testimoniales, incompletos, muy superficiales o poco minuciosos, con muy escasas reseñas al huevo, ovirruptor, larva neonata o quetotaxia, y mayoritariamente atendían a caracteres de la coloración tegumentaria, que presenta cierto grado de variabilidad intraespecífica y en parte desaparece en los ejemplares conservados en alcohol, por lo que es un carácter que únicamente puede ser aplicado sobre ejemplares vivos.

Las primeras descripciones detalladas en las que se incluían caracteres de pigmentación y quetotaxia cefálica, torácica y abdominal fueron las realizadas 
por Principi (1940, 1946, 1947, 1954, 1956a, b), que merecen especial mención, no sólo por las espléndidas ilustraciones (Figs. 2, 3), sino también, por la minuciosidad y detalle con el que son descritos los estadios larvarios, aportando valiosa información sobre la morfología, biología y comportamiento de diversas especies mediterráneas. Desde entonces, la información sobre la morfología de los estadios preimaginales de la familia Chrysopidae ha ido aumentando de forma esporádica y fragmentaria, ya que en la mayoría de las ocasiones los trabajos han ido aportando información al respecto, y describen, con mayor o menor detalle, la morfología larvaria de otras especies, mayoritariamente europeas/paleárticas. Tal es el caso de los trabajos realizados por Crouzel \& Saini (1979); Tsukaguchi (1978, 1979); New (1981, 1983, 1986a, b); Barnard \& Brooks (1984); Canard \& Labrique (1989); Labrique (1990); Labrique \& Canard (1989); Monserrat (1978, 1982a, b, 1984a, 1989); Díaz-Aranda \& Monserrat (1988a, 1990a, b, 1991, 1992, 1994, 1996); Tauber et al. (1992, 1995), Hölzel \& Monserrat (1992), etc., que son de gran utilidad para ampliar el limitado conocimiento existente sobre el tema que tratamos. Por otra parte resultan escasos aquellos trabajos en los que se aborda el estudio integrado de varias especies, bien pertenecientes a un mismo género, o bien a una misma región geográfica, como son los realizados por Muma (1959); Toschi (1965); Tauber (1969, 1974, 1975, 2003, 2004, 2010); Tauber \& Tauber (1973); Tauber \& León (1998, 2001); Tauber et al. (1998, 2000a, b, 2001, 2006a, b, 2008a, b); Monserrat \& Freitas (2005); Freitas (2007); Mantoanelli et al. (2011) para distintas especies americanas y pacíficas de los géneros Leucochrysa McLachlan, 1868, Meleoma Fitch, 1855, Chrysoperla Steinmann, 1942, Ceraeochrysa Adams, 1982, Nodita Navás, 1916, Anomalochrysa McLachlan, 1883, Santocellus Tauber et al., 2008, Ungla Navás, 1911, Gonzaga, Navás, 1913, Chrysopodes Navás, 1913, Plesiochrysa Adams, 1982, Berchmansus Navás, 1913, Vieira Navás, 1913, o Yumachrysa Banks, 1950, y Boros (1984) para especies de distintos géneros de la fauna australiana, Tsukaguchi (1978) para las especies japonesas del género Chrysopa, Gepp (1983, 1984a, b, 1986, 1989) para especies pertenecientes a distintos géneros centroeuropeos, etc. Recientemente, y a nivel más general, DíazAranda \& Monserrat (1995) aportan una clave de larvas neonatas y maduras de los géneros europeos, y Díaz-Aranda, Monserrat \& Tauber (2001) realizan una recopilación a nivel mundial sobre la información hasta entonces conocida sobre las larvas de las distintas especies de esta familia, y aportan una clave de larvas neonatas y maduras de los géneros europeos y americanos.

Centrándonos en la fauna de la Península Ibérica, la mayoría de sus representantes pertenecen a la subfamilia Chrysopinae, y más concretamente a la tribu Chrysopini, ya que 43 de las 49 especies que habitan en la Península Ibérica, pertenecen a 10 géneros de Chrysopini, 2 especies a un género de Belonopterygini y las 3 especies restantes a 2 géneros de Nothochrysinae (Tabla 1). Se trata de la fauna más rica y diversa del continente europeo, ya que en ella están representados todos los géneros conocidos del continente (Hölzel \& Ohm, 1972; Aspöck et al, 1980, 2001; Aspöck, 1992), todos ellos tratados en la presente contribución.

En cuanto a la información existente sobre la morfología larvaria de las especies ibéricas, Aspöck et al. (1980) en su revisión de la fauna europea indican que los estadios preimaginales son conocidos en 19 especies ibéricas, pertenecientes a 9 géneros. Posteriormente, Gepp (1984a, 1986), recopila la información disponible al respecto $\mathrm{y}$ anota que los estadios preimaginales han sido descritos para 21 especies ibéricas, pertenecientes a 9 géneros. Desde entonces, nuevas especies han sido citadas o descritas en la fauna ibérica, y los trabajos de Canard \& Labrique (1989); Labrique \& Canard (1989) y Labrique (1990) por un lado, y los realizados por Monserrat (1984a, 1989, 2008, 2010); Monserrat \& Díaz-Aranda (1989a, b); Monserrat \& Rodrigo (1992), o Díaz-Aranda \& Monserrat (1988, 1990a, b, 1991, 1992, 1994, 1995, 1996), han aumentado considerablemente el nivel de conocimiento al respecto sobre la fauna de crisópidos ibéricos, incrementando el número de especies y la información larvaria existente sobre ellas a 34 especies, pertenecientes a 12 géneros, ya que en ellos se describen los estadios preimaginales de 4 especies del género Pseudomallada Tsukaguchi, 1995, de 1 del género Rexa Navás, 1920, de 1 de Brinckochrysa Tjeder, 1966, y de 2 de Suarius Navás, 1914, y que tras la presente contribución se alcanzan 38 especies, pertenecientes a todo los géneros de la fauna ibérica/europea.

Dada la riqueza taxonómica de la fauna ibérica de crisópidos (Tabla 1), la necesidad de abordar un estudio detallado de sus estadios preimaginales es 
Tabla 1.- Lista de las especies de crisópidos ibéricos: * con estadios juveniles conocidos en la bibliografía o con nuevos datos ahora aportados, ${ }^{* *}$ previamente desconocidos y ahora descritos.

Table 1.- List of Iberian chrysopid species: * with larval stages known in the literature or with new data now provided, ** larvae previously unknown and now described.

\begin{tabular}{|c|c|}
\hline \multicolumn{2}{|c|}{ CHRYSOPIDAE } \\
\hline $\begin{array}{l}\text { SUBFAMILIA NOTHOCHRYSINAE Navás, } 1910 \\
\text { * Nothochrysa capitata (Fabricius, 1793) } \\
\text { * Nothochrysa fulviceps (Stephens, 1836) } \\
\text { * Hypochrysa elegans (Burmeister, 1839) } \\
\text { SUBFAMILIA CHRYSOPINAE Schneider, 1851 } \\
\text { TRIBU BELONOPTERYGINI Navás, 1913 } \\
\text { * Italochrysa italica (Rossi, 1790) } \\
\text { * Italochrysa stigmatica (Rambur, 1842) } \\
\text { TRIBU CHRYSOPINI Schneider, 1851 } \\
\text { * Brinckochrysa nachoi Monserrat, } 1977 \\
\text { * Chrysopa dorsalis Burmeister, 1839 } \\
\text { Chrysopa dubitans Mclachlan, 1887 } \\
\text { * Chrysopa formosa Brauer, 1850 } \\
\text { Chrysopa nierembergi Navás, 1908 } \\
\text { * Chrysopa nigricostata Brauer, 1850 } \\
\text { * Chrysopa pallens (Rambur, 1838) } \\
\text { * Chrysopa perla (Linnaeus, 1758) } \\
\text { * Chrysopa phyllochroma Wesmael, 1841 } \\
\text { * Chrysopa viridana Schneider, 1845 } \\
\text { * Chrysoperla carnea (Stephens, 1836) s.I } \\
\text { Chrysoperla carnea (Stephens, 1836) s. str. } \\
\text { Chrysoperla lucasina (Lacroix, 1912) } \\
\text { Chrysoperla pallida Henry et al., 2002 } \\
\text { * Chrysoperla agilis Henry et al., 2003 } \\
\text { Chrysoperla mediterranea (Hölzel, 1972) }\end{array}$ & $\begin{array}{l}\text { Chrysoperla mutata (McLachlan, 1898) } \\
\text { * Chrysoperla ankylopteryformis Monserrat \& Díaz-Aranda, } 1989 \\
\text { * Chrysopidia (Chrysotropia) ciliata (Wesmael, 1841) } \\
\text { * Cunctochrysa albolineata (Killington, 1935) } \\
\text { * Cunctochrysa baetica (Hölzel, 1972) } \\
\text { * Pseudomallada alarconi (Navás, 1915) } \\
\text { * Pseudomallada clathratus (Schneider, 1845) } \\
\text { * Pseudomallada flavifrons (Brauer, 1850) } \\
\text { * Pseudomallada genei (Rambur, 1842) } \\
\text { * Pseudomallada granadensis (Pictet, 1865) } \\
\text { * Pseudomallada ibericus (Navás, 1903) } \\
\text { * Pseudomallada inornatus (Navás, 1901) } \\
\text { * Pseudomallada picteti (McLachlan, 1880) } \\
\text { * Pseudomallada prasinus (Burmeister, 1839) } \\
\text { * Pseudomallada subcubitalis (Navás, 1901) } \\
\text { * Pseudomallada venosus (Rambur, 1842) } \\
\text { * Pseudomallada ventralis (Curtis, 1834) } \\
\text { * Pseudomallada zelleri (Schneider, 1851) } \\
\text { * Nineta flava (Scopoli, 1763) } \\
\text { * Nineta guadarramensis (Pictet, 1865) } \\
\text { * Nineta pallida (Schneider, 1851) } \\
\text { * Peyerimhoffina gracilis (Schneider, 1851) } \\
\text { * Rexa lordina Navás, 1919 } \\
\text { * Suarius iberiensis Hölzel, 1974 } \\
\text { * Suarius tigridis (Morton, 1921) } \\
\text { * Suarius walsinghami Navás, 1914 }\end{array}$ \\
\hline
\end{tabular}

el objeto principal de esta contribución, tratando con ello de contribuir al esclarecimiento de la clasificación y sistemática de esta familia. Además, el citado interés económico que sus larvas presentan como agentes de control biológico (McEwen et al., 2001), fue otro de los motivos que nos animaron a llevar a cabo su estudio, ya que dentro de las múltiples posibilidades que las larvas de esta familia ofrecen como campo de investigación, y teniendo en cuenta que se hacía imposible abarcar todos y cada una de ellos, esta contribución se ha enfocado, fundamentalmente, en la descripción minuciosa de la morfología externa de los estadios preimaginales de las especies que habitan en la Península Ibérica, ya que el esclarecimiento y la precisa identificación específica son la base que ofrecemos a los especialistas para su aplicación práctica o cualquier otro tipo de estudio posterior.

Teniendo en cuenta que el principal objetivo de este trabajo era la búsqueda de caracteres morfoló- gicos externos que pudieran resultar válidos en la diferenciación de los estadios preimaginales, tanto a nivel de subfamilia, como de tribu, género y especie, se hizo necesario el estudio detallado de los estadios de todas y cada una de las especies incluidas en este trabajo, para poder realizar claves de identificación y establecer comparaciones entre los caracteres observados, y así mismo, proponer los que son taxonómicamente válidos o, por el contrario, cuestionar la opinión basada en los caracteres de los imagos.

Así mismo, nos hemos visto en la necesidad de redescribir de forma completa y detallada los estadios preimaginales de 9 especies ibéricas, debido a que las descripciones realizadas por otros autores previos nos resultaban testimoniales, muy someras, o incompletas, y no aportaban caracteres de morfología útiles, a nuestro parecer, en estudios taxonómicos y sistemáticos. Además se ha procedido al estudio detallado de los estadios preimaginales de 

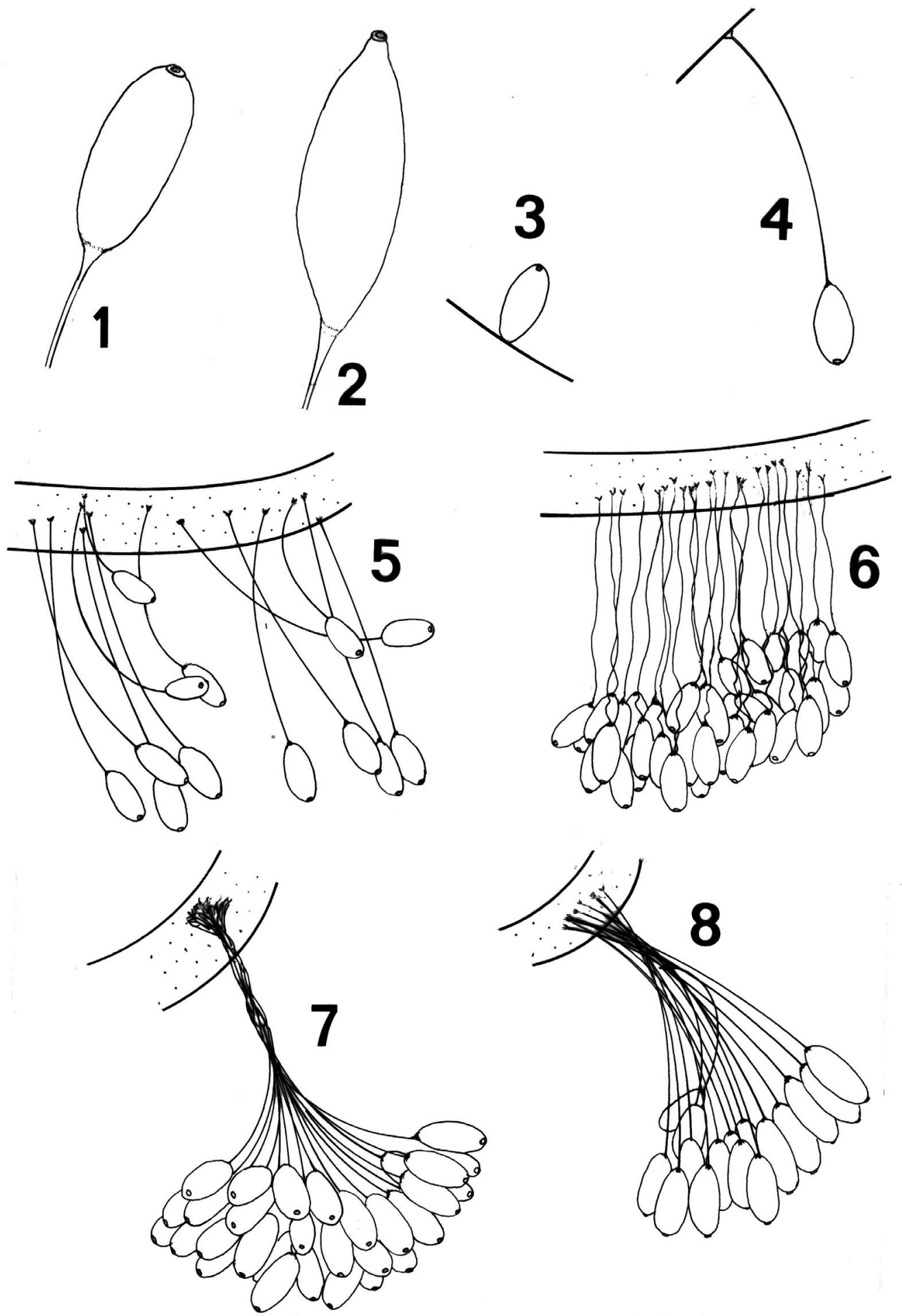

Fig. 1.- 1, Huevo elipsoide típico. 2, Huevo del género Italochrysa. 3, Huevo del género Anomalochrysa. 4, Puesta aislada. 5 y 6 , Puesta en grupos. 7 y 8 , Puesta en racimos.

Fig. 1.- 1, Ellipsoid egg of many genera. 2, Fusiform egg of Italochrysa. 3, Unstalked egg of Anomalochrysa. 4, Isolated. 5 and 6, Oviposition in groups. 7 and 8, Oviposition in clusters. 
otras 13 especies ibéricas, independientemente de que su morfología hubiera sido detalladamente descrita con anterioridad, anotando nuevos datos que consideramos relevantes, y comentamos e ilustramos los caracteres morfológicos que consideramos válidos en la diferenciación de todas estas larvas.

Como complemento se aportan, aunque más sucintamente, los datos actualizados sobre la biología, comportamiento y distribución altitudinal y fenológica de las especies ibéricas, tendentes a compilar y ampliar la información existente sobre ellas en nuestra fauna.

Con el objeto de facilitar al lector la ubicación de los taxas citados, se anota en la Tabla 1 la posición de las especies ibéricas dentro de la actual clasificación general de la familia (Brooks \& Barnard, 1990). Con un asterisco $\left(^{*}\right)$ se resaltan las especies ibéricas cuyos estadios larvarios eran bien conocidos, o más o menos conocidos, pero de los que hemos aportado nuevos datos mucho más precisos; con dos asteriscos $(* *)$, aquellas cuyos estadios larvarios eran previamente desconocidos, y con ninguno, aquellas cuyas fases juveniles son aún desconocidas.

\section{Caracerísticas generales de biología, comporta- miento y morfología de los estadios preimaginales}

Las crisopas (Insecta, Neuroptera, Chrysopidae) son insectos holometábolos que durante su desarrollo pasan por 3 fases o estadios larvarios (neonata o L-1, inmadura en segundo estadio L-2, y madura en tercer estadio o L-3), con particulares diferencias entre L-1 y L-2/L-3, a veces con estadio de prepupa, y con estadio de pupa e imago. Sus larvas son campodeiformes, terrestres, de vida libre y, como hemos citado, activas predadoras de pequeños artrópodos de cuerpo blando. Datos sobre generalidades de su biología pueden ser recabados en Canard et al. (1984); New (1989, 1999); McEwen et al. (2001).

\section{HuEVO Y OVOPOSICIÓN}

Los huevos de Chrysopidae son elipsoides (Fig. 1.1) (excepto en Belonopterygini, ver el género Italochrysa Principi, 1946, que son fusiformes y presentan el polo micropilar muy alargado, Fig. 1.2), y se caracterizan por ser depositados sobre el sustrato en el extremo de un largo y fino pedúnculo hialino (excepto en el género hawaiiano Anomalochrysa McLachlan, 1883, Fig. 1.3) de naturaleza proteica
(Figs. 1.4-8). La estructura y composición química del mismo ha sido estudiada por Parker \& Rudall (1957) y Lucas et al. (1957) respectivamente. Muchos autores han especulado sobre la función del pedúnculo, adjudicándole una misión protectora contra predadores, especialmente hormigas (Chen \& Young, 1941; Eisner et al., 1996) o contra parásitos y canibalismo (Duelli, 1984, 1986; Duelli \& Johnson, 1992; New, 1989, 1999, etc.).

Sobre la morfología y estructura del huevo de esta familia puede recabarse información en Mazzini (1974, 1976); Hinton (1981) o Gepp (1984b, 1989, 1990). La longitud del huevo oscila entre 0,7 a 2, $3 \mathrm{~mm}$, dependiendo de los géneros. Las dimensiones del mismo están, lógicamente, relacionadas con el tamaño de la hembra (Duelli, 1984), y en la mayoría de los géneros es, aproximadamente, de $1 \mathrm{~mm}$ de longitud y unos $0,4 \mathrm{~mm}$ de diámetro. Los huevos pueden presentar coloración verde, que varía entre distintas tonalidades, o coloración más o menos blanquecina, siendo este carácter constante para cada especie. En el polo micropilar poseen un micropilo circular, de aproximadamente $9 \mu \mathrm{m}$ de alto y $40 \mu \mathrm{m}$ de diámetro, que presenta unos 30 orificios micropilares en su superficie. El corion está uniformemente ornamentado exteriormente y las esculturas de éste pueden variar considerablemente de unos géneros a otros $y$, en ocasiones, entre especies de un mismo género, y aunque carece de visibles estructuras respiratorias especializadas, entre las esculturas del exocorion se localizan pequeños aeropilos.

El comportamiento de ovoposición de las hembras ha sido descrito por varios autores (Smith, 1921, 1992; Neumark, 1952; Duelli, 1984; Gepp, 1989; etc.). Los lugares elegidos por las hembras para la ovoposición suelen estar cercanos a potenciales fuentes de alimento para su prole, como colonias áfidos o la entrada de hormigueros, facilitando la localización de presas a las neonatas. A veces se presumen elecciones muy específicas.

Los huevos pueden ser depositados de varias formas distintas, y el tipo de puesta es característico en las especies de esta familia. Las formas más generales de depositar los huevos son:

AISLADOS: Las hembras van depositando los huevos en distintos lugares, distanciándolos uno a uno o, en ocasiones, depositando 2-3 huevos cercanos entre sí (Fig. 1.4).

EN GRUPOS: En este caso la hembra deposita todos los huevos en el mismo lugar, más o menos 
cercanos unos a otros, dando lugar a grupos que pueden estar formados por:

-Un elevado número de huevos (generalmente de 20 a 40), muy cercanos unos a otros, y regularmente espaciados, a menudo formando hileras más o menos paralelas (Fig. 1.6).

-Un menor número de huevos, más distanciados e irregularmente espaciados entre sí (Fig. 1.5).

EN RACIMOS: La hembra deposita todos los huevos en el mismo punto formando un racimo. Cada huevo posee su propio pedúnculo, pero puede ocurrir que: -Los pedúnculos queden unidos, trenzados o enlazándose unos con otros según muestra la Fig. 1.7. -Los pedúnculos permanezcan individualizados, separados unos de otros (Fig. 1.8).

Varios autores han especulado sobre el significado adaptativo de las distintas estrategias de ovoposición. Entre ellos, Duelli (1981) y Duelli \& Johnson (1992) interpretan los grupos y racimos de huevos como una ventaja selectiva que facilita el canibalismo de larvas neonatas en hábitats con intensas fluctuaciones de alimento, comparándolo con la producción de huevos tróficos en otras especies de insectos. A este respecto, nosotros hemos observado canibalismo de neonatas en varias especies (ver como ejemplo: biología y comportamiento del género Chrysopa Leach, 1815), y el hecho de observar que distintas hembras de Pseudomallada prasinus (Burmeister, 1839) realicen la puesta de dos formas distintas (en racimos y aislados), hace presumir que estemos frente a un grupo de especies distintas (Cianchi \& Bullini, 1992), con imagos hasta ahora agrupados bajo la citada denominación.

\section{DESARROLLO EMBRIONARIO}

El desarrollo embrionario de crisópidos fue ya descrito en detalle por Bock (1939) para Chrysopa perla Linnaeus, 1758. La duración de este período varía ligeramente de unas especies a otras (ver biología y comportamiento para cada género), y parece estar influido por las fluctuaciones de temperatura (Canard \& Principi, 1984). En cualquier caso, el desarrollo embrionario se manifiesta externamente por cambios en la coloración del huevo, y a medida que transcurre este período, los huevos se tornan pardos y se hacen visibles, a través del corion, las manchas metaméricas, estemas, y otras estructuras del embrión.

\section{ECLOSIÓN}

La eclosión del huevo en esta familia fue descrita por primera vez por Hagen (1859), y poste- riormente otros autores han realizado descripciones más o menos detalladas de este proceso, mereciendo ser destacado el trabajo de Principi (1940), en el que se ilustran las diferentes fases de eclosión en Chrysopa pallens (Rambur, 1838) (Figs. 2.1-6).

La ruptura del corion se lleva a cabo mediante la práctica de una fisura longitudinal, que se extiende ventralmente desde el polo micropilar (quedando el micropilo en un lateral) hasta aproximadamente un tercio de la longitud del huevo (Fig. 1.2). Para la realización de dicha fisura, la larva neonata se ayuda del ovirruptor, estructura denticulada (Figs. 7.1, 17.1, 45.1), más o menos esclerotizada, emplazada mediodorsalmente sobre la región cefálica de la cutícula embrionaria. El ovirruptor, tras la eclosión, queda adosado en el extremo final de la fisura practicada, y según Toschi (1965) y New (1989), su denticulación puede tener cierto valor taxonómico.

Tras la eclosión, la larva neonata permanece sobre el corion del huevo durante un cierto tiempo, endureciendo el tegumento y activando la musculatura (Fig. 2.6). Cuando finalmente abandona éste, emprende su ávida búsqueda de presas.

\section{LARVA}

Como ya se mencionó al principio de este capítulo, las especies de la familia aquí tratada presentan 3 estadios larvarios, denominados en este estudio:

- Primer estadio: Larva neonata o L-1 (para el pie de figuras en inglés: fisrt instar)

- Segundo estadio: Larva inmadura o L-2 (para el pie de figuras en inglés: second instar)

- Tercer estadio: Larva madura o L-3 (para el pie de figuras en inglés: third instar)

Existen numerosos datos publicados sobre la duración de los estadio larvarios y sobre los factores ambientales/climáticos (especialmente fotoperiodo y temperatura) que afectan al desarrollo larvario, así como de la influencia en éste en los distintos tipos de dietas (Canard \& Principi, 1984; Canard et al., 1984 y Mc Ewen et al., 2001).

Las larvas, durante todo su desarrollo, son activas predadoras de pequeños artrópodos de cuerpo blando y mayoritariamente no parecen mostrar una marcada especificidad por las presas que constituyen sus dietas, tanto en condiciones naturales como en el laboratorio. Sólo a modo de ejemplo, Canard \& Principi (1984) citan un amplio rango de ellas: áfidos, cócidos, aleyródidos, psocópteros, huevos y larvas de algunos lepidópteros, etc., y Monserrat \& Marín (1994) anotan mayoritariamente entre las especies 


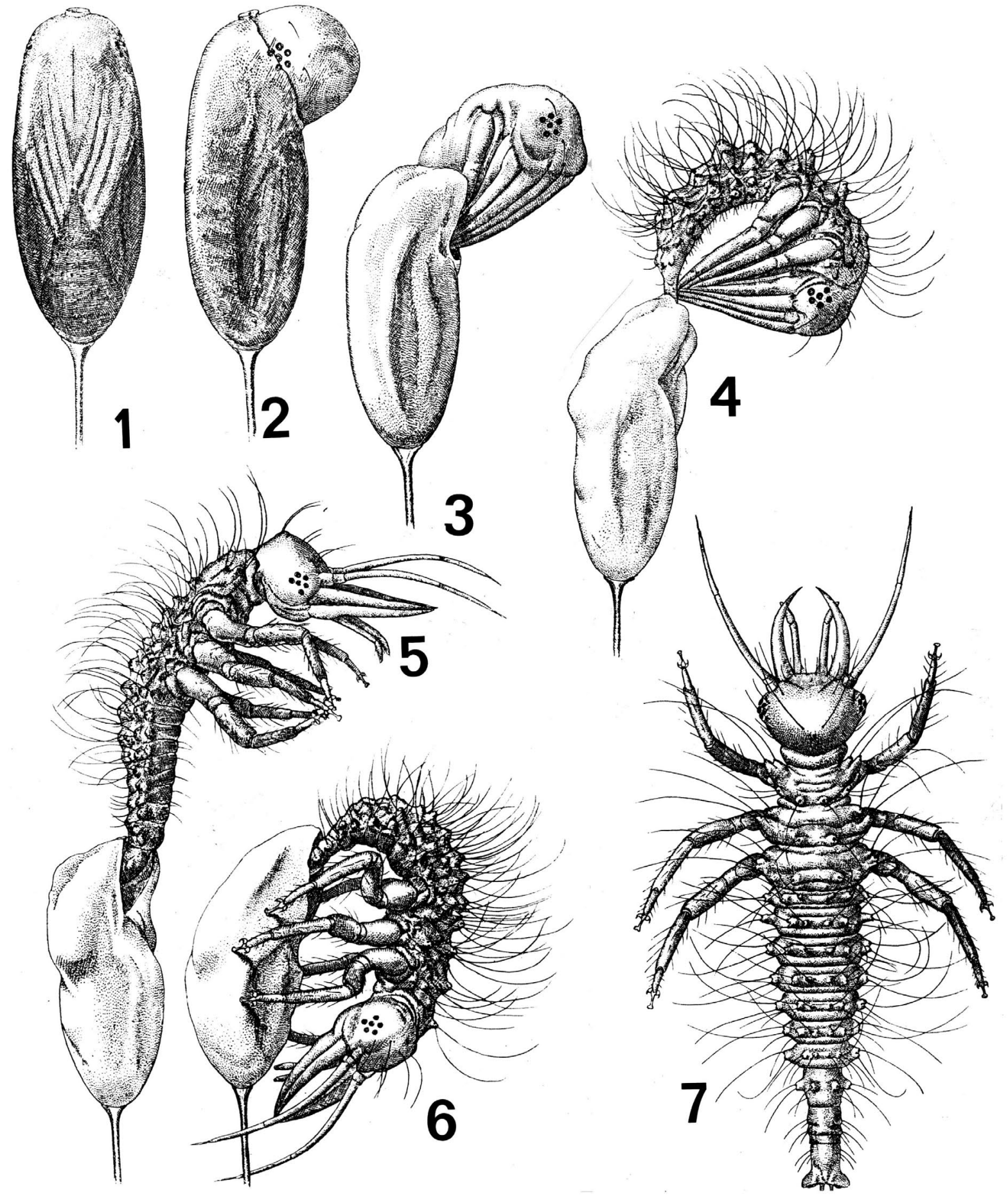

Fig. 2.- 1-6, Fases de eclosión de Chrysopa pallens. 7, Larva neonata de C. pallens. Adaptado de Principi (1940).

Fig. 2.- 1-6, Phases of hatching by Chrysopa pallens. 7, Neonate larva of C. pallens. Adapted from Principi (1940). 
ibéricas más de 6 sustratos vegetales diferentes (hasta 89) y una amplitud de hábitat (AH) superior a 3 en la mayoría de ellas, y Monserrat \& Marín (2001) llegan a las mismas conclusiones en modo comparativo con otras familias ibéricas de neurópteros de larvas depredadoras (Hemerobiidae, Coniopterygidae).

Sin embargo, es conocido y hemos observado que otras muchas especies son muy específicas del medio/sustrato vegetal $\mathrm{y}$, consecuentemente, lo serán de las presas que vivan en esos sustratos. Dos de las especies de esta familia en las que se ha observado una mayor especificidad por el tipo de presa son Italochrysa italica (Rossi, 1790), que depreda únicamente sobre larvas y pupas de hormigas de la especie Crematogaster scutellaris (Olivier, 1791) (Principi, 1946) o Chrysopa slossonae Banks, 1924, que lo hace exclusivamente sobre el áfido Prociphilus tesselatus (Fitch, 1865), a cuyas colonias está íntimamente asociada (Eisner et al., 1978; Tauber \& Tauber, 1987). También en el caso de las especies ibéricas, algunas parecen ser muy específica en su dieta, ya que, al contrario de lo anteriormente citado, han sido mayoritariamente halladas sobre un determinado y específico sustrato vegetal (Pseudomallada subcubitalis sobre Tamarix, Rexa lordina sobre oleáceas, Brinckochrysa nachoi sobre Eucaliptus, Peyerimhoffina gracilis sobre abetos, Nineta guadarramensis sobre robles, P. alarconi sobre enebros, Chrysoperla mediterranea sobre pinos, etc.) (Monserrat \& Marín, 1994), y en lo que respecta a estas especies ibéricas, anotamos oportunamente su potencial especificidad en cada caso. Por otro lado, es frecuente observar canibalismo en las larvas sometidas a falta de alimento (Arzet, 1973; Duelli, 1981; Duelli \& Johnson, 1992, etc.).

El comportamiento de búsqueda y captura de presas ha sido discutido por Fleschner (1950), Butler \& May (1971) o Bond (1980). También Canard \& Duelli (1984) lo describen en detalle para Chrysoperla carnea (Stephens, 1836), y puede ser generalizado para las restantes especies.

Se pueden distinguir dos tipos básicos de larvas en función de sus hábitos de camuflaje con el medio: las denominadas larvas portadoras de capa de camuflaje y las larvas desnudas.

Las primeras (Fig. 3.3) cubren su dorso con los restos de las presas consumidas, exuvias de la propia larva, pequeños fragmentos de vegetales y otros materiales, construyendo así una capa de camuflaje que, en algunas especies, puede incluso llegar a cubrir la totalidad de la larva, aunque lo más fre- cuente es que la cabeza, la región anterior del tórax y los últimos segmentos abdominales queden visibles dorsalmente. En orden a retener dicha capa, las larvas de este tipo presentan ciertas modificaciones morfológicas, especialmente tipos de setas, que son indicadas más adelante.

El método de fabricación de la capa de camuflaje ha sido descrito detalladamente en distintas especies por Smith (1922, 1931, 1926); Principi (1940); New (1969); Manson et al. (1991), etc., y en ocasiones son bastante elaboradas (Hölzel \& Monserrat, 1992). Varios autores le han adjudicado función protectora no sólo contra predadores interespecíficos (Principi, 1946; Eisner et al., 1978; Bristow, 1988; Manson et al., 1991; etc.), sino también contra el canibalismo (New, 1969). En los cultivos realizados por nosotros, el nivel de canibalismo en larvas con capa de camuflaje ha sido considerablemente inferior a lo observado en las larvas desnudas.

El segundo tipo de larva (Fig. 3.1), que denominamos larva desnuda, por no cubrir su dorso con resto alguno, se caracteriza por ser generalmente más activa: son más voraces, con rápido crecimiento y ciclo de desarrollo, sin intervención de diapausa, que transcurre en un período de tiempo menor que en las anteriores. Suelen mostrar rápidos y súbitos movimientos, y un comportamiento ofensivo/defensivo contra sus enemigos (Kennett, 1948 y LaMunyon \& Adams, 1987). En cualquier caso, estas larvas suelen presentar coloración más o menos críptica, como la de Hypochrysa elegans (Burmeister, 1839) (Figs. 48.1, 49.1), y en ocasiones marcadamente disruptiva, como en el caso de Brinckochrysa nachoi Monserrat, 1977 (Fig. 8.1).

\section{FABRICACIÓN DEL CAPULLO}

Cuando la larva ha completado su desarrollo se prepara para fabricar el capullo, adquiere una apariencia más aplanada dorsoventralmente, pierde la mayoría de sus setas y su movilidad queda considerablemente reducida. Información detallada acerca de la fabricación del capullo puede encontrarse en Smith (1922); Lacroix (1925); Principi (1940); Canard \& Principi (1984), etc., y sobre su estructura y composición en Spiegler (1962) y Rudall \& Kenchington (1971). La seda empleada para la fabricación del mismo (Fig. 3.2) es producida por una secreción elaborada en los tubos de Malpighi y es exudada por el ano. La forma del capullo es esférica o subesférica, dependiendo de las especies, y 


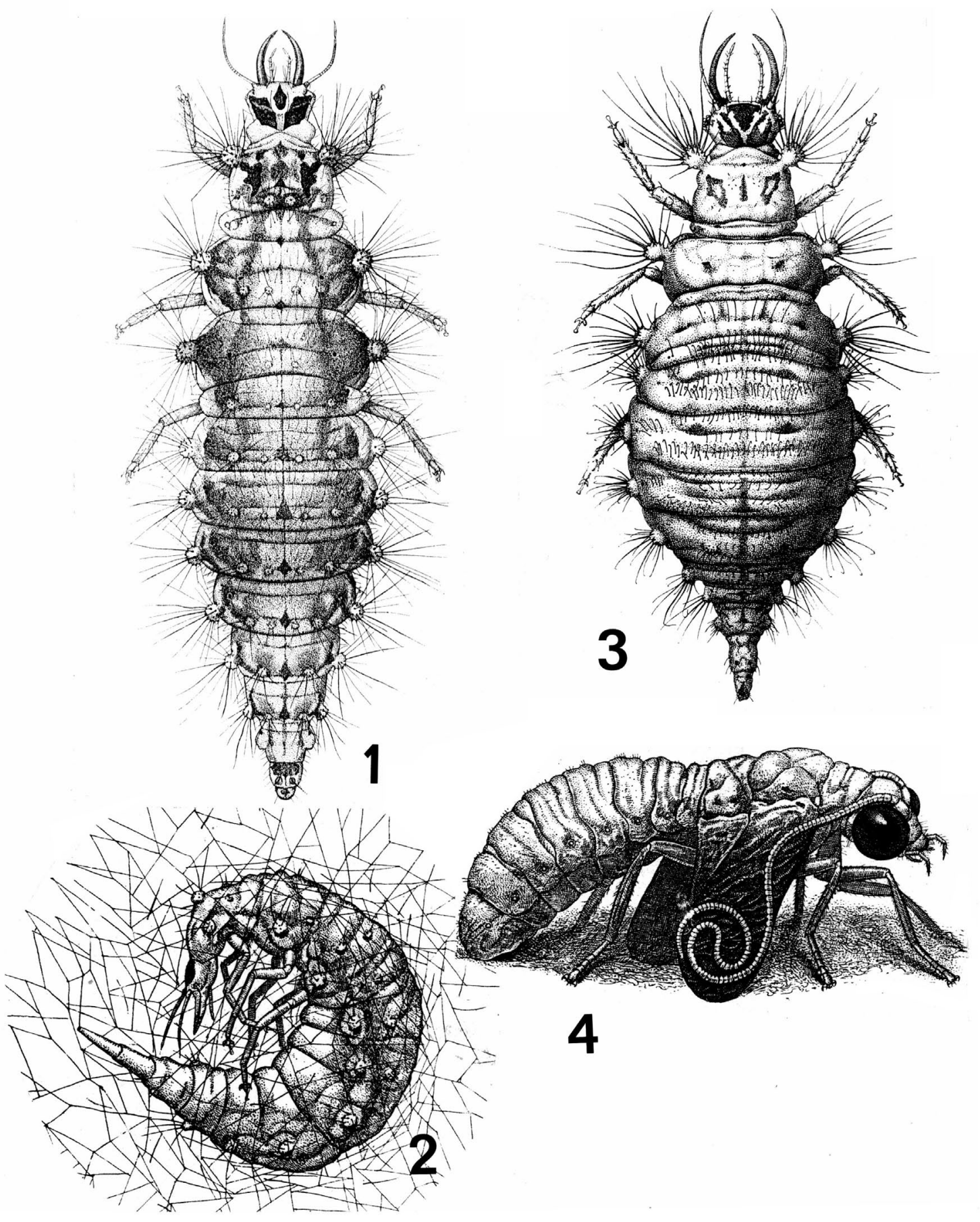

Fig. 3.- 1, Larva desnuda, L-3, de Chrysopa pallens. 2, L-3 de C. pallens fabricando el capullo. Adaptado de Principi (1940). 3, Larva portadora de capa de camuflaje (omitida), L-3, de Pseudomallada prasinus. 4, Pupa de P. prasinus. Adaptado de Principi (1956).

Fig. 3.- 1, Naked Larva, L-3 (third instar larva), of Chrysopa pallens. 2, L-3 of C. pallens making a cocoon. Adapted from Principi (1940). 3, Trash carrying larva (debris omitted), L-3, of Pseudomallada prasinus. 4, Pupa of $P$. prasinus. Adapted from Principi (1956). 
sus dimensiones dependen de la talla de la larva, aunque dentro de una misma especie los capullos de los futuros machos suelen ser ligeramente menores. En aquellas especies portadoras de capa de camuflaje es frecuente que la larva incorpore también el material que componía esta capa, quedando el capullo total o parcialmente cubierto/oculto. Los lugares seleccionados para su fabricación y el tiempo transcurrido hasta que emerge el imago varían en función de la especie. La mayoría de las especies permanecen en el interior del capullo en estadio de prepupa y mudan a pupa pocos días antes de abandonar éste. Sin embargo, algunas especies mudan inmediatamente después de su fabricación y transcurren este período en estadio de pupa. La muda de prepupa a pupa es fácilmente detectable desde el exterior del capullo, ya que la exuvia de la larva L-3 queda desplazada hacia el polo caudal y puede observarse por trasparencia como un disco de color pardo oscuro en esa zona. Los crisópidos poseen pupas exaradas y decticas con capacidad locomotora (Fig. 3.4).

\section{EMERGENCIA DEL IMAGO}

Los métodos adoptados por la pupa para la ecdisis y para la ruptura y abandono del capullo fueron descritos por Smith (1922) y Principi (1940). Cuando la pupa está preparada para salir del capullo, ejerciendo presión desde el interior y ayudándose en ocasiones con las mandíbulas, consigue realizar un limpio corte transversal en el polo cefálico del mismo. Después de emerger, la pupa se mueve una cierta distancia en busca de un soporte vertical donde llevar a cabo la emergencia del imago (Fig. 3.4).

CARACTERÍSTICAS GENERALES DE LA MORFOLOGÍA LARVARIA: TERMINOLOGÍÁ UTILIZADA

Información detallada sobre la morfología y anatomía de las larvas de la familia Chrysopidae puede ser recabada en Smith (1922); Killington (1937); Principi (1940, 1956a); Rousset (1966, 1969); Gaumont (1976); Tsakaguchi (1978, 1995); Gepp (1984b); Díaz-Aranda \& Monserrat (1995); Tauber et al. (2000); Díaz-Aranda et al. (2001), etc.

Son larvas oligopodas, campodeiformes, la forma del cuerpo puede variar en función de su hábitat y su adaptación a portar o no capa de camuflaje (Figs. 3.1, 3). Así, las larvas desnudas o no portadras de dicha capa (Fig. 3.1) son generalmente fusiformes, alargadas y aplanadas dorsoventralmente, mientras que en las larvas portadoras de dicha capa (Fig. 3.3) el cuerpo es menos alargado, con el abdomen más globoso.

La cápsula cefálica (Figs. 4.1-4), parcialmente embutida en el protórax, es prognata, aplanada dorsoventralmente y de forma más o menos trapecial. Presenta una fuerte esclerotización y las suturas cefálicas no son bien visibles, observándose, únicamente en algunos casos, la sutura epicraneal. Las fosetas de los brazos anteriores del tentorio presentan un refuerzo tegumentario que aparece fuertemente esclerotizado. En la región posterolateral de la cápsula cefálica, cubierta por la parte anterior del protórax, se aprecian dos líneas oblicuas fuertemente esclerotizadas, que delimitan los denominados escleritos occipitales (Fig. 4.4).

La pigmentación estructural de la cápsula cefálica consiste en una serie de manchas situadas sobre el tegumento, cuya denominación adoptada es la siguiente:

- Mancha frontoclipeal: Mancha impar situada en la región clípeo-labral, limitada posteriormente por las suturas frontales (Fig. 4.3).

- Manchas epicraneales: Son dos manchas emplazadas, cada una de ellas, a ambos lados de la sutura coronal (Fig. 4.3).

- Manchas genales: Manchas situadas sobre las genas, en las caras laterales de la cápsula cefálica y en posición posterior a los ojos (Figs. 4.3-4).

- Manchas ventrales: Englobamos con este término las manchas situadas sobre el cardo y estipe maxilar y también a la del labio (Fig. 4.4).

La ausencia o presencia de las citadas manchas y el diseño que presentan es característico para la mayoría de las especies, resultando por ello un carácter taxonómico de gran valor, utilizado con anterioridad por otros autores (Tauber, 1974; Tsukaguchi, 1978; Labrique, 1990, etc.).

La quetotaxia cefálica (Figs. 4.1-2) resulta ser, en general, constante dentro de los distintos géneros de esta familia, por lo que también resulta un buen carácter taxonómico. La terminología seguida en este estudio es la propuesta por Rousset (1966) (Figs. 4.1-2).

Los ojos, situados en los ángulos anterolaterales de la cápsula cefálica, están formados por 6 estemmata, de los que habitualmente 1 es central y los otros 5 periféricos a éste, dispuestos según Figs. 4.1-4.4.

Las antenas (Fig. 5.4), insertadas sobre una prominencia dorsolateral de la región anterior de la cápsula cefálica, son filiformes, generalmente más 

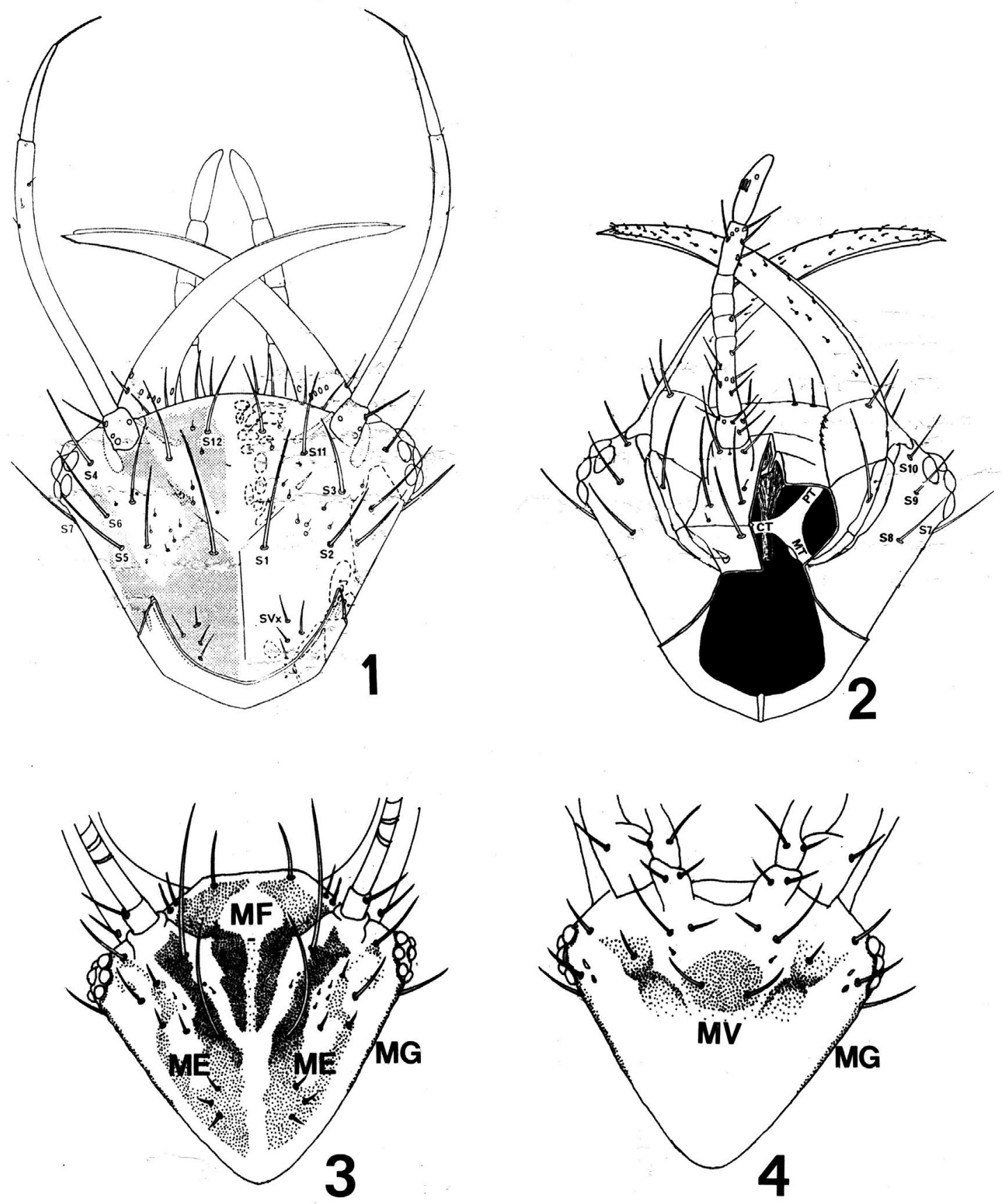

Fig. 4.- 1, Terminología de la quetotaxia cefálica (VD). 2, Ídem (VV). Adaptado de Rousset (1966). 3, Pigmentación cefálica (VD). 4, Ídem (VV). MF: Mancha frontoclipeal. ME: Manchas epicraneales. MG: Manchas genales. MV: Manchas ventrales.

Fig. 4.- 1, Terminology of cephalic chaetotaxy (DV). 2, Ditto (VV). Adapted from Rousset (1966). 3, Cephalic pigmentation (DV). 4, Ditto (VV). MF: Frontoclypeal marking. ME: Epicranial marking. MG: Genal marking. MV: Ventral marking. 
largas que las piezas bucales, excepto en el género Brinckochrysa Tjeder, 1966 (Figs. 7.2, 8.1), y son trisegmentadas. El escapo es muy corto y porta 1 ó 2 setas y 3 órganos placoideos. El pedicelo es más largo, a veces presenta una serie de anulaciones (segmentación secundaria) que le dan aspecto pluriarticulado y porta apicalmente una gruesa y corta seta. El flagelo, de interés taxonómico, presenta anulaciones más marcadas, pequeñas e irregulares que el anterior segmento, y en su extremo apical porta una larga y fina seta y varias sensilas (Fig. 5.3).

Las piezas bucales están adaptadas para succionar los líquidos internos de las presas. La boca consiste en una pequeña abertura, casi cerrada, limitada dorsalmente por el clípeo-labro y ventralmente por el labio. En orden a ingerir dietas exclusivamente líquidas, las mandíbulas y lóbulos maxilares son muy alargados y están íntimamente relacionados en toda su longitud formando un canal de succión (Figs. 5.1, 2,6), abierto únicamente en su ápice y base. Las maxilas (Fig. 5.1) están compuestas por cardo, estipe y lóbulo maxilar. Este último posee apicalmente un grupo de setas y sensilas presumiblemente con función olfatoria o gustativa y porta basalmente, en su cara ventral, una seta. Las mandíbulas (Fig. 5.2) son apicalmente serradas en su borde interno, ayudando así en la retención de presas y poseen basalmente 1 o 2 setas y 6 órganos placoides en su cara dorsal. El labio (Fig. 4.2), constituido por una pieza subtriangular ligeramente esclerotizada, posee 2 palpos labiales trisegmentados (Fig. 5.4). El segmento basal es muy corto, el segundo es más largo y presenta segmentación secundaria, variable en número tanto intra- como interespecíficamente y está provisto de numerosas setas. El tercer segmento es fusiforme y posee varias (generalmente 3) sensilas sobre su cara externa y un grupo de éstas en su extremo apical.

Tórax (Figs. 3.1, 3.3) con los tres segmentos bien desarrollados, siendo el protórax más largo y estrecho que el meso- y metatórax. Cada uno de ellos está dividido en acroterguito y postnoto, de los que el anterior es mucho más pequeño. El acroterguito del protórax abraza parcialmente la cápsula cefálica, el del mesotórax es el más desarrollado y porta laterodorsalmente el único par de espiráculos presentes en el tórax y, finalmente, el metatorácico es pequeño y poco aparente.

Los espiráculos mesotorácicos (Figs. 6.1-3) presentan morfología variable según las especies y distinguimos básicamente tres tipos distintos:
- Espiráculos de aspecto troncocónico, que pueden estar situados en el extremo distal de una elevación tegumentaria: espiráculo troncocónico prominente (Fig. 6.1), o no situarse sobre la citada elevación: espiráculo troncocónico no prominente (Fig. 6.2).

- Espiráculos con forma circular, nunca situados sobre una elevación tegumentaria: espiráculos circulares (Fig. 6.3).

Cada uno de los segmentos torácicos posee laterodorsalmente pequeñas áreas fuertemente esclerotizadas: escleritos laterodorsales (Figs. 3.1 y 3.3), que, generalmente, son alargados y de aspecto trapecial en el pronoto, y circulares y más pequeños en meso- y metanoto.

Los tres segmentos torácicos poseen lateralmente un par de tubérculos setígeros: tubérculos laterales, portadores de varias setas. La morfología y desarrollo de dichos tubérculos varía en función de los hábitos de las larvas. Así, en larvas portadoras de capa de camuflaje, los tubérculos laterales están modificados para la retención de la mencionada capa, siendo generalmente pedunculados y portadores de largas setas (Fig. 3.3). Sin embargo, en las larvas desnudas, los citados tubérculos son frecuentemente semiesféricos, portadores de setas más cortas y rectas (Fig. 3.1), o no están desarrollados (Fig. 8.1). Tanto el número, como el color y longitud de las setas resultan caracteres de gran valor taxonómico a nivel específico.

El tegumento torácico aparece cubierto por una densa microsetación y está provisto de numerosas setas, de diversa longitud, más o menos uniformemente repartidas. Los terguitos poseen además pequeños tubérculos portadores de 1 sola seta (denominados chalaza por Tauber, 1974 y otros autores) que en las larvas portadoras de capa de camuflaje se disponen formando una serie o hilera transversal (Fig. 3.3), que interviene también en el soporte de la capa de camuflaje. La hilera transversal de setas del metanoto está presente en todos los géneros cuyas larvas portan dicha capa, sin embargo la hilera del mesonoto aparece sólo en algunos de ellos. Por otro lado, las larvas desnudas presentan en el tórax pequeños tubérculos submedianos y laterodorsales portadores usualmente de varias setas (Fig. 3.1).

Las patas (Figs. 5.7, 5.8) son típicamente marchadoras y robustas, el pretarso posee un par de uñas entre las que se sitúa un órgano de adhesión, el empodio (Fig. 5.8). La estructura y función del 

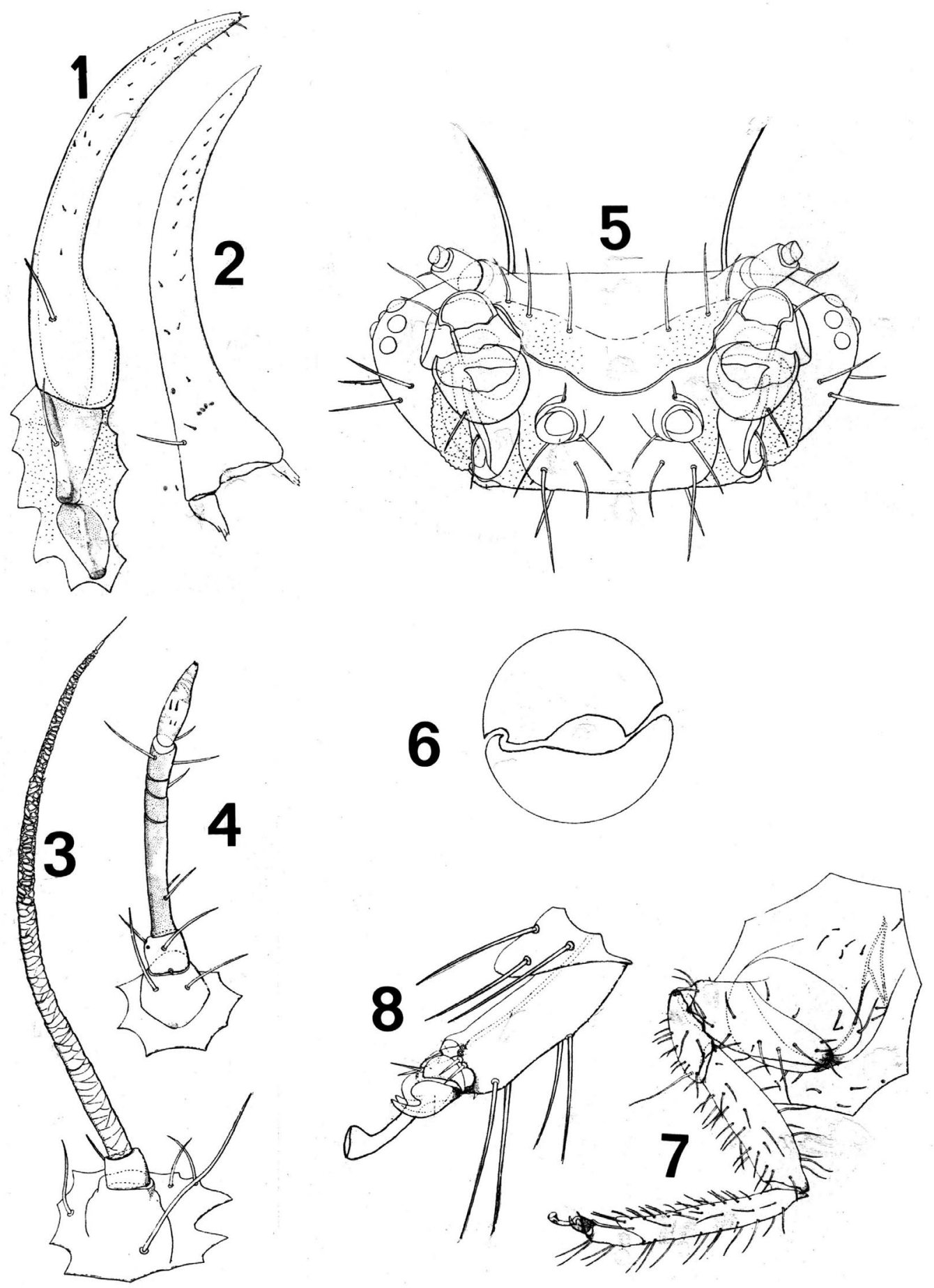

Fig. 5.- 1, Maxila (VV). 2, Mandíbula (VD). 3, Antena. 4, Palpo labial. 5, Cápsula cefálica (V. frontal). 6, Corte transversal del tubo de succión mandíbula-maxila. 7, Pata. 8, Detalle del empodio y uñas. Adaptado de Principi (1940).

Fig. 5.- 1, Maxilla (VV). 2, Mandible (D-V). 3, Antenna. 4, Labial palp. 5, Head capsule (Frontal). 6, Cross section of the suction mandibulo-maxillary channel. 7, Leg. 8, Detail of empodium and claws. Adapted from Principi (1940). 
mismo ha sido estudiada por Kirby (1984). Existen tres tipos básicos de uñas:

- Uñas fuertemente acodadas en su margen interno, adquiriendo un aspecto cuadrangular (Fig. 6.4): uñas cuadrangulares.

- Uñas suavemente acodadas en su margen interno, adquiriendo un aspecto triangular con base muy amplia (Fig. 6.5): uñas triangulares dilatadas en su base.

- Uñas no acodadas en su margen interno, adquiriendo un aspecto triangular de base estrecha (Fig. 6.6): uñas triangulares no dilatadas en su base.

El tipo de uña es un carácter taxonómico de gran utilidad, que se mantiene en los imagos de las especies estudiadas.

El abdomen está constituido por 10 segmentos (enumerados en este estudio del I al X), de los cuales el primero es más pequeño y corto que los restantes, y los tres últimos son telescopables (Figs. 3.1, 3). Los segmentos I-VIII portan un par de espiráculos traqueales en posición laterodorsal anterior. Los terguitos de estos mismos segmentos están transversalmente divididos en dos regiones, de las que la anterior, el arcroterguito, es mucho más corta. Además, en los segmentos II-VII puede aparecer una ligera sutura posterior. Estos segmentos poseen tubérculos laterales portadores de varias setas (Figs. 3.1, 3).

El tegumento abdominal también se encuentra cubierto de una densa microsetación. La quetotaxia varía considerablemente en función del tipo de larva: en aquellas portadoras de capa de camuflaje, en orden a retener dicha capa, los tubérculos laterales portan setas largas, frecuentemente recurvadas laterodorsalmente y los terguitos están provistos de hileras transversales de setas uncinadas, siendo especialmente largas en el segmento I. Sin embargo, en larvas desnudas, las setas de los tubérculos laterales son generalmente cortas y rectas, y los terguitos abdominales presentan tubérculos submediales y laterodorsales portadores de varias setas rectas, nunca uncinadas (Figs. 3.1, 3.3, 8.1, 39.1, 49.1).

Los segmentos VIII-X presentan morfología similar en ambos tipos de larvas, dichos segmentos son telescopables y generalmente poseen áreas fuertemente esclerotizadas y grupos de setas cuyo número y disposición es prácticamente constante para la familia, exceptuando el número de setas de la hilera transversal emplazada posteroventralmente en el segmento X (Figs. 34.9, 10), resultando un carácter taxonómico de gran valor en la diferenciación de las larvas de las especies del mismo género.
La quetotaxia, tanto torácica como abdominal, suele estar constituida por diversos tipos de setas, que suelen ser características para cada género. Los términos seta filiforme, espatulada, uncinada, truncada, baciliforme y denticulada, hacen referencia a la terminología empleada e ilustrada respectivamente en las Figs. 6.7-12.

\section{Material y métodos}

\section{OBTENCIÓN DE IMAGOS}

Con el objeto de obtener hembras grávidas, puestas, larvas o información sobre biología y distribución de las distintas especies que habitan en los diversos medios de la Península Ibérica, se iniciaron en 1987 una serie de campañas encaminadas a la recogida de material para la obtención de material y que se han prolongado hasta 2011. Se han visitando cientos de localidades de toda la geografía ibérica, que han contribuido, no sólo a obtener el material en el que se basa el presente estudio, sino a aumentar notablemente el conocimiento general sobre los crisópidos ibéricos.

Debido al mayoritario desconocimiento previo sobre los estadios preimaginales de muchas especies ibéricas de crisópidos, el objetivo con el que se planearon los muestreos, fue el de recogida de hembras grávidas de cada especie, que individualmente aisladas, se utilizaron para la obtención de puestas y posterior cría en el laboratorio. De este modo, tanto huevos como larvas así obtenidos eran incuestionablemente asignables a una determinada especie, sin posible error.

Para la obtención de los ejemplares, en cada una de las localidades visitadas se barrían, con ayuda de una manga entomológica, las especies de árboles y arbustos más representativos del lugar. Este método de captura se complementó con el empleo trampas de luz ultravioleta instaladas al crepúsculo, y mantenidas en funcionamiento durante varias horas de la noche, bien con el objetivo de obtener hembras de las especies que usualmente no viven sobre este tipo de vegetación, o bien en zonas subdesérticas con práctica ausencia de árboles y arbustos. Además se empleó, con cierta frecuencia, el vareo de las ramas de los árboles con paraguas japonés, donde se recogían los ejemplares desprendidos, tendente, sobre todo, a la captura de larvas de crisópidos, para disponer de un mayor número de ejemplares, teniendo en cuenta que dichos ejempla- 

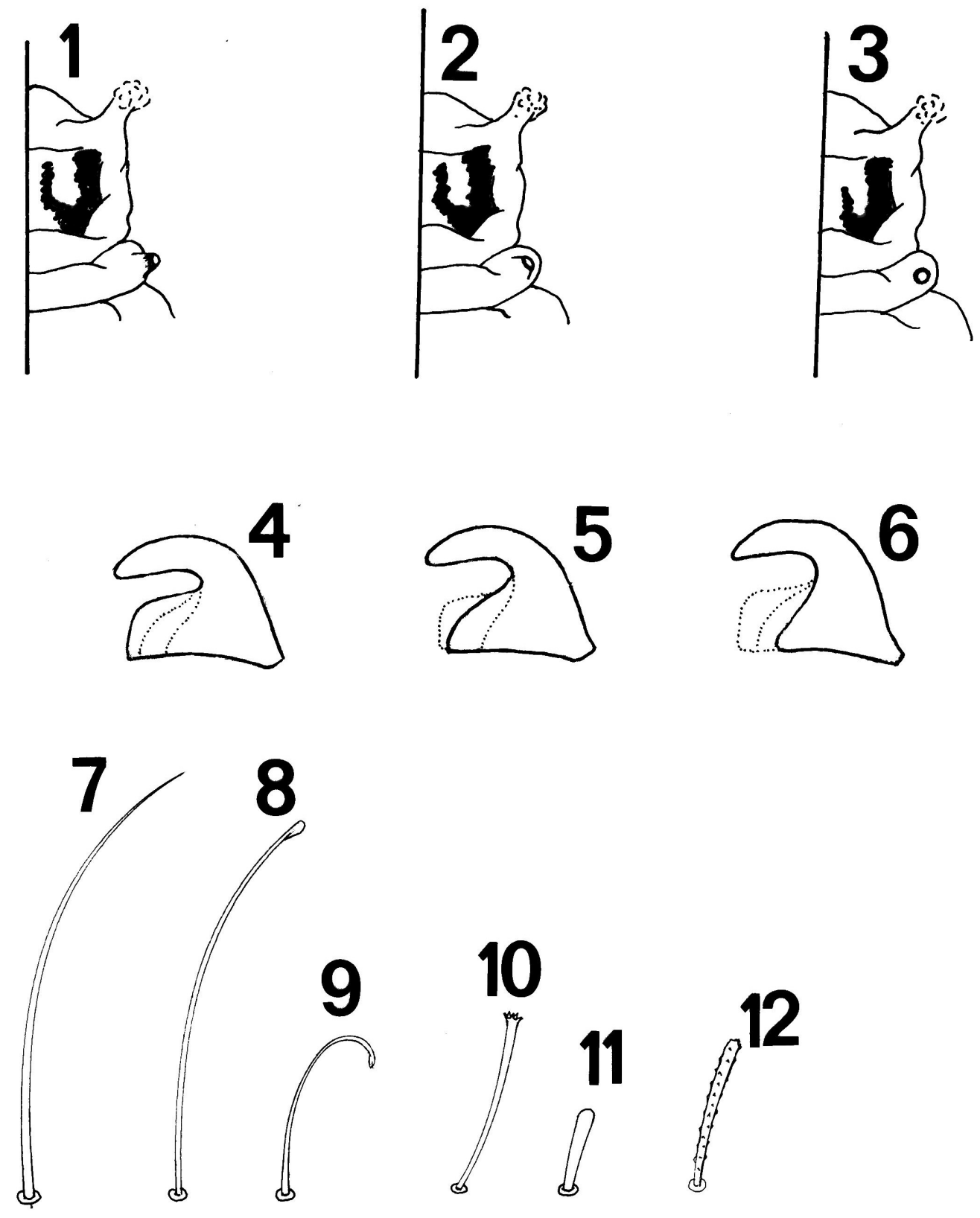

Fig. 6.- 1-3, Variación en los espiráculos mesotorácicos. 1, Espiráculo troncocónico prominente. 2, Ídem, troncocónico no prominente. 3, Ídem, circular. 4-6, Tipos de uña. 4, Cuadrangular. 5, Triangular dilatada en su base. 6, Triangular no dilatada en su base. 7-12, Tipos de setas. 7, Filiforme. 8, Espatulada. 9, Uncinada. 10, Truncada. 11, Baciliforme. 12, Denticulada.

Fig. 6.- 1-3, Variation in chrysopid mesothoracic spiracles.1, Conical truncated prominent. 2, Conical truncated not prominent. 3, Circular. 4-6, Chrysopids claws. 4, Quadrangular base. 5, Triangular dilated base. 6, Triangular undilated base. 7-12, Chrysopid setae, 7, Filiform. 8, Spatulate. 9, Uncinate. 10, Truncated. 11, Bacilliform. 12, Denticulate. 
res no han sido utilizados en las descripciones hasta no haber conseguido completar el ciclo biológico de la especie en el laboratorio, y por tanto, hasta no estar completamente seguros de su identidad taxonómica. Los datos de captura (localidad, fecha y sustrato vegetal) aparecen convenientemente reflejados para cada especie en el apartado denominado "Material Utilizado".

\section{OBTENCIÓN DE LAS PUESTAS}

Las hembras grávidas capturadas eran introducidas en cajas de cultivo cilíndricas de plástico transparente, de $9 \mathrm{~cm}$ de alto $\times 7 \mathrm{~cm}$ de diámetro, en cuya tapadera se había practicado un orificio de 5 $\mathrm{cm}$ de diámetro ocluido con una malla de gasa tupida que sirviera como respiradero. Teniendo en cuenta que la mayoría de los muestreos transcurrían durante los meses más calurosos del año, las cajas de cultivo se introducían en una nevera portátil, conectada a la batería del vehículo, que mantenía unos niveles de temperatura y humedad aceptables para la supervivencia de los ejemplares durante su transporte hasta el laboratorio. En cada caja de cultivo, y con la idea de proporcionar a la hembra un sustrato donde realizar la ovoposición, se introducían pequeñas ramitas / hojas de la especie vegetal sobre la que se habían capturado.

De este modo, las hembras eran transportadas al laboratorio donde se procedía al etiquetado del material, anotando la localidad, fecha, sustrato y método de captura, y se asignaba un código de identificación a cada una de las hembras colectadas, código que sería utilizado posteriormente para reconocer los estadios preimaginales de todos y cada uno de los individuos obtenidos a partir de una misma hembra. Hecho esto, las cajas de plástico eran introducidas en una cámara de cultivo HERAEUS HPL 400, ajustando las condiciones de temperatura, humedad relativa y fotoperiodo de acuerdo con las características del medio donde se hallaba cada especie (los valores de temperatura $/ \mathrm{T}^{\mathrm{a}}$, humedad relativa /HR y fotoperiodo/L.D. seleccionados en cada caso se detallan en cada apartado de "Biología y Comportamiento"). En estas condiciones, las hembras fueron alimentadas diariamente, en función de sus requerimientos, con distintas dietas: polen comercial humedecido con agua, miel, pulgones, o una dieta semiartificial elaborada con $50 \mathrm{ml}$ de leche, 2 huevos, 30 gr de fructosa, 20 gr de miel, 30 gr de levadura (Saccharomyces cerevisiae) y 30 gr de germen de trigo (M. Stelzl, com. pers.). Hay que anotar que, en algunos casos, cuando nuestra experiencia nos indicaba la dificultad que determinadas especies tenían para realizar la ovoposición de manera natural, se modificaron tanto la dieta, como las condiciones ambientales de la cámara de cultivo, con la intención de provocar de manera artificial la puesta de huevos, siguiendo, en este caso, las recomendaciones de determinados autores (Canard \& Grimal, 1984; Duelli, 1984; Rousset, 1984; etc.) que ya habían obtenido resultados satisfactorios con este procedimiento.

Una vez obtenidas las puestas, se anotaban datos sobre la coloración, tipo y tamaño de las mismas, aislando las hembras en nuevas cajas de cultivo y tomando la precaución de conservar 2 o 3 huevos para su posible estudio morfológico posterior.

\section{CUlTivo de LAS LARVAS}

En las condiciones citadas, y tras la eclosión de los huevos, el corion abandonado era guardado para llevar a cabo el posterior estudio del ovirruptor, y las larvas neonatas eran instaladas, individualmente, en cajas de cultivo similares a las ya descritas, pero de menor tamaño $(2 \mathrm{~cm} \times 2 \mathrm{~cm} \mathrm{x} 4 \mathrm{~cm})$, de manera que fuera más fácil controlar la localización y evolución de estas pequeñas larvas recién nacidas. A estas cajas se añadían diariamente pequeñas ninfas de áfidos, que constituirían su alimento. No siempre se utilizaron las mismas especies de pulgones, dependiendo de una u otra especie, de la facilidad de obtención de los mismos o de, en algunos casos concretos, las necesidades nutricias de la larva en cuestión. No obstante, en el apartado dedicado al estudio de su biología y comportamiento, se detallan las especies de áfidos utilizadas en cada caso.

A partir de la primera muda, el tamaño de las larvas permitía llevar un control más adecuado de su comportamiento y ubicación, por lo que se trasladaron a cajas de cultivo de mayores dimensiones ( $4 \mathrm{~cm}$ de alto $\times 7 \mathrm{~cm}$ de diámetro). Además, los áfidos elegidos para alimentarlas también podían ser de mayor tamaño, lo que permitía la introducción, en las cajas de cultivo, de hojas y tallos poblados de pulgones, asegurándonos de este modo su alimentación durante un período de tiempo mayor. Dado el peculiar comportamiento de algunas larvas, como en la especie corticícola Brinckochrysa nachoi Monserrat, 1977, en el interior de las cajas de cultivo, hubo que habilitar unas delgadas láminas de poliuretano sobre las que se practicaron pequeñas incisiones intentando imitar, en la medida de lo posible, el hábitat en el que se desenvuelve 
esta especie en estado larvario en la naturaleza, y tales incisiones fueron utilizadas por la mayoría de estas larvas criadas en estas condiciones.

Finalmente, debemos decir que el material recolectado durante la realización de este trabajo ha quedado depositado en las colecciones del Departamento de Biología Animal de la Universidad de Alcalá de Henares y de V. J. Monserrat.

OBTENCIÓN DE DATOS SOBRE LA MORFOLOGÍA Y EL COMPORTAMIENTO

Durante todo el período comprendido entre la puesta de los huevos y la emergencia del imago, todas las cajas de cultivo eran observadas al menos una vez al día, con el objeto de anotar el mayor número posible de datos sobre su coloración, morfología, comportamiento y desarrollo, tales como la fabricación o no de capa de camuflaje, tiempo transcurrido entre cada estadio preimaginal, cambios en la coloración, morfología, etc. A lo largo de este proceso se separaban y conservaban para su posterior estudio varios ejemplares de cada una de las fases de desarrollo: huevo (conservado para su potencial posterior estudio con microscopía de barrido), corion abandonado, larvas del primer, segundo y tercer estadio, exuvias de cada muda, capullo abandonado, exuvia pupal e imago.

El corion de los huevos con su pedúnculo eran montados en un portaobjetos con líquido Hoyer, con el fin de tomar las medidas del pedúnculo y estudiar la denticulación del ovirruptor.

Tras anotar los datos de las larvas observados en vivo, las larvas, una vez separadas, eran fijadas introduciéndolas en solución KAAD (queroseno comercial: alcohol etílico al 95\%: ácido acético glacial, en proporción 1:10:2) durante 15-20 minutos, tomando la precaución de colocar el recipiente en posición horizontal para que la larva quedara totalmente estirada (véase Peterson, 1964 y Stehr, 1990 para las ventajas de este procedimiento). Posteriormente, las larvas se conservaban en alcohol etílico al $70 \%$ con una pequeña cantidad de glicerina. Para el estudio al microscopio óptico de la quetotaxia, coloración estructural y otras estructuras tegumentarias, las larvas se aclaraban en ácido láctico caliente, para montarlas después, inmersas en glicerina, en portaobjetos excavados. Estructuras tales como las uñas, patas, mandíbulas, maxilas, palpos labiales y antenas eran montados en preparaciones permanentes con líquido Hoyer. Todas las ilustraciones se realizaron con ayuda de una cámara clara de dibujo acoplada a un microscopio óptico Nikon Labophot y a una lupa binocular Zeiss SV 8. Las mediciones de los ejemplares y sus estructuras se realizaron con la ayuda de un ocular graduado en el caso de las observaciones al microscopio, y con la de un portaobjetos milimetrado, cuando las observaciones se realizaban en la lupa binocular.

Como complemento a las descripciones realizadas sobre ejemplares obtenidos en el laboratorio a partir de hembras grávidas y con la intención de estudiar el mayor número posible de individuos de una misma especie, tendente a dilucidar la posible variabilidad intraespecífica de algunos caracteres morfológicos externos, se estudiaron también todas aquellas larvas capturadas en el campo, sobre las que, después de anestesiarlas con $\mathrm{CO}_{2}$, se realizaba una breve descripción de los caracteres externos más conspicuos. Hecho lo cual, se criaban en el laboratorio hasta la obtención del imago para tener una absoluta certeza sobre su identidad taxonómica. Además, y con la misma idea, se revisó todo el material de larvas de crisópidos depositado en las colecciones de los Departamentos de Biología Animal de las Universidades de Alcalá de Henares y Complutense de Madrid, así como en las colecciones de los autores y algunas particulares, haciendo la salvedad de que en este último caso, sólo se estudiaron aquellas larvas que, por sus peculiares características morfológicas, no dejaban lugar a dudas sobre su correcta asignación específica.

Con objeto de evitar en lo posible lo farragoso y reiterativo de un excesivo número de descripciones, dentro del capítulo dedicado al "Estudio de los Estadios Preimaginales", se opta por:

- Al abordar el estudio de un género representado en la Península Ibérica por varias especies, sólo se ha procedido a la descripción e ilustración detallada de aquellas en las que el conocimiento previo sobre su morfología larvaria era muy escaso o inexistente, limitándonos a señalar e ilustrar del resto de las especies en la discusión del género, aunque su estudio ha sido igualmente minucioso. Sólo se describen aquellos caracteres morfológicos que presentan un indudable valor taxonómico y que, lógicamente, permiten establecer diferencias entre las especies del mismo género.

- Cuando se trata de géneros representados en la Península Ibérica por una única especie, se ha procedido a la descripción e ilustración detallada de cada una de ellas, independientemente de que ya hubieran sido descritas con anterioridad, 
haciendo hincapié, en este caso, en aquellos caracteres de valor taxonómico intergenérico.

Pese al esfuerzo realizado, hay que decir que lamentablemente no se ha podido disponer de material sobre el que realizar las descripciones de algunas especies y que, por lo tanto, no se incluyen en este trabajo. Las causas de ello son muy variadas:

- En algunos casos ha resultado imposible la captura de hembras grávidas con las que iniciar los cultivos, como ha sucedido con especies muy raras, escasamente citadas en la Península Ibérica y de biología prácticamente desconocida en ella (Chrysopa nierembergi, C. phyllochroma, C. nigricostata, etc.), cuya localización dependía más del azar que de otros factores.

- En otros casos, ha sido imposible conseguir que las hembras grávidas recolectadas realizaran la ovoposición en el laboratorio, como ha ocurrido con Chrysoperla mutata, Pseudomallada alarconi e Italochrysa italica, de las que se han colectado hembras grávidas durante los años que ha durado la realización de este trabajo, y en los que en ningún caso se han obtenido puestas de esta especie.

- En determinadas especies, las hembras capturadas realizaron la ovoposición, pero el ciclo de vida quedó interrumpido en alguna de sus fases. Así, por ejemplo, en Nothochrysa fulviceps (Stephens, 1836) y Nothochrysa capitata (Fabricius, 1873) el desarrollo embrionario no llegó a su fin en ninguno de los huevos depositados, razón por la que ha sido imposible describir la larva neonata de ambas especies. Sus larvas maduras, sin embargo, han podido ser descritas basándonos en ejemplares colectados en el campo, ya que ninguna de las dos especies plantea problemas de error en su identificación larvaria.

\section{Clave de subfamilias y géneros de las larvas de Crisópidos ibéricos}

Como introducción al estudio detallado de cada una de las especies, aportamos una clave de determinación de las subfamilias y géneros incluidos en este trabajo, basada en las características morfológicas de las larvas L-1 y L-3.

\section{Clave de subfamilias - Larvas L-1 y L-3}

1 Último segmento antenal piriforme, muy corto, de morfología y dimensiones similares a las del último segmento del palpo labial (Fig. 49.8). Último segmento del palpo labial con 4 o más sensilas en su cara externa (Fig. 49.6) NOTHOCHRYSINAE

- Último segmento antenal alargado, aproximadamente 1/3 de la longitud del segundo segmento (Fig. 4.1). Ultimo segmento del palpo labial con 3 sensilas en su cara externa (Fig. 4.2) CHRYSOPINAE

\section{Clave de géneros}

Subfamilia Nothochrysinae - Larvas L-1 y L-3

1 Larvas desnudas, cuerpo alargado y estrecho, aplanado dorsoventralmente. Larvas maduras con cabeza amarilla y tórax y abdomen de color verde en su totalidad. Manchas cefálicas consistentes en una banda longitudinal central y dos laterodorsales (Fig. 49.2). Setas muy cortas, baciliformes y/o claviformes (Fig. 49.12)

Hypochrysa

- Larvas portadoras de capa de camuflaje, con abdomen ligeramente abombado (Fig. 46.1, 5). Manchas cefálicas muy desarrolladas, ocupando prácticamente la totalidad de la superficie cefálica dorsal (Fig. 47.2, 8). Patas desproporcionadamente largas en relación al tamaño del cuerpo (Fig. 46.1, 5). Setas relativamente largas, uncinadas y filiformes (Fig. 46.1, 5)

Nothochrysa

\section{Subfamilia Chrysopinae - Larvas L-1}

1 Tubérculos laterales del tórax palmeados, portadores de 8 a 10 setas denticuladas (Fig. 45.2). Meso- y metanoto cubiertos por numerosas setas uncinadas (Fig. 45.2). Mandibulas-maxilas muy cortas, de longitud notablemente menor a la de la cápsula cefálica (Fig. 45.2) ........ TRIBU BELONOPTERYGINI: Italochrysa

- Tubérculos laterales del tórax portadores, como mucho, de 3 setas (Fig. 9.2). Meso- y metanoto nunca cubiertos por numerosas setas uncinadas (Fig. 9.2). Mandibulas-maxilas de longitud similar o superior a la de la cápsula cefálica (Fig. 21.1)

TRIBU CHRYSOPINI: 2

2 Antenas más cortas que las mandíbulas-maxilas (Fig. 7.8). Tubérculos laterales del tórax ausentes o muy poco desarrollados, portadores de 1 seta (Fig. 7.2). Setas truncadas (Fig. 7.12) Brinckochrysa

- Antenas más largas que las piezas bucales. Tubérculos laterales del pro-, meso- y metatórax desarrollados, portadores, respectivamente, de 2, 3 y 3 setas (Fig. 9.2). Setas nunca truncadas ......................................... 3

3 Abdomen globoso, con numerosos tubérculos dorsales portadores de setas uncinadas (Fig. 20.2) ......... 4

- Abdomen aplanado dorsoventralmente, con tubérculos dorsales y/o laterodorsales portadores de setas filiformes (Fig. 9.2)

4 Meso- y metanoto con 4 tubérculos dorsales portadores, cada uno, de 1 larga seta (Fig. 22.4) ................. 5

- Tubérculos dorsales del mesonoto ausentes (Fig. 25.2)

5 Setas dorsales del metanoto notablemente más largas que las del mesonoto (Fig. 20.2). Seta cefálica S-2 de igual o mayor longitud que las setas S-3, S-5 y S-6 (Fig. 20.3) Chrysopidia 
- Setas dorsales del meso- y metanoto de longitud similar (Fig. 22.4). Seta cefálica S-2 mucho más corta que las setas S-3, S-5 y S-6 (Fig. 23.3) ...... Cunctochrysa

6 Segmentos abdominales II-V con 12 tubérculos dorsales como máximo (Fig. 22.2). Tubérculos laterodorsales presentes en los segmentos abdominales V-VII (Fig. 25.2)

Pseudomallada

- Segmentos abdominales II-V con más de 12 tubérculos dorsales (Fig. 42.2). Tubérculos laterodorsales presentes en los segmentos abdominales VI-VII (Fig. 42.2)

Suarius

7 Mandíbulas-maxilas de longitud similar a la de la cápsula cefálica. Tubérculos laterales del tórax alargados (Fig. 40. 2). Segmentos abdominales con 4 tubérculos dorsales, portadores de 1 seta larga (Fig. 40.2) ...... Rexa

- Mandíbulas-maxilas de longitud superior a la de la cápsula cefálica. Tubérculos laterales del tórax no alargados (Fig. 9.2). Segmentos abdominales con dos tubérculos laterodorsales portadores, cada uno, de 2 setas (Fig. 9.2)

8

8 Seta cefálica S-12 ausente $\left(^{\star}\right)$. Mancha frontoclipeal presente (Fig. $11.1 \mathrm{a}$ - 10) ........................... Chrysopa

- Seta cefálica S-12 presente. Mancha frontoclipeal ausente (Fig. 16.2)

9 Tubérculos laterales del tórax bien desarrollados (Fig. 16.1). Setas torácicas y abdominales relativamente largas (Fig. 16.1) Chrysoperla

- Tubérculos laterales del tórax muy poco desarrollados, portadores de setas muy cortas (Fig. 38.1). Setas torácicas y abdominales muy cortas (Fig. 38.1) ........... 10

10 Seta cefálica S-4 muy larga en relación a las setas $S-$ 2, S-3 S-5 y S-6 (Fig. 35.2)

Nineta

- Setas cefálicas S-2, S-3, S-4, S-5 y S-6 de longitud similar (Fig. 38.2) Peyerimhoffina

(*) Excepto en Chrysopa viridana

\section{Subfamilia Chrysopinae - Larvas L-3}

1 Mandíbulas-maxilas de longitud notablemente inferior a la de la cápsula cefálica, bruscamente atenuadas en su ápice (Fig. 45. 2). Dorso fuertemente convexo, tanto en tórax como en abdomen (Fig. 45. 2). Setas cefálicas y setas de los tubérculos laterales denticuladas (Fig. 45. 2 , 3, 11-13). Tegumento dorsal cubierto por numerosas hileras de setas uncinadas, tanto en tórax como en abdomen (Fig. 45.2). Larvas asociadas a hormigas del género Crematogaster

TRIBU BELONOPTERYGINI: Italochrysa

- Mandíbulas-maxilas de longitud similar o mayor que la de la cápsula cefálica (Fig. 21.1). Larvas, bien aplanadas dorsoventralmente o bien con abdomen globoso, pero nunca el tórax (Fig. 30.1). Setas nunca denticuladas. Tegumento torácico nunca cubierto por numerosas hileras de setas uncinadas (Fig. 21.1). Larvas de vida libre, predadoras de pequeños artrópodos fitófagos .................................... TRIBU CHRYSOPINI: $\mathbf{2}$

2 Antenas más cortas que mandíbulas-maxilas (Fig. 8.1). Setas torácicas y abdominales truncadas (Fig. 8.2). Tubérculos laterales ausentes (Fig. 8.1). Larvas con coloración disruptiva a base de bandas blancas y pardo rojizas (Fig. 8.1)

Brinckochrysa
- Antenas más largas que mandíbulas-maxilas (Fig. 10.1). Setas torácicas y abdominales nunca truncadas. Tubérculos laterales desarrollados, en distinto grado según los géneros (Fig. 10.1 y 39.1). Coloración no disruptiva 2

3 Larvas portadoras de capa de camuflaje. Abdomen más o menos globoso, con numerosas hileras dorsotransversales de setas uncinadas (Fig. 26.1). Tubérculos laterales del tórax generalmente alargados o pedunculados, portadores de setas muy largas (Fig. 26.1). Tubérculos laterales del abdomen portadores de setas largas, generalmente recurvadas laterodorsalmente (Fig. 26.1) ...... 4

- Larvas desnudas. Abdomen aplanado dorsoventralmente, generalmente con tubérculos laterodorsales, más o menos desarrollados, portadores de 2-5 setas (Fig. 10.1). Tubérculos laterales del tórax semiesféricos o poco desarrollados, pero nunca alargados, portadores de setas relativamente cortas (Fig. 10.1). Tubérculos laterales del abdomen portadores de setas relativamente cortas, no recurvadas laterodorsalmente (Fig. 10.1) .......... 8

4 Mandíbulas-maxilas de longitud igual o ligeramente menor a la de la cápsula cefálica (Fig. 40.2). Tubérculos laterales del tórax muy robustos, poco alargados y con pedúnculo grueso. Segmentos abdominales con 2-3 hileras dorsotransversales de setas uncinadas y una hilera posterior compuesta por setas uncinadas y ganchudas, más largas y gruesas que las de las hileras anteriores (Fig. 41.1) ..................... Rexa

- Mandíbulas-maxilas de longitud superior a la de la cápsula cefálica (Fig. 26.1). Tubérculos laterales del tórax bastante alargados y de pedúnculo fino (Fig. 26.1, 28.1). Segmentos abdominales con varias hileras transversales de setas uncinadas, de morfología y dimensiones iguales en todas las hileras (Fig. 26.1) .................. 5

5 Seta cefálica S-12 ausente o microscópica (Fig. 13.1 10). Tubérculos laterodorsales presentes en los segmentos abdominales V-VII (Fig. 30.1). Larvas generalmente blancas o blanco-amarillentas, con manchas dorsales pardas en tórax y/o abdomen (Fig. 26. 1) ...... Pseudomallada

- Seta cefálica S-12 presente (Fig. 21.2). Tubérculos laterodorsales presentes en los segmentos abdominales VI-VII (Fig. 21.1) .. 6

6 Tubérculos laterales del pro-, meso- y metatórax muy alargados y finos, apenas ensanchados en su ápice y de igual longitud en los 3 segmentos torácicos (Fig. 21.1). Larvas totalmente blancas con escleritos laterodorsales del pronoto muy patentes (Fig. 21.1) ........ Chrysopidia - Tubérculos laterales del meso- y metatórax menos alargados que los del protórax (Fig. 24.1). Larvas con manchas pardas o rojizas en el dorso de tórax y abdomen. Escleritos laterodorsales del pronoto poco patentes (Fig. 23.11)

7 Mesonoto con una hilera transversal de largas setas (Fig. 24. 1). Abdomen moderadamente globoso (Fig. 24.1). Tubérculos laterales del abdomen portadores de setas generalmente filiformes (Fig. 24.1). Larvas blanquecinas con difusas manchas dorsales pardas o rojizas y dos patentes manchas oblicuas en el metanoto. Capa de camuflaje muy pequeña o ausente

Cunctochrysa 
- Metanoto sin hilera transversal de setas (Fig. 43.1). Abdomen extremadamente globoso (Fig. 43.2). Tubérculos laterales del abdomen portadores de setas uncinadas (Fig. 43.1). Larvas blanquecinas con bandas laterodorsales de color pardo. Capa de camuflaje grande, tapando el abdomen y parte del tórax ...... Suarius

8 Abdomen sin tubérculos laterodorsales (Fig. 39.1) con hileras transversales de setas espatuladas, abatidas sobre el dorso y orientadas hacia la línea media (Fig. 39.1)

Peyerimhoffina

- Abdomen con tubérculos laterodorsales más o menos desarrollados, portadores de 2 o más setas filiformes, nunca con hileras transversales de setas espatuladas o uncinadas (Fig. 18.1)

9

9 Larvas de tamaño grande (12-14 mm), muy alargadas y estrechas, con patas muy largas en relación al tamaño del cuerpo. Tubérculos laterales de tórax muy poco desarrollados, portadores de setas cortas. (Fig. 37.1, $37.3,7)$

Nineta

- Larvas más pequeñas (máximo $11 \mathrm{~mm}$ ), con cuerpo fusiforme y patas no muy largas en relación al tamaño del cuerpo. Tubérculos laterales del tórax bien desarrollados, portadores de setas relativamente largas (Fig. 10.1) .. 10

10 Seta cefálica S-12 presente. Mancha frontoclipeal ausente o muy poco desarrollada (Fig. 18.2). Tubérculos laterales del abdomen portadores de 2 setas (Fig. 18.1)

Chrysoperla

- Seta cefálica S-12 ausente $\left(^{*}\right)$. Mancha frontoclipeal presente (Fig. 10.2). Tubérculos laterales del abdomen portadores de más de 2 setas (Fig. 10.1) Chrysopa

(*) Exceptuando a C. viridana

Los estadios preimaginales de los crisópidos ibéricos

La estructuración de este apartado se ha realizado por géneros, y dentro cada uno por especies, contemplando los siguientes apartados:

INTRODUCCIÓN: en la que se aporta información general sobre el género y se indica el estado de conocimiento sobre la morfología larvaria de las especies que lo constituyen.

MORFOLOGÍA LARVARIA: dividido en:

Características generales: Se indican los caracteres morfológicos larvarios generales que definen dicho género.

Dentro de cada una de las especies, se indican:

* Las referencias bibliográficas, en caso de que las hubiera, donde han sido previamente descritos los estadios preimaginales.

* Material utilizado: La procedencia del material en el que basamos este estudio.

* Descripción de los estadios preimaginales: Se lleva a cabo la descripción de los estadios prei- maginales de las especies cuyos estadios no han sido debidamente descritos con anterioridad, o lo han sido de forma poco satisfactoria, resaltando las figuras y los caracteres generales, tanto de L1 como de L-3, que permiten la diferenciación de las larvas.

Discusión: se indican las diferencias morfológicas existentes entre las larvas, y se proponen y comentan los caracteres morfológicos que resultan de utilidad en la diferenciación de las larvas de las especies de un mismo género. Se proporcionan, además, claves de determinación para las larvas L-1 y las larvas L-3 en el caso de géneros no monoespecíficos.

BIOLOGÍA Y COMPORTAMIENTO: se aportan los datos observados por nosotros sobre el tipo de puesta realizado por las hembras, la duración de cada uno de los estadios primaginales y datos que consideremos oportunos sobre el comportamiento de las larvas. Así mismo, se indican las condiciones de cultivo y las especies de los áfidos empleadas en la dieta. También se anotan los sustratos vegetales donde cada especie ha sido hallada, cuando resultan de utilidad complementaria para la identificación. Sobre este particular se recomienda consultar Monserrat \& Marín (1994, 2001).

DISTRIBUCIÓN GEOGRÁFICA Y ALTITUDINAL, FENOLOGÍA: para las especies de distribución geográfica menos generalista o para las más escasamente conocidas, se hace referencia al tipo de distribución que presentan las distintas especies en la Península Ibérica, de su amplitud altitudinal y su fenología conocida en la bibliografía y actualizada con los nuevos datos inéditos recolectados por nosotros hasta el año 2011.

\section{Género Brinckochrysa}

El género Brinckochrysa Tjeder, 1966 es conocido del Viejo Mundo, en las regiones Afrotropical, Oriental, Australiana y sur de la región Paleártica. Incluye hasta el presente 17 especies (Hölzel, 1987; Brooks \& Barnard, 1990; Aspöck et al., 2001), de las cuales sólo se conocen los estadios preimaginales de cuatro especies (Díaz-Aranda \& Monserrat, 1992).

En Europa el género Brinckochrysa está representado por dos especies: B. chlorosoma (Navás, 1914), ampliamente distribuida por la región Etiópica y extendida desde Cabo Verde y norte de África hacia la Oriente Medio, Mediterráneo orien- 


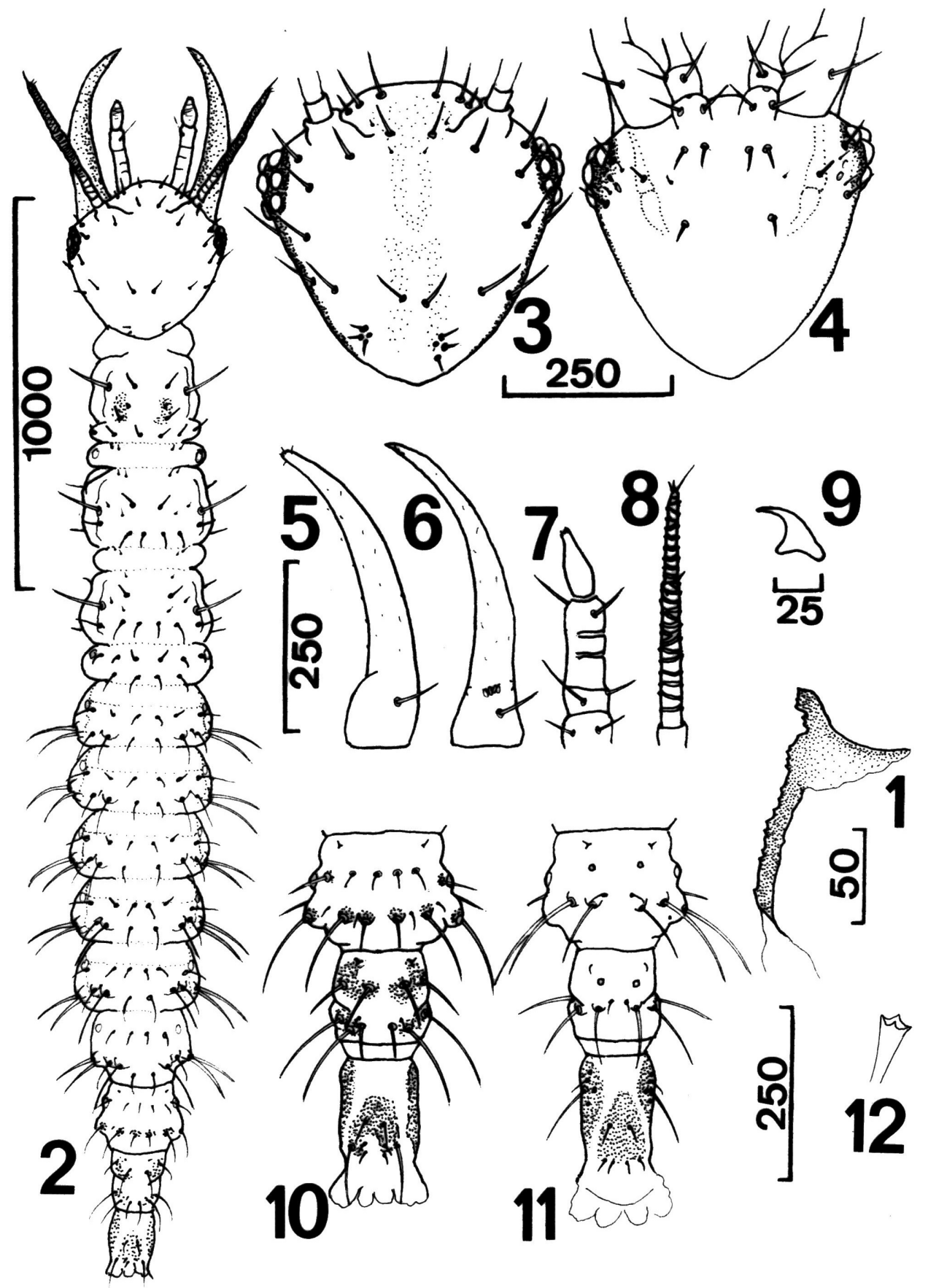

Fig. 7.- Brinckochrysa nachoi (L-1). 1, Ovirruptor. 2, Aspecto general (VD). 3, Cápsula cefálica (VD). 4, Ídem (VV). 5, Maxila. 6, Mandíbula. 7, Palpo labial. 8, Antena. 9, Uña. 10, Segmentos abdominales VIII-X (VD). 11, Ídem (VV). 12, Detalle del ápice de una seta del tegumento dorsal de tórax y abdomen. Escalas en $\mu$ m. Adaptado de Díaz-Aranda \& Monserrat (1992).

Fig. 7.- Brinckochrysa nachoi (L-1) (first instar larva). 1, Oviruptor. 2, Habitus (DV). 3, Head capsule (DV). 4, Ditto (VV). 5, Maxilla. 6, Mandible. 7, Labial palp. 8, Antenna. 9, Claw. 10, Abdominal segments VIII-X (DV). 11, Ditto (VV). 12, Detail of apex of a seta on the thoracic or abdomen dorsum. Scales in $\mu \mathrm{m}$. Adapted from Díaz-Aranda \& Monserrat (1992). 
tal, Península Arábiga, antigua URSS, y ha sido citada de Europa en Grecia, Malta y Creta, y $B$. nachoi Monserrat, 1977, que sólo es conocida del sur de España, Francia e Italia. Sus fases juveniles, biología, comportamiento y distribución fueron estudiadas y descritas por Díaz-Aranda \& Monserrat (1992), y ahora actualizamos los registros ibéricos entonces dados.

Material utilizado. Hembras grávidas: España, Cádiz, Tahibilla, 3.VI.1991, sobre Eucaliptus globulus.

\section{ESTADIOS LARVARIOS}

Características generales: (L-1: Figs. 7.1-12, L3: Figs. 8.1-11).

Cuerpo longilíneo, muy alargado y muy aplanado dorso-ventralmente (Figs. 7.2, 8.1).

Larvas desnudas, no portadoras de capa de camuflaje (Figs. 7.2, 8.1).

Larvas L-3 con coloración disruptiva, blanca con manchas dorsales pardo-rojo muy oscuras (Fig. 8.1).

Setación cefálica, torácica y abdominal formada por setas muy cortas, de 2 tipos: filiformes y truncadas, éstas últimas son características del género.

Antenas más cortas que las piezas bucales (Figs. 7.2, 8.1).

Manchas epicraneales no extendidas anteriormente hacia las fosetas pretentoriales, estando reducidas a una corta banda longitudinal a cada lado de la sutura epicraneal (Figs. 7.3, 8.3).

Seta cefálica S-12 presente (Figs. 7.3, 8.3).

Tórax con tubérculos laterales poco/ nada desarrollados, portadores de una seta lateral (Figs. 7.2, 8.1).

Abdomen con tubérculos laterales de los segmentos II-VII poco o nada desarrollados, portadores de dos setas laterales (Figs. 7.2, 8.1).

De la larva neonata (Figs. 7.1-12). Los anteriormente indicados, salvo: Coloración apenas marcadamente disrruptiva y setación cefálica, torácica $\mathrm{y}$ abdominal formada por setas que presentan 4 puntas apicales (Fig. 7.12).

De la larva madura (Figs. 8.1-11). Los anteriormente indicados salvo: Setación cefálica, torácica y abdominal formada por setas que presentan 6 puntas apicales (Fig. 8.2).

Discusión. Las larvas conocidas del género Brinckochrysa se caracterizan por presentar un patrón de coloración disruptiva muy conspicua, que en el caso del único representante en la fauna ibérica (B. nachoi) consistente en 2 bandas longitudinales laterodorsales de color rojo muy oscuro, que se interrumpen a nivel de los segmentos meso-, meta- torácicos y abdominales III y IV, quedando así bandas transversales blancas sobre cada uno de estos segmentos (Fig. 8.1). Los datos generales anteriormente citados, sobre todo la pigmentación y quetotaxia cefálica y tegumentaria (Figs. 7.2-12, 8.1-11), y especialmente la presencia de setas truncadas de extremo estrellado (Figs. 1.12, 8.2), y las antenas más cortas que las piezas bucales son característicos. No existe en la fauna ibérica ninguna especie con larvas que presenten estos elementos.

BiOLOGÍA Y COMPORTAMIENTO. En relación a sus fases juveniles, datos sobre número de huevos por puesta (entre 7 a 13), tipo de puestas (huevos aislados), duración del desarrollo embrionario (5 días), biología y comportamiento de las larvas (desnudas sin capa de camuflaje, activas y presuntamente corticícolas), duración de los estadios larvarios (entre 7-8 días para L-1, 7-10 días para L-2 y 10-20 días para L-3, en condiciones de temperatura: $25^{\circ} \mathrm{C}$, fotoperiodo: 16L:8D, humedad relativa: $60-80 \%$, áfidos suministrados (Aphis craccivora Koch, 1854 y Aphis fabae Scopoli, 1763) y periodo de pupación (15-20 días) pueden obtenerse de Díaz-Aranda \& Monserrat (1992).

La biología del imago de $B$. nachoi es poco conocida, existiendo datos sobre el régimen alimenticio, parásitos y fenología de los imagos en Monserrat (1977, 1979, 1982b); Canard (1981); Díaz-Aranda \& Monserrat (1992). Los adultos conocidos en la Península Ibérica se han recolectado sobre Olea europaea, Quercus ilex, pero especial- y mayoritariamente sobre Eucaliptus globulus (Monserrat, 1977, 1979, 1982b; Monserrat \& Díaz-Aranda, 1989a; Monserrat \& Rodrigo, 1992; Monserrat \& Marín, 1994).

DisTRIBUCIÓN GEOGRÁFICA Y ALTITUDINAL, FENOLOGíA. Los imagos de esta especie son conocidos en la Península Ibérica únicamente de las provincias de Cádiz y Cáceres. Su rango altitudinal 40-400 m, y han sido hallados entre los meses de mayo y agosto.

\section{Género Chrysopa}

El género Chrysopa Leach, 1815 incluye unas 10 especies neárticas y 50 paleárticas (Brooks \& Barnard, 1990, Aspöck et al., 2001), cifra que ha crecido desde entonces, y de las cuales 8 están representadas en la Península Ibérica: C. perla (Linnaeus, 1768); C. pallens (Rambur, 1838); C. phyllochroma Wesmael, 1841; C. viridana Schneider, 1845; C. formosa Brauer, 1850; C. nigricostata Brauer, 1850; $C$. 


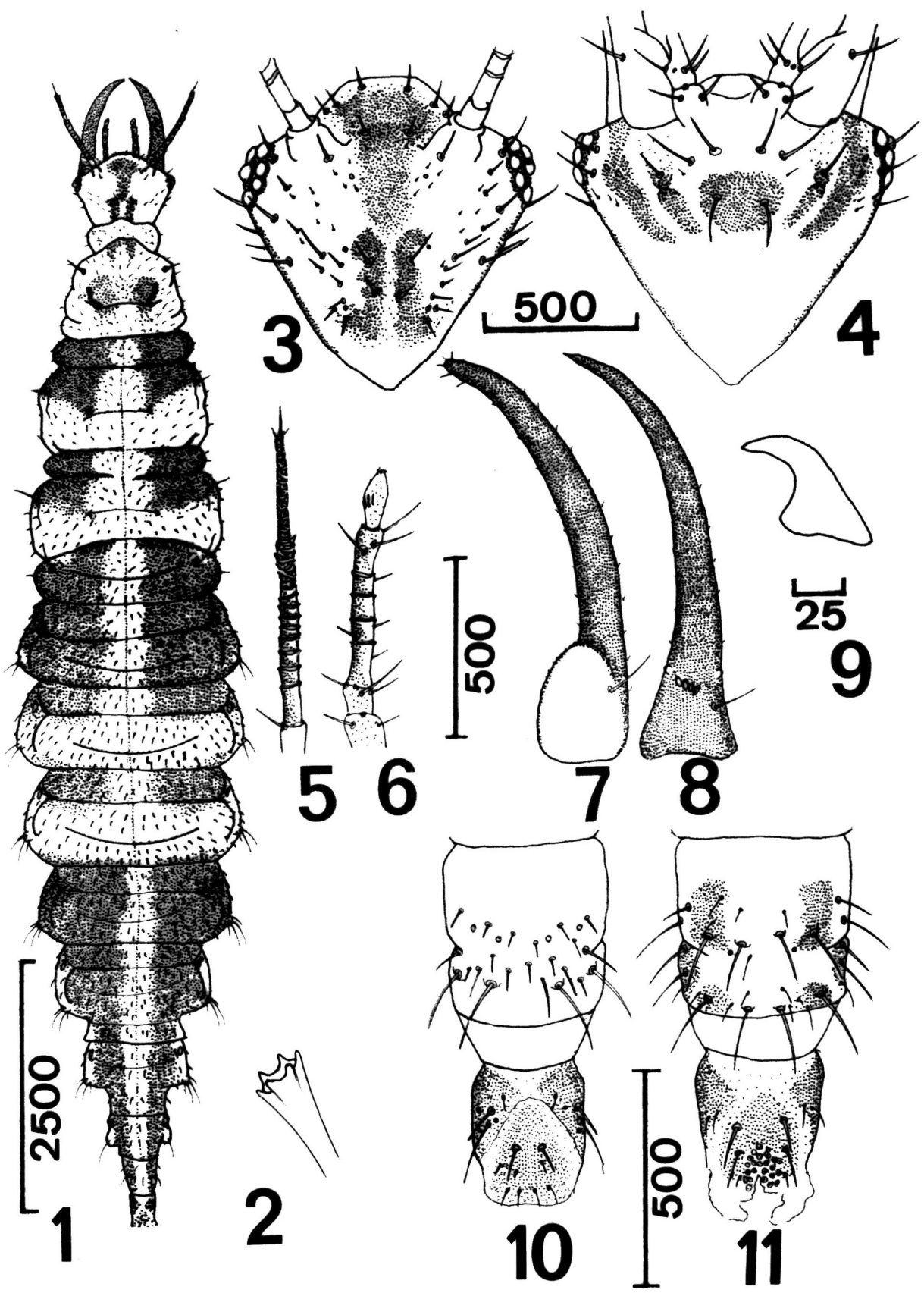

Fig. 8.- Brinckochrysa nachoi (L-3). 1, Aspecto general (VD). 2, Detalle del ápice de una seta truncada del tegumento dorsal. 3, Cápsula cefálica (VD). 4, Ídem (VV). 5, Antena. 6, Palpo labial. 7, Maxila. 8, Mandíbula. 9, Uña. 10, Quetotaxia y pigmentación de los segmentos abdominales IX-X (VV). 11, Ídem (VD). Escalas en $\mu \mathrm{m}$. Adaptado de Díaz-Aranda \& Monserrat (1992).

Fig. 8.- Brinckochrysa nachoi (L-3) (third instar larva). 1, Habitus (DV). 2, Detail of the apex of a truncated seta from dorsal integument. 3, Head capsule (VD). 4, Ditto (VV). 5, Antenna. 6, Labial palp. 7, Maxilla. 8, Mandible. 9, Claw. 10, Chaetotaxy and pigmentation of the abdominal segments IX-X (VV). 11, Ditto (DV). Scales in $\mu \mathrm{m}$. Adapted from Díaz-Aranda \& Monserrat (1992). 
nierembergi Navás, 1908 y C. dorsalis Burmeister, 1839.

La información existente sobre la morfología larvaria de este género es, en general, escasa y fragmentaria, y sólo se conocen en detalle los estadios larvarios de 5 especies neárticas (Smith, 1922; Clancy, 1946; Toschi, 1965; Tauber \& Tauber, 1972; Penny et al., 2000), y de 6 descritas por Tsukaguchi (1978) para las paleárticas orientales, otras por Withycombe (1923), Killington (1937) para la fauna inglesa, otras por Principi (1940, 1947, 1954) para algunas de distribución mediterránea, y Gepp (1983, 1994 b, 1989) para otras centroeuropeas.

En cuanto a las especies ibéricas, los estadios preimaginales de C. perla, C. pallens, C. phyllochroma, C. viridana y C. formosa han sido descritos, con mayor o menor detalle, por diversos autores (las referencias correspondientes son indicadas, para cada especie, en el apartado de "Material utilizado"). La larva de $C$. nigricostata fue descrita muy someramente por Brauer (1850) y posteriormente Gepp (1983) reitera esta información anterior y no aporta nuevos datos, motivo por cual creemos necesario la realización una nueva descripción de sus estadios preimaginales, cuyos datos discutiremos. También la morfología larvaria de $C$. dorsalis, que ahora describimos (Figs. 9.1-11, 10.110), fue utilizada por Monserrat (2008) para la diagnosis y taxonomía de la especie, y la morfología larvaria de C. nierembergi es, hasta el presente, desconocida.

Material utilizado. Para cada especie anotamos la información existente y el material recolectado por nosotros (hembras grávidas / larvas) a partir del cual hemos obtenido / basado las descripción de las fases juveniles.

\section{MORFOLOGÍA LARVARIA}

Características generales: (L-1: Figs. 9.1-11, 11.1-10, 12.1-7, L-3.: Figs. 10.1-10, 13.1-10, 14.17, 15.1-8).

Cuerpo fusiforme, aplanado dorsoventralmente, abdomen no globoso (Figs. 9.2, 12.1-5, 14.1-5).

Larvas desnudas, sólo las neonatas de algunas especies cubren su dorso con restos del corion de los huevos abandonados (Figs. 9.2, 12.1-5, 14.1-5).

Todas las setas son filiformes (Figs. 9.2, 12.1-5, 13.1-10, 14.1-5).

Mancha frontoclipeal y epicraneales bien definidas (Figs. 9.2-3, 10.2, 11.1-5, 13.1-5).

Seta S-12 ausente, excepto en $C$. viridana (Figs. 9.2-3, 10.2, 11.6-10, 13.6-10).
Tubérculos laterales torácicos, bien desarrollados y de similar tamaño en los tres segmentos (Figs. 9.1, 10.1, 12.1-5, 14.1-5).

Meso- y metatórax con tubérculos submediales y laterodorsales bien desarrollados (Figs. 9.1, 10.1, $12.1-5,14.1-5)$.

De la larva neonata (Figs. 9.1-11, 11.1-10, 12.1-7).

Tubérculos laterales torácicos portadores de 2 largas setas en protórax y de 3 en meso- y metató$\operatorname{rax}$ (Figs. 9.2, 12.1-5).

Meso- y metatórax con 4 tubérculos dorsales portadores de largas setas (Figs. 9.2, 12.1-5).

Segmentos abdominales II-VII con tubérculos laterales portadores de 2 largas setas (Figs. 9.2, 12.1-5).

Segmentos abdominales I-VII con 2 tubérculos laterodorsales portadores de 2 largas setas, con 2 pequeños tubérculos submediales portadores de 1 seta, que se va haciendo paulatinamente más corta hacia la región caudal, y con una hilera transversal anterior de 4 pequeñas setas (Figs. 9.2, 12.1-5).

Segmento I-VIII con una pequeña seta anterior a cada espiráculo (Figs. 9.2, 12.1-5).

De la larva madura (Figs. 10.1-10, 13.1-10, 14.1-7, 15.1-8).

Larvas de tamaño relativamente grande (8-11 mm) (Figs. 10.1, 14.1-5).

Tubérculos laterales de pro- meso- y metatórax bien desarrollados, semiesféricos, portadores de setas relativamente largas (Figs. 10.1, 14.1-5).

Tórax con tubérculos dorsales en los 3 segmentos torácicos, de desarrollo variable según especies.

Espiráculo mesotorácico no prominente, circular (Figs. 10.1, 14.1-5).

Segmentos abdominales II-VII con tubérculos laterales semiesféricos, bien desarrollados, portadores de varias setas, de igual longitud que las de los torácicos. Algunas especies presentan un pequeño tubérculo lateral en el segmento I, portador de setas cortas (Figs. 10.1, 14.1-5).

Segmentos I-VII con 2 tubérculos laterodorsales portadores de varias setas hialinas y 2 o 5 (dependiendo de las especies) setas negras, con 2 tubérculos submediales portadores de 1-2 setas y con 1-2 hileras transversales de pequeñas setas (Figs. 10.1, 14.1-5).

Chrysopa perla (Linnaeus, 1768)

La morfología larvaria de esta especie ha sido descrita por diversos autores: Brauer (1850); Lacroix 


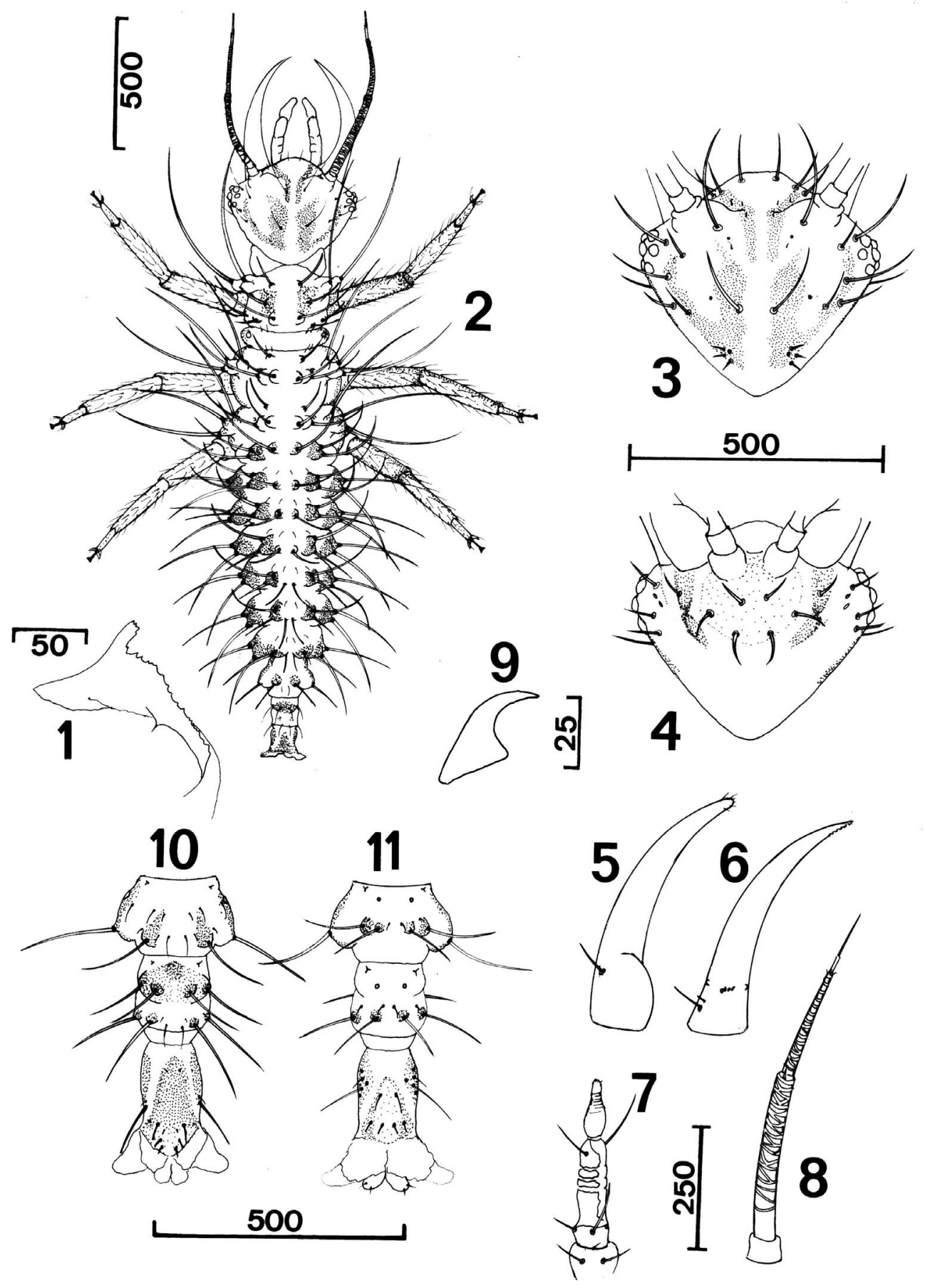

Fig. 9.- Chrysopa dorsalis (L-1). 1, Ovirruptor. 2, Aspecto general. 3, Cápsula cefálica (VD). 4, Ídem (VV). 5, Maxila. 6, Mandíbula. 7, Palpo labial. 8, Antena. 9, Uña. 10, Segmentos abdominales VIII-X (VD). 11, Ídem (VV). Escalas en $\mu$ m. Adaptado de Monserrat (2008).

Fig. 9.- Chrysopa dorsalis (L-1) (first instar larva). 1, Oviruptor. 2, Habitus. 3, Head capsule (DV). 4, Ditto (VV). 5, Maxilla. 6, Mandible. 7, Labial palp. 8, Antenna. 9, Claw. 10, Abdominal segments VIII-X (DV). 11, Ditto (VV). Scales in $\mu \mathrm{m}$. Adapted from Monserrat (2008). 


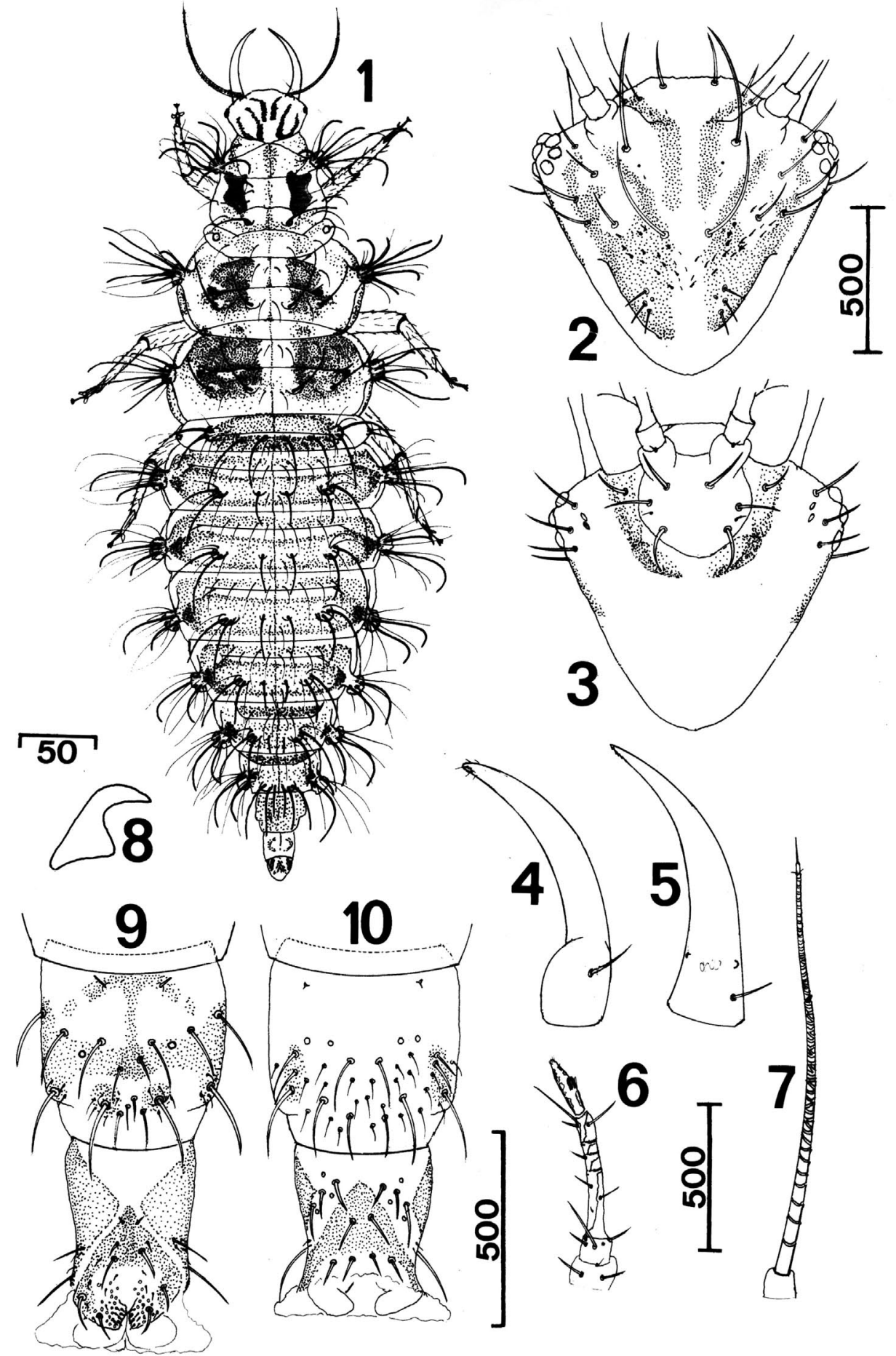

Fig. 10.- Chrysopa dorsalis (L-3). 1, Aspecto general. 2, Cápsula cefálica (VD). 3, Ídem (VV). 4, Maxila. 5, Mandíbula. 6, Palpo labial. 7, Antena. 8, Uña. 9, Segmentos abdominales IX-X (VD). 10, Ídem (VV). Escalas en $\mu$ m. Adaptado de Monserrat (2008).

Fig. 10.- Chrysopa dorsalis (L-3) (third instar larva). 1, Habitus. 2, Head capsule (DV). 3, Ditto (VV). 4, Maxilla. 5, Mandible. 6, Labial palp. 7, Antenna. 8, Claw. 9, Abdominal segments IX-X (DV). 10, Ditto (VV). Scales in $\mu$ m. Adapted from Monserrat (2008). 
(1921); Withycombe (1923); Killington (1937); Gepp (1983, 1986, 1989, 1999), etc. Estos trabajos describen la morfología del huevo y larva, pero mayoritariamente nos resultan muy superficiales, ya que se basan, sobre todo, en caracteres de coloración tegumentaria y no aportan detalles de otro tipo de caracteres morfológicos válidos en la diferenciación de la larva de ésta y otras especies del género.

Material utilizado. Hembras grávidas: España, Burgos, Cilleruelo de Bezana, 3.VII.1989, sobre Quercus robur. Huesca, Sallent de Gallego, 9.VII. 1988, sobre Corylus avellana.

\section{Descripción de los estadios preimaginales L-1: Figs. 11.1, 11.6 y 12.1. L-3: Figs. 13.1, 13.6 y 14.1.}

\section{Chrysopa pallens (Rambur, 1838)}

Los estadios preimaginales de esta especie (bajo la denominación de Chrysopa septempunctata Wesmael, 1841), han sido descritos por Withycombe (1923); Killington (1937); Principi (1940); Agekjan (1973); Tsukaguchi (1978), Pantaleoni (1983), Gepp (1983, 1989), etc. De entre ellos merece ser destacado el realizado por Principi (1940), en el que son descritos en detalle el huevo, larva neonata, larva madura y pupa, aportándose profusamente datos sobre su comportamiento.

Material utilizado. Hembras grávidas: España, Madrid, Alcalá de Henares, 6.VIII.1988, en trampa de luz.

Larvas: España, Madrid, Alcalá de Henares, 13.VII.88, sobre Robinia pseudoacacia.

Descripción de los estadios preimaginales

L-1: Figs. 11.4, 11.9, 12.4 y Figs 2.1 a 2.7 (de Principi, 1940).

L-3: Figs. 13.4, 13.9 y 14.4.

\section{Chrysopa phyllochroma Wesmael, 1841}

Ampliamente distribuida en Europa, pero muy escasamente citada en la fauna ibérica, existiendo identificaciones, no siempre incuestionables, de escasos ejemplares: Navás (1915, 1924, 1925); Vidal \& López (1943); Aspöck et al. (1980); Monserrat (1987) y Monserrat \& Díaz-Aranda (1989a).

A pesar de haber sido buscada intensamente, nos ha sido imposible obtener hembras grávidas con las que iniciar los cultivos para la obtención de larvas. No obstante, esta especie puede ser incluida en la clave de determinación basándonos en las descripciones de sus estadios larvarios realizadas por Withycombe (1925); Killington (1937); Gepp (1983, 1989) y Tsukaguchi (1978).
Descripción de los estadios preimaginales

L-3: Figs. 15.1-10 de Tsukaguchi (1978), y coloración de Gepp (1983).

\section{Chrysopa viridana Schneider, 1845}

Los estadios preimaginales de esta especie han sido descritos en detalle por Principi (1954). Otros datos sobre su morfología larvaria, aunque más superficiales, son aportados por Gepp (1983) y Pantaleoni (1983).

Material utilizado. Hembras grávidas: España, Jaén, Puerto de Tíscar, 10.VIII.1988, sobre Q. rotundifolia.

Larvas: España, Cáceres, Presa de Proserpina, 4.VI.1990, sobre Q. ilex. Castellón, Villafranca del Cid, 4.VIII.1987, sobre Q. faginea. Guadalajara, Alustante, 14.VIII.1984, 5.IX.1984, sobre $Q$. faginea, Torrebeleña, 13.VIII. 1984, sobre $Q$. faginea.

Descripción de los estadios preimaginales

L-1: Figs. $11.5,11.10$ y 12.5

L-3: Figs. $13.5,13.10$ y 14.5 .

\section{Chrysopa formosa Brauer, 1850}

Los estadios preimaginales de esta especie han sido minuciosamente descritos por Principi (1947) y Tsukaguchi (1978). Descripciones más someras, basadas en la coloración tegumentaria, han sido realizadas por Gepp (1983) y Pantaleoni (1983).

Material utilizado. Hembras grávidas: España, Almería, Cabo de Gata, Rambla de Morales, 18.VII. 1988, a la luz.

Larvas: España, Madrid, Alcalá de Henares, 7.VIII.1991, sobre Robinia pseudoacacia.

\section{Descripción de los estadios preimaginales}

L-1: Figs. $11.2,11.7$ y 12.2

L-3: Figs. 13.2, 13.7 y 14.2.

\section{Chrysopa abbreviata Curtis, 1834}

La única cita de esta especie en la fauna ibérica fue dada por Whittington (2002) con referencia: Spain (sin más datos). Ya Monserrat (2011) discutía y descartaba varias citas erróneas dadas por este autor para la fauna de la Península Ibérica. Salvo esta cita, que consideramos descartable, esta especie no ha sido nunca relacionada con nuestra fauna (Aspöck et al., 1980, 2001), por lo que no ha sido considerada en este estudio.

\section{Chrysopa nigricostata Brauer, 1850}

A pesar de haber sido citada con relativa frecuencia en la Península, se nos plantean ahora dudas acerca de la correcta asignación específica de dichas citas, ya que en repetidas ocasiones, las larvas obte- 

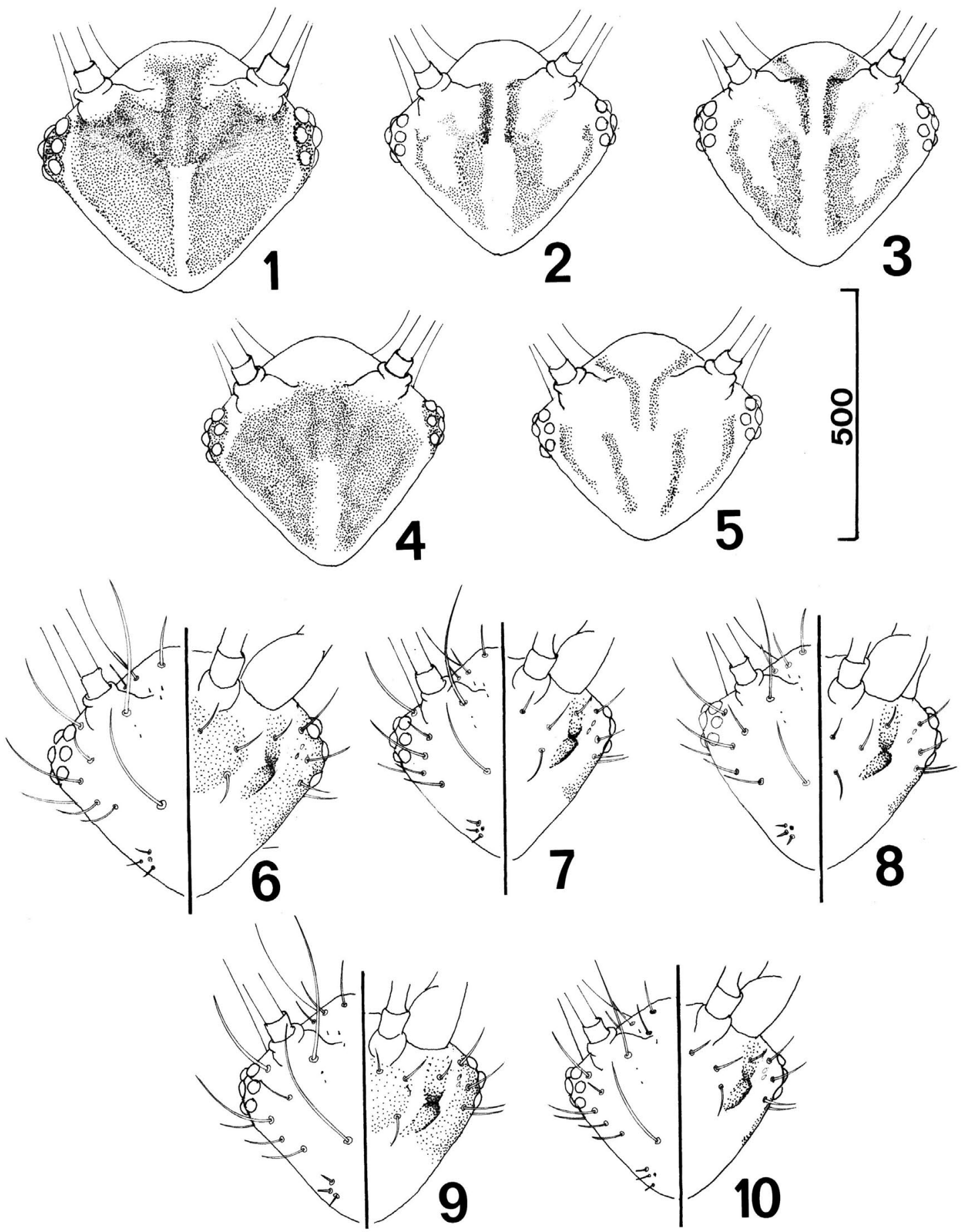

Fig. 11.- Larvas L-1 del género Chrysopa. 1-5: Pigmentación cefálica (VD). 1, C. perla. 2, C. formosa. 3, C. dorsalis. 4, C. pallens. 5, C. viridana. 6-10: Quetotaxia cefálica (izda.:VD /dcha.:VV). 6, C. perla. 7, C. formosa. 8, C. dorsalis. 9, C. pallens. 10, C. viridana. Escala en $\mu \mathrm{m}$.

Fig. 11.- First instar larvae (L-1) of the genus Chrysopa. 1-5: Cephalic pigmentation (DV). 1, C. perla. 2, C. formosa. 3, C. dorsalis. 4, C. pallens. 5, C. viridana. 6-10: Cephalic chaetotaxy (left: DV / right: VV). 6, C. perla. 7, C. formosa. 8, C. dorsalis. 9, C. pallens. 10, C. viridana. Scale in $\mu \mathrm{m}$. 
nidas por nosotros a partir de alguno de estos ejemplares parecen pertenecer género Cunctochrysa, motivo por el que las identificaciones asignadas a esta especie podrían cuestionarse, y sin haber aún estudiado adecuadamente los imagos de donde proceden estas larvas, nos limitamos, por ahora, a citar este dato. Como indicamos, los estadios preimaginales de esta especie han sido descritos de forma testimonial por Brauer (1850) y Gepp (1983), por lo que no hemos podido incluirla en las claves.

\section{Chrysopa dubitans (McLachlan, 1887)}

Algo similar ocurre con esta especie, de la que existe una cita en Murcia (Hölzel \& Ohm, 1972) que ha generado numerosas referencias posteriores para la fauna ibérica. Siendo precisamente una zona especialmente muestreada por nosotros (Díaz Aranda \& Monserrat, 1988b; Monserrat \& Díaz Aranda, 1989; Monserrat, 1984b, 1985, 1987, 1988b; Marín \& Monserrat, 1991; Monserrat \& Rodrigo, 1992), nunca la hemos hallado, y nos reservamos cuestionar la autenticidad de la identificación. En cualquier caso no ha sido incluida en nuestro estudio.

\section{Chrysopa walkeri McLachlan, 1893}

Igual ocurre con esta especie, ya que desde que Navás (1924) la cita como probable en Cataluña, y posteriormente la incluye en su clave de "especies ibéricas" (Navás, 1925), aún mencionando que no existe en la Península Ibérica, son numerosas las reseñas de esta especie que la mencionan en ella, pero hasta ahora no hay datos reales que lo avalen. Por ello la especie no ha sido considerada.

\section{Chrysopa nierembergi Navás, 1908}

Especie ibérica de biología prácticamente desconocida y muy poco citada (Monserrat \& Rodrigo, 1992; Monserrat \& Díaz-Aranda, 1989a). Durante los muestreos realizados en este trabajo no hemos conseguido hembras grávidas con las que poder obtener huevos y larvas.

\section{Chrysopa dorsalis Navás, 1915}

Especie muy poco conocida y de la que la morfología de sus estadios preimaginales no ha sido descrita con anterioridad, existiendo únicamente datos puntuales sobre captura de imagos y sobre su ciclo biológico en Canard (1986). Las figuras ahora aportadas, fueron utilizadas por Monserrat (2008) para la diagnosis de esta especie en relación a su especie sinónima C. regalis Navás, 1915, pero la larva no había sido descrita hasta ahora.

Material utilizado. Hembras grávidas: España, Teruel, Sierra de Albarracín, Fuente de la Señora, 10.VII. 1990, a la luz.

Descripción de los estadios preimaginales

L-1: Figs. 9.1 - 11, 11.3, 11.8 y 12.3

L-3: Figs. $10.1-10,13.3,13.8$ y 14.3.

Huevo. Huevos verdes con micropilo blanco. Longitud del huevo: 0.9-1 mm. Longitud del pedúnculo: $8.2-9.5 \mathrm{~mm}$.

Ovirruptor. Ligeramente esclerotizado, con denticulación según Fig. 9.1.

Larva neonata. Aspecto general según Fig. 9.2. Coloración pardo-pálida con los tubérculos laterodorsales y laterales del abdomen de color pardo.

Cabeza amarillenta con manchas cefálicas pardas. Mancha frontoclipeal longitudinalmente dividida en dos (Fig. 9.3), epicraneales fuertemente bifurcadas (Fig. 9.3) y genales bifurcadas en su extremo anterior y ligeramente extendidas a la cara ventral (Fig. 9.4). Cardo y estipe ligeramente esclerotizados (Fig. 9.4). Quetotaxia dorsal y ventral de la cápsula cefálica según Figs. 9.3 y 9.4. Maxila (Fig. 9.5) y mandíbula (Fig. 9.6) ámbar. Palpos labiales (Fig. 9.7) y antenas (Fig. 9.8) crema muy pálido. Ojos formados por 6 estemmata de color negro.

Tórax crema amarillento con escleritos laterodorsales pardos. Pro-, meso- y metatórax con tubérculos dorsales y laterodorsales portadores de 1 seta (Fig. 9.2). Tubérculos laterales portadores de 2 largas setas en el protórax y de 3 en el meso- y metatórax (Fig. 9.2). Patas hialinas, empodio pardo-oscuro. Uñas ámbar, triangularmente dilatadas en su base (Fig. 9.9).

Abdomen crema amarillento, con tubérculos laterodorsales y laterales fuertemente esclerotizados (Fig. 9.2). Segmentos I-VII con tubérculos laterodorsales portadores de 2 setas y tubérculos submediales, menos desarrollados, portadores de 1 seta (Fig. 9.2). Segmento I sin seta lateral. Segmentos II-VII con tubérculos laterales portadores de 2 setas. Quetotaxia y pigmentación dorsal y ventral de los segmentos VIII-X según Figs. 9.10 y 9.11 respectivamente. Segmento X con 4 setas en el margen posteroventral (Fig. 9.11).

Larva madura. Aspecto general según Fig. 10.1. Coloración blanquecina o crema con manchas dorsales pardas o pardo oscuras. 
Cabeza amarillenta con manchas cefálicas pardo oscuras. Mancha frontoclipeal longitudinalmente dividida en dos (Fig. 10.2). Manchas epicraneales fuertemente bifurcadas (Fig. 10.2). Genales bifurcadas en su margen anterior y muy ligeramente extendidas a la cara ventral (Fig. 10.3). Cardo y estipe fuertemente esclerotizados (Fig. 10.3). Quetotaxia dorsal y ventral de la cápsula cefálica según Figs. 10.2 y 10.3 respectivamente. Maxilas (Fig. 10.4) y mandíbulas (Fig. 10.5) ámbar. Palpos labiales pardopálidos, con el $2^{\circ}$ segmento dividido en 4 artejos (Fig. 10.6). Antena (Fig. 10.7) pardo pálido basalmente y pardo oscuro distalmente. Ojos formados por 6 estemmata negros, dispuestos según Figs. 10.2-3.

Tórax con coloración blanquecina o crema, con escasas y dispersas manchas en el pronoto y 2 manchas pardas, una a cada lado de la línea media, en meso- y metanoto (Fig. 10.1). Escleritos laterodorsales poco patentes (Fig. 10.1). Tubérculos dorsales y laterodorsales portadores de una larga seta negra (Fig. 10.1). Tubérculos laterales semiesféricos, portadores de numerosas setas hialinas y negras (Fig. 10.1). Patas de color crema con empodio pardo oscuro. Uñas ámbar, triangularmente dilatadas en su base (Fig. 10.8).

Abdomen de coloración blanquecina o crema, con manchas pardas cubriendo la superficie dorsal de los segmentos I-VIII, salvo los tubérculos submediales y laterodorsales, que aparecen de color crema (Fig. 10.1). Segmento I sin tubérculo lateral o muy reducido, portador de 2 pequeñas setas. Segmentos II-VII con tubérculos laterales esféricos bien desarrollados, portadores de varias setas hialinas y 2 setas negras (Fig. 10.1). Segmentos I-VII con tubérculos laterodorsales bien desarrollados, portadores de varias setas hialinas y 2 setas negras, y tubérculos submediales, menos desarrollados que los anteriores, portadores de una seta negra (Fig. 10.1). Quetotaxia y pigmentación dorsal y ventral de los segmentos IX-X según Fig. 10.9 y 10.10 respectivamente. Segmento X con 4 setas en el margen posteroventral (Fig 10.10).

Discusión. A pesar de que las larvas del género Chrysopa presentan una morfología considerablemente homogénea, existen ciertos caracteres que permiten establecer diferencias entre sus especies. Los caracteres morfológicos externos aquí estudiados son suficientemente constantes, presentando una escasa variabilidad intraespecífica y permitiendo así una correcta asignación de las larvas, tanto neonatas como maduras, de este género.
En el caso de las larvas neonatas, las similitudes entre las distintas especies son bastante acusadas, sin embargo existen ciertos caracteres morfológicos que resultan de gran utilidad en la diferenciación de las mismas. Estos son: pigmentación y quetotaxia de la cápsula cefálica, quetotaxia abdominal y la esclerotización de los tubérculos laterodorsales y laterales de tórax y abdomen. Veámoslas por separado.

La forma y dimensiones de las manchas cefálicas frontoclipeal y epicraneales presentan, generalmente, diferencias acusadas entre las especies de este género, resultando por ello uno de los caracteres de mayor utilidad en la diferenciación de las larvas. En las larvas de las especies ibéricas, las manchas frontoclipeal y epicraneales aparecen fuertemente unidas en una única mancha cefálica en el caso de $C$. perla (Fig. 11.1) y C. pallens (Fig. 11.4). Diferenciándose entre sí en función de que la macha frontoclipeal se extienda anteriormente rebasando las fosetas pretentoriales (Fig. 11.1) o que se extienda solo hasta éstas (Fig. 11.4). En las restantes especies las manchas epicraneales y frontoclipeal son independientes (Figs. 11.2, 3, 5), sin embargo $C$. viridana se diferencia por poseer las manchas epicraneales longitudinalmente divididas en dos finas ramas (Fig. 11.5), mientras que en $C$. formosa y $C$. dorsalis dichas manchas aparecen fuertemente bifurcadas, pero no divididas totalmente (Figs. 11.2-3). A su vez estas dos últimas especies pueden ser diferenciadas en función de que su mancha frontoclipeal se extienda hacia la región clípeo-labral, rebasando las fosetas pretentoriales (Fig. 11.3: C. dorsalis) o sólo hasta las mencionadas fosetas (Fig. 11.2: C. formosa).

La quetotaxia cefálica, sin embargo, es común en todas las especies estudiadas exceptuando la presencia o ausencia de la seta cefálica S-12. En nuestro caso, dicha seta sólo aparece en $C$. viridana (Fig. 11.10) y no está desarrollada o es microscópica en el resto de las especies (Figs. 11.6-9).

El número y disposición de las setas torácicas y abdominales, al igual que la quetotaxia cefálica, es prácticamente idéntico en todas las especies, exceptuando: La presencia o ausencia de una seta lateral en el segmento abdominal I, carácter ya utilizado por Tsukaguchi (1978) en la diferenciación de las larvas neonatas de este género (la presencia de esta seta está relacionada con el desarrollo del tubérculo lateral, de ese mismo segmento, en las larvas maduras, y dicha seta está presente en C. pallens (Fig. 12.4) y $C$. viridana (Fig. 12.5) y ausente en el resto de las espe- 
cies estudiadas por nosotros (Figs. 12.1, 2, 3), y el número de setas de la hilera transversal del margen posteroventral del segmento abdominal $X$, que es un carácter, utilizado por primera vez en la diferenciación de las larvas y se mantiene, además, en las larvas L-3. Así, en $C$. perla y $C$. viridana el número de setas es siempre de 6 (Fig. 12.7), mientras que en el resto de las especies es siempre de 4 (Fig. 12.6).

El número de tubérculos laterales y laterodorsales que aparecen esclerotizados también es un carácter utilizado por primera vez y puede ayudar, junto con los mencionados anteriormente, en la correcta asignación de las larvas neonatas. C. perla posee los tubérculos laterales y laterodorsales de todos los segmentos torácicos y abdominales fuertemente esclerotizados (Fig. 12.1). En C. pallens los tubérculos laterales del protórax y segmento abdominal II y los tubérculos laterodorsales del tórax no están esclerotizados, presentando el resto de los tubérculos una fuerte esclerotización (Fig. 12.4). En C. formosa (Fig. 12.2) y C. dorsalis (Fig. 12.3) sólo están esclerotizados los tubérculos, tanto laterales como laterodorsales, del abdomen. Por último, en $C$. viridana (Fig. 12.5) únicamente los tubérculos laterodorsales de los segmentos abdominales IV-VII presentan esclerotización.

Las larvas del tercer estadio en este género presentan diferencias más acusadas entre sus especies que las larvas neonatas, pudiéndolas diferenciar fácilmente en base a los siguientes caracteres morfológicos: Pigmentación y quetotaxia de la cápsula cefálica, morfología de la uña, quetotaxia abdominal y coloración tegumentaria de tórax y abdomen. Pasemos a ellos.

En cuanto al primer carácter, caben las mismas consideraciones que lo expuesto anteriormente para la larva neonata. Aunque las manchas cefálicas presentan variabilidad intraespecífica con el desarrollo de las larvas, las dimensiones y forma de las mismas se mantienen constantes para cada uno de los estadios. Este hecho, unido a la facilidad de observación de las citadas manchas, tanto en ejemplares vivos como fijados, hace de éste uno de los caracteres de mayor utilidad en la diferenciación de las larvas, motivo por el cual ha sido utilizado por diversos autores (ver, por ejemplo, Tauber, 1974 o Tsukaguchi, 1978). Así, en las especies aquí estudiadas, la mancha frontoclipeal puede aparecer como una única mancha impar o bien como una mancha dividida longitudinalmente en dos ramas, separándose $C$. perla (Fig. 13.1) y $C$. pallens (Fig. 13.4) de las restantes especies (Figs. 13.2, 3, 5).
A su vez, esta mancha puede extenderse hacia la zona clipeal rebasando las fosetas pretentoriales, o extenderse sólo hasta éstas, no rebasándolas, diferenciándose por un lado $C$. perla (Fig. 13.1) de C. pallens (Fig. 13.4) y por otro $C$. formosa (Fig. 13.2) de $C$. dorsalis y $C$. viridana (Figs. 13.3, 5). Estas dos últimas especies quedan separadas en función de que sus manchas epicraneles estén fuertemente bifurcadas $(C$. dorsalis, Fig. 13.3) o estén completamente divididas (C. viridana, Fig. 13.5).

En relación a la quetotaxia cefálica, al igual que en las larvas L-1, ésta parece ser prácticamente idéntica en las distintas especies, manteniéndose constante en L-3 y apareciendo como única diferencia la presencia en $C$. viridana de la seta cefálica S-12 bien desarrollada (Fig. 13.10).

La morfología de la uña, segundo carácter propuesto, se mantiene en los imagos de las especies estudiadas y resulta también de gran utilidad en la distinción de los especímenes larvarios, tanto en éste como en otros géneros de la familia. En el caso que nos ocupa se distinguen claramente dos tipos morfológicos de uña:

- uñas triangularmente dilatadas en su base (Fig. 6.6). - uñas cuadrangularmente dilatadas en su base (Fig. 6.4).

En las especies aquí estudiadas, sólo $C$. dorsalis y, según Tsukaguchi (1978) C. phyllochroma poseen el primer tipo de uña y el resto de las especies el segundo.

El tercer carácter citado, la quetotaxia abdominal, nos permite establecer diferencias entre las especies basándonos en:

- La presencia o ausencia de tubérculo lateral en el segmento abdominal I. C. pallens y $C$. viridana poseen, en dicho segmento, un tubérculo lateral bien desarrollado, portador de varias setas (Figs. 14.4-5), mientras que en el resto de las especies este tubérculo se encuentra considerablemente reducido, portando un par de setas, o es ausente (Figs. 14.1-3).

- Sobre el número de setas negras presentes en los tubérculos laterodorsales, en todas las especies dichos tubérculos son portadores de dos tipos de setas: setas hialinas en número variable y setas negras, generalmente más largas y conspicuas, en número de 5 en el caso de $C$. perla y $C$. pallens (Figs. 14.1,4) y en número de 2 en el caso de $C$. formosa, C. dorsalis y C. viridana (Figs. 14.2, 3, 5).

- Sobre el número de setas de la hilera posteroventral del segmento abdominal $X$, es un carácter que 

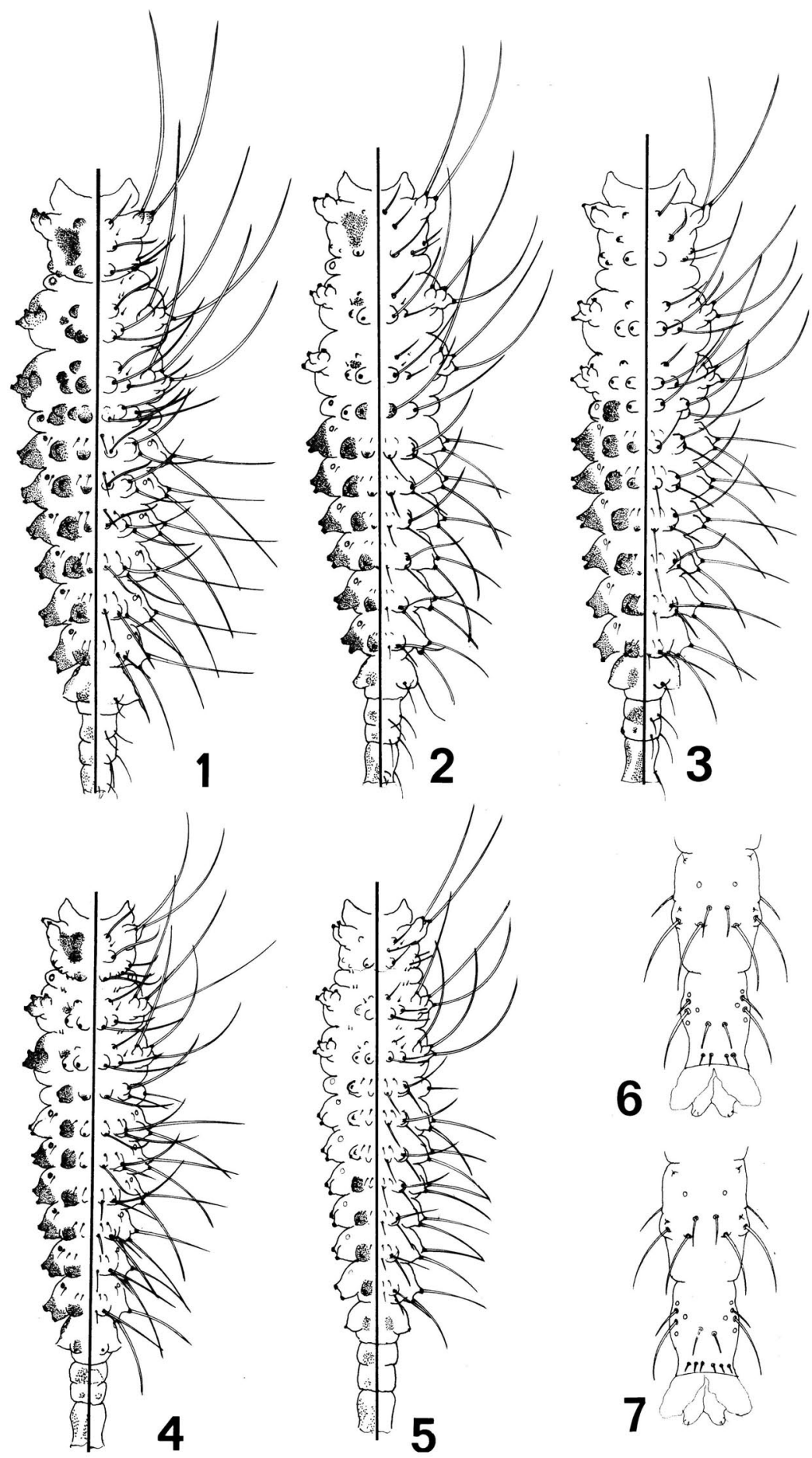

Fig. 12.- Larvas L-1 del género Chrysopa. 1-5: Pigmentación (izquierda) y quetotaxia (derecha) del tórax y abdomen (VD). 1, C. perla. 2, C. formosa. 3, C. dorsalis. 4, C. pallens. 5, C. viridana. 6-7, Quetotaxia ventral del segmento abdominal X.

Fig. 12.- First instar larvae (L-1) of the genus Chrysopa. 1-5: Pigmentation (left) and chaetotaxy (right) of thorax and abdomen (DV). 1, C. perla. 2, C. formosa. 3, C. dorsalis. 4, C. pallens. 5, C. viridana. 6-7, Ventral chaetotaxy of abdominal segment $\mathrm{X}$. 
se mantiene en L-3 y, al igual que en L-1, C. perla y $C$. viridana poseen 6 setas (Fig. 14.7), mientras que en el resto de las especies poseen sólo 4 setas (Fig. 14.6).

Por último, la coloración tegumentaria dorsal de tórax y abdomen sea quizá el carácter más conspicuo, utilizado y accesible para la diferenciación de las larvas vivas. Sin embargo dicho carácter está sometido a cierto grado de variabilidad en función de factores tales como los hábitos alimenticios de las larvas, estado de nutrición de las mismas, periodo de tiempo transcurrido desde la última muda, etc. Es por ello que, si este carácter se utiliza de forma exclusiva, puede conducir a errores en la asignación de las larvas.

Mientras que la extensión y coloración de las manchas dorsales presentan generalmente cierto grado de variabilidad intraespecífica, la disposición de las mismas se mantiene normalmente constante. Las larvas de $C$. dorsalis, $C$. perla y $C$. pallens presentan coloración base crema o blanco amarillento con manchas dorsales pardas o pardo oscuras, tanto en tórax como en abdomen. Sin embargo, son fácilmente distinguibles en función de que los tubérculos laterales de meso- y metatórax estén o no pigmentados de pardo. En C. dorsalis los tubérculos laterales de ambos segmentos torácicos son enteramente de color crema, en C. perla los tubérculos del metatórax están enteramente pigmentados de pardo, y en $C$. pallens lo están también los del mesotórax. Por otro lado, las larvas de C. formosa y C. viridana presentan coloración amarillenta o anaranjada con manchas dorsales rojizas o pardo-rojizas. Ambas especies son claramente diferenciables en base a que C. formosa presenta, de forma constante, 2 conspicuas manchas pardo oscuras o negruzcas ocupando gran parte de la superficie dorsal del meso y metatórax y en $C$. viridana estas manchas pardas nunca aparecen.

Antes de terminar, creemos necesario indicar que, como ya hemos comentado anteriormente, $C$. viridana es la única especie de este género, tanto de las especies aquí descritas como de las estudiadas por otros autores, que posee seta cefálica S-12. Como se verá más adelante, la ausencia o presencia de dicha seta es característico a nivel de género, manteniéndose siempre constante en todas las especies estudiadas dentro de uno de ellos. La presencia de seta S-12 en esta especie, junto al escaso desarrollo de los tubérculos laterodorsales del abdomen y a la longitud, relativamente corta, de las setas de los tubérculos laterales, dos caracteres que, en un princi- pio, entran dentro del margen de variabilidad interespecífica de un género, hacen que esta especie se separe marcadamente de las restantes del género. Con relación a ello, Bullini \& Cianchi (1984) y Bullini et al. (1980, 1983), mediante la realización de estudios electroforéticos de enzimas, anota que $C$. viridana es una especie genéticamente muy diferente a las otras especies del género Chrysopa estudiadas en dicho trabajo. Este hecho, unido a las diferencias encontradas en la morfología larvaria de C. viridana, hace que resulte necesario un estudio más detallado que dilucide la ubicación de esta especie en la actual taxonomía habitualmente aceptada.

Por último, y basándonos en los caracteres comentados para la diferenciación de las larvas, anotamos una clave de determinación para los estadios larvarios conocidos L-1 y L-3 de las especies ibéricas del género Chrysopa:

\section{Clave para larvas L-1}

1 Mancha frontoclipeal no dividida y completamente unida a las manchas epicraneales. Manchas epicraneales no bifurcadas (Figs. 11.1, 11.4 y 15.1) .................. 2

- Mancha frontoclipeal dividida longitudinalmente en dos. No, o ligeramente unida a las manchas epicraneales. Manchas epicraneales fuertemente bifurcadas (Figs. 11.2, 11.3 y 11.5)

2 Margen anterior de la mancha frontoclipeal rebasando claramente las fosetas pretentoriales (Fig. 11.1). Tubérculos laterodorsales de tórax esclerotizados (Fig. 12.1). Margen posteroventral del segmento abdominal $X$ con una serie transversal de 6 setas (Fig. 12.7)

C. perla

- Margen anterior de la mancha frontoclipeal no rebasando las fosetas pretentoriales (Figs. 11.4 y 15.1). Tubérculos laterodorsales del tórax sin esclerotizar (Fig. 12.4). Margen posteroventral del segmento abdominal $X$ con una serie transversal de 4 setas (Fig. 12.6)

3 Segmento abdominal I con 1 seta lateral (Fig. 12.4). Escleritos laterodorsales del pronoto completamente esclerotizados (Fig. 12.4) .............................. C. pallens

- Segmento abdominal I sin seta lateral. Escleritos laterodorsales protorácicos no esclerotizados internamente (Fig. 15) C. phyllochroma

4 Manchas epicraneales fuertemente bifurcadas en su margen anterior (Figs. 11.2 y 11.3). Seta cefálica S-12 ausente. Tubérculos laterales abdominales esclerotizados (Figs. 12.2 y 12.3). Segmento abdominal I sin seta lateral. Margen posteroventral del segmento abdominal $X$ con una serie transversal de 4 setas (Fig. 12.6) .... 5

- Manchas epicraneales completamente divididas en dos (Fig. 11.5). Seta S-12 presente (Fig. 11.10). Tubérculos laterales abdominales sin esclerotizar (Fig. 12.5). Segmento abdominal I con una seta lateral (Fig. 12.5). Margen posteroventral del segmento abdominal $X$ con una serie transversal de 6 setas (Fig. 12.7)

C. viridana 

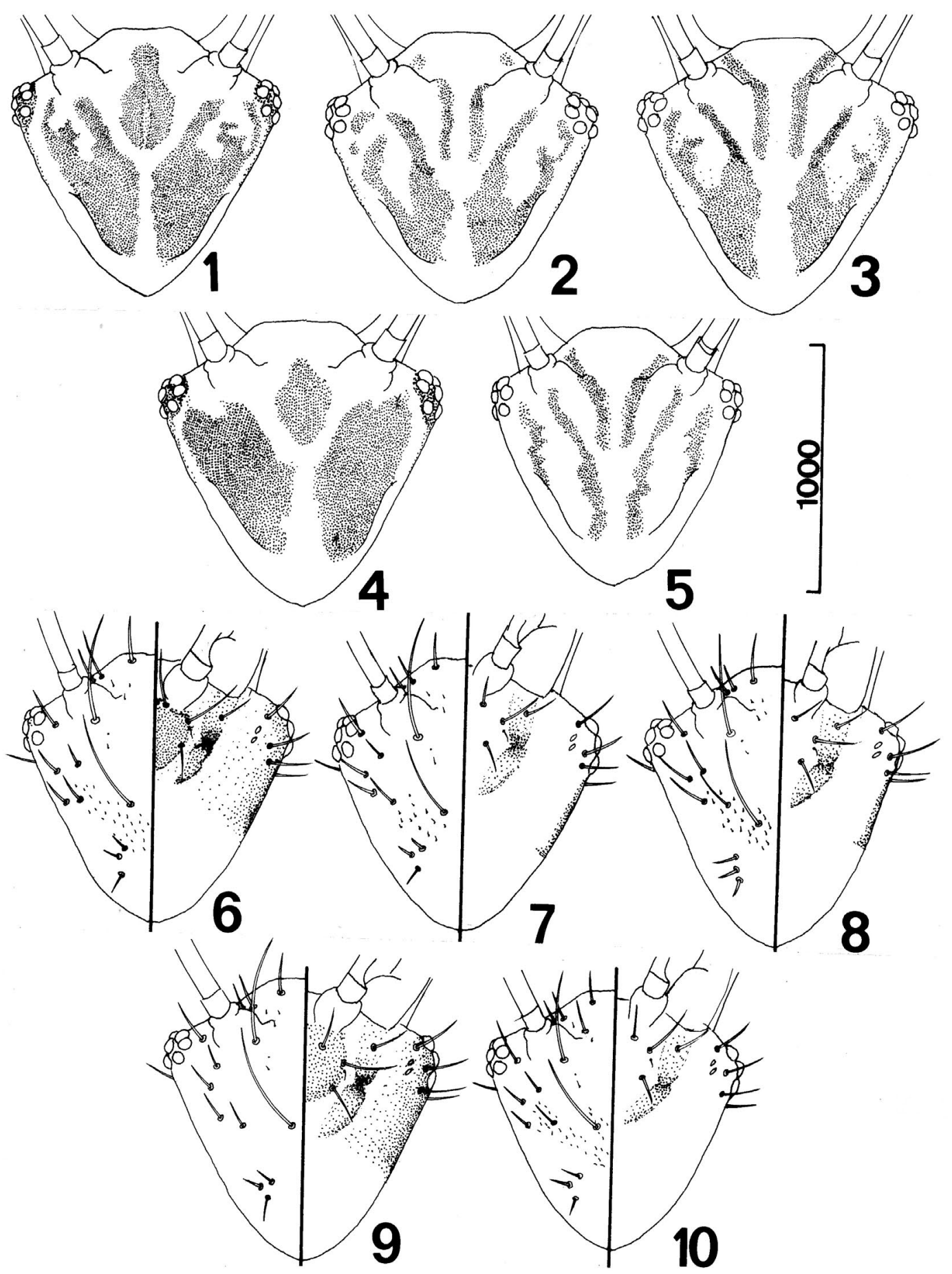

Fig. 13.- Larvas L-3 del género Chrysopa. 1-5: Pigmentación cefálica (VD). 1, C. perla. 2, C. formosa. 3, C. dorsalis. 4, C. pallens. 5, C. viridana. 6-10: Quetotaxia cefálica (izda.: VD/dcha.:VV). 6, C. perla. 7, C. formosa. 8, C. dorsalis. 9, C. pallens. 10, C. viridana. Escala en $\mu \mathrm{m}$.

Fig. 13.- Third instar larvae (L-3) of the genus Chrysopa. 1-5: Cephalic pigmentation (DV). 1, C. perla. 2, C. formosa. 3 , C. dorsalis. 4, C. pallens. 5, C. viridana. 6-10: Cephalic chaetotaxy (left DV / right:VV). 6, C. perla. 7, C. formosa. 8, C. dorsalis. 9, C. pallens. 10, C. viridana. Scale in $\mu \mathrm{m}$. 

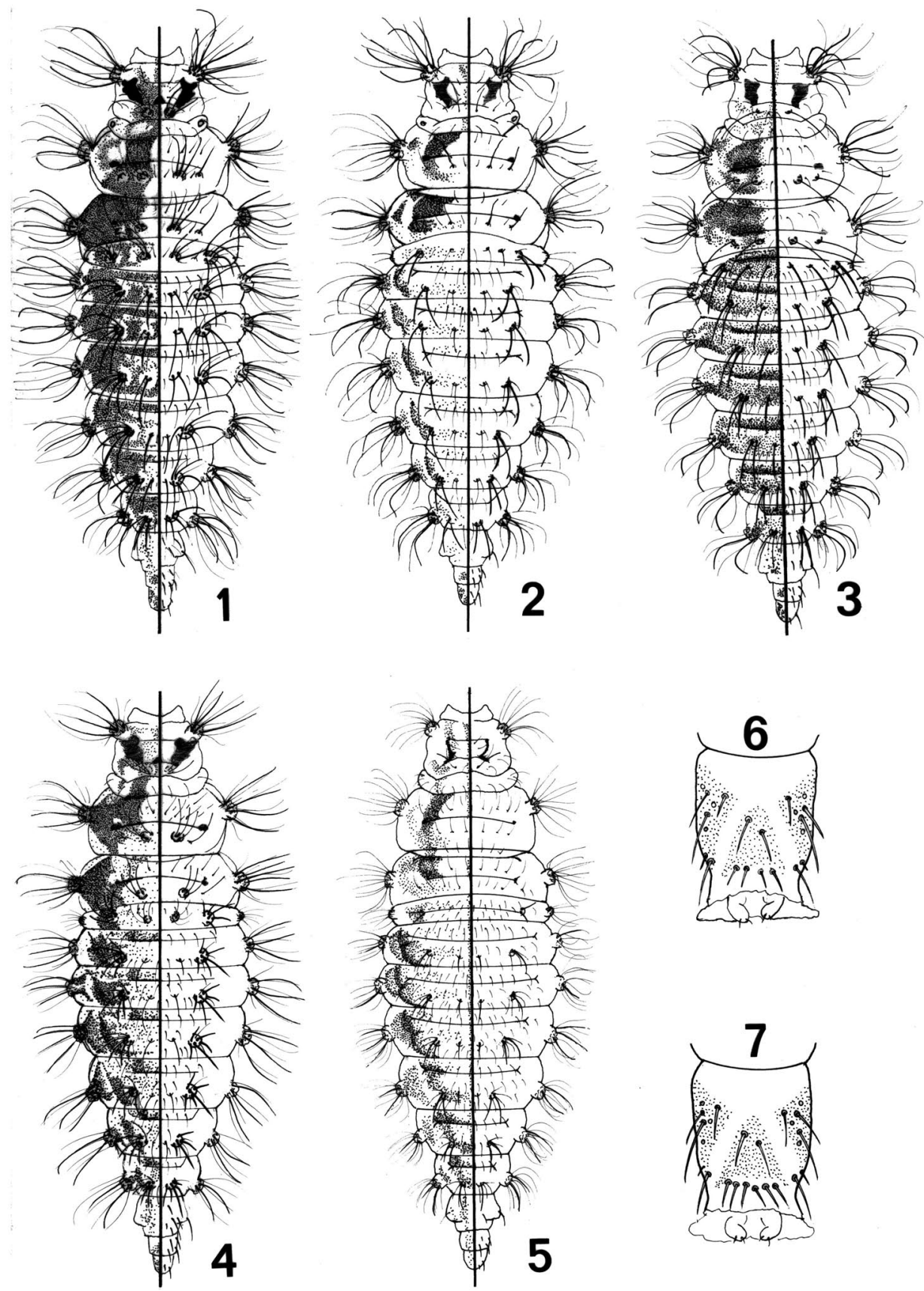

Fig. 14.- Larvas L-3 del género Chrysopa. 1-5: Pigmentación (izquierda) y quetotaxia (derecha) del tórax y abdomen (VD). 1, C. perla. 2, C. formosa. 3, C. dorsalis. 4, C. pallens. 5, C. viridana. 6-7, Quetotaxia ventral del segmento abdominal X.

Fig. 14.- Third instar larvae (L-3) of the genus Chrysopa. 1-5: Pigmentation (left) and chaetotaxy (right) of thorax and abdomen (DV). 1, C. perla. 2, C. formosa. 3, C. dorsalis. 4, C. pallens. 5, C. viridana. 6-7, Ventral chaetotaxy of the abdominal segment $X$. 
5 Margen anterior de la mancha frontoclipeal no rebasando las fosetas pretentoriales (Fig. 11.2). Margen posterior de la mancha frontoclipeal ligeramente unido a las manchas epicraneales (Fig. 11.2) C. formosa

- Margen anterior de la mancha frontoclipeal rebasando claramente las fosetas pretentoriales (Fig. 11.3). Margen posterior de la mancha frontoclipeal no unido a las manchas epicraneales (Fig. 11.3) C. dorsalis

\section{Clave para larvas L-3}

1 Mancha frontoclipeal no dividida (Figs. 13.1 y 13.2). Tubérculos laterodorsales de tórax y abdomen muy desarrollados, estos últimos son portadores de 5 setas negras (Figs. 14.1 y 14.4)

- Mancha frontoclipeal dividida longitudinalmente en dos ramas (Figs. 13.2, 3, 5). Tubérculos laterodorsales de tórax y abdomen poco desarrollados, estos últimos son portadores de 2 setas negras (Figs. 14.2, 3, 5) ........ 3

2 Manchas epicraneales ligeramente bifurcadas (Fig. 13.1). Mancha frontoclipeal rebasando las fosetas pretentoriales (Fig. 13.1). Segmento abdominal I sin tubérculo lateral (Fig. 14.1). Setas negras de los tubérculos laterodorsales del abdomen muy largas, de igual longitud que las de los tubérculos laterales (Fig. 14.1). Margen posteroventral del segmento abdominal $X$ con 6 setas (Fig. 14.7). Tubérculo lateral mesotorácico no pigmentado de pardo (Fig. 14.1) C. perla

- Manchas epicraneales no bifurcadas (Fig. 13.4). Mancha frontoclipeal no rebasando las fosetas pretentoriales (Fig. 13.4). Segmento abdominal I con tubérculo lateral bien desarrollado (Fig. 14.4). Setas negras de los tubérculos laterodorsales abdominales de menor longitud que las de los tubérculos laterales (Fig. 14.4). Margen posteroventral del segmento abdominal $\mathrm{X}$ con 4 setas (Fig. 14.6). Tubérculo lateral mesotorácico completamente pigmentado de pardo (Fig. 14.4)

C. pallens

3 Manchas epicraneales fuertemente bifurcadas (Figs. $13.2,3)$. Seta cefálica S-12 ausente. Segmento abdominal I sin tubérculo lateral o muy reducido (Figs. 14.2 $y$ 14.3). Margen posterior del segmento abdominal $X$ con 4 setas ventrales (Fig. 14.6). Manchas dorsales del tórax de color pardo o pardo-oscuro

- Manchas epicraneales completamente divididas en dos (Fig. 13.5). Seta cefálica S-12 presente (Fig. 13.10). Segmento abdominal I con tubérculo lateral bien desarrollado (Fig. 14.5). Margen posterior del segmento abdominal X con 6 setas ventrales (Fig. 14.7). Manchas dorsales del tórax de color rojizo

C. viridana

4 Mancha frontoclipeal rebasando claramente las fosetas pretentoriales (Fig. 13.3). Uñas triangularmente dilatadas en su base (Fig. 6.6). Larvas de color crema con abundantes manchas dorsales de color pardo o gris en el abdomen, formando bandas transversales en cada uno de los segmentos

- Mancha frontoclipeal no rebasando las fosetas pretentoriales (Fig. 13.2). Uña cuadrangularmente dilatada en su base (Fig. 6.4). Larvas de color anaranjado con escasas y dispersas manchas dorsales de color pardo rojizo en el abdomen C. formosa

5 Tórax con dos bandas laterodorsales de color pardo muy oscuro o negro, una a cada lado de la línea media, abarcando los tres segmentos torácicos. Escleritos laterodorsales del protórax sin esclerotizar en su parte interna (Fig. 15)

C. phyllochroma

- Tórax con manchas dorsales pardas o pardo-oscuras, nunca formando 2 bandas longitudinales. Protórax con escasas y dispersas manchas dorsales pardas. Escleritos laterodorsales del protórax fuertemente esclerotizados en toda su superficie (Fig. 14.3) .... C. dorsalis

Biología Y COMPORTAMIENTO. Los datos sobre el tipo de puesta realizada por las hembras y la duración de cada uno de los estadios preimaginales escritos, así como las condiciones de cultivo y los áfidos empleados en la dieta son indicados en las siguientes tablas:

\begin{tabular}{|c|c|c|c|c|c|c|c|}
\hline \multirow[t]{2}{*}{ ESPECIE } & \multirow{2}{*}{\multicolumn{4}{|c|}{$\begin{array}{c}\text { CONDICIONES } \\
\text { DE CULTIVO }\end{array}$}} & \multirow{2}{*}{\multicolumn{3}{|c|}{$\begin{array}{c}\text { AFIDOS } \\
\text { EMPLEADOS }\end{array}$}} \\
\hline & & & & & & & \\
\hline C. perla & $21^{\circ} \mathrm{C}$ & \multicolumn{2}{|c|}{ 16L:8D } & $80 \%$ & \multicolumn{3}{|c|}{$\begin{array}{c}\text { Aphis fabae y } \\
\text { A. hederae }\end{array}$} \\
\hline C. formosa & $25^{\circ} \mathrm{C}$ & \multicolumn{2}{|c|}{ 16L:8D } & $60 \%$ & \multicolumn{3}{|c|}{$\begin{array}{l}\text { A. fabae y } \\
\text { A. nerii }\end{array}$} \\
\hline C. dorsalis & $21^{\circ} \mathrm{C}$ & \multicolumn{2}{|c|}{ 14L:10D } & $80 \%$ & \multicolumn{3}{|c|}{$\begin{array}{c}\text { A. pomi y } \\
\text { A. craccivora }\end{array}$} \\
\hline C. pallens & $25^{\circ} \mathrm{C}$ & \multicolumn{2}{|c|}{ 16L:8D } & $80 \%$ & \multicolumn{3}{|c|}{$\begin{array}{l}\text { Chaitophorus } \\
\text { leucomelas }\end{array}$} \\
\hline C. viridana & $25^{\circ} \mathrm{C}$ & \multicolumn{2}{|c|}{ 16L:8D } & $80 \%$ & \multicolumn{3}{|c|}{ A.fabae } \\
\hline \multirow[t]{3}{*}{ ESPECIE } & \multirow{3}{*}{\multicolumn{2}{|c|}{$\begin{array}{l}\text { TIPO DE } \\
\text { PUESTA }\end{array}$}} & \multirow{2}{*}{\multicolumn{5}{|c|}{$\begin{array}{c}\text { DURACION DE LOS } \\
\text { ESTADIOS (días) }\end{array}$}} \\
\hline & & & & & & & \\
\hline & & & $\mathrm{H}$ & L-1 & L-2 & L-3 & $\mathrm{P}$ \\
\hline C. perla & \multicolumn{2}{|c|}{ AISLADOS } & $4-5$ & $3-4$ & $2-3$ & $2-3$ & $*$ \\
\hline C. formosa & \multicolumn{2}{|c|}{ EN GRUPO } & 4 & $2-3$ & $2-3$ & $2-3$ & $8-13$ \\
\hline C. dorsalis & \multicolumn{2}{|c|}{ AISLADOS } & 5 & 4 & $3-4$ & 5 & 15 \\
\hline C. pallens & \multicolumn{2}{|c|}{ EN GRUPOS } & 4 & $2-3$ & $2-3$ & 3 & $10-13$ \\
\hline C. viridana & \multicolumn{2}{|c|}{ AISLADOS } & 4 & 3 & 3 & 3 & $11-13$ \\
\hline
\end{tabular}

(*) Hiberna como prepupa en el interior del capullo.

Las hembras de $C$. formosa y C. pallens depositaron de 15 a 30 huevos en el techo de la caja de cultivo, lo que nos hace pensar que seguramente en la naturaleza realicen la ovoposición en el envés de las hojas. Las hembras de las restantes especies depositaron un menor número de huevos (10-15), de forma aislada, tanto en el techo como en las paredes de la caja de cultivo y, en un elevado número de ocasiones, en el envés, márgenes laterales y ápice de las hojas añadidas a dichas cajas.

En todas las especies estudiadas, las larvas son de tipo desnudo y sólo algunas neonatas presentan en el dorso algunos restos de corion del huevo abandonado. Durante todo su desarrollo exhiben una gran actividad, son muy voraces, realizan rápidos movimientos y muestran, cuando son molestadas, un comportamiento ofensivo-defensivo, secretando por el ano un fluido de color amarilloanaranjado (Lamunyon \& Adams, 1987). 


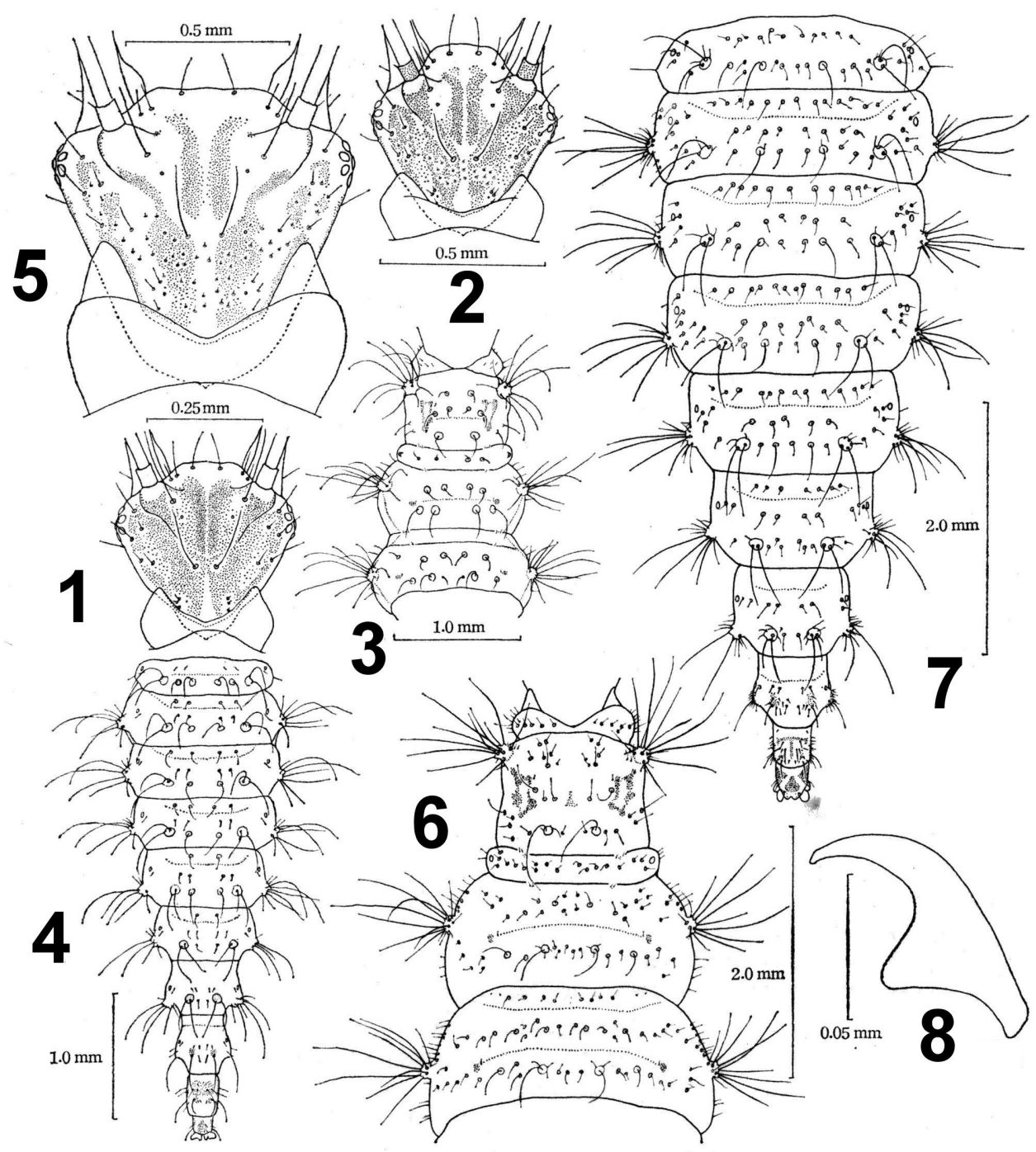

Fig. 15.- Chrysopa phyllochroma. 1: L-1, Cápsula cefálica (VD). 2-4: L-2, 2, Cápsula cefálica (VD). 3, Quetotaxia torácica (VD). 4, Quetotaxia abdominal (VD). 5-8: L-3, 5, Cápsula cefálica (VD). 6, Quetotaxia torácica (VD). 7, Quetotaxia abdominal (VD). 8, Uña. Escalas en mm. Adaptado de Tsukaguchi (1978).

Fig. 15.- Chrysopa phyllochroma (L-1, 2, 3: First, second, third intars larva). 1: L-1, Head capsule (DV). 2-4: L-2, 2, Head capsule (DV). 3, Thoracic chaetotaxy (DV). 4, Abdominal chaetotaxy (DV). 5-8: L-3, 5, Head capsule (DV). 6, Thoracic chaetotaxy (DV). 7, Abdominal chaetotaxy (DV). 8, Claw. Scales in mm. Adapted from Tsukaguchi (1978).

En las larvas sometidas a falta de alimento se observó un elevado porcentaje de canibalismo en todas las especies, y en las larvas neonatas de $C$. formosa y C. pallens hemos observado, además, oofagia. Las larvas recién nacidas de estas especies, inmediatamente después de abandonar el huevo, emprenden una ávida búsqueda de presas, y si encuentran otro huevo próximo, ascienden por su pedúnculo y lo devoran. El hecho de que sean precisamente estas dos especies las únicas que depositan los huevos en grupo, nos hace pensar que pueda tratarse de una estrategia adaptada por la hembra para asegurar la supervivencia de las larvas recién nacidas. Canard \& Duelli (1984) anotan excelentes datos al respecto, y Duelli \& Johnson (1992) anotan, para C. pallens, el mismo 
comportamiento en larvas sometidas a falta de alimento.

En cuanto a la biología de estas especies, solamente indicar que C. viridana, C. pallens y C. formosa son especies muy generalistas, euroicas, sin presentar una marcada afinidad por algún tipo de sustrato vegetal, ya que han sido capturadas, tanto en estado de imago como de larva, en un elevado número de especies vegetales (Monserrat \& Marín, 1994 anotan para estas especies 25,21 y 20 sustratos vegetales diferentes respectivamente). Sin embargo $C$. dorsalis muestra una marcada preferencia por diversas especies de pinos y enebros, sustratos sobre los que ha sido colectada en la mayoría de las ocasiones (21 de los 23 ejemplares recolectados sobre diversas plantas, según Monserrat \& Marín, 1994 y también la mayoría de los ejemplares citados por Monserrat, 2008), y C. perla parece estar asociada a la vegetación herbácea, de ribera, y a planifolios $(Q$. robur, Coprylus avellana) característicos de la Región Eurosiberiana (22 ejemplares sobre esa vegetación frente a 31 en vegetación de cualquier otro tipo citan Monserrat \& Marín, 1994). La biología de las especies restantes, $C$. phyllochroma y $C$. nierembergi, es en la actualidad prácticamente desconocida, de la primera solo hay datos de muy escasas capturas a la luz (la primera citada sobre Ulmus y Crataegus por Hölzel \& Ohm, 1972), y de la segunda (de cuya identidad tenemos ciertas dudas) sus larvas han sido citadas sobre Genista sphaerocarpa y sus imagos sobre Ceratonia siliqua. Por último, los imagos y larvas de lo que hasta ahora hemos citado como $C$. nigricostata parece fuertemente asociada a Pinus sylvestris, aunque sus larvas se corresponden con Cunctochrysa y la posición taxonómica de estos ejemplares está por dilucidar. Monserrat \& Marín (1994) dan sobrada información sobre el sustrato vegetal preferido por las diferentes especies ibéricas de este género, y más información sobre la biología de las especies ibéricas aquí estudiadas puede recabarse en Canard et al. (1984); McEwen et al. (2001); Monserrat \& Rodrigo (1992); Monserrat \& DíazAranda (1989a) y Monserrat (2008).

DISTRIBUCIÓN GEOGRÁFICA Y ALTITUDINAL, FENOLOGÍA. Como citábamos anteriormente, y relacionado con ello, C. viridana, $C$. pallens y $C$. formosa son especies muy generalistas y están geográfica-, altitudinal- y fenológicamente ampliamente repartidas por la Península Ibérica. Algo más montana y limitada es la distribución de $C$. dorsalis, conocida de zonas montanas de las provincias de Madrid,
Segovia, Tarragona, Granada, Huesca, Vizcaya, Guipúzcoa, Cuenca, Castellón, Teruel, Lérida, Barcelona, Zaragoza, Jaén, Albacete y Soria en España, y de $S^{a}$. Estrela y $S^{a}$ do Morao en Portugal. $\mathrm{Su}$ rango altitudinal es marcadamente montano (300-1350 m), y han sido hallados imagos entre los meses de mayo y septiembre. Mucho más limitada es la distribución de $C$. perla, circunscrita a la región de influencia eurosiberiana de la Península, habiéndose citado asociada a zonas de mayor humedad de la región eurosiberiana de la Península (Gerona, Barcelona, Huesca, Lérida, Cantabria, Lugo, Orense, Pontevedra, Burgos, Zamora, Navarra en España y de Douro Litoral en Portugal), en los meses de junio-agosto, a alturas que oscilan entre 800-1890 m. De C. phyllochroma apenas existen datos (Granada, Lérida y Almería en juniojulio, entre 10-1500 m), y C.nierembergi parece mayoritariamente circunscrita a la zona litoral y continental de la región mediterránea (Alicante, Almería, Castellón, Granada, Guadalajara, Málaga, Madrid, Tarragona, Teruel, Zaragoza en España y San Fiel en Portugal) entre mayo y septiembre, habiéndose recolectado entre 10-1317 m. Por último, lo que hasta ahora conocíamos como C.nigricostata, parece estar distribuida en pinares de la zona continental, habiéndose citado en España (Cuenca, Huesca, Madrid, Orense, Segovia, Jaén, Lérida, Granada, Guadalajara, Teruel, Toledo, Zamora y Zaragoza) y en Ribatejo y Beira Alta en Portugal en zonas medias y altas (entre 770-2000 $\mathrm{m})$, entre abril y octubre.

\section{Género Chrysoperla}

El género Chrysoperla Steinmann, 1964, posee una distribución geográfica prácticamente cosmopolita e incluye unas 52 especies (Brooks \& Barnard, 1990). Es sin duda uno de los géneros más conflictivos, ya que la situación taxonómica de algunas especies de la Región Holártica, Paleártica Occidental y de las europeas en particular, dista mucho de estar resuelta desde que se descubrió la existencia de un complejo de especies crípticas, reproductivamente aisladas por diferentes tipos de cantos de reclamo y apareamiento, sin la presencia de diferencias morfológicas similares a las existentes entre las especies de otros géneros (ver discusión y referencias en Monserrat, 2008), y por ello sin que exista una clara y definitiva diferenciación 
morfológica que permita la identificación de los ejemplares por los métodos tradicionales y normalmente accesibles (Brooks, 1994; Henry, 1984, 1985; Henry et al., 2001; Gruppe, 2002; Canard \& Thierry, 2007, etc.). Esto ha creado una situación taxonómica y nomenclatorial especialmente compleja dentro del grupo de Chrysoperla carnea s. l., con vivas discusiones, foros, contribuciones e incluso frecuente descripción de nuevas especies, situación y argumentos en los que no es el momento de participar.

En relación a esta problemática situación, y en lo que compete a la fauna ibérica, varias especies han sido segregadas, sean Chrysoperla carnea (Stephens, 1836) s.str., Chrysoperla lucasina (Lacroix, 1912), Chrysoperla pallida Henry, Brooks, Duelli \& Johnson, 2002, Chrysoperla agilis Henry, Brooks, Duelli \& Johnson, 2003, etc., que a duras penas, y con un elevado margen de error, pueden "identificarse" con los caracteres de morfología y genitalia anotados por algunos autores que tratan de resolver esta interesante cuestión (ver Thierry et al., 1992, 1996; Duelli, 1999; Canard \& Thierry, 2007 y Monserrat, 2008), sin tener en cuenta los fenotipos de sus sonidos que no pueden considerarse en ejemplares secos montados o conservados en alcohol, y esperamos que nuevas contribuciones aclaren definitivamente la posición de estas especies.

En lo que respecta a esta contribución, y ya que varias de estas especies no estaban descritas o segregadas cuando realizamos la descripción de los estadios larvarios de las especies ibéricas de este género (Díaz-Aranda \& Monserrat, 1990 a), preferimos mantener este criterio, y dado lo conflictivo de la situación, denominar a este grupo de especies como Chrysoperla carnea (s.l.), conscientes de que estamos hablando de un pul de especies.

Al margen de este grupo de especies (Chrysoperla carnea s.l.), nuevas especies han sido halladas o descritas en la Península Ibérica: $C$. mediterranea (Hölzel, 1972), C. ankylopteryformis Monserrat y Díaz-Aranda, 1989 (de identidad cuestionada frente a Chrysoperla renoni (Lacroix, 1933) y aún por dilucidar de forma satisfactoria y definitiva), o C. mutata. (McLachlan, 1898), que son especies bien diferenciables (Monserrat y DíazAranda, 1989; Monserrat \& Rodrigo, 1992; Monserrat, 2008).

En lo que respecta a las fases juveniles de las especies ibéricas, de Chrysoperla carnea (s.l.) han sido descritos en numerosos trabajos, entre los que podemos citar: Schneider (1851); Pariser (1917); Smith (1922); Steinke (1922); Withycombe (1923, 1925); Lacroix (1929); Stitz (1931); Frankenberg (1936); Killington (1937); Smirnoff (1953); Fleshner \& Scriven (1957); Muma (1959); Hoffmann (1962); Bansch (1966); Toschi (1965); Agekjan (1973); Tauber \& Tauber (1973); Egger (1974); Principi \& Canard (1974); Tauber (1974); Tsukaguchi (1977); Duelli (1981); Gepp (1983, 1989); Pantaleoni (1983); Canard, Semeria \& New (1984), y un largo etc. Sin embargo, algunos de ellos no pasan de ser meramente testimoniales, e incluso nos plantean ciertas dudas sobre su correcta asignación específica, y más en la situación actual de esta "especie". De C. mediterranea existe únicamente la somera referencia que sobre el huevo y la larva hace Duelli (1987), y, como se ha indicado, las fases juveniles de Chrysoperla carnea (s.l.), $C$. ankylopteryformis y $C$. mediterranea fueron descritas por Díaz-Aranda \& Monserrat (1990 a), y ahora aportamos datos sobre el cultivo de los ejemplares por nosotros estudiados y nuevos datos actualizados sobre su biología, distribución y fenología. Por último anotar que no hemos conseguido nuevas hembras grávidas de C. mutata, que nos permitieran obtener y describir sus fases juveniles, ni estamos en condiciones de diferenciar con absoluta seguridad la identidad del resto de especies aquí citadas bajo la denominación Chrysoperla carnea (s.l.). De momento ésta es la situación.

\section{Material utilizado.}

Chrysoperla carnea s.l. (Stephens, 1836)

Hembras grávidas: España, Madrid, Alcalá de Henares, 9.V.1988, en trampa de luz.

Larvas: España, Almería, Las Estancias, 23.VII.1983, sobre Q. rotundifolia, Los Lobos, 27.V.1983, sobre Olea europaea. Ávila, Navalperal de Tormes, 23.VII.1990, sobre Senecio sp., Navarredonda de Gredos, 23. VII.1990, sobre Senecio sp. Cádiz, Benalup de Sidonia, 2.VI. 1990, sobre O. europaea. Chiclana de la Frontera, 2.VI.1990, sobre Pistacia lentiscus. Jaén, Arquillos, 15.IV.1976, sobre O. europaea, Sierra de Cazorla, 4.VI.1991, sobre Phillysea latifolia. Lugo, Robra, 7.VIII.1983, sobre $Q$. robur. Madrid, Alcalá de Henares, 6.VII.1991, sobre Robinia pseudoacacia, Pradera del Rincón, 23.VII. 1988, sobre Erica sp. Orense, Arroyo de S. Salvador, 7.IX.1977, sobre Q. robur, Luintra, 18.VIII.1977, sobre Q. robur. Santander, Villafufre, 27.VIII. 1988, sobre Castanea sativa. Teruel, San Agustín, 5.VIII.1987, sobre Juniperus thurifera.

\section{Chrysoperla mediterranea (Hölzel, 1972)}

Hembras grávidas: España, Guadalajara, Valdenoches, 2.VII.1988, sobre Pinus halepensis.

Larvas: España, Almería, Huercal Overa, 4.I.1981. Cádiz, Véjer de la Frontera, 27.VII.1976. Castellón, Cuestas de 
Ragudo, 29.IV.1987. Granada, Puerto de la Mora, 3.VI.1986. Guadalajara, Valdenoches, 24.V.1988. Madrid, Campo Real, 27.VIII.1984. Teruel, Montalbán, 3.VIII.1987, Valdealgorfa, 10.IX.1987. Todos los ejemplares en estado de larva fueron recolectados sobre Pinus halepensis.

Chrysoperla ankylopteryformis Monserrat y Díaz-Aranda, 1989. Hembras grávidas: España, Almería, Rambla de Morales, Cabo de Gata, 18.VII.1988, a la luz.

\section{ESTADIOS LARVARIOS}

Características generales (L-1: Figs. 16.1-2, 17.1-8, L-3: Fig. 18.1-2, 19.1-7).

Las características morfológicas correspondientes a las distintas fases larvarias del género Chrysoperla fueron definidas por Tauber (1974) para especies norteamericanas, que se hicieron perfectamente extensibles a las especies ibéricas descritas por Díaz-Aranda \& Monserrat (1990 a). Estas características son:

Cuerpo fusiforme, aplanado dorsoventralmente, abdomen no globoso (Figs. 16.1, 18.1).

Larvas desnudas, no portadoras de capa de camuflaje (Figs. 16.1, 18.1).

Mancha frontoclipeal ausente o muy reducida. Manchas epicraneales formando 2 líneas longitudinales que se extienden desde el esclerito occipital hasta la base de las antenas (Figs. 16.1-2, 18.1-2).

Seta cefálica S-12 presente (Figs. 16.1-2, 18.1-2).

Setas siempre filiformes, nunca uncinadas.

De la larva neonata (Figs. 16.1-2, Fig. 17.1-8).

Tubérculos laterales del tórax no alargados, portadores de 2 setas en protórax y 3 en meso y metatórax (Fig. 16.1).

Meso- y metanoto con 4 tubérculos dorsales portadores de 1 seta (Fig. 16.1).

Segmentos abdominales II-VII con tubérculos laterales portadores de 2 setas (Fig. 16.1).

Segmentos I-VII con una hilera transversal anterior de 4 pequeñas setas, 2 tubérculos laterodorsales portadores de 2 largas setas y 2 pequeños tubérculos submediales, centrales a los anteriores, portadores de 1 seta (Fig. 16.1).

De la larva madura (Figs. 18.1-2, Figs. 19.1-7).

Larvas con coloración amarillenta y manchas dorsales variables de rojizas a pardas, formando dos bandas laterodorsales, una a cada lado de la línea media, que recorren tórax y abdomen en toda su longitud (Fig. 18.1).

Tubérculos laterales de tórax y abdomen semiesféricos, nunca pedunculados, portadores de setas relativamente cortas (Fig. 18.1).

Espiráculo mesotorácico circular, no prominente (Fig. 18.1).
Segmentos abdominales I-VII con 2 hileras transversales de pequeñas setas, 2 tubérculos laterodorsales portadores de 2 setas y 2 pequeños tubérculos submediales, centrales a los anteriores, portadores de 1 seta (Fig. 18.1).

Discusión. Al margen de los datos ya anotados anteriormente sobre las especies citadas, la información existente sobre las fases preimaginales de las especies pertenecientes al género Chrysoperla es, en general, poco conocida y muy dispersa. A pesar de la escasa variabilidad intraespecífica observada por los autores en el material estudiado y de la anotada en la bibliografía citada, en particular en Tauber \& Tauber (1973) y Tauber (1974), puede considerarse al género Chrysoperla como un género bien definido desde el punto de vista de su morfología, setación y quetotaxia larvaria. Aparentemente todas las especies conocidas del género siguen un patrón bien delimitado $\mathrm{y}$, en general, diferente al existente en otros géneros de la familia Chrysopidae.

Circunscribiéndonos a las especies ibéricas de este género y debido a la citada homogeneidad morfológica, las fases larvarias de C. carnea (s.l.), $C$. mediterranea y $C$. ankylopteryformis son muy similares entre sí. Sin embargo, un examen más detallado de algunos de los caracteres indicados para las larvas maduras de estas tres especies, nos permiten diferenciarlas inequívocamente. Dichos caracteres son: pigmentación cefálica, morfología de la uña y número de setas de los tubérculos laterales del tórax y abdomen.

En relación a las manchas cefálicas epicraneales, cuyo interés taxonómico ya ha sido anotado por Tauber \& Tauber (1973) y Tauber (1974), las de $C$. ankylopteryformis son muy estrechas y nunca se extienden a lo largo del esclerito occipital (Fig. 18.2a). En C. mediterranea son más anchas, de contorno más irregular y se acodan levemente sobre el citado esclerito (Fig. 18.2b). Por último, en C. carnea (s.l.) estas manchas adquieren un aspecto más triangular al extenderse y continuarse a lo largo de todo el esclerito occipital (Fig. 18.2c), y esta característica ya había sido anotada por Pariser (1917); Withycombe (1923); Killington (1937); Tauber \& Tauber (1973); Tauber (1974); Gepp (1983), etc.

Por otro lado, sólo C. carnea (s.l.) posee mancha frontoclipeal, en distinto grado de desarrollo. Así, entre el material estudiado se han observado ejemplares que poseen desde una simple sombra, a uno y otro lado de la línea media (Fig. 18.2c), a una patente mancha oscura a ambos lados de la línea 

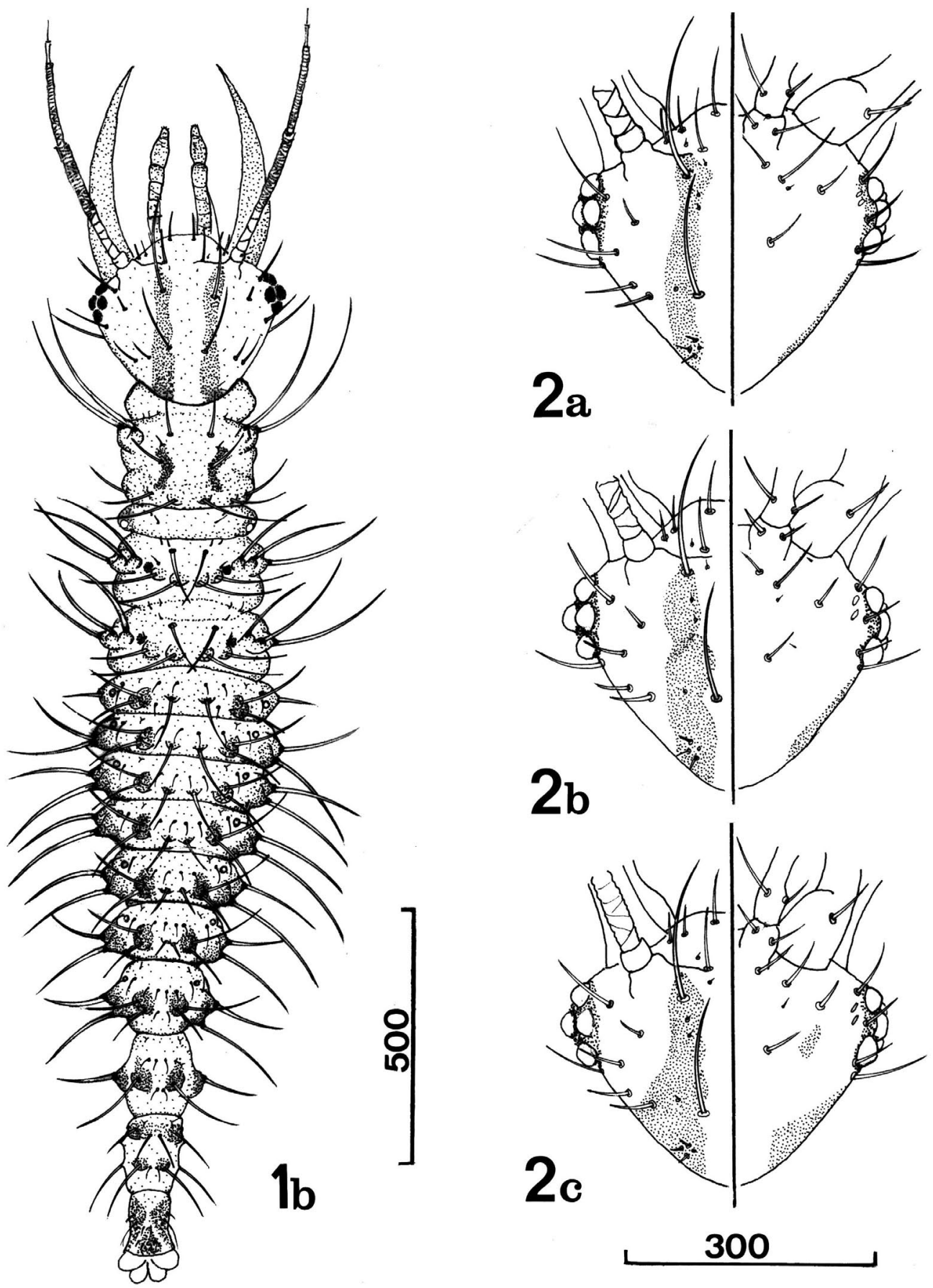

Fig. 16.- Género Chrysoperla (L-1), a: C. ankylopteryformis, b: C. mediterranea, c: C. carnea (s.l.). 1, Aspecto general (VD). 2, Cápsula cefálica (izda.:VD/ dcha.:VV). Escalas en $\mu \mathrm{m}$. Adaptado de Díaz-Aranda \& Monserrat (1990a).

Fig. 16.- Genus Chrysoperla (L-1) (first instar larva), a: C. ankylopteryformis, b: C. mediterranea, c: C.carnea (s.l.). 1, Habitus (DV). 2, Cephalic capsule (left DV / right VV). Scales in $\mu$ m. Adapted from Díaz-Aranda \& Monserrat (1990a). 

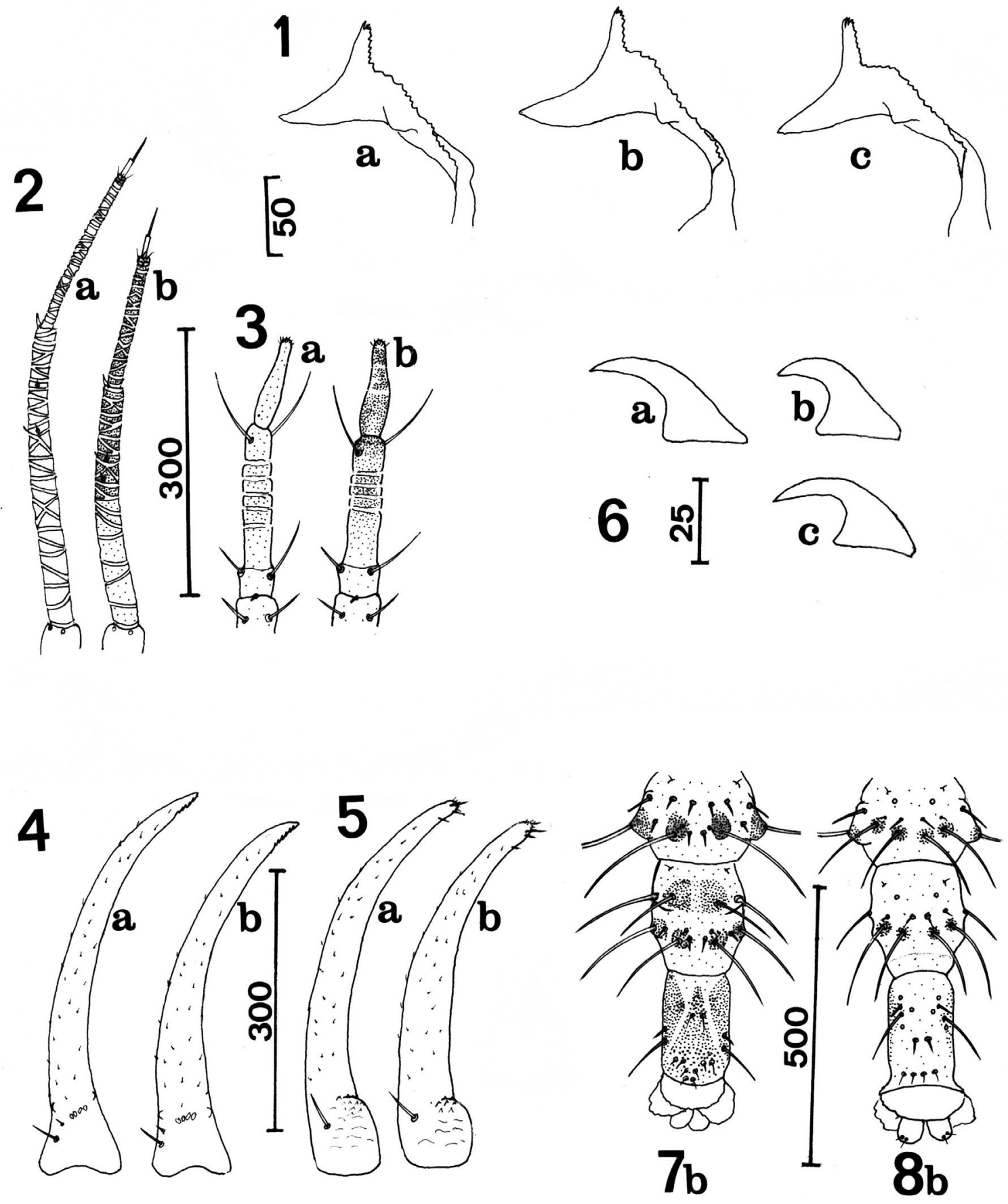

Fig. 17.- Género Chrysoperla (L-1), a: C. ankylopteryformis, b: C. mediterranea, c: C. carnea (s.l.). 1, Ovirruptor. 2, Antena. 3, Palpo labial. 4, Mandibula. 5, Maxila. 6, Uña. 7, Segmentos abdominales VIII-X (VD). 8, Ídem (VV). Escalas en $\mu$ m. Adaptado de Díaz-Aranda \& Monserrat (1990a).

Fig. 17.- Genus Chrysoperla (L-1) (first instar larva), a: C. ankylopteryformis, b: C. mediterranea, c: C. carnea (s.l.). 1, Oviruptor. 2, Antenna. 3, Labial palp. 4, Mandible. 5, Maxilla. 6, Claw. 7, Abdominal segments VIII-X (DV). 8, Ditto (VV). Scales in $\mu \mathrm{m}$. Adapted from Díaz-Aranda \& Monserrat (1990a). 

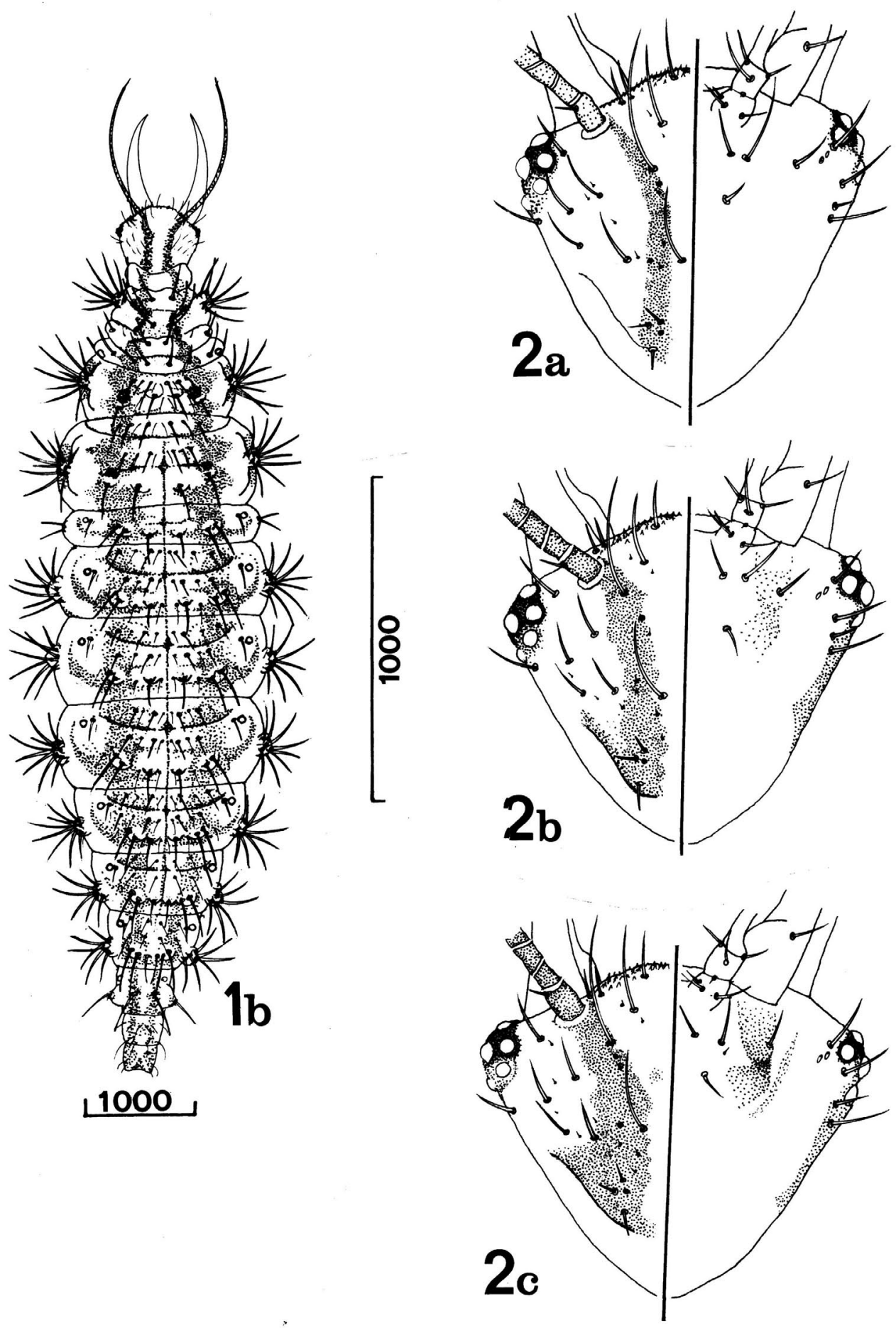

Fig. 18.- Genero Chrysoperla (L-3), a: C. ankylopteryformis, b: C. mediterranea, c: C. carnea (s.I.). 1, Aspecto general (VD). 2, Cápsula cefálica (izda.: VD/ dcha.:VV). Escalas en $\mu$ m. Adaptado de Díaz-Aranda \& Monserrat (1990a).

Fig. 18.- Genus Chrysoperla (L-3) (third instar larva), a: C. ankylopteryformis, b: C. mediterranea, c: C. carnea (s.I.). 1, Habitus (DV). 2, Cephalic capsule (left: DV / right VV). Scales in $\mu \mathrm{m}$. Adapted from Díaz-Aranda \& Monserrat (1990a). 
media, que pueden en algunos ejemplares estar fusionadas sobre ella, de forma similar a lo indicado por Schneider (1851); Pariser (1917); Withycombe (1923); Killington (1937); Smirnoff (1953); Tauber \& Tauber (1973); Tauber (1974); Principi \& Canard (1974); Gepp (1983), etc., que es reflejo tanto de la posible variabilidad, como consecuencia del pul de especies que estamos considerando. En cualquier caso, esta mancha cefálica nunca ha sido observada ni en $C$. mediterranea ni en C. ankylopteryformis.

Las manchas genales y ventrales de la cápsula cefálica siempre están presentes en $C$. carnea (s.l.) y en $C$. mediterranea en distinto grado de desarro1lo (Figs. 18.2b, c), pero en C. ankylopteryformis las genales son muy poco patentes y las ventrales son inexistentes (Fig. 18.2a).

Todas las características de pigmentación cefálica anteriormente anotadas son prácticamente extensibles a lo observado en las larvas neonatas de estas especies (Figs. 16.2a, b, c).

El segundo carácter digno a tener en cuenta es la morfología de las uñas, que hasta ahora no había sido empleado en la distinción específica de las larvas de este género y que, en el caso que nos ocupa, este carácter se mantiene en los imagos de las especies citadas. Así, las larvas del tercer estadio de $C$. carnea (s.l.) poseen uñas dilatadas y fuertemente acodadas en su base, dándole un aspecto cuadrangular (Fig. 19.5c). Por el contrario, en C. ankylopteryformis y $C$. mediterranea las uñas, a pesar de estar dilatadas en su base, carecen de este proceso, dándoles un aspecto más triangular (Figs. 19.5a, b). De ellas, en $C$. mediterranea el margen interno de la parte basal de la uña se acoda suavemente con el margen interno de la parte distal (Fig. 19.5b), mientras que en $C$. ankylopteryformis ambos márgenes se disponen de forma más continuada (Fig. 19.5a). Estos caracteres, observados en las larvas desarrolladas, se encuentran intuidos en las fases neonatas (Figs. 17.6a, b, c).

Por último, deben anotarse ciertos datos en relación a la quetotaxia torácica y abdominal. Así, Bruch (1917); Tauber (1974) y Ru et al. (1975) observaron que el número de setas de los tubérculos laterales de pronoto, mesonoto y metanoto es de 7 , 9 y 9 respectivamente, y el número de setas de los tubérculos laterales de los segmentos abdominales II-VII es de 7 a 9 para las especies americanas. Estos datos se cumplen en los ejemplares de C. carnea (s.l.) y C. mediterranea estudiados, no así en $C$. ankylopteryformis, cuyo número de setas es de 7, 11 y 11 para los tubérculos laterales del pronoto, mesonoto y metanoto respectivamente y de 8 a 10 setas para los abdominales. Así mismo, las setas en $C$. mediterranea y C. ankylopteryformis son hialinas, mientras que en C. carnea (s.l.) son ahumadas.

Otros caracteres anteriormente comentados, de morfología y pigmentación, de menor importancia (como la anchura del pronoto o el color de las bandas laterodorsales del tórax y abdomen) han sido estudiados en las tres especies, que junto a los 3 caracteres más relevantes de pigmentación cefálica, morfología de las uñas y quetotaxia torácica y abdominal anteriormente mencionados, permiten identificar a las larvas de las tres especies ibéricas de este género según la clave que aportamos.

\section{Clave para larvas L-1}

1 Mancha epicraneal de aspecto triangular, ensanchada en su margen posterior sobre la sutura occipital (Fig. 16.2c). Porción distal de las uñas muy curvada sobre su porción basal (Fig. 17.6 c) ..................... C. carnea (s.l.)

- Mancha epicraneal no triangular, ni ensanchada posteriormente sobre la sutura occipital (Figs. 16.2a, b). Porción distal de las uñas levemente curvada sobre su porción basal (Figs. 17.6a, b)

2 Mancha epicraneal estrecha y arqueada (Fig. 16.2a). Antenas y palpos labiales hialinos (Figs. 17.2a, 17.3a). Uñas con porción distal muy desarrollada (Fig. 17.6a)

C. ankylopteryformis

- Mancha epicraneal ancha y de contorno irregular (Fig. 16.2b). Antenas y palpos labiales pardos en su porción distal (Figs. 17.1b, 3b). Uñas con la porción distal poco desarrollada (Fig. 17.6 b)

C. mediterranea

\section{Clave para larvas L-3}

1 Uñas con porción basal fuertemente acodada en su margen interno, dándole un aspecto cuadrangular (Fig. 19.5c) C. carnea (s.l.)

- Uñas con porción basal no, o suavemente acodada en su margen interno, dándole un aspecto triangular (Figs. $19.5 a, b)$

2 Mancha epicraneal estrecha y no extendida sobre el esclerito occipital (Fig. 18.2a). Tubérculos laterales del pronoto, mesonoto y metanoto con 7,11 y 11 setas respectivamente. Tubérculos laterales de los segmentos abdominales II-VII portadores de 8 a 10 setas. Uñas con la porción basal del margen interno no acodada con la porción distal (Fig. 19.5a)

C. ankylopteryformis

- Mancha epicraneal ancha, acodada y extendida sobre la sutura occipital (Fig. 18.2b). Tubérculos laterales del pronoto, mesonoto y metanoto con 7, 9 y 9 setas respectivamente. Tubérculos laterales de los segmentos abdominales II-VII portadores de 7 a 9 setas. Uñas con la porción basal del margen interno acodada con la porción distal (Fig. 19.5b)

C. mediterranea 

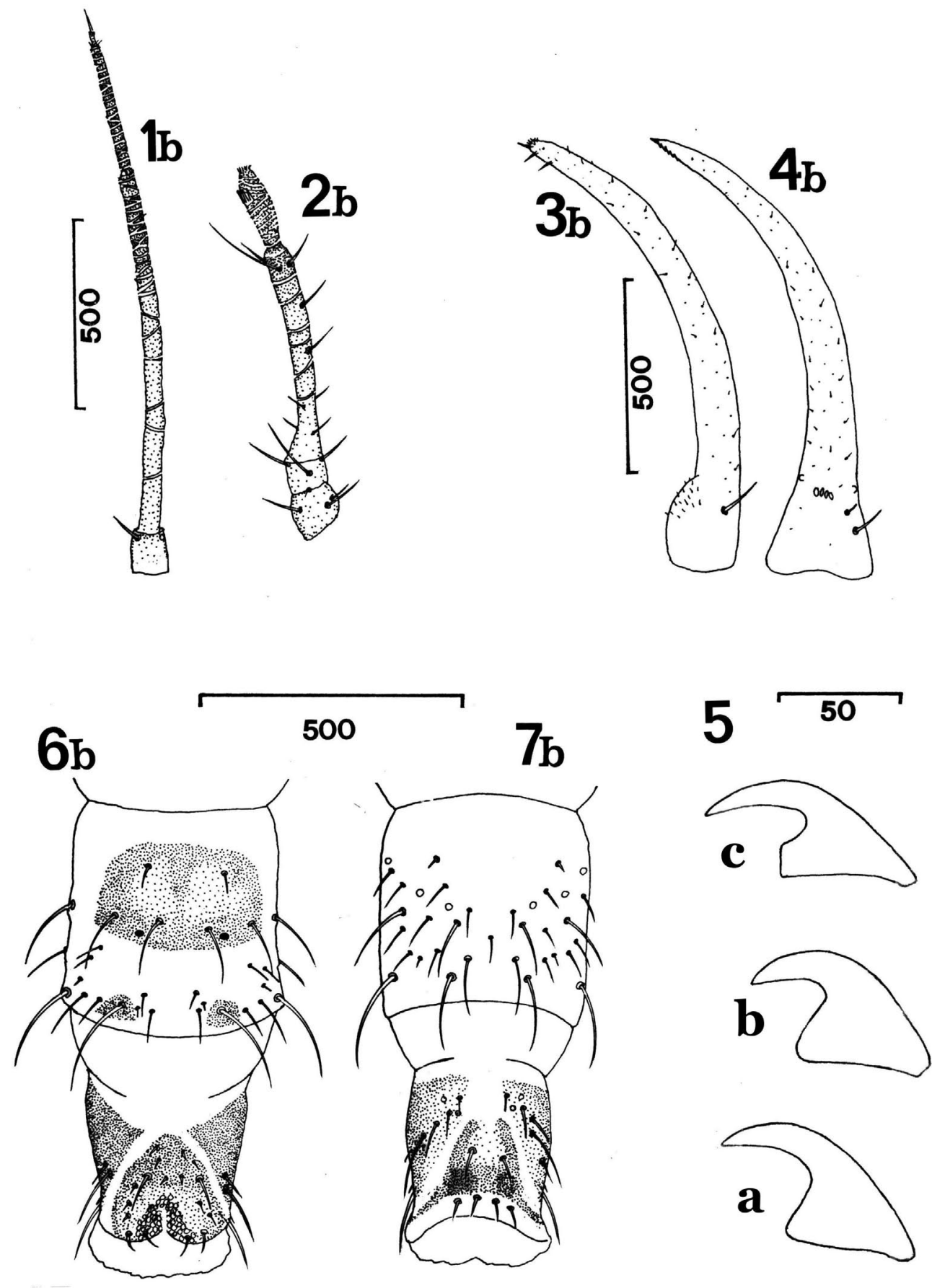

Fig. 19.- Género Chrysoperla (L-3), a: C. ankylopteryformis, b: C. mediterranea, c: C. carnea (s.l.). 1, Antena. 2, Palpo labial. 3, Maxila. 4, Mandíbula. 5, Uña. 6, Segmentos abdominales IX-X (VD). 7, Ídem (VV). Escalas en $\mu$ m. Adaptado de Díaz-Aranda \& Monserrat (1990a).

Fig. 19.- Genus Chrysoperla (L-3) (third instar larva), a: C. ankylopteryformis, b: C. mediterranea, c: C. carnea (s.I.). 1, Antenna. 2, Labial palp. 3, Maxilla. 4, Mandible. 5, Claw. 6, Abdominal segments IX-X (DV). 7, Ditto (VV). Scales in $\mu$ m. Adapted from Díaz-Aranda \& Monserrat (1990a). 
Biología y COMPORTAMiento. Datos sobre las puestas, el comportamiento de las larvas y duración de sus periodos ya fueron anotados por Díaz-Aranda \& Monserrat (1990a). Sus larvas son desnudas, y no se cubren con restos de presas (Figs. 16.1, 18.1).

En cuanto a la biología del imago de las tres especies estudiadas, C. carnea (s.l.) es extremadamente eurioica (Monserrat \& Marín, 1994 la citan sobre 89 sustratos vegetales diferentes), ocupando prácticamente todos los medios existentes en la Península Ibérica. Sin embargo, nuevos datos nos permitirán segregar esta información ahora dada como un conjunto.

C. mediterranea posee tendencias termófilas, $\mathrm{y}$ está fuertemente asociada a coníferas, especialmente del género Pinus, y a $P$. halepensis en particular, donde se han contabilizado la mayoría de las capturas, tanto en estado de imago como de larva (Hölzel \& Ohm, 1972; Monserrat, 1985, 1987, 2008; Duelli, 1987; Díaz-Aranda \& Monserrat, 1988b; Monserrat \& Rodrigo, 1992; Monserrat \& Marín, 1994, etc.).

De C. mutata apenas hay más de un par de datos poco relevantes (imagos sobre Eucaliptus globulus, Olea europea, Ceratonia siliqua y Quercus rotundifolia), y por último, sobre la biología de C. ankylopteryformis carecemos de datos ya que ha sido recolectada a la luz en ramblas con cañizares. Más información puede recabarse de Monserrat \& DíazAranda, 1989; Díaz-Aranda \& Monserrat (1990 a); Monserrat \& Rodrigo, 1992; Monserrat \& Marín, 1994, o Monserrat, 2008.

DiSTRIBUCIÓN GEOGRÁFICA Y ALTITUDINAL, FENOLogíA. En la Península Ibérica C. carnea (s.l.) representa sin duda el crisópido más frecuente y de dispersión geográfica, altitudinal y fenológica más extensa, habitando en toda la Península Ibérica, con un enorme rango altitudinal y fenológico. C. mediterranea, de distribución más mediterránea y tendencias termófilas, siendo por ello frecuente en las zonas peninsulares de mayor influencia termomediterránea. Está citada en las provincias de Albacete, Alicante, Almería, Barcelona, Cáceres, Guadalajara, Huesca, Baleares (Mallorca, Ibiza, Formentera), Jaén, Cádiz, Castellón, Cuenca, Granada, Lérida, Madrid, Murcia, Soria, Teruel, Valencia y Zaragoza en España y en Algarve, Trás os Montes e Alto Douro, y Beira Alta en Portugal. Su rango altitudinal oscila entre los 10-1900 m y han sido hallados larvas e imagos entre los meses de enero-diciembre. C.mutata sólo la conocemos de Jaén, Almería, Granada, Madrid, Valencia y Ávila, entre mayo y octubre, entre 271-640 m. Por último, C. ankylopteryformis sólamente ha sido citada hasta ahora en nuestra fauna de zonas áridas el S-SE peninsular (Almería, Málaga) (Monserrat \& Díaz-Aranda, 1989; Monserrat \& Rodrigo, 1992 y Monserrat, 2008). Su rango altitudinal 10-40 m, y han sido hallados entre los meses de mayo-agosto.

\section{Género Chrysopidia}

El género Chrysopidia Navás, 1910, está compuesto en la actualidad por 14 especies, 2 de las cuales pertenecen al subgénero Chrysopidia (s.str.) Navás, 1910, 3 al subgénero Chrysotropia Navás, 1911, y 9 al subgénero Anachrysa Hölzel, 1973 (Brooks \& Barnard, 1990).

En Europa está representado por Chrysopidia (Chrysotropia) ciliata (Wesmael, 1841), (mayoritariamante conocida y citada como Chrysotropia ciliata), especie paleártica que habita en la Península Ibérica, siendo además la única especie de este género cuyos estadios preimaginales han sido descritos: El huevo, larva neonata y larva madura de esta especie han sido descritos por Withycombe (1923) y Killington (1937), y datos sobre la morfología y quetotaxia de la larva madura pueden ser recabados en Gepp $(1983,1989)$. Sin embargo, estas descripciones nos resultan muy superficiales y no aportan detalles sobre numerosos caracteres morfológicos útiles, a nuestro parecer, para la diferenciación de las larvas. Por este motivo, en el presente apartado, se describe más detalladamente el huevo, larva neonata y larva adulta de esta especie.

Material utilizado. Hembras grávidas recolectadas: España, Santander, Cosgaya, 1.VIII.1989, sobre Corylus avellana.

Larvas: España, Asturias: Covadonga, 31.VII.1989, sobre C. avellana, Ortigueiros, 2.VIII.1989, sobre C. avellana. Lérida: Bosost, 21.IX.1991, sobre Quercus robur. Santander: Cosgaya, 31.VII.1989, sobre C. avellana.

\section{ESTADIOS LARVARIOS}

Características generales (L-1: Figs. 20.1-11, L-3: Figs. 21.1-10).

Larvas portadoras de capa de camuflaje muy compacta y de gran tamaño, cubriendo casi la totalidad de la larva.

Abdomen globoso (Figs. 20.2, 21.1).

Setas torácicas filiformes y setas abdominales de tipo uncinado y espatulado (Figs. 20.2, 21.1).

Seta cefálica S-12 presente (Figs. 20.3, 21.2). 
De la larva neonata (Figs. 20.1-11).

Tórax con tubérculos laterales portadores de 2 , 3 y 3 largas setas filiformes en pro-, meso- y metatórax respectivamente (Fig. 20.1).

Meso- y metanoto con 4 pequeños tubérculos dorsales portadores de 1 seta filiforme, notablemente más largas en el metanoto que en el mesonoto (Fig. 20.1).

Segmentos abdominales II-V con tubérculos laterales portadores de 2 largas setas, espatuladas las orientadas laterodorsalmente, y filiformes y más cortas las orientadas lateroventralmente (Fig. 20.1).

Segmentos VI-VII con tubérculos laterales portadores de 2 largas setas, ambas filiformes (Fig. 20.1).

Segmentos I-V con pequeños tubérculos dorsales portadores de setas uncinadas (Fig. 20.1).

Segmentos VI-VII sin setas uncinadas y con 2 tubérculos submediales portadores de 1 larga seta filiforme (Fig. 20.1).

De la larva madura (Figs. 21.1-10).

Larvas de color blanco.

Escleritos laterodorsales del pronoto muy patentes (Fig. 21.1).

Tubérculos laterales de los tres segmentos torácicos muy alargados y no ensanchados en su ápice, portadores de largas setas filiformes (Fig. 21.1).

Meso- y metanoto con una hilera transversal de 4-6 setas filiformes, notablemente más largas en el metanoto (Fig. 21.1).

Tubérculos laterales del abdomen semiesféricos, portadores de setas uncinadas en los segmentos IIVI y de setas filiformes en los segmentos VII-VIII (Fig. 21.1).

\section{Descripción de los estadios preimaginales}

Huevo. Son huevos pedunculados, elipsoides, de color verde pálido con micropilo blanco. La longitud del huevo es de aproximadamente $0.9 \mathrm{~mm}$ y la del pedúnculo oscila entre 7-8 $\mathrm{mm}$.

Ovirruptor. Ovirruptor ligeramente esclerotizado, con denticulación según Fig. 20.1.

Larva L-1. Aspecto general según Fig. 20.2. Cabeza de color crema amarillento con manchas cefálicas pardas. Mancha frontoclipeal longitudinalmente dividida en dos (Fig. 20.3). Manchas epicraneales formando dos bandas longitudinales, una a cada lado de la sutura coronal (Fig. 20.3). Manchas genales patentes (Fig. 20.3). Setas cefálicas muy largas. Seta S-12 presente. Quetotaxia dorsal y ventral de la cápsula cefálica según Fig. 20.3, 4 respectivamente. Antenas (Fig. 20.5) y palpos labiales (Fig. 20.6) de color crema pálido. Maxilas (Fig. 20.7) y mandíbulas (Fig. 20.8) de color ámbar. Ojos negros, formados por 6 estemmata dispuestos según Fig. 20.3, 4.

Tórax con tubérculos laterales de pro- meso- y metatórax portadores respectivamente de 2,3 y 3 largas setas filiformes. Quetotaxia dorsal de los tres segmentos torácicos según Fig. 20.2. Patas hialinas con uñas de color ámbar (Fig. 20.9).

Segmentos abdominales II-V con tubérculos laterales portadores de dos largas setas, espatuladas las dirigidas laterodorsalmente y filiformes las de orientación lateroventral (Fig. 20.2). Segmentos VI-VII con tubérculos laterales portadores de 2 largas setas, ambas filiformes (Fig. 20.2). Segmentos $\mathrm{I}-\mathrm{V}$ con pequeños tubérculos dorsales portadores de setas uncinadas (Fig. 20.2). Segmentos VI-VII sin setas uncinadas, con dos tubérculos laterodorsales portadores de 1 larga seta filiforme (Fig. 20.2). Quetotaxia ventral y dorsal de los segmentos VIII$\mathrm{X}$ según Fig. 20.10, 11 respectivamente.

Larva L-3. Aspecto general según Fig. 21.1, son blancas con escleritos laterodorsales del tórax de color pardo oscuro.

Cabeza amarillenta con manchas cefálicas pardo oscuras. Mancha frontoclipeal longitudinalmente dividida en dos (Fig. 21.2). Manchas epicraneales fuertemente bifurcadas, con su rama externa contactando con las manchas genales (Fig. 21.2). Manchas genales muy patentes, unidas a las epicraneales y fuertemente extendidas a la cara ventral de la cápsula cefálica, en contacto con las esclerotizaciones del cardo y estipe (Fig. 21.3). Quetotaxia dorsal y ventral de la cápsula cefálica según Fig. 21.1, 3 respectivamente. Seta S-12 presente. Maxilas (Fig. 21.4) y mandíbulas (Fig. 21.5) de color ámbar. Palpos labiales (Fig. 21.6) y antenas (Fig. 21.7) de color pardo basalmente y pardo oscuro distalmente. Ojos de color negro, formados por 6 estemmata dispuestos según Fig. 21.2, 3.

Tórax de color blanquecino con dos pequeñas manchas pardas en la región anterolateral del mesoy metatórax, cerca de la base de los tubérculos laterales de dichos segmentos. Escleritos laterodorsales pardo oscuros, de aspecto rectangular, muy desarrollados en el pronoto y circulares y más pequeños en el meso- y metanoto (Fig. 21.1). Tubérculos laterales muy alargados y no ensanchados en su ápice (Fig. 21.1), portadores de largas setas filiformes, ahumadas e hialinas en el protórax y únicamente hialinas en el meso- y metatórax. Setas dorsales del tórax dispuestas según Fig. 21.1. Metanoto con una 


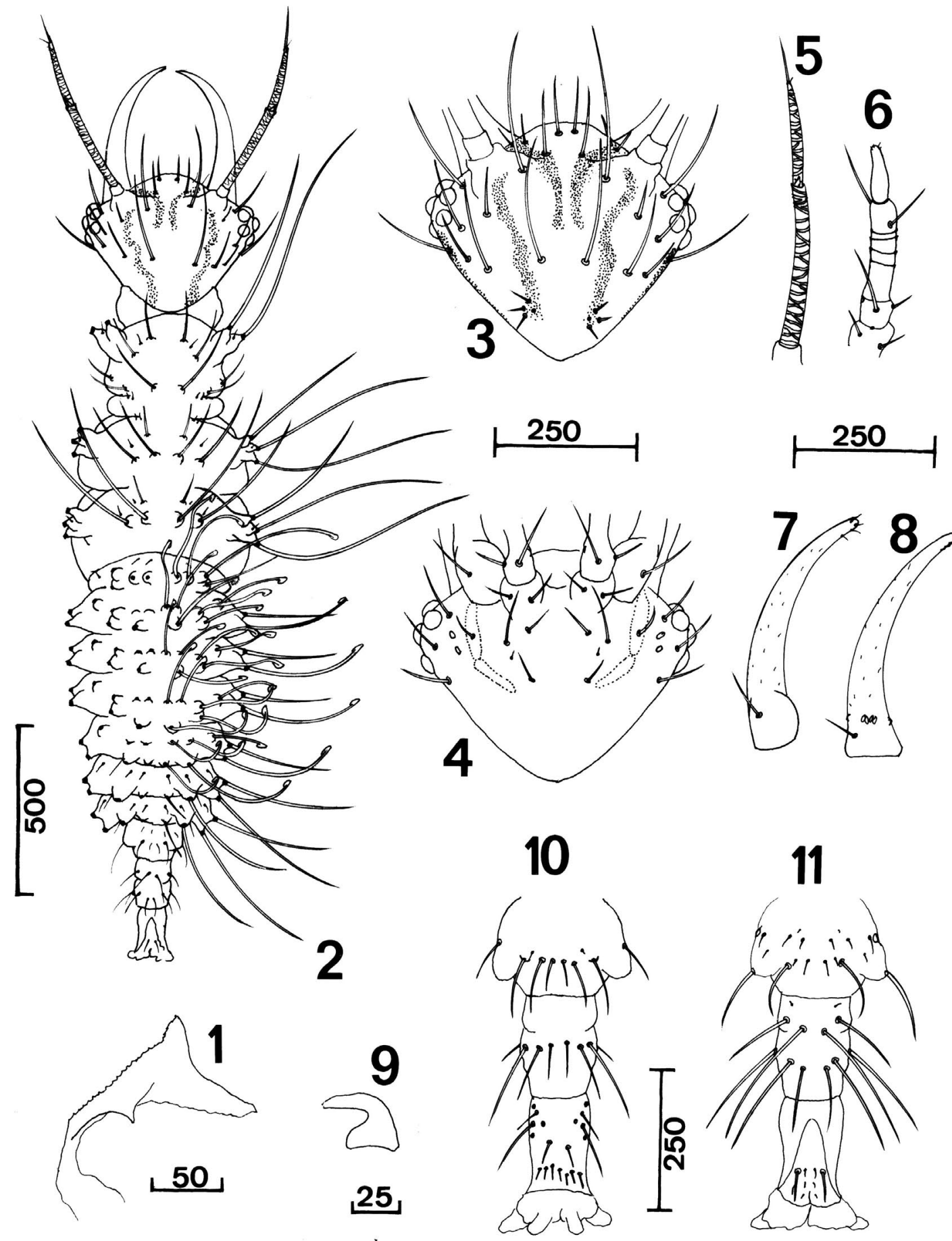

Fig. 20.- Chrysopidia (Chrysotropia) ciliata (L-1). 1, Ovirruptor, 2, Aspecto general (VD). 3, Cápsula cefálica (VD). 4, Ídem (VV). 5, Antena. 6, Palpo labial. 7, Maxila. 8, Mandíbula. 9, Uña. 10, Segmentos abdominales VIII-X (VD). 11, Ídem (VV). Escalas en $\mu \mathrm{m}$.

Fig. 20.- Chrysopidia (Chrysotropia) ciliata (L-1) (first instar larva). 1, Oviruptor, 2, Habitus (DV). 3, Head capsule (DV). 4, Ditto (VV). 5, Antenna. 6, Labial palp. 7, Maxilla. 8, Mandible. 9, Claw. 10, Abdominal segments VIII-X (DV). 11, Ditto (VV). Scales in $\mu \mathrm{m}$. 
hilera transversal de largas setas filiformes (Fig. 21.1). Patas de color crema pálido. Uñas ámbar, con base rectangular (Fig. 21.8).

Abdomen globoso. Segmentos II-V con tubérculos laterales portadores de setas uncinadas (Fig. 21.1). Segmentos VI-VII con tubérculos laterales portadores de setas filiformes, notablemente más largas que las de los segmentos precedentes y dirigidas hacia la región caudal (Fig. 21.1). Segmentos $\mathrm{I}-\mathrm{V}$ con hileras transversales de setas uncinadas (Fig. 21.1). Segmentos VI-VII con tubérculos laterodorsales portadores de 1-2 largas setas filiformes, orientadas hacia la región caudal (Fig. 21.1). Quetotaxia dorsal y ventral de los segmentos IX-X según Fig. 21.9, 10 respectivamente.

Discusión. La larva de C. ciliata puede ser diferenciada a simple vista de las larvas de las restantes especies ibéricas de esta familia por la combinación de las características anotadas en la diagnosis anteriormente citada y por la capa de camuflaje que portan. Dicha capa es muy compacta y de gran tamaño, generalmente cubre la totalidad del dorso de la larva y suele estar fabricada con pequeñas partículas de naturaleza vegetal.

Respecto a las características de morfología externa que nos permitan establecer relaciones entre ésta y otras especies de Chrysopidae, y como ya se indicó en la introducción, no existía información disponible a este respecto sobre las otras especies del género, y por ello únicamente mencionaremos las características morfológicas que nos permitan diferenciarla de las especies pertenecientes a los géneros de la subfamilia Chrysopinae incluidos en esta contribución.

La larva de $C$. ciliata queda incluida en el grupo de larvas portadoras de capa de camuflaje, presentando por ello una serie de modificaciones morfológicas que ayudan en la fijación de dicha capa. Así, determinados caracteres morfológicos de las larvas maduras, como abdomen globoso, setas de tipo uncinado y espatulado, tubérculos laterales del protórax alargados y portadores de largas setas, metanoto con una hilera transversal de setas filiformes, etc, son compartidos con las especies de los géneros Pseudomallada, Suarius, Cunctochrysa y Rexa, cuyas larvas son también portadoras de capa de camuflaje y por lo tanto poseen una morfología externa muy similar a la de la larva aquí estudiada. Aún así, la larva madura de C.ciliata puede ser fácilmente diferenciada de las restantes basándonos en la longitud de los tubérculos laterales del protó- rax. Generalmente, en las larvas portadoras de capa, dichos tubérculos son alargados y ligeramente ensanchados en su ápice, pero en C.ciliata son muy estrechos, no ensanchados en su ápice y notablemente más largos (Fig. 21.1).

Las larvas neonatas, sin embargo, presentan un mayor grado de similitud, haciéndose más complicada la diferenciación entre géneros. No obstante, las larvas de Suarius (Fig. 42.2) y Pseudomallada (Fig. 25.2) presentan en el metatórax cuatro tubérculos dorsales portadores, cada uno de ellos, de 1 larga seta, mientras que en las de $C$. ciliata (Fig. 20.2) y Cunctochrysa (Figs. 22.4, 5) estos tubérculos aparecen también en el mesotórax. En estos dos últimos géneros el número y disposición de las setas de tórax y abdomen es idéntico y las larvas de ambos géneros pueden ser diferenciadas únicamente en base a la quetotaxia cefálica (Figs. 20.3, 4), y aunque el número y disposición de setas cefálicas también resulta idéntico en ambos géneros, no así la longitud de las mismas, ya que en las larvas neonatas del género Cunctochrysa la seta S-2 es mucho más corta que las setas que la rodean, S-3, S-4, S-5 y S-6 (Fig. 23.2), mientras que en las especie ahora estudiada dicha seta presenta una longitud considerable, siendo de mayor longitud que las setas S-3, S-4, S-5 y S-6 (Fig. 20.3).

Biología y COMPortamiento. Aunque en la bibliografía citada y en Aspöck et al. (1980) o Mc Ewen et al. (2001) se recoge abundante información sobre esta especie, aportamos los datos que hemos obtenido.

Las hembras depositaron los huevos de forma aislada en el envés de las hojas añadidas a las cajas de cultivo.

Las larvas, durante todo su desarrollo, son portadoras de una capa de camuflaje de grandes dimensiones que llega a cubrir, en la mayoría de los casos, la totalidad de la larva. Dicha capa, en las larvas capturadas en la naturaleza, está compuesta por pequeñas partículas de material vegetal, fuertemente unidas al dorso de la larva y entre sí, formándose así una capa de camuflaje muy densa y compacta, que cubre el dorso y zonas laterales de la larva, hecho que, como hemos anotado, permite diferenciar fácilmente a las larvas de esta especie. Son larvas poco activas y, frecuentemente, permanecen en reposo en el envés de las hojas añadidas a las cajas de cultivo.

Las condiciones de cultivo y la duración de los estadios preimaginales de esta especie fueron los siguientes: 


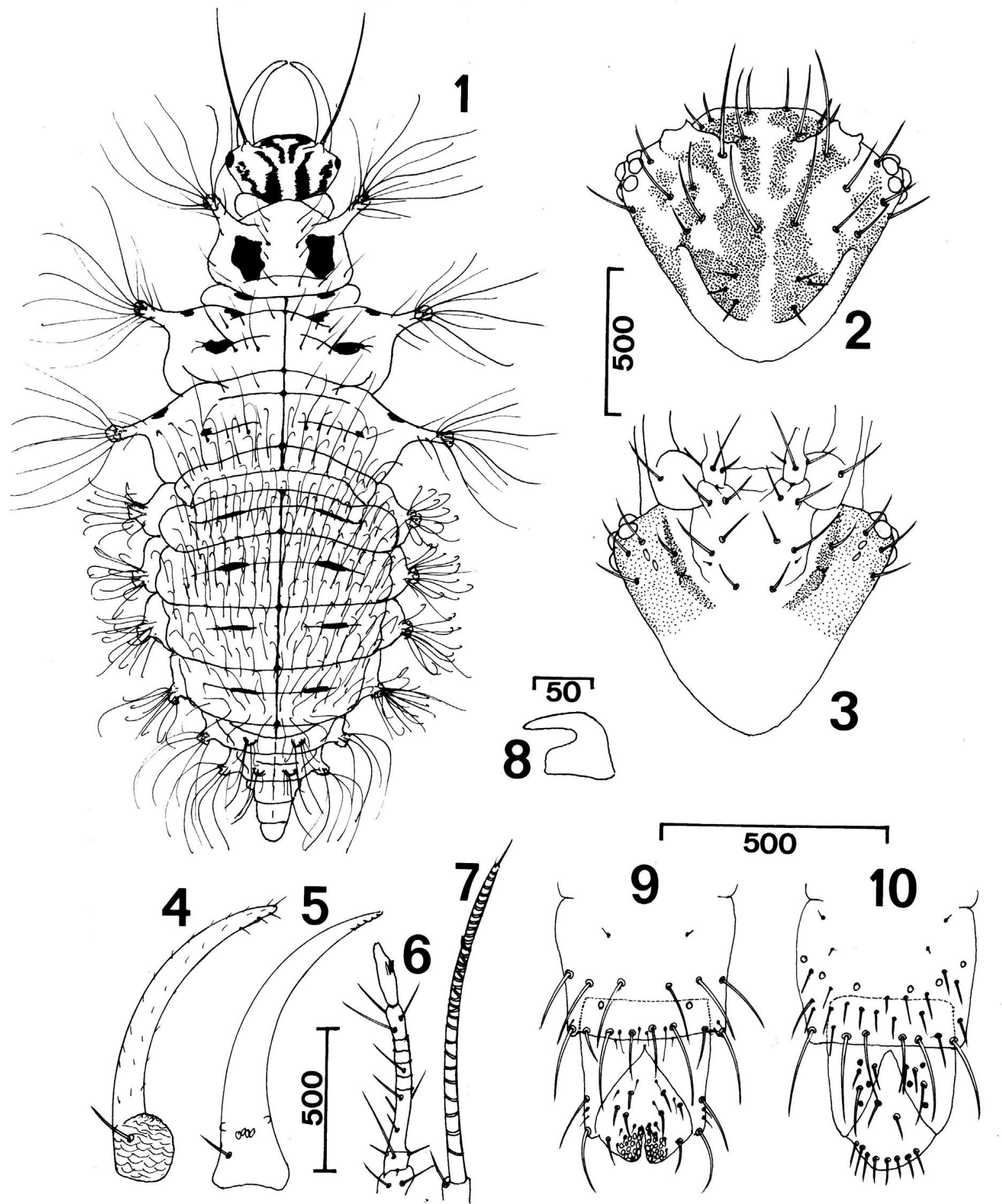

Fig. 21.- Chrysopidia (Chrysotropia) ciliata (L-3). 1, Aspecto general (VD). 2, Cápsula cefálica (VD). 3, Ídem (VV). 4, Maxila. 5, Mandíbula. 6, Palpo labial. 7, Antena. 8, Uña. 9, Segmentos abdominales IX-X (VD). 10, Ídem (VV). Escalas en $\mu \mathrm{m}$.

Fig. 21.- Chrysopidia (Chrysotropia) ciliata (L-3) (third instar larva). 1, Habitus (DV). 2, Head capsule (DV). 3, Ditto (VV). 4, Maxilla. 5, Mandible. 6, Labial palp. 7, Antenna. 8, Claw. 9, Abdominal segments IX-X (DV). 10, Ditto (VV). Scales in $\mu$ m. 


$\begin{array}{ccccc}\text { DURACION } & \text { DE LOS ESTADIOS PREIMAGINALES (días) } \\ \text { H } & \text { L-1 } & \text { L-2 } & \text { L-3 } & \text { P } \\ 5 & 7-8 & 9-10 & 15-18 & *\end{array}$

CONDICIONES DE CULTIVO

DIETA

$21^{\circ} \mathrm{C} \quad 16 \mathrm{~L}: 8 \mathrm{D} \quad 80 \%$ H.R. Aphis craccivora

(*) Hiberna como prepupa en el interior del capullo.

En la Península Ibérica, tanto imagos como larvas de esta especie, han sido colectados sobre planifolios en zonas de influencia eurosiberiana, especialmente sobre avellanos y robles (Corylus y Quercus) y en menor medida Fagus, Betula, Salix o Castanea (Monserrat \& Díaz-Aranda, 1989; Monserrat \& Marín, 1994; Monserrat \& Rodrigo, 1992; Monserrat, 2008).

DiSTRIBUCIÓN GEOGRÁFICA Y ALTITUDINAL, FENOLOGíA. Esta especie es conocida en la Península Ibérica únicamente de la región más septentrional de influencia eurosiberiana (provincias de Asturias, León, Pontevedra, Lugo, Cantabria, Lérida, Barcelona, Vizcaya y Guipuzcoa). Su rango altitudinal oscila entre los 60-1320 m, y ha sido hallada entre los meses de abril y septiembre.

\section{Género Cunctochrysa}

El género Cunctochrysa Hölzel, 1970 comprende en la actualidad 5 especies conocidas del sur de África, Región Paleártica y Nepal (Brooks \& Barnard, 1990; Aspöck et al., 2001).

En Europa el género Cunctochrysa está representado por dos especies: C. albolineata (Killington, 1935), ampliamente distribuida en la Región Paleártica, desde Portugal a Corea, y $C$. baetica (Hölzel, 1972), especie holomediterránea distribuida en la región desde el sur de Europa, Marruecos y Túnez a Anatolia, ambas están representadas en la Península Ibérica. Una tercera especie C. bellifontensis Leraut, 1988 de Francia ha sido propuesta como sinónima de una y otra especie, y su estatus está aún por definir. La morfología larvaria de las especies de este género sólo es conocida en las especies europeas: C. albolineata (Withycombe, 1923; Killington, 1928, 1937; Agekjan, 1973; Tsukaguchi, 1977; Gepp, 1983, 1989), y C. baetica (Pantaleoni, 1983; Duelli, 1989), aunque a veces no pasan de ser descripciones o fotografías meramente testimoniales, con escasa y fragmentaria información verdaderamente solvente y disgnóstica. Conocemos la existencia de una posible tercera especie ibérica aún no dilucidada, que anteriormente hemos citado en relación a Chrysopa nigricostata. Para las especies ibéricas ( $C$. albolineata y C. baetica), sus fases juveniles, biología, comportamiento y distribución fueron estudiadas y descritas con mayor detalle por Díaz-Aranda \& Monserrat (1994), y ahora actualizamos los registros ibéricos conocidos.

\section{Material utilizado.}

Cunctochrysa albolineata (Killington, 1935)

Hembras grávidas: España, Santander, Cosgaya, 14.VIII.1989, sobre Quercus robur.

Larvas: España, Guadalajara, Cantalojas, 18.IX.1988, sobre Quercus pirenaica, La Huerce, 13.VIII.1984, sobre Q. pyrenaica. Huesca, Embalse de Paso Nuevo, 31.VIII.1990, sobre Corylus avellana. Lérida, Bosost, 21.IX.1991, sobre C.avellana, Naut Aran, 29. VIII.1991, sobre Fraxinus angustifolia. Segovia, Riofrío de Riaza, 30.IX. 1989, sobre Fagus sylvatica. Teruel, Orihuela del Tremedal, 13.IX.1987, 30.VIII.1989, sobre Q. pyrenaica.

Cunctochrysa baetica (Hölzel, 1972)

Hembras grávidas: España, Madrid, Alcalá de Henares, 21.IX.1990, a la luz.

Larvas: España, Albacete, Sotuélamos, 13.VII.1991, sobre Q. rotundifolia. Castellón, Villafranca del Cid, 4.VIII.1987, sobre $Q$. rotundifolia. Guadalajara, Mirabueno, 21.X.1984, sobre $Q$. rotundifolia. Huelva, Cumbres de Enmedio, 3.VI.1990, sobre Q. rotundifolia. Lérida, Adrall, 20.VI.1991, 1.VIII.1991, sobre $Q$. faginea, Barranco de Ortedó, 23.IX.1991, sobre $Q$. faginea, Montfalcó, 20.VI.1991, sobre $Q$. rotundifolia. Segovia, Santibáñez de Ayllón, 8.VII.1989, sobre Q. rotundifolia.

\section{ESTADIOS LARVARIOS}

Características generales (L-1: Figs. 22.1-6, 23.1-10, L-3: Figs. 24.1-8).

Cuerpo alargado con abdomen moderadamente globoso (Fig. 24.1).

Larvas portadoras de una pequeña capa de camuflaje o desnudas (Fig. 24.1).

Tres tipos morfológicos de setas: filiformes, espatuladas y uncinadas (Figs. 22.1-3).

Mancha frontoclipeal abierta en su margen anterior, longitudinalmente dividida en dos. Manchas epicraneales bifurcadas (Fig. 22.4, Figs. 23.2, 24.2).

Mesonoto con una banda de largas setas (Fig. 24.1).

Seta cefálica S-12 presente (Figs. 22.4, 23.2, 24.3).

De la larva neonata (Figs. 22.1-6, 23.1-10).

Segmento abdominal $\mathrm{V}$ con una hilera transversal de 4 pequeñas setas filiformes o uncinadas (Fig. 22.4).

De la larva madura (Figs. 24.1-8).

Manchas epicraneales fuertemente bifurcadas, bien casi divididas en dos en toda su longitud (Fig. 


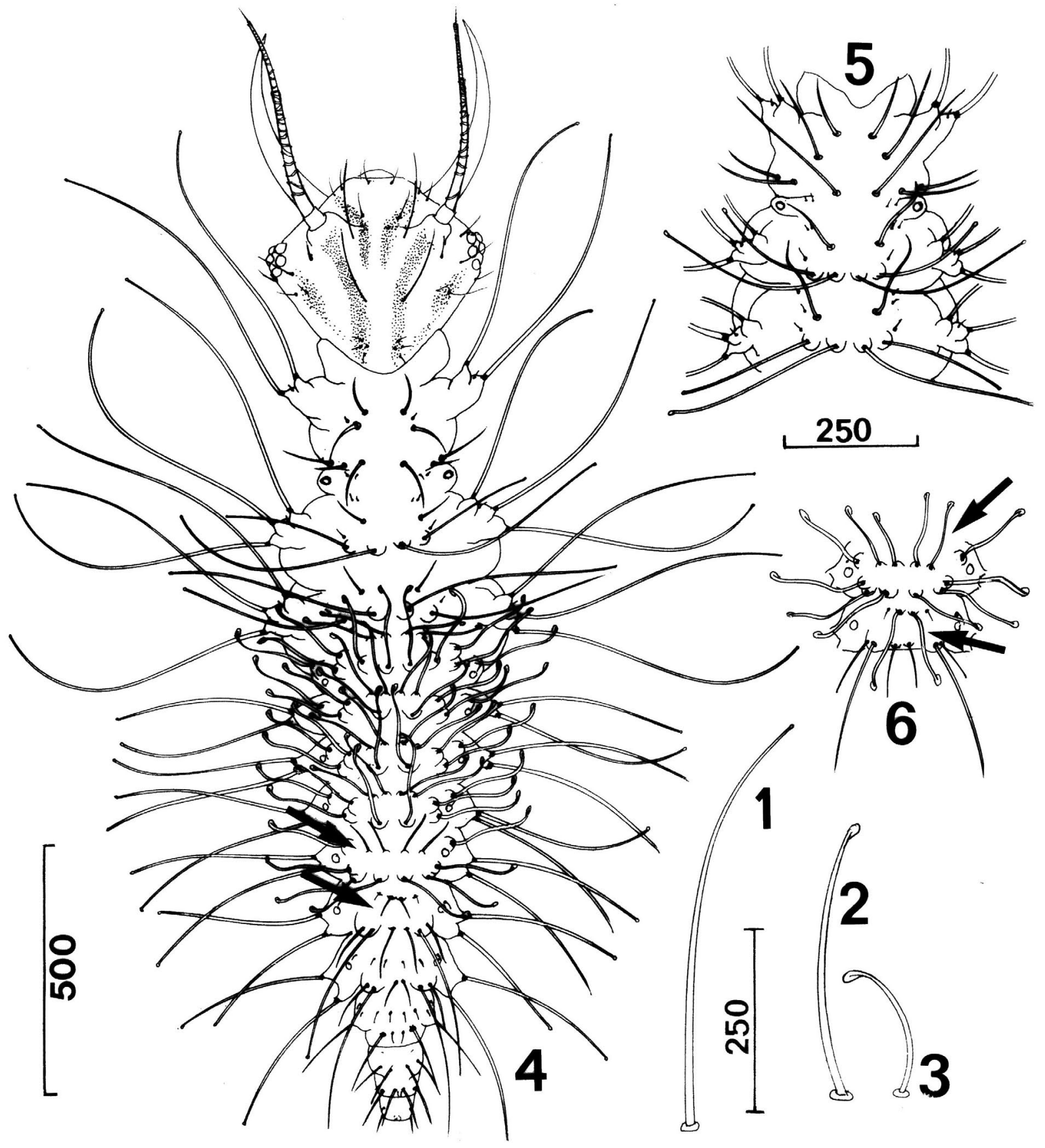

Fig. 22.- Género Cunctochrysa (L-1). 1-4: C. baetica, 1, Seta filiforme. 2, Seta espatulada. 3, Seta uncinada. 4, Aspecto general (VD). 5-6: C.albolineata, 5, Quetotaxia torácica (VD). 6, Quetotaxia de los segmentos abdominales V-VI (VD). Escalas en $\mu \mathrm{m}$. Para flechas ver texto. Adaptado de Díaz-Aranda \& Monserrat (1994).

Fig. 22.- Genus Cunctochrysa (L-1) (first instar larva). 1-4: C. baetica, 1, Filiform seta. 2, Spatulate seta. 3, Uncinate seta. 4, Habitus (DV). 5-6: C.albolineata, 5, Thoracic chaetotaxy (DV). 6, Chaetotaxy of abdominal segments V-VI (DV). Scales in $\mu \mathrm{m}$. For arrows see text. Adapted from Díaz-Aranda \& Monserrat (1994). 
24.2b), o bifurcadas en su mitad o su tercio posterior (Fig. 24.2a).

Discusión. Las larvas conocidas del género Cunctochrysa se caracterizan por los datos generales anteriormente anotados, sobre todo por la presencia sobre el mesotórax de una banda de largas setas (Fig. 24.1), abdomen moderadamente globoso (Fig. 24.1), tipos de setas (Figs. 22.1-3), pigmentación y quetotaxia cefálica y tegumentaria (Figs. $24.1,2)$, sin o con escasa capa de camuflaje, y especialmente por su coloración blanquecina con dos bandas rojizas sobre el meso- y metanoto (Fig. 24.1), que son características. No existe en la fauna ibérica otras especies con larvas que presenten una combinación de estos elementos.

En relación a la caracterización de ambas especies ibéricas consideremos por separado las diferencias halladas entre sus respectivas larvas neonatas y maduras.

Las larvas neonatas de ambas especies son prácticamente idénticas en cuanto a su morfología externa, habiéndose encontrado únicamente un par de caracteres que permiten su correcta asignación. Uno se trata de la distinta morfología de algunas de las setas de los segmentos abdominales V y VI, similar a lo expuesto posteriormente para las larvas L-1 del género Pseudomallada. En este caso, $C$. baetica posee una hilera transversal anterior de 4 pequeñas setas filiformes en ambos segmentos (Fig. 22.4), mientras que en C. albolineata la hilera trasversal anterior del segmento $\mathrm{V}$ está compuesta por 4 setas uncinadas (Fig. 22.6) y la del segmento VI por 2 setas centrales uncinadas y 2 laterales, pequeñas y filiformes (Fig. 22.6). Otra diferencia encontrada entre las neonatas de las dos especies es la longitud relativa de las setas dorsales del tórax. En C. albolineata (Fig. 22.5) estas setas son considerablemente más largas que en $C$. baetica (Fig. 22.4), pero dada la variabilidad de este carácter, no puede ser empleado con exclusividad y serviría sólo como apoyo del primero.

Las larvas L-3 de las dos especies ibéricas de este género son, a simple vista, idénticas, presentando patrones de coloración, quetotaxia cefálica, torácica y abdominal, morfología de la uña, morfología de los escleritos y de los espiráculos, prácticamente idénticos. Entre los caracteres morfológicos externos estudiados, únicamente dos de ellos permiten diferenciar las larvas maduras de las dos especies. Estos caracteres presentan un reducido grado de variabilidad y son por ello de gran utilidad en la correcta asigna- ción de las larvas. Dichos caracteres son: pigmentación dorsal de la cápsula cefálica (Figs. 24.2a, b) y la longitud relativa de las antenas, palpos labiales, mandíbulas y maxilas. Las manchas epicraneales aparecen fuertemente bifurcadas en ambas especies, sin embargo las de $C$. baetica están casi divididas en dos en toda su longitud (Fig. 24.2b), mientras que en C. albolineata dichas manchas se bifurcan en su mitad o, a lo sumo, en su tercio posterior (Fig. 24.2a). Respecto al segundo carácter (diferencia de longitud de las mandíbulas, maxilas, antenas y palpos labiales existente entre ambas especies), las medidas de dichas estructuras han sido tomadas como muestra la Fig. 24.5a, para mandíbula y maxila, y la fig $24.7 \mathrm{a}$, para antena y palpo labial. La media y desviación típica (expresada en $\mu \mathrm{m}$ ) de los valores obtenidos para $\mathrm{n}=20$ en $C$. albolineata y $\mathrm{n}$ $=28$ en $C$. baetica, ya anotaban Díaz-Aranda \& Monserrat (1994) y se muestran en la siguiente tabla:

$\begin{array}{lcc}\text { ESTRUCTURA } & \text { C. albolineata } & \text { C. baetica } \\ \text { MANDIBULA } & 1223,5 \pm 1,75 \mu \mathrm{m} & 930 \pm 2,94 \mu \mathrm{m} \\ \text { MAXILA } & 1196,7 \pm 2,07 \mu \mathrm{m} & 917,5 \pm 1,2 \mu \mathrm{m} \\ \text { PALPO LABIAL } & 985 \pm 1,38 \mu \mathrm{m} & 732,5 \pm 1,2 \mu \mathrm{m} \\ \text { ANTENA } & 1610 \pm 5,29 \mu \mathrm{m} & 1242 \pm 2,87 \mu \mathrm{m}\end{array}$

Los valores obtenidos son siempre mayores en C. albolineata que en C. baetica, no habiéndose encontrado valores intermedios (ver tabla) y resultando por ello un carácter métrico de gran utilidad en la diferenciación de las larvas de ambas especies.

Otros caracteres que, a pesar de presentar un mayor grado de variabilidad, pueden ayudar en la diferenciación de las larvas son: La setación secundaria de la cápsula cefálica, más densa en C. albolineata (Figs. 24.3a, b) y el número de palpómeros del $2^{\circ}$ segmento del palpo labial, en C. baetica subdividido en 5 palpómeros (Fig. 24.6b), mientras que en $C$. albolineata es siempre mayor de 5 , variando entre 7 a 8 en los ejemplares estudiados (Fig. 24.6a).

\section{Clave para larvas L-1}

1 Segmentos abdominales $\mathrm{V}$ y $\mathrm{VI}$ con una hilera transversal anterior de 4 pequeñas setas filiformes (Fig. 22.4)

C. baetica

- Segmento abdominal V con una hilera transversal anterior de 4 setas uncinadas y segmento $\mathrm{VI}$ con 2 centrales uncinadas y 2 laterales filiformes, mucho más cortas (Fig. 22.6) C.albolineata

\section{Clave para larvas L-3}

1 Manchas epicraneales fuertemente bifurcadas, casi completamente divididas en dos (Fig. 24.2b). Mandíbula-maxila nunca más largas de $1 \mathrm{~mm}$. Antena 
nunca más larga de 1,4 mm. Palpo labial con el $2^{\circ} \mathrm{seg}$ mento dividido en 5 palpómeros (Fig. 24.6b). Microsetación cefálica poco desarrollada (Fig. 24.3b)

C. baetica

- Manchas epicraneales bifurcadas desde su medio o, a lo sumo, tercio posterior, nunca divididas (Fig. 24.2a). Mandíbula-maxila siempre más larga de $1 \mathrm{~mm}$. Antena siempre más larga de $1,4 \mathrm{~mm}$. Palpo labial con el $2^{\circ}$ segmento dividido en 7-8 palpómeros (Fig. 24.6a). Microsetación cefálica muy desarrollada (Fig. 24.3a) .. C.albolineata

BIOLOGÍA Y COMPORTAMIENTO. En relación a sus fases juveniles, datos sobre sus huevos (de corto pedúnculo), tipo de puestas (huevos aislados sobre los márgenes de hojas añadidas a las cajas de cultivo), duración del desarrollo embrionario de $C$. albolineata / C. baetica (6/6 días), biología y comportamiento de las larvas (desnudas y sin capa de camuflaje o con capa de camuflaje escasa, compuesta por algunos restos de presas y sus propias exuvias, siempre presente en $C$. baetica, y aunque Duelli, 1989 anota que las larvas de C. albolineata pierden su capa de camuflaje en el último periodo L-3, este hecho no ha sido observado por nosotros), duración de los estadios larvarios (7/ 6-7 días para L-1, 9-11/ 9-13 días para L-2 y 18-20/ 15-20 días para L-3, en condiciones de temperatura: $21^{\circ} \mathrm{C} / 25$ ${ }^{\circ} \mathrm{C}$, fotoperiodo: $16 \mathrm{~L}: 8 \mathrm{D} / 16 \mathrm{~L}: 8 \mathrm{D}$, humedad relativa: $80 \% / 60 \% /$, áfidos suministrados (Aphis craccivora Koch, 1854 y A. pomi De Geer, 1773 / Aphis craccivora y A. fabae Scopoli, 1763) y periodo de pupación (desde 20 a 30 días a pasar el invierno como prepupa en el interior del capullo, emergiendo de 5 a 7 meses después) pueden obtenerse de Díaz-Aranda \& Monserrat (1994).

La biología de ambas especies en la Península Ibérica no es demasiado conocida. Tanto adultos como larvas de C. albolineata se han recolectado mayoritariamente en medios húmedos y boscosos sobre (robles, avellanos, fresnos, hayas y vegetación de ribera), mientras que $C$. baetica ha sido mayoritariamente recolectada en medios más térmicos y secos (especialmente sobre Quercus rotundifolia) donde se han realizado la mayoría de las capturas de esta especie, tanto en estado de larva como de imago. Monserrat (1979, 1982b, 2008); Monserrat \& Rodrigo (1992); Monserrat \& DíazAranda (1989a). Monserrat \& Marín (1994) anotan datos sobre la biología de estas especies.

DisTRIBUCIÓN GEOGRÁFICA Y ALTITUDINAL, FENOLogíA. En la Península Ibérica, la biología de ambas especies no es demasiado conocida, y por lo ante- riormente anotado, las dos especies presentes en ella parecen segregarse, ocupando $C$. baetica las zonas centrales y meridionales de mayor influencia mediterránea (provincias de Albacete, Alicante, Almería, Barcelona, Lérida, Granada, Badajoz, Cáceres, Cádiz, Cuenca, Baleares (Mallorca), Huelva, Jaen, Murcia, Madrid, Salamanca, Soria, Segovia, Guadalajara, Gerona, Huesca, Tarragona, Castellón, Teruel, Toledo, Valencia, Zamora y Zaragoza en España, y Beira Alta en Portugal), y por el contrario C. albolineata parece circunscrita a biotopos más húmedos, siendo más frecuente en las zonas septentrionales de influencia eurosiberiana (provincias de Asturias, León, Barcelona, Huesca, Lérida, Lugo, Orense, Cantabria, Teruel, Guadalajara, Cuenca, Soria, Segovia, Madrid, Zamora y Andorra), entre abril-octubre, y entre 10 -1900 m para la primera, y en los meses de junio-septiembre, y desde 430-1500 m para la segunda (Hölzel \& Ohm, 1972; Monserrat \& Rodrigo, 1992; Monserrat \& Marín, 1994; Monserrat, 2008).

Antes de finalizar, ha de indicarse que los estadios juveniles cultivados a partir de algunos ejemplares asignables por su morfología externa a lo que entendíamos como Chrysopa nigricostata parecen pertenecer al género Cunctochrysa, y como hemos indicado anteriormente, la identidad de los ejemplares ibéricos de esta "especie" está aún por dilucidar.

\section{Género Pseudomallada}

El género Pseudomallada Tsukaguchi, 1995 (recientemente la Comisión Internacional de Nomenclatura Biológica, Opinion 2254, Case 3399, en su boletín de 2010, 67, 3:261-262 ha validado este género anteriormente relacionado con otros géneros como Anisochrysa, Mallada, Dichochrysa) se compone en la actualidad unas 130 especies censadas por Brooks \& Barnard (1990). Mayoritariamente distribuidas por las Regiones Paleártica, Oriental y Afrotropical. De ellas, 13 especies están presentes en la Península Ibérica: $P$. ventralis (Curtis, 1834), $P$. prasinus (Burmeister, 1839), P. genei (Rambur, 1842), P. venosus (Rambur, 1842), P. clathratus (Schneider, 1845), P. flavifrons (Brauer, 1850), P. granadensis (Pictet, 1865), P. picteti (McLachlan, 1880), P. inornatus (Navás, 1901), P. subcubitalis (Navás, 1901), P. ibericus (Navás, 1903) y P. alarconi (Navás, 1907), a las que muy recientemente (Monserrat, 2008) se ha añadido P. zelleri (Schneider, 1851). 


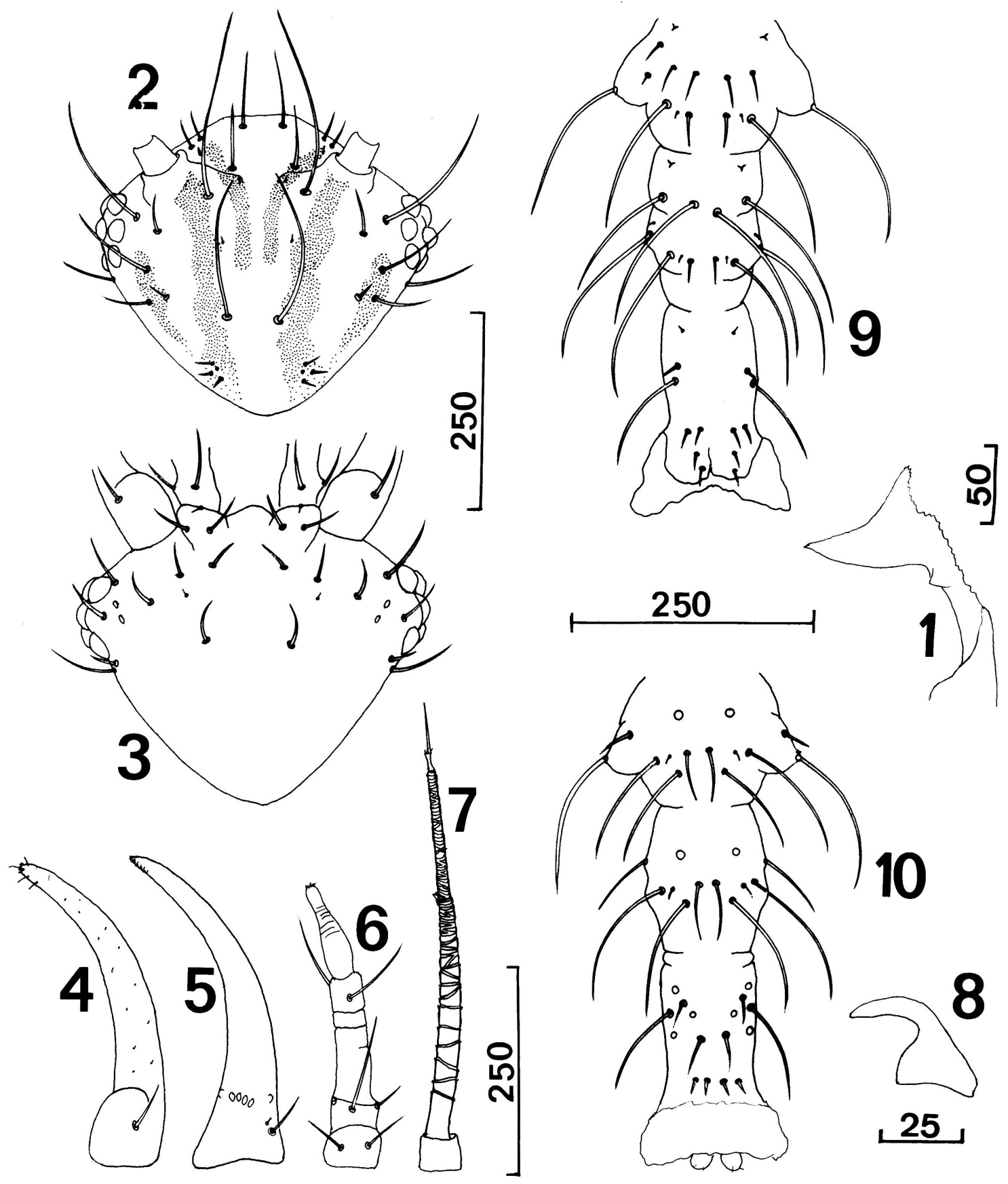

Fig. 23.- Cunctochrysa baetica (L-1). 1, Ovirruptor. 2, Cápsula cefálica (VD). 3, Ídem (VV). 4, Maxila. 5, Mandibula. 6, Palpo labial. 7, Antena. 8, Uña. 9, Quetotaxia de los segmentos abdominales VIII-X (VD). 10, Ídem (VV). Escalas en $\mu$ m. Adaptado de Díaz-Aranda \& Monserrat (1994).

Fig. 23.- Cunctochrysa baetica (L-1) (first instar larva). 1, Oviruptor. 2, Cephalic capsule (VD). 3, Ditto (VV). 4, Maxilla. 5, Mandible. 6, Labial palp. 7, Antenna. 8, Claw. 9, Chaetotaxy of abdominal segments VIII-X (VD). 10, Ditto (VV). Scales in $\mu \mathrm{m}$. Adapted from Díaz-Aranda \& Monserrat (1994). 


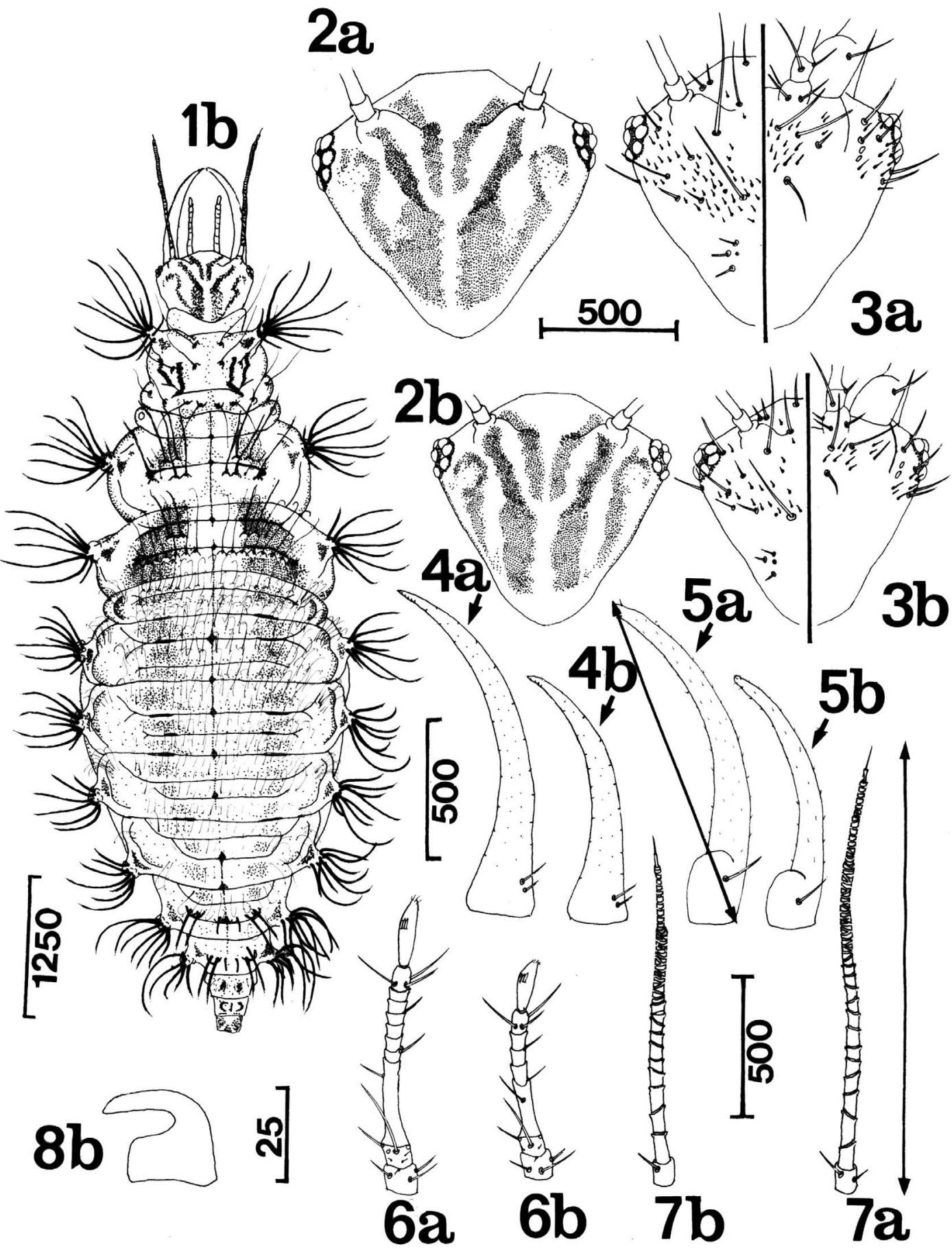

Fig. 24.- Género Cunctochrysa (L-3), a: C. albolineata, b: C. baetica. 1, Aspecto general (VD). 2, Pigmentación cefálica (VD). 3, Quetotaxia cefálica (izda.: VD/ dcha.: VV). 4, Mandíbula. 5, Maxila. 6, Palpo labial. 7, Antena. 8, Uña. Escalas en $\mu \mathrm{m}$. Adaptado de Díaz-Aranda \& Monserrat (1994).

Fig. 24.- Genus Cunctochrysa (L-3) (third instar larva), a: C. albolineata, b: C. baetica. 1, Habitus (DV). 2, Cephalic pigmentation (DV). 3, Cephalic chaetotaxy (left: DV / right: VV). 4, Mandible. 5, Maxilla. 6, Labial palps. 7, Antenna. 8, Claw. Scales in $\mu \mathrm{m}$. Adapted from Díaz-Aranda \& Monserrat (1994). 
La información existente sobre la morfología larvaria de este género es, en general, escasa y muy dispersa, y de sus especies descritas sólo los estadios larvarios de 21 de ellas son conocidos (ver referencias en el apartado de "Material Utilizado"). En lo referente a las especies presentes en la fauna ibérica, las primeras descripciones detalladas y completas, en las que se aportan datos sobre quetotaxia y pigmentación, fueron las realizadas sobre los estadios preimaginales de $P$. flavifrons, $P$. prasinus y $P$. clathratus (Principi, 1940, 1956a), ya que las descripciones realizadas con anterioridad por otros autores, tanto sobre estas especies, como sobre $P$. ventralis y $P$. inornatus, resultan muy superficiales y no aportan caracteres detallados (ver referencias en el apartado de "Material Utilizado"). Recientemente Labrique \& Canard (1989); Labrique (1990) y Monserrat (1984a, 1989) han aumentado considerablemente la información sobre la morfología larvaria de las especies ibéricas de este género, describiendo con detalle los estadios preimaginales de $P$. ibericus, $P$. picteti, $P$. genei y $P$. subcubitalis respectivamente, y más recientemente, la morfología larvaria de $P$. granadensis, $P$. venosus y $P$. picteti ha sido descrita por Díaz-Aranda \& Monserrat (1988 a, 1990 b, 1991). El nivel de conocimiento de este género en nuestra fauna es pues bastante satisfactorio, y anotamos ahora nuevos datos.

Material utilizado. Anotamos de cada especie tanto las hembras grávidas a partir de las cuales hemos obtenido las fases juveniles, como las larvas recolectadas por nosotros. La descripción se hará de forma conjunta en el apartado de discusión.

\section{ESTADIOS LARVARIOS}

Características generales (Figs. 25-34).

Las larvas de las especies ibéricas del género Pseudomallada quedan definidas en base a la combinación de los siguientes caracteres morfológicos:

Larvas portadoras de capa de camuflaje.

Cuerpo ancho, con abdomen globoso (Figs. 26.1, 28.1, 30.1).

Mancha frontoclipeal siempre presente (Figs. $25.2,3,26.1-2,27.2,3,29.2,3,28.1-2,30.1-2$, 33.1-10).

Ausencia de seta cefálica S-12 (Figs. 25.2-3, 26.1-2, 27.2-3, 28.1-2, 29.2-3, 30.1-2, 33.1-10).

Protórax con tubérculos laterales muy alargados, dirigidos hacia la región cefálica (Figs. 25.2, 26.1, 27.2, 28.1, 29.2, 30.1, 34.1-5).

Presentan setas filiformes, espatuladas y uncinadas (Figs. 25.2-3, 10, 11, 26.1-2, 9, 10, 27.2-3, 10, $11,28.1-2,9,10,29.2-3,9,30.1-2,8,9)$.
Metanoto con una hilera transversal de setas (Figs. 25.2, 26.1, 27.2, 28.1, 29.2, 30.1).

Segmentos abdominales V-VII con tubérculos laterodorsales (Figs. 25.2, 26.1, 27.2, 28.1, 29.2, 30.1).

De la larva neonata (Figs. 25, 27, 29, 31, 32).

Protórax con tubérculos laterales muy alargados, portadores de 2 largas setas filiformes dirigidas hacia la región cefálica (Figs. 25.2, 27.2, 29.2).

Meso- y metatórax con tubérculos laterales, menos alargados, portadores de 3 largas setas filiformes orientadas laterodorsalmente (Figs. 25.2, 27.2, 29.2).

Metanoto con cuatro tubérculos dorsales portadores, cada uno de ellos, de una larga seta filiforme (Figs. 25.2, 27.2, 29.2).

Segmentos abdominales II-VII con tubérculos laterales bien desarrollados, portadores de 2 largas setas (Figs. 25.2, 27.2, 29.2, 32.1-4).

Segmentos abdominales I-IV con pequeños tubérculos dorsales, portadores de setas uncinadas (Figs. 25.2, 27.2, 29.2).

Segmentos abdominales V-VII con 2 tubérculos laterodorsales portadores de 1 larga seta orientada hacia la región caudal (Figs. 25.2, 27.2, 29.2, 32.1-4).

De la larva madura (Figs. 26, 28, 30, 33, 34).

Longitud variable entre $5-7 \mathrm{~mm}$.

Son en su mayoría larvas totalmente blancas o blanco-amarillentas, presentando algunas especies manchas pardas o pardo oscuras en el dorso de tórax y abdomen (Figs. 26.1, 28.1, 30.1, 34.1-5).

Tubérculos laterales de los 3 segmentos torácicos alargados y engrosados en su ápice (Figs. 26.1, $28.1,30.1,34.1-5)$. Tubérculos protorácicos muy alargados y dirigidos hacia la región cefálica (Figs. 26.1, 28.1, 30.1, 34.1-5). Tubérculos meso- y metatorácicos algo menos alargados y orientados lateralmente (Fig. 26.1, 28.1, 30.1). Todos ellos portadores de largas setas rectas y filiformes.

Metanoto con una hilera transversal de largas setas filiformes, variables en número según las especies.

Abdomen globoso, con tubérculos laterales semiesféricos, más o menos desarrollados, portadores de numerosas setas filiformes y algunas espatuladas, variables en longitud según las especies y frecuentemente orientadas laterodorsalmente (Figs. 26.1, 28.1, 30.1).

Terguitos de los segmentos abdominales con varias hileras transversales de setas uncinadas, generalmente mucho más finas y cortas que las de los tubérculos laterales (Fig. 26.1, 28.1, 30.1). 
Segmentos abdominales V-VII con 2 tubérculos laterodorsales portadores de varias setas uncinadas y 1-2 largas setas, espatuladas o filiformes, orientadas hacia la región caudal (Fig. 26.1, 28.1, 30.1).

Pseudomallada ventralis (Curtis, 1834)

Los estadios preimaginales de esta especie han sido descritos por Withycombe (1923), Killington (1937) y Gepp $(1983,1989)$.

Material utilizado. Hembras grávidas: España, Burgos, Cilleruelo de Bezana, 3.VII.1989, sobre Quercus robur. Huesca, Sallent de Gallego, 25.VII.1988, sobre Corylus avellana.

Descripción de los estadios preimaginales

L-1: Figs. 31.1, 32.1, 32.5.

L-3: Figs. 33.1, 34.1, 4, 6, 8 .

Pseudomallada prasinus (Burmeister, 1839)

Los estadios preimaginales de esta especie han sido detalladamente descritos por Withycombe (1923) y Principi (1956a). En los trabajos de Tsukaguchi (1977) y Gepp $(1983,1989)$ se aportan, más someramente, ciertos datos sobre su morfología larvaria.

Material utilizado. Hembras grávidas: España, Guadalajara: Villar del Olmo, 16.V.1988, sobre Quercus rotundifolia, Chiloeches, 24.VI.1988, sobre $Q$. rotundifolia.

Larvas: España, Almería, Enix, 2.IX.1987, sobre Q. rotundifolia. Cuenca, Masegosa, 25.VIII.1990, sobre Q. rotundifolia. Guadalajara, Cantalojas, 13.X.1987, sobre Q. pyrenaica. Huesca, Embalse de Paso Nuevo, 20.VIII.1988, sobre Corylus avellana. Madrid, Alcalá de Henares, 11.VI.1991, sobre Robinia pseudoacacia.

Descripción de los estadios preimaginales

L-1: Figs. 31.2, 32.1, 32.5.

L-3: Figs. 33.2, 34.1, 4, 6, 9.

Pseudomallada genei (Rambur, 1842)

Los estadios larvarios de esta especie han sido descritos por Monserrat (1984a).

Material utilizado. Hembras grávidas: España, Almería, Cabo de Gata, Rambla de Morales, 18.VII.1988, a la luz. Alhabia, Rambla de Andarax, 20.VII.1989, a la luz.

Descripción de los estadios preimaginales

L-1: Figs. 31.3, 32.1, 32.6.

L-3: Figs. 33.3, 34.1, 5, 34.8, 9.

Pseudomallada venosus (Rambur, 1842)

Sus estadios preimaginales han sido descritos por Díaz-Aranda \& Monserrat (1990b) en base al material aquí estudiado. Con anterioridad existe la somera referencia que, bajo la denominación de Hemerobius venosa, hace Rosenhauer (1856) sobre una larva, cuya descripción resulta meramente testimonial, planteando incluso dudas sobre su correcta asignación.

Material utilizado. Hembras grávidas: España, Almería, Rambla de Andarax, Alhabia, 28.VII.1983, 20.VII.1988, a la luz, Rambla de Tabernas, 19.VII.1991, a la luz.

Descripción de los estadios preimaginales

L-1: Figs. 25.1-.11, 31.4, 32.3, 5.

L-3: Figs. 26.1- 10, 33.4, 34.1, 10.

Pseudomallada clathratus (Schneider, 1845)

No hemos conseguido puestas de hembras grávidas de esta especie para poder conseguir datos. Información sobre la morfología larvaria de esta especie pueden recabarse en Principi (1956a) y Pantaleoni (1983), de donde hemos tomado los datos ahora anotados.

Material utilizado. Hembras grávidas: España, Teruel, Puerto de Cuarto Pelado, 19.VI.1987, 4.VII.1987, sobre Pinus sylvestris.

Descripción de los estadios preimaginales

L-1: Fig. 31.5, 32.3, 5.

L-3: Fig. 33.5, 34.2, 4, 7.

Pseudomallada flavifrons (Bauer, 1850)

Principi (1940, 1956a) describe detalladamente los estadios preimaginales de esta especie y otra información más somera de su morfología larvaria ha sido dada por Lacroix (1922), Withycombe (1923), Killington (1937) y Gepp (1983, 1989).

Material utilizado. Hembras grávidas: España, Cádiz, Venta del Retín, 27.V.1987, sobre Eucaliptus globulus, Barbate, 9.VI.1988, sobre E. globulus. Santander: Santoña, 27.VI.1988, sobre Quercus rotundifolia.

Descripción de los estadios preimaginales

L-1: Figs. 31.6, 32.3, 5.

L-3: Figs. 33.6, 34.4, 5, 7.

\section{Pseudomallada granadensis (Pictet, 1865)}

Los estadios preimaginales de esta especie han sido descritos en Díaz-Aranda \& Monserrat (1988a) en base al material aquí anotado.

Material utilizado. Hembras grávidas: España, Almería, Rambla Honda, 26.V.1983, sobre Ulmus sp. Castellón, Castelló de Villamalefa, 19.VI.1987, sobre Pinus halepensis. Teruel, Mora de Rubielos, 19.VI.1987, sobre Quercus rotundifolia, Puerto de Cuarto Pelado, 4.VIII.1987, sobre Pinus sylvestris. 


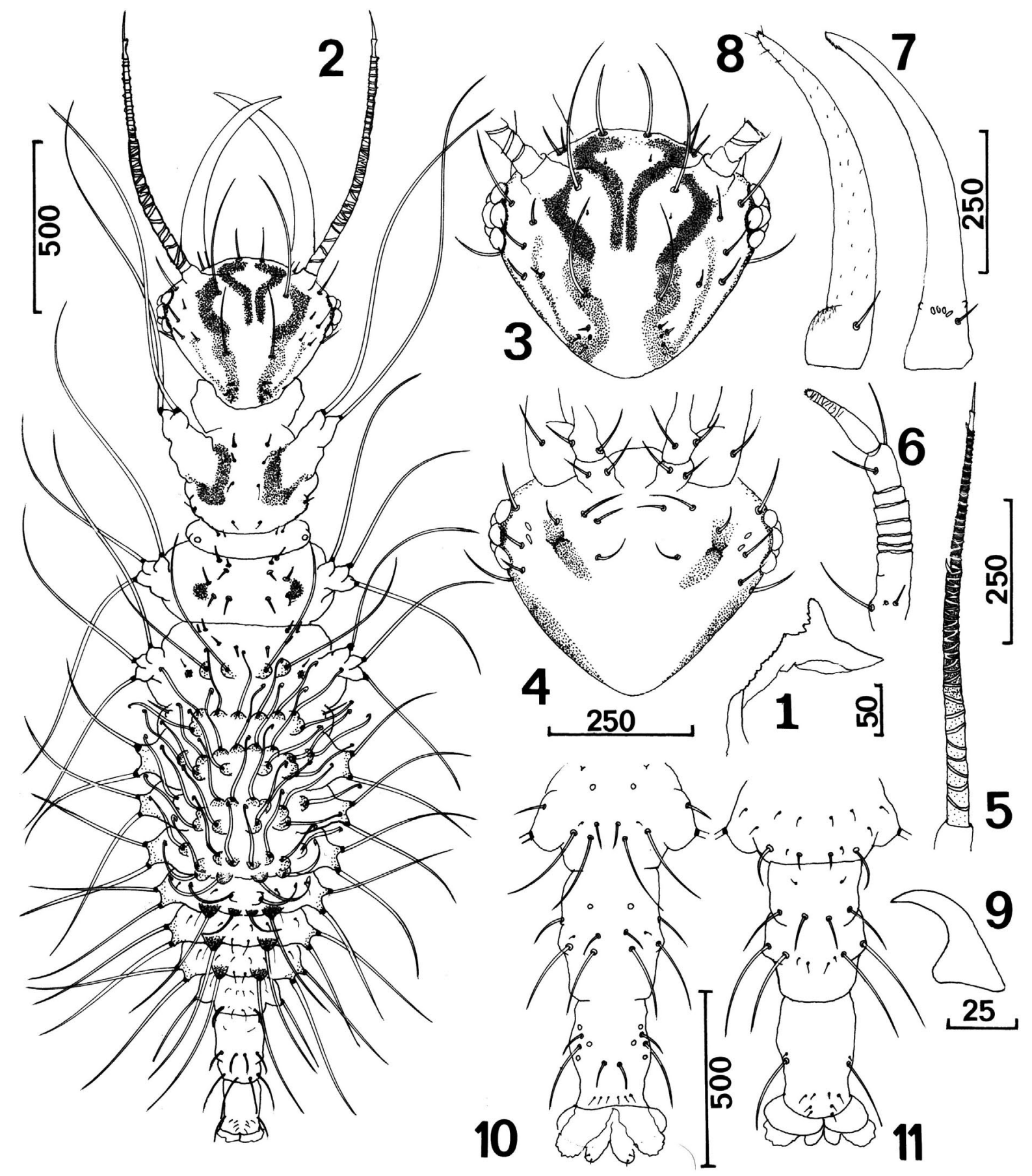

Fig. 25.- Pseudomallada venosus (L-1). 1, Ovirruptor. 2, Aspecto general (VD). 3, Cápsula cefálica (VD). 4, Ídem (VV). 5, Antena. 6, Palpo labial. 7, Mandíbula. 8, Maxila. 9, Uña. 10, Segmentos abdominales VIII-X (VV). 11, Ídem (VD). Escalas en $\mu \mathrm{m}$. Adaptado de Díaz-Aranda \& Monserrat (1990b).

Fig. 25.- Pseudomallada venosus (L-1) (first instar larva). 1, Oviruptor. 2, Habitus (DV). 3, Cephalic capsule (DV). 4, Ditto (VV). 5, Antenna. 6, Labial palp. 7, Mandible. 8, Maxilla. 9, Claw. 10, Abdominal segments VIII-X (VV). 11, Ditto (DV). Scales in $\mu \mathrm{m}$. Adapted from Díaz-Aranda \& Monserrat (1990b). 
Descripción de los estadios preimaginales

L-1: Figs. 27.1-.11, 31.7, 32.2, 6.

L-3: Figs. 28.1-10, 33.7, 34.2, 5, 7.

Pseudomallada picteti (McLachlan, 1880)

Los estadios preimaginales de esta especie han sido descritos por Labrique (1990) y, en base al material aquí estudiado, por Díaz-Aranda \& Monserrat (1991).

Material utilizado. Hembras grávidas: España, Almería, Cabo de Gata, 15.VII.1988, sobre Chamaerops hummilis. Cádiz, Llano de las Maravillas, 9.VI.1988, sobre Eucaliptus globulus.

Descripción de los estadios preimaginales

L-1: Figs. 29.1- 10, 31.8, 32.4, 32.6.

L-3: Figs. 30.1- 9, 33.8, 34.4, 5, 7.

Pseudomallada inornatus (Navás, 1901)

Los estadios preimaginales de esta especie han sido descritos en Lacroix (1925) y Gepp (1983, 1984b, 1989, 1999). Durante los muestreos realizados en este trabajo no hemos conseguido obtener hembras grávidas con las que iniciar los cultivos y, además, ninguna de las larvas capturadas en el campo, y que posiblemente pudieran pertenecer a esta especie, llevó a término su ciclo de desarrollo, por lo que no creemos conveniente incluirla en este trabajo hasta no tener una absoluta certeza de su identidad taxonómica. Aún así, queda incluida en las claves de determinación basándonos en la descripción realizada por Gepp (1983) (Figs. 34.1, 4).

Pseudomallada zelleri (Schneider, 1851)

Sólo tenemos referencia fidedigna de dos machos recolectados e identidicados por P. Duelli (en Navarra), por lo que no hemos conseguido obtener puestas y haber podido estudiar sus fases juveniles que son desconocidas (Aspöck et al., 1980), por lo que no hemos podido incluirla en este estudio.

Pseudomallada subcubitalis (Navás, 1901)

Los estadios preimaginales de esta especie han sido descritos por Monserrat (1989).

Material utilizado. Hembras grávidas: España, Almería, Cabo de Gata, Rambla de Morales, 18.VII.1988, a la luz. Cádiz, Sierra del Aljibe, 6.VI.1988, en vegetación de ribera.

Descripción de los estadios preimaginales

L-1: Figs. 31.9, 32.4, 33.6.

L-3: Figs. 33.9, 34.2, 4, 34.8, 9.
Pseudomallada ibericus (Navás, 1903)

Especie cuyos estadios preimaginales fueron descritos por Labrique \& Canard (1989).

Material utilizado. Hembras grávidas: España, Teruel, Montalbán, 18.VI.1987, sobre Pinus halepensis, Rubielos de Mora, 28.VIII.1989, sobre Juniperus oxycedrus.

Descripción de los estadios preimaginales

L-1: Figs. 31.10, 32.3, 32.5.

L-3: Figs. 33.10, 34.2, 5, 8, 10.

\section{Pseudomallada alarconi (Navás, 1915)}

A pesar de tratarse de una especie muy rara, se han colectado hembras grávidas durante todos los años transcurridos en la realización de este trabajo. Sin embargo, en ningún caso conseguimos que dichas hembras realizaran la ovoposición, ni aún cambiando las condiciones de cultivo y la dieta, con el fin de provocar, de manera artificial, la puesta de huevos. Monserrat \& Marín (1991) recolectaron una larva sobre Juniperus thurifera, de la que obtuvieron un imago, anotando algún dato sobre su desarrollo, pero sin datos sobre su morfología.

\section{Pseudomallada abdominalis (Brauer, 1856)}

Esta especie es conocida de Centroeuropa (Aspöck et al, 2011) y que fue erróneamente citada de España por Navás (1901), quien posteriormente (Navás, 1903) asigna estos ejemplares a P. ibericus. Por ello no ha sido considerada en este estudio.

Discusión. Las larvas del género Pseudomallada presentan acusadas similitudes entre sus especies, resultando marcadamente uniformes en su morfología externa. Este hecho hace muy difícil la distinción de todas ellas, pudiéndose diferenciar sólo algunas de las especies en base a determinados caracteres morfológicos.

En las larvas neonatas, donde las similitudes entre especies son aún más acusadas, los caracteres empleados son los siguientes: Tipo de setas que componen la hilera transversal anterior del segmento abdominal $\mathrm{V}$, número de setas de la hilera posteroventral del último segmento abdominal, y diseño de las manchas cefálicas.

El número, disposición y tipos de setas dorsales del tórax y abdomen de las larvas neonatas es idéntico en las especies ibéricas aquí estudiadas, con excepción de las del segmento abdominal V. Dicho segmento posee una hilera transversal anterior de 4 setas que varían en morfología y longitud en función de las especies y se mantiene constante para 


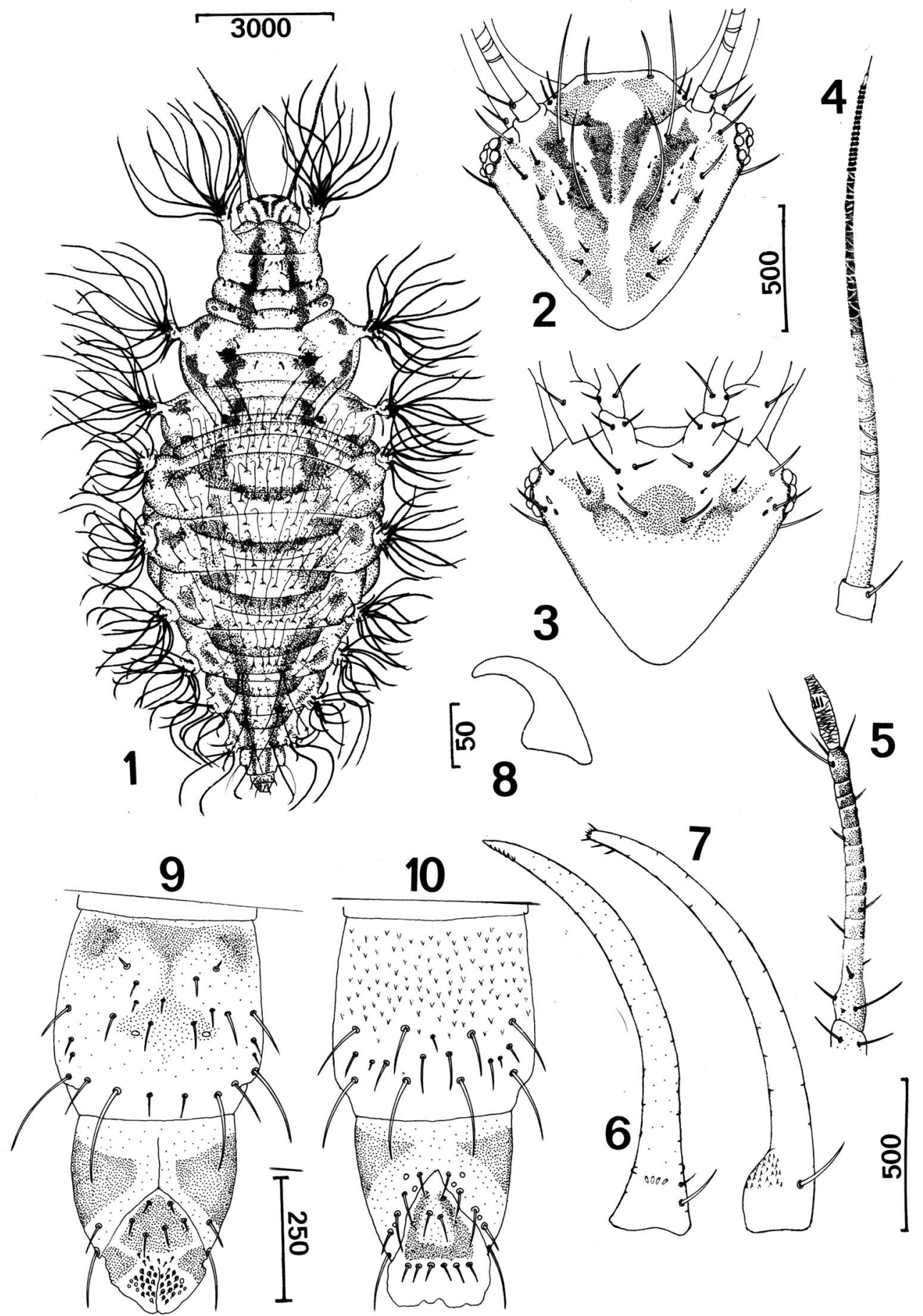

Fig. 26.- Pseudomallada venosus (L-3). 1, Aspecto general (VD). 2, Cápsula cefálica (VD), 3, Ídem (VV). 4, Antena. 5, Palpo labial. 6, Mandíbula. 7, Maxila. 8, Uña. 9, Segmentos abdominales IX-X (VD). 10, Ídem (VV). Escalas en $\mu$ m. Adaptado de Díaz-Aranda \& Monserrat (1990b).

Fig. 26.- Pseudomallada venosus (L-3) (third instar larva). 1, Habitus (DV). 2, Cephalic capsule (DV). 3, Ditto (VV). 4, Antenna. 5, Labial palp. 6, Mandible. 7, Maxilla. 8, Claw. 9, Abdominal segments IX-X (DV). 11, Ditto (VV). Scales in $\mu$ m. Adapted from Díaz-Aranda \& Monserrat (1990b). 


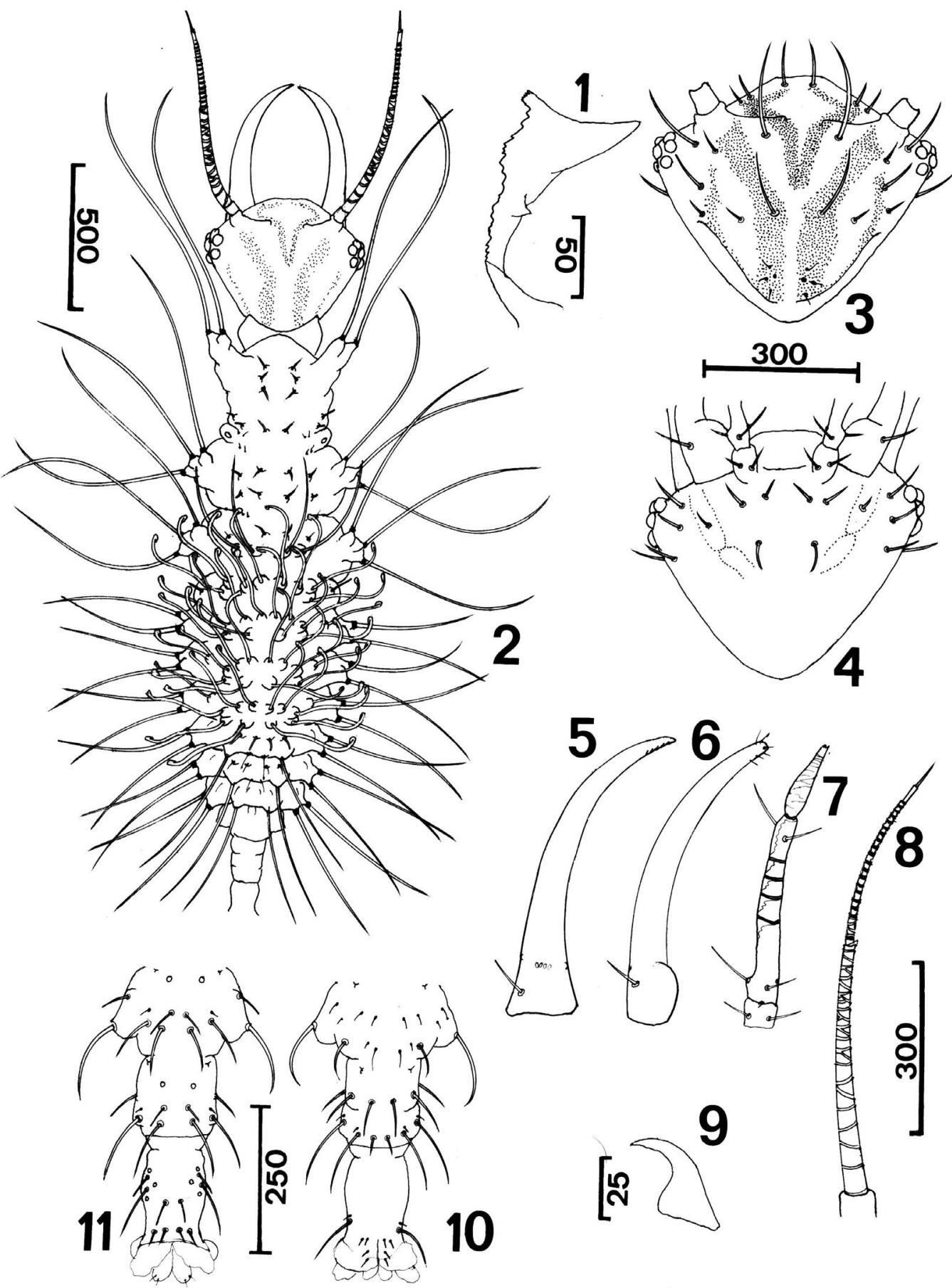

Fig. 27.- Pseudomallada granadensis (L-1). 1, Ovirruptor. 2, Aspecto general (VD). 3, Cápsula cefálica (VD). 4, Ídem (VV). 5, Mandíbula. 6, Maxila. 7, Palpo labial. 8, Antena. 9, Uña. 10, Segmentos abdominales VIII-X (VD). 11, İdem (VV). Escalas en $\mu \mathrm{m}$. Adaptado de Díaz-Aranda \& Monserrat (1988).

Fig. 27.- Pseudomallada granadensis (L-1) (first instar larva). 1, Oviruptor. 2, Habitus (DV). 3, Cephalic capsule (DV). 4, Ditto (VV). 5, Mandible, 6, Maxilla. 7, Labial palp. 8, Antenna. 9, Claw. 10, Abdominal segments VIII-X (DV). 11, Ditto (VV). Scales in $\mu \mathrm{m}$. Adapted from Díaz-Aranda \& Monserrat (1988). 
cada una de ellas, resultando por ello un carácter de gran utilidad en la diferenciación de las mismas. Este carácter ya fue utilizado por Principi (1956 a) en la diferenciación de las larvas neonatas del género que nos ocupa.

Dicha hilera transversal puede estar compuesta por 4 setas uncinadas (Fig. 32.1), como es el caso de $P$. ventralis, $P$. prasinus y $P$. genei, por 4 pequeñas setas filiformes (Fig. 32.2), únicamente observado en $P$. granadensis, o por 2 setas centrales uncinadas y 2 laterales filiformes mucho más cortas, de longitud similar a la seta del espiráculo de ese mismo segmento (Fig. 32.3, 4). A su vez, dentro de este último grupo, las larvas de $P$. subcubitalis y $P$. picteti pueden ser diferenciadas de las restantes en base a la longitud de las setas insertadas entre los dos tubérculos laterodorsales del segmento VI. En estas dos especies dichas setas son de longitud similar a la de las setas uncinadas (Fig. 32.4), mientras que en $P$. clathratus, $P$. flavifrons, $P$. venosus y $P$. ibericus son mucho más cortas y finas, de aproximadamente igual longitud que las setas de la hilera transversal anterior de ese mismo segmento (Fig. 32.3).

El siguiente carácter de utilidad en la diferenciación de las larvas, que ya hemos empleado en otros géneros, hace referencia al número de setas que componen la hilera transversal del margen posteroventral del último segmento abdominal. Este carácter se mantiene además en las larvas maduras. Según esto, en $P$. genei, $P$. subcubitalis, $P$. granadensis y $P$. picteti el número de setas es siempre de 4 (Fig. 32.6), mientras que en el resto de las especies ibéricas es de 6 (Fig. 32.5).

El diseño de las manchas frontoclipeal y epicraneales presenta mayor uniformidad intraespecífica que los caracteres anteriormente citados, y puede también ser empleado en la diferenciación de las larvas. Así, en las especies estudiadas la mancha frontoclipeal aparece bien como una única mancha impar o bien dividida longitudinalmente en dos. A su vez, en cada caso, puede presentar el margen anterior pigmentado, quedando un área interna no pigmentada en la región clipeo-labral (Figs. 31.2, 5, $7,10)$ definiéndola aquí como mancha frontoclipeal cerrada en su margen anterior, o puede ocurrir que dicho margen no esté o esté sólo ligeramente pigmentado (Figs. 31.1, 3, 4, 8), hablando entonces de mancha frontoclipeal abierta en su margen anterior.

Las manchas epicraneales son siempre bifurcadas en las especies ibéricas de este género y permi- ten diferenciar un grupo de ellas de otro en función del mayor o menor grado de bifurcación. Así, determinadas especies poseen manchas epicraneales fuertemente bifurcadas, casi completamente divididas, resultando una rama interna mucho más gruesa que la externa y de aproximadamente igual grosor en toda su longitud (Figs. 31.1-4, 7, 8) o puede ocurrir que estas manchas estén bifurcadas sólo desde su mitad posterior, aparentando estar la rama externa fuertemente ensanchada posteriormente hacia el lateral del esclerito cervical (Figs. $31.5,6,9,10)$.

Existe una última diferencia que, junto a los 3 caracteres hasta ahora citados, puede ayudar a la correcta asignación de las larvas de algunas de las especies. La quetotaxia cefálica es prácticamente idéntica en las distintas especies, existiendo sólo sensibles diferencias en la longitud de las setas cefálicas (Figs. 31.1-10), con excepción de la seta S-1, que en $P$. granadensis (Fig. 31.7) y $P$. picteti (Fig. 31.8) es considerablemente más corta que en el resto de las especies, siendo de longitud similar a la de la seta S-4.

Basándonos en todos estos caracteres morfológicos se ha realizado un clave de determinación para las larvas neonatas de este género que permite la distinción de la mayoría de las especies ibéricas. No obstante y debido a la acusada homogeneidad existente entre ellas, especies tales como $P$. clathratus, $P$. flavifrons y $P$. ibericus quedan dentro de un mismo grupo al no haberse encontrado ningún carácter que permita la diferenciación entre ellas.

Con respecto a las larvas del tercer estadio, más fácilmente diferenciables por su morfología externa, se ha encontrado un mayor número de caracteres que permiten, entre todos, la diferenciación de las distintas especies ibéricas.

Labrique (1990) realiza una clave de determinación para las larvas maduras de algunas especies del género Pseudomallada basándose, además de en el $2^{\circ}, 3^{\circ}$ y $6^{\circ}$ caracteres aquí enunciados, y en otros tales como forma de la cápsula cefálica y quetotaxia cefálica que, a nuestro parecer, no son de utilidad para una correcta asignación de las larvas, por tratarse de caracteres muy similares o prácticamente idénticos en las distintas especies de este género (al menos en las especies ibéricas).

Los caracteres utilizados por nosotros son: Coloración tegumentaria de tórax y abdomen, diseño de las manchas cefálicas, morfología de los escleritos laterodorsales de tórax y abdomen, mor- 

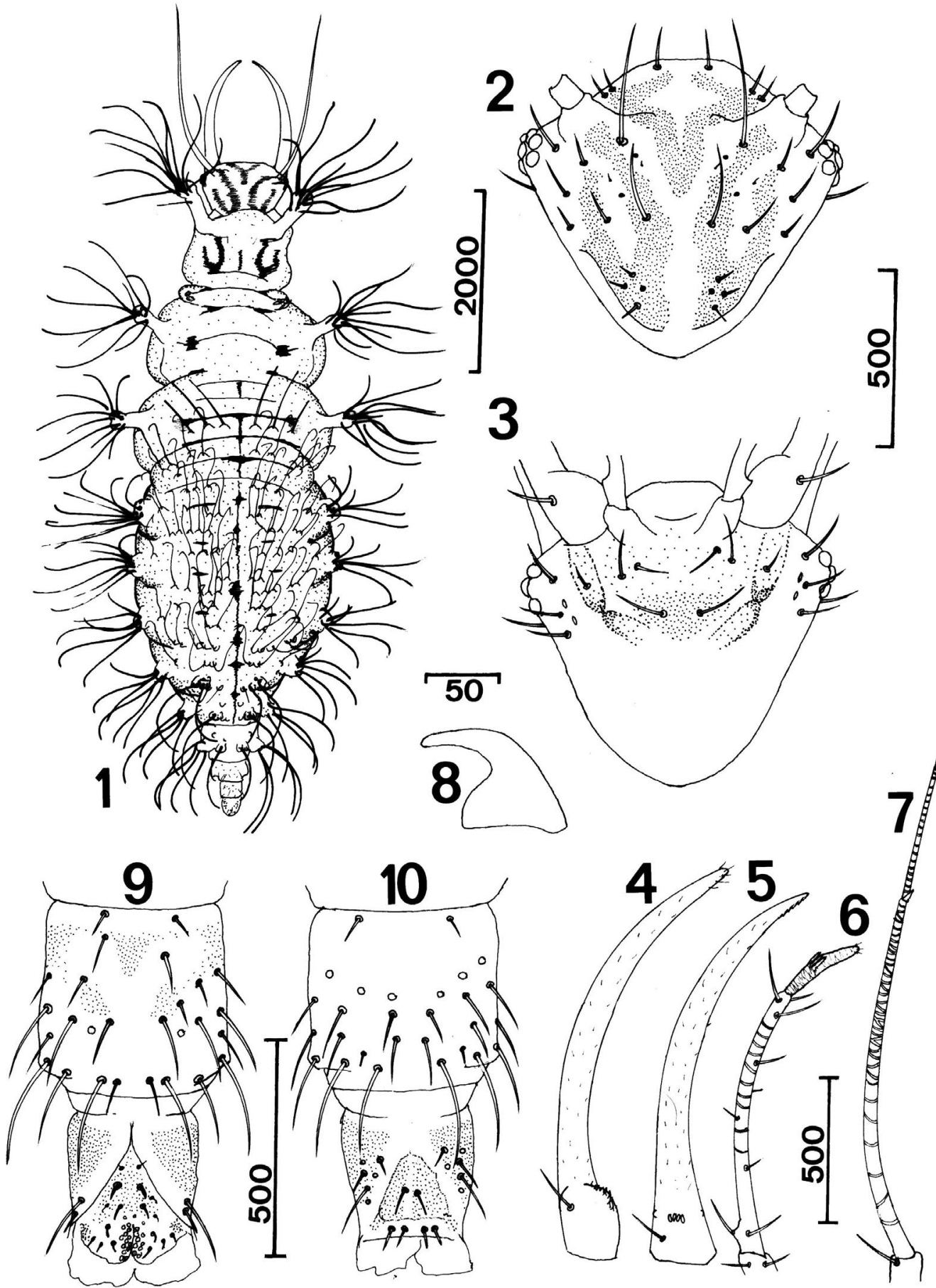

Fig. 28.- Pseudomallada granadensis (L-3). 1, Aspecto general (VD). 2, Cápsula cefálica (VD). 3, Ídem (VV). 4, Maxila. 5, Mandíbula. 6, Palpo labial. 7, Antena. 8, Uña. 9, Segmentos abdominales IX-X (VD). 10, İdem (VV). Escalas en $\mu$ m. Adaptado de Díaz-Aranda \& Monserrat (1988).

Fig. 28.- Pseudomallada granadensis (L-3) (third instar larva). 1, Habitus (DV). 2, Cephalic capsule (DV). 3, Ditto (VV). 4, Maxilla. 5, Mandible, 6, Labial palp. 7, Antenna. 8, Claw. 9, Abdominal segments IX-X (DV). 10, Ditto (VV). Scales in $\mu$ m. Adapted from Díaz-Aranda \& Monserrat (1988). 


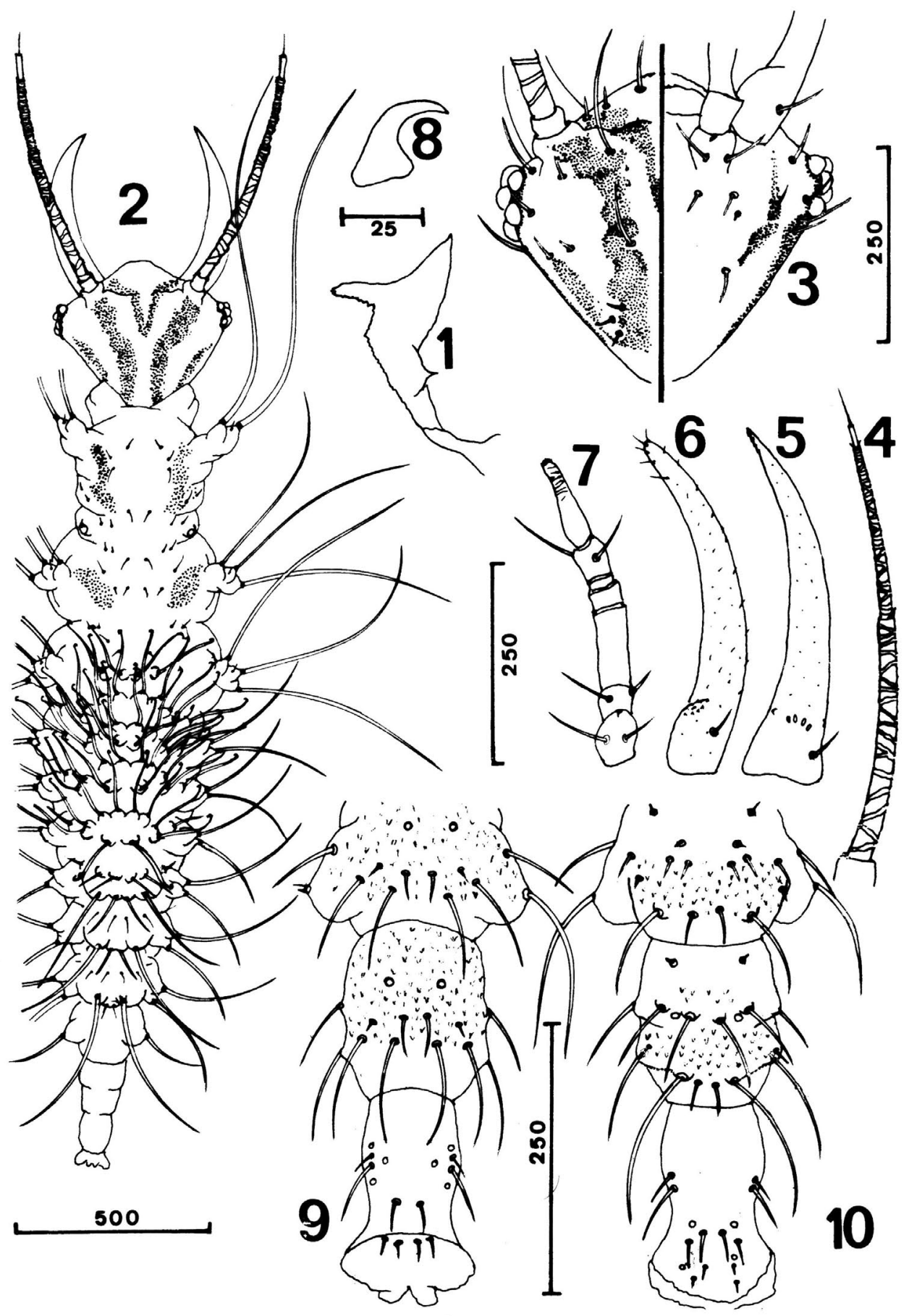

Fig. 29.- Pseudomallada picteti (L-1). 1, Ovirruptor. 2, Aspecto general (VD). 3, Cápsula cefálica (izda.:VD/ dcha.:VV). 4, Antena. 5, Mandibula. 6, Maxila. 7, Palpo labial. 8, Uña. 9, Segmentos abdominales VIII-X (VV). 10, Ídem (VD). Escalas en $\mu \mathrm{m}$. Adaptado de Díaz-Aranda \& Monserrat (1991).

Fig. 29.- Pseudomallada picteti (L-1) (first instar larva). 1, Oviruptor. 2, Habitus (DV). 3, Cephalic capsule (left: DV/ right: VV). 4, Antenna. 5, Mandible, 6, Maxilla. 7, Labial palp. 8, Claw. 9, Abdominal segments VIII-X (VV). 11, Ditto (DV). Scales in $\mu \mathrm{m}$. Adapted from Díaz-Aranda \& Monserrat (1991). 


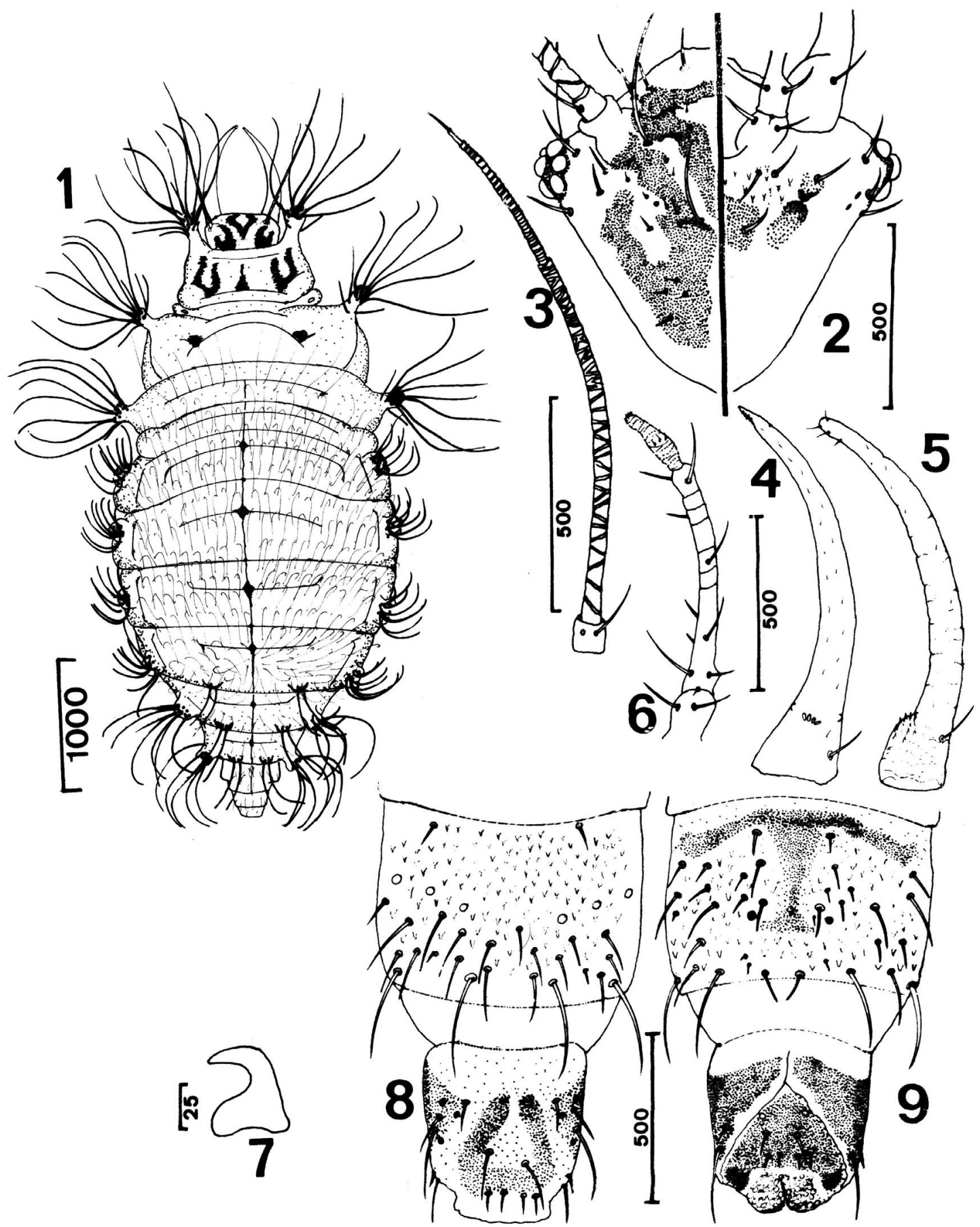

Fig. 30.- Pseudomallada picteti (L-3). 1, Aspecto general (VD). 2, Cápsula cefálica (izda.:VD/ dcha.:VV). 3, Antena. 4, Mandíbula. 5, Maxila. 6, Palpo labial. 7, Uña. 8, Segmentos abdominales IX-X (VV). 9, Ídem (VD). Escalas en $\mu$ m. Adaptado de Díaz-Aranda \& Monserrat (1991).

Fig. 30.- Pseudomallada picteti (L-3) (third instar larva). 1, Habitus (DV). 2, Cephalic capsule (left: DV/ right: VV). 3, Antenna. 4, Mandible. 5, Maxilla. 6, Labial palp. 7, Claw. 8, Abdominal segments IX-X (VV). 9, Ditto (DV). Scales in $\mu$ m. Adapted from Díaz-Aranda \& Monserrat (1991). 
fología del espiráculo torácico, morfología de las uñas, número de setas de la hilera transversal del metanoto, longitud de las setas de los tubérculos laterales del abdomen, y número de setas que componen la hilera transversal del margen posteroventral del último segmento abdominal.

Basándonos en la coloración general de las larvas podemos establecer, a groso modo, dos grandes grupos. Uno de ellos estaría formado por aquellas especies cuyas larvas presentan en su totalidad coloración blanquecina o blanco amarillenta. En este grupo estarían incluidas especies como $P$. ventralis, $P$. prasinus, $P$. clathratus, $P$. flavifrons, $P$. granadensis, $P$. picteti y $P$. inornatus. Las dos primeras especies pueden ser separadas de las restantes por presentar una pequeña mancha circular, de color pardo, en la base de los tubérculos laterales torácicos. En el otro gran grupo quedan incluidas aquellas especies cuyas larvas poseen coloración blanquecina o blanco amarillenta con manchas de color pardo o pardo oscuro en el dorso del tórax y/o abdomen. Este es el caso de $P$. venosus, $P$. genei, $P$. subcubitalis y $P$. ibericus.

Atendiendo al diseño de las manchas cefálicas caben las mismas consideraciones que lo expuesto anteriormente para las larvas neonatas. En este caso debemos incluir que el grado de pigmentación es mayor y la mancha frontoclipeal puede aparecer internamente sin pigmentar (Figs. 33.3, 4, 7, 8) o totalmente pigmentada (Figs. 33.1, 2, 5, 6, 10), quedando así separadas $P$. genei, $P$. venosus, $P$. granadensis y $P$. picteti de las restantes especies ibéricas. Dentro de estas últimas el grado de pigmentación de dicha mancha varía de unas especies a otras y puede aparecer, a su vez, como una mancha fuertemente pigmentada en toda su superficie $(P$. clathratus: Fig. 33.5, P. flavifrons: Fig. 33.6 y P. ibericus: Fig. 33.10), o con una pequeña área interna ligeramente más clara $(P$. ventralis: Fig. 33.1, P. prasinus: Fig. 33.2 y P. subcubitalis: Fig. 33.9).

Las manchas epicraneales, a su vez, pueden estar fuertemente bifurcadas como ocurre en $P$. prasinus, $P$. genei, $P$. venosus, $P$. granadensis y $P$. picteti (Figs. 33.2-4, 7, 8 respectivamente) o ligeramente bifurcadas (Figs. 33.1, 5, 6, 9, 10). Dentro de este último caso puede ocurrir que la rama externa sea de mayor grosor que la interna, como es el caso de $P$. clathratus (Fig. 33.5) y P. flavifrons (Fig. 33.6) o que, como ocurre en $P$. subcubitalis (Fig. 33.9) y $P$. ibericus (Fig. 33.10), ambas ramas presenten un grosor similar. Únicamente en el caso de $P$. ventra- lis (Fig. 33.1) las manchas espicraneales se encuentran unidas a las manchas genales.

Por último, debemos resaltar que $P$. prasinus presenta una mayor variabilidad de este carácter que las restantes especies, quizás porque estemos hablando de un pul de especies (Cianchi \& Bullini, 1992).

En cuanto al tercer carácter mencionado, las larvas de este género poseen en el pronoto dos escleritos laterodorsales y uno medio-dorsal. Los laterodorsales pueden presentar forma trapezoidal, sin esclerotizar en su interior (Fig. 34.4), que denominados aquí escleritos cerrados, o presentar forma de V (Fig. 34.5), que ahora llamamos escleritos abiertos. $P$. ventralis, $P$. prasinus, $P$. inornatus, $P$. clathratus y $P$. flavifrons poseen el primer tipo de escleritos laterodorsales, siendo muy patentes en las tres primeras especies y más tenues en las dos últimas. Las restantes especies poseen escleritos abiertos.

El esclerito medio-dorsal aparece en todas las larvas estudiadas, exceptuando las de P. venosus, y puede estar o no basalmente ensanchado, adquiriendo un aspecto más o menos triangular (Fig. 34.4) o alargado (Fig. 34.5) respectivamente. En el caso que nos ocupa, únicamente $P$. granadensis y $P$. genei presentan este último tipo de esclerito.

El tipo de espiráculo torácico, carácter ya utilizado por otros autores (Principi, 1956a; Gepp, 1983; etc.), permite diferenciar a las larvas en tres grandes grupos en función de que éste sea circular (Fig. 34.3), troncocónico no prominente (Fig. 34.2) o troncocónico prominente (Fig. 34.1). De las especies ibéricas, $P$. picteti y $P$. flavifrons presentan espiráculo circular, $P$. ibericus, $P$. clathratus, $P$. subcubitalis y $P$. granadensis troncocónico no prominente, y las restantes especies lo presentan troncocónico prominente. En este último caso la elevación tegumentaria puede estar esclerotizada en su totalidad, resultando así un espiráculo muy conspicuo y siendo fácilmente diferenciables las larvas que lo presentan, como es el caso de $P$. ventralis, $P$. prasinus y $P$. inornatus o puede ocurrir que la esclerotización afecte únicamente a su porción distal, es decir, al espiráculo propiamente dicho, como sucede en las larvas de $P$. genei y $P$. venosus.

La morfología de la uña, como ya se mencionó anteriormente, resulta ser un carácter de gran utilidad en la diferenciación de las larvas de éste y de otros géneros de crisópidos. En las larvas de las 

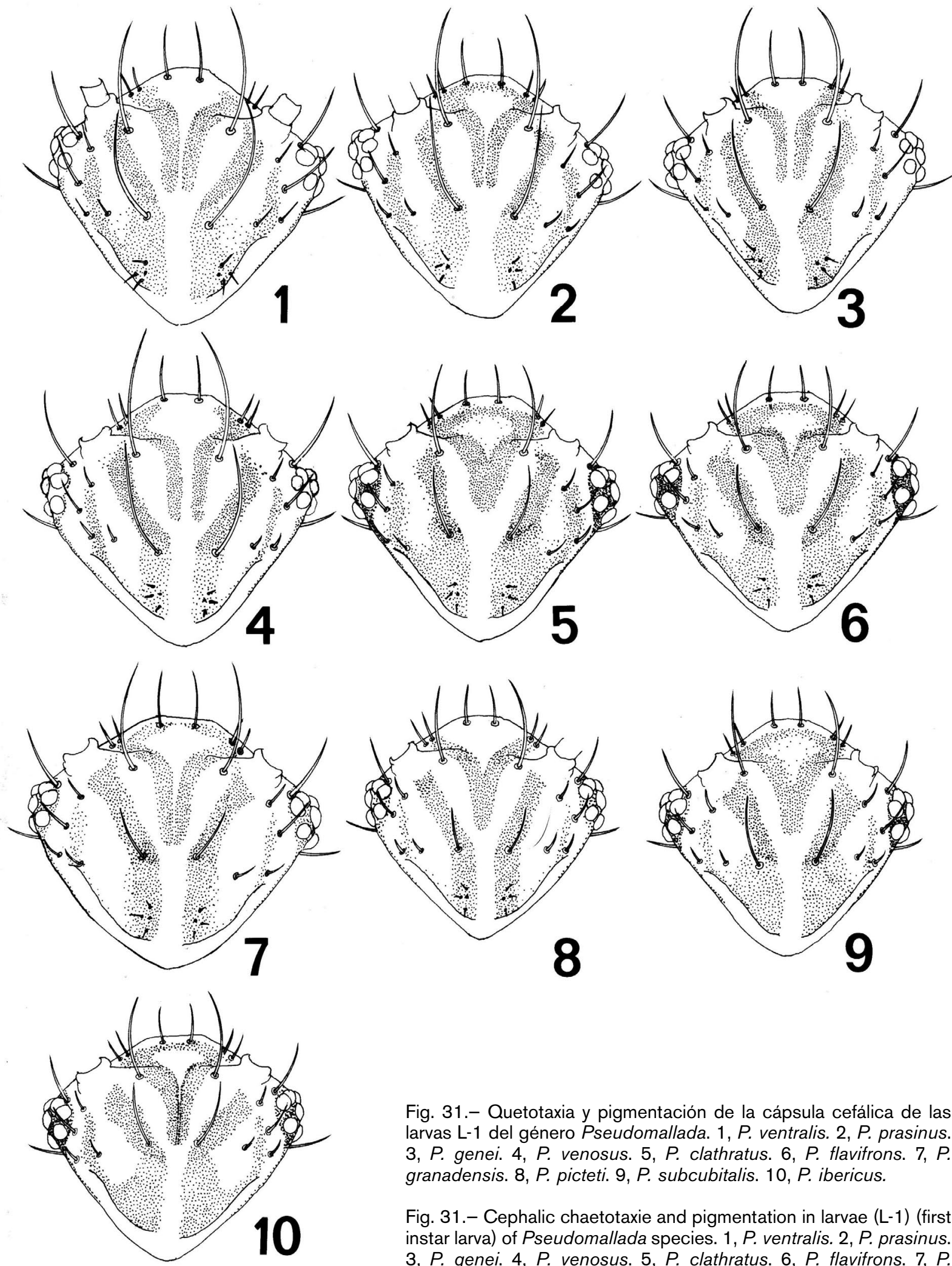

Fig. 31.- Quetotaxia y pigmentación de la cápsula cefálica de las larvas L-1 del género Pseudomallada. 1, $P$. ventralis. 2, $P$. prasinus. $3, P$. genei. $4, P$. venosus. $5, P$. clathratus. $6, P$. flavifrons. $7, P$. granadensis. $8, P$. picteti. 9, P. subcubitalis. 10, P. ibericus.

Fig. 31.- Cephalic chaetotaxie and pigmentation in larvae (L-1) (first instar larva) of Pseudomallada species. $1, P$. ventralis. 2, P. prasinus. 3, $P$. genei. $4, P$. venosus. $5, P$. clathratus. $6, P$. flavifrons. $7, P$. granadensis. 8, P. picteti. 9, P. subcubitalis. 10, P. ibericus. 
especies de este género podemos diferenciar tres tipos de uñas:

- Uñas bruscamente acodadas en su margen interno, adquiriendo un aspecto cuadrangular (Fig. 34.6): P. ventralis y $P$. prasinus.

- Uñas suavemente acodadas en su margen interno, adquiriendo un aspecto más o menos triangular fuertemente ensanchado en su base (Fig. 34.7): $P$. granadensis, $P$. picteti, $P$. clathratus y $P$. flavifrons.

- Uñas no acodadas en su margen interno, adquiriendo aspecto triangular ligeramente ensanchado en su base (Fig. 34.8): P. genei, $P$. venosus, $P$. subcubitalis y P. ibericus.

La longitud de las setas de los tubérculos laterales del abdomen es un carácter que permite diferenciar cómodamente a las especies en dos grandes grupos: el primero de ellos estaría constituido por aquellas cuyas larvas poseen las setas de los tubérculos laterales de igual longitud en todos los segmentos, y a su vez de longitud similar o ligeramente menor que la de las setas de los tubérculos laterales torácicos. Estas setas, además, están suavemente orientadas laterodorsalmente. En este grupo quedan incluidas $P$. ventralis, $P$. prasinus, $P$. venosus, $P$. genei y $P$. granadensis. Las restantes especies ibéricas quedan agrupadas por poseer las setas de los tubérculos laterales de los segmentos II-V notablemente más cortas que las de los segmentos VI-VII. Estando las primeras fuertemente recurvadas hacia el dorso del abdomen.

Como ya se mencionó en las características generales, las larvas del género Pseudomallada, poseen una hilera transversal de largas setas filiformes en la mitad posterior del metanoto. El número de setas que componen dicha hilera varía en función de las especies y se mantiene constante para cada una de ellas. Así, en $P$. granadensis el número de setas es de 4 (2 a cada lado de la línea mediodorsal: 2-2), en P. picteti de 3-3, en P. subcubitalis, $P$. ibericus, $P$. clathratus y $P$. flavifrons de 4-4, en $P$. genei y $P$. venosus de $5-5$ y por último, $P$. ventralis y $P$. prasinus poseen una hilera formada por numerosas setas, de las cuales 5-5 son más largas y gruesas que las restantes.

Además de los caracteres mencionados se han encontrado otras diferencias morfológicas externas, aunque de menor relevancia, que pueden ayudar en la correcta asignación de las larvas:

Una de ellas es el número de hileras transversales de los terguitos abdominales y la mayor o menor abundancia de setas uncinadas que componen dichas hileras. Entre las larvas estudiadas, $P$.granadensis es, con mucho, la especie que menor número de setas posee. En $P$. genei y $P$. venosus el número de setas es algo mayor y en el resto de las especies, tanto hileras como setas que las componen, es mucho más abundante. Este hecho coincide además con la longitud de las citadas setas, ya que en las 3 especies citadas es considerablemente mayor que en las restantes.

La última diferencia encontrada se basa en la pigmentación de la inserción de las setas en los tubérculos laterales. $P$. ventralis, $P$. prasinus y $P$. inornatus presentan la inserción de dichas setas fuertemente pigmentada de pardo-oscuro en todos los segmentos, tanto torácicos como abdominales, resultando por ello muy conspicuas. En el resto de las especies ibéricas se ha encontrado un cierto grado de variabilidad, pero en general $P$. genei, $P$. venosus y $P$. granadensis no presentan pigmentación en ninguno de los tubérculos, siendo así la inserción totalmente translúcida o hialina. P. picteti posee pigmentación únicamente en los tubérculos protorácicos y el resto de las especies, donde encontramos un mayor grado de variabilidad, generalmente aparecen pigmentados los 3 tubérculos torácicos y en algunas ocasiones, como en el caso de $P$. ibericus, también los abdominales.

\section{Clave para larvas L-1}

1 Segmento abdominal V con una hilera transversal anterior de 4 setas, filiformes o uncinadas, de igual longitud (Figs. 32.1, 2)

- Segmento abdominal V con una hilera transversal anterior de 4 setas de distinta longitud, 2 centrales largas y uncinadas y 2 laterales, mucho más cortas y filimormes (Figs. 32.3, 4)

2 Hilera de setas anterotransversal del segmento abdominal $V$ con las 4 setas cortas y filiformes, de aproximadamente igual longitud que las del espiráculo (Fig. 32.2). Seta cefálica S-1 de igual longitud que S-4 (Fig. 31.7) .................................................... g. granadensis

- Hilera transversal anterior del segmento abdominal V con las 4 setas largas y uncinadas, de mayor longitud que las del espiráculo (Fig. 32.1). Seta cefálica S-1 notablemente más larga que S-4 (Fig. 31.1) ............. 3

3 Mancha frontoclipeal cerrada en su margen anterior (Fig. 31.2)

$P$. prasinus

- Mancha frontoclipeal abierta en su margen anterior (Fig. 31.3) ................................................................................ 4

4 Segmento abdominal $X$ con 4 setas en su margen posteroventral (Fig. 32.6)

P. genei

- Segmento abdominal X con 6 setas en su margen posteroventral (Fig. 32.5) .................................... P. ventralis

5 Mancha frontoclipeal abierta en su margen anterior (Fig. 31.3) 

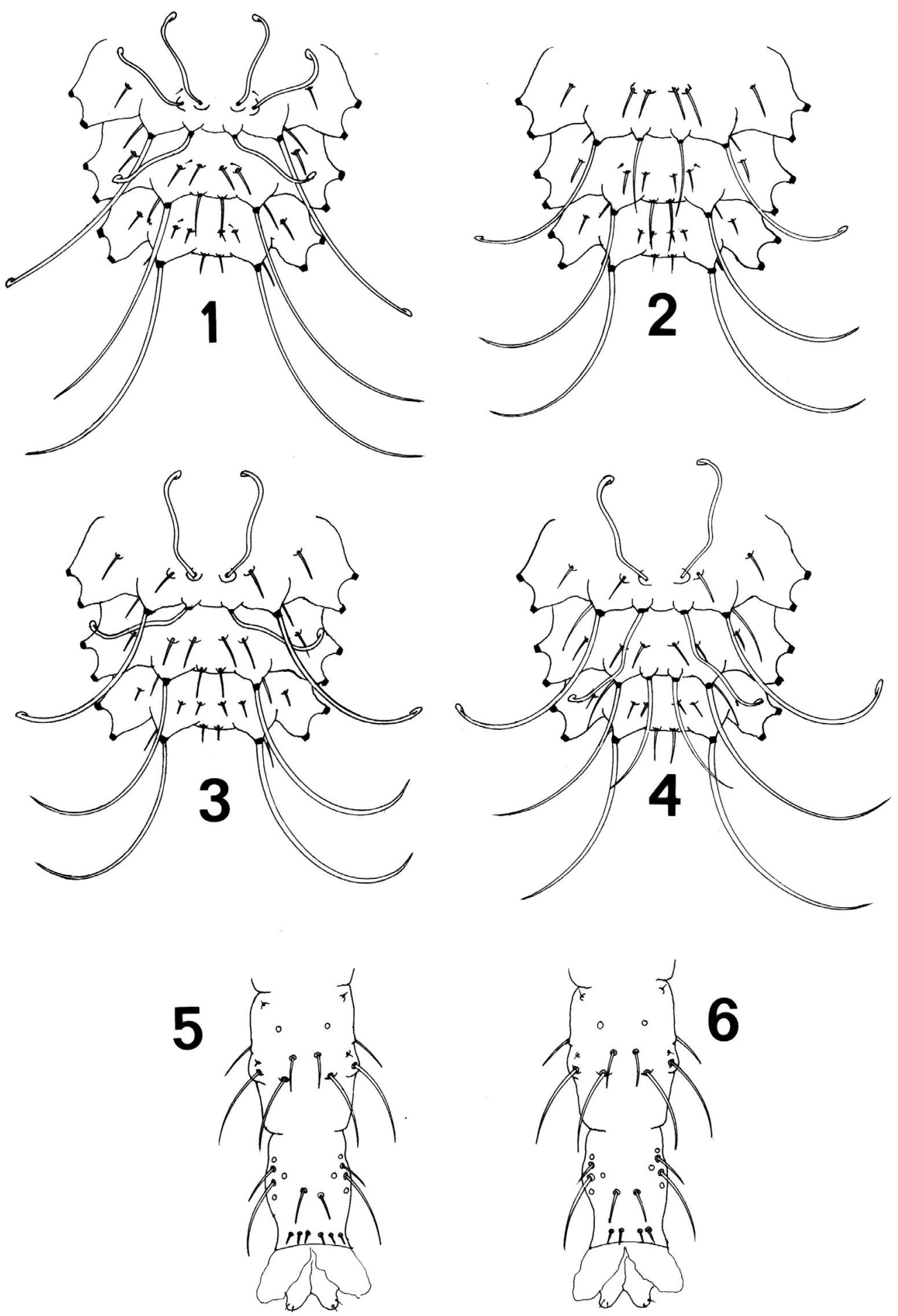

Fig. 32.- Género Pseudomallada (L-1). 1-4, Quetotaxia de los segmentos abdominales V-VII (VD). 5-6, Quetotaxia de los segmentos abdominales IX-X (VV).

Fig. 32.- Genus Pseudomallada (L-1) (first instar larva). 1-4, Chaetotaxy of abdominal segments V-VII (DV). 5-6, Chaetotaxy of abdominal segments IX-X (VV). 
- Mancha frontoclipeal cerrada en su margen anterior (Fig. 31.2) 7

6 Segmento abdominal $X$ con 4 setas en su margen posteroventral (Fig. 32.6). Mancha frontoclipeal en forma de $\mathrm{V}$, no dividida longitudinalmente (Fig. 31.8). Seta cefálica S-1 de igual longitud que S-4 (Fig. 31.8) ........

P. picteti

- Segmento abdominal X con 6 setas en su margen posteroventral (Fig. 32.5). Mancha frontoclipeal longitudinalmente dividida en su parte posterior (Fig. 31.4). Seta cefálica S-1 notablemente más larga que S-4 (Fig. 31.4)

$P$. venosus

7 Segmento abdominal $X$ con 4 setas en su margen posteroventral (Fig. 32.6). Setas situadas entre los tubérculos laterodorsales del segmento abdominal VI notablemente más largas que las de la serie transversal anterior de ese mismo segmento (Fig. 32.4)

P. subcubitalis

- Segmento abdominal X con 6 setas en su margen posteroventral (Fig. 32.5). Setas situadas entre los tubérculos laterodorsales del segmento abdominal VI de igual longitud que las de la serie transversal anterior (Fig. 32.3) ....... P. clathratus, P. ibericus, P. flavifrons

\section{Clave para larvas L-3}

1 Setas de los tubérculos laterales de igual longitud en los segmentos abdominales II-VII y de longitud similar o ligeramente menor a las de los torácicos (Fig 26.1) .......... 2

- Setas de los tubérculos laterales de los segmentos abdominales II-V mucho más cortas que las de los segmentos VI-VII y que las de los torácicos, fuertemente recurvadas laterodorsalmente (Fig. 30.1) 7

2 Espiráculo mesotorácico troncocónico, prominente (Fig. 34.1). Metanoto con 10 largas setas filiformes, 5 a cada lado de la línea mediodorsal. Tubérculos laterales protorácicos más alargados que los meso- y metatorácicos, todos ellos engrosados en su ápice (Fig. 26.1). Dorso de los segmentos abdominales con 4-5 hileras transversales de numerosas setas uncinadas

- Espiráculo mesotorácico troncocónico, no prominente (Fig. 34.3). Metanoto con 4 largas setas filiformes, 2 a cada lado de la línea mediodorsal. Tubérculos laterales de los 3 segmentos torácicos muy alargados y poco engrosados en su ápice (Fig. 28.1). Dorso de los segmentos abdominales con 3 hileras de setas escasas y uncinadas. Larva blanca en su totalidad. Escleritos laterodorsales protorácicos abiertos (Fig. 34.5) $P$. granadensis

3 Espiráculo torácico muy conspicuo, prominente, con la elevación esclerotizada en su totalidad. Pronoto con escleritos laterodorsales cerrados, muy patentes y esclerito mediodorsal más o menos triangular. Uñas bruscamente acodadas en su margen interno, de aspecto cuadrangular (Fig. 34.6). Setas dorsales del segmento abdominal I de igual longitud que las de los restantes segmentos abdominales, notablemente más cortas que las del metanoto. Inserción de las setas fuertemente pigmentada de pardo oscuro en todos los tubérculos laterales. Larvas blancas en su totalidad

- Espiráculo torácico menos conspicuo, con la elevación esclerotizada sólo en su extremidad distal. Pronoto con escleritos laterodorsales abiertos y mediodorsal alargado o ausente. Uñas no acodadas en su margen interno, de aspecto triangular (Fig. 34.8). Setas dorsales del segmento abdominal I más largas que las de los restantes segmentos abdominales, de longitud aproximada a las del metanoto. Inserción de las setas translúcida en todos los tubérculos laterales. Larvas blancas con patentes manchas pardas en el dorso del tórax y abdomen

4 Tórax con una pequeña mancha circular de color pardo en la base de cada uno de los tubérculos laterales .... 5

- Tórax sin la citada mancha P. inornatus

5 Manchas epicraneales ligeramente bifurcadas, a nivel del límite posterior de la mancha frontoclipeal (Fig. 33.1). Rama externa de la mancha frontoclipeal ligeramente unida a la mancha genal (Fig. 33.1). Setas de los tubérculos laterales del abdomen oscuras ............ P. ventralis

- Manchas epicraneales fuertemente bifurcadas, antes del límite posterior de la mancha frontoclipeal (Fig. 33.2). Rama externa de la mancha epicraneal no unida con la mancha genal (Fig. 33.2). Setas de los tubérculos laterales del abdomen hialinas P. prasinus

6 Mancha frontoclipeal bifurcada y con el margen anterior abierto, en forma de V (Fig. 33.3). Esclerito medio-dorsal protorácico alargado (Fig. 34.5). Segmento abdominal $X$ con 4 setas en su margen posteroventral (Fig. 34.9). Tórax y abdomen con dos bandas longitudinales de color pardo o pardo oscuro $P$. genei

- Mancha frontoclipeal longitudinalmente dividida en dos en su parte posterior y con su margen anterior cerrado (Fig. 33.4). Esclerito mediodorsal protorácico ausente. Segmento abdominal $\mathrm{X}$ con 6 setas en su margen posteroventral (Fig. 34.10). Bandas pardas o pardo oscuras dispuestas longitudinalmente en pro- y mesonoto y bandas dorso-transversales en los segmentos abdominales II-V

$P$. venosus

7 Larvas enteramente blancas. Uñas suavemente acodadas en su margen interno, con un aspecto triangular fuertemente ensanchado en su base (Fig. 34.7) ........ 8

- Larvas con manchas dorsales pardas en tórax y/o abdomen. Uñas no acodadas en su margen interno, con aspecto triangular ligeramente ensanchado en su base (Fig. 34.8)

8 Mancha frontoclipeal sin pigmentar internamente. Manchas epicraneales fuertemente bifurcadas (Fig. 33.8). Metanoto con una hilera transversal de 6 setas, 3 a cada lado de la línea mediodorsal. Segmento abdominal $\mathrm{X}$ con 4 setas en su margen posteroventral (Fig. 33.4). Inserción de las setas pigmentadas únicamente en los tubérculos laterales protorácicos .......... P. picteti

- Mancha frontoclipeal enteramente pigmentada. Manchas epicraneales apenas bifurcadas. Metanoto con una hilera transversal de 8 setas, 4 a cada lado de la línea mediodorsal. Segmento abdominal $X$ con 6 setas en su margen posteroventral (Fig. 34.10). Inserción de las setas de los tubérculos laterales pigmentadas, al menos, en los de pro-, meso- y metatórax

... 9

9 Espiráculo mesotorácico troncocónico, no prominente (Fig. 34.2). Setas de los tubérculos laterales del abdomen negras P. clathratus 

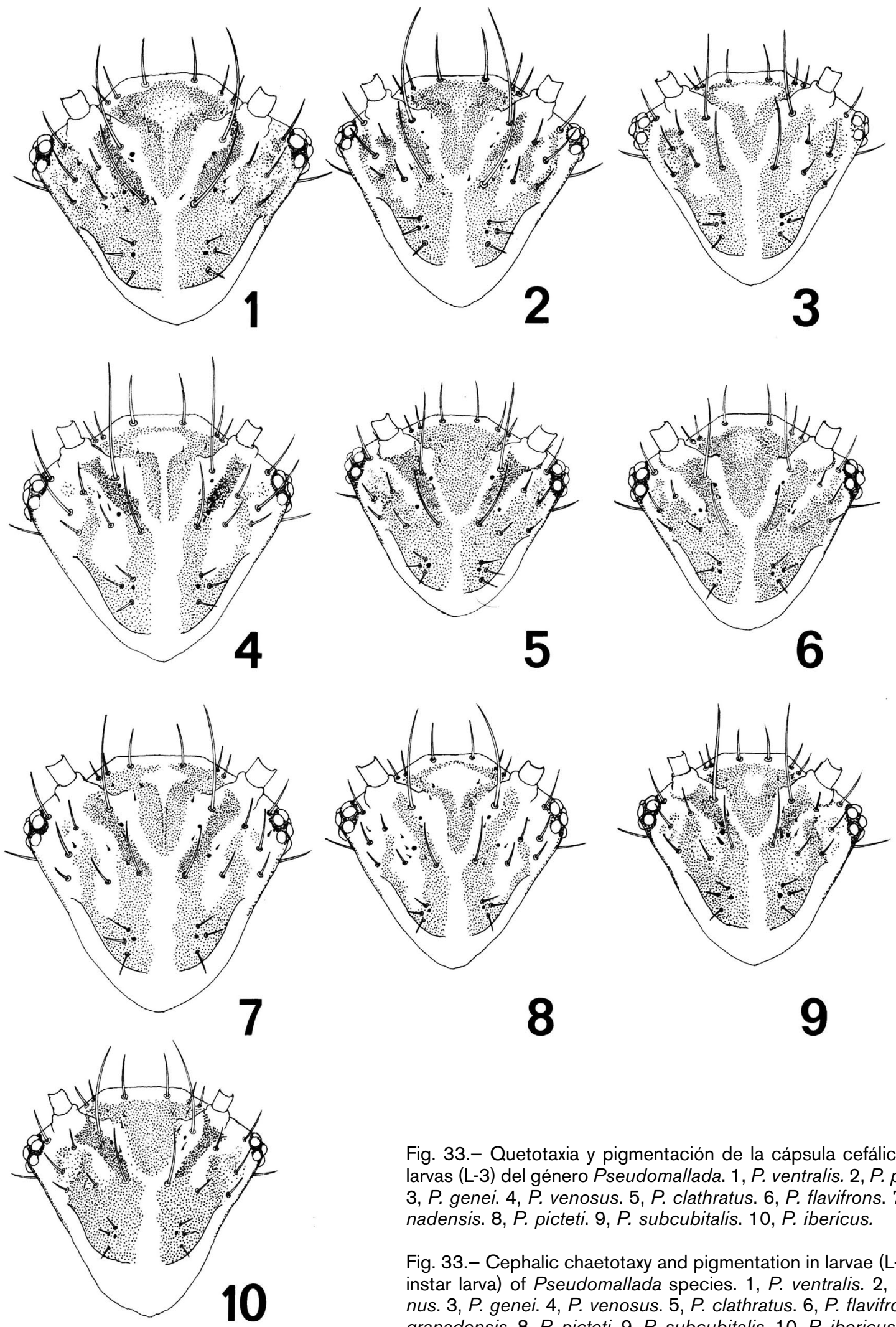

9

Fig. 33.- Quetotaxia y pigmentación de la cápsula cefálica de las larvas (L-3) del género Pseudomallada. 1, P. ventralis. 2, P. prasinus. $3, P$. genei. 4, P. venosus. 5, P. clathratus. $6, P$. flavifrons. $7, P$. granadensis. $8, P$. picteti. 9, $P$. subcubitalis. $10, P$. ibericus.

Fig. 33.- Cephalic chaetotaxy and pigmentation in larvae (L-3) (third instar larva) of Pseudomallada species. 1, P. ventralis. 2, P. prasinus. $3, P$. genei. $4, P$. venosus. $5, P$. clathratus. $6, P$. flavifrons. $7, P$. granadensis. 8, P. picteti. 9, P. subcubitalis. 10, P. ibericus. 
- Espiráculo mesotorácico circular (Fig. 34.3). Setas de los tubérculos laterales del abdomen hialinas

\section{P. flavifrons}

10 Mancha frontoclipeal con una pequeña área interna menos pigmentada en la zona clipeo-labral (Fig. 33.9). Segmento abdominal $X$ con 4 setas en su margen posteroventral (Fig. 34.9). Larvas con manchas pardas dispersas sobre los 3 segmentos torácicos

P. subcubitalis

- Mancha frontoclipeal fuertemente pigmentada en toda su superficie (Fig. 33.10). Segmento abdominal $X$ con 6 setas en su margen posteroventral (Fig. 34.10). Larvas con dos bandas longitudinales pardo-oscuras en el dorso del tórax y abdomen $P$. ibericus

Biología Y COMPORTAMiEnTO. Los tipos de puestas son característicos para todas las especies estudiadas exceptuando a $P$. prasinus, en la que un determinado número de hembras depositaron los huevos en racimos y otras aislados (de nuevo se sugiere el hecho del pul de especies anteriormente citado). Por el contrario, $P$. ventralis, $P$. ibericus y $P$. subcubitalis depositan los huevos de forma aislada, y $P$. venosus y $P$. genei lo hacen también de forma aislada, pero es frecuente encontrar grupos de 2-3 huevos. El tamaño de la puesta en las especies citadas varió entre 20-40 huevos. En las restantes especies las hembras depositaron los huevos en racimos y el tamaño de la puesta osciló entre 820 huevos.

El comportamiento tras la eclosión y en la búsqueda de presas es básicamente el mismo al indicado en el apartado de características generales. Las larvas de todas las especies del género aquí estudiado son portadoras, durante todo su desarrollo, de capa de camuflaje, cuya dimensión varía en función de la especie. Así, P. genei y P. venosus presentan una capa de camuflaje desproporcionadamente grande en relación al tamaño del cuerpo de la larva, y en las restantes especies, la capa de camuflaje es de menores dimensiones y llega a cubrir, generalmente, el abdomen y metanoto de la larva, dejando visibles la cabeza y parte anterior del tórax.

Son larvas poco activas, de movimientos relativamente lentos y permanecen en reposo en el envés de las hojas añadidas a las cajas de cultivo. Únicamente hemos observado canibalismo en las larvas neonatas, sometidas a falta de alimento, inmediatamente después de su eclosión.

Los capullos fabricados por las larvas de estas especies, suelen estar cubiertos con materiales de distinta naturaleza, sobre todo de aquellos que formaban parte de la capa de camuflaje de la larva.
Los lugares elegidos para la fabricación del capullo varían en función de la especie.

El tiempo (en días) empleado por cada una de las especies en completar su ciclo de desarrollo, se indica en la siguiente tabla. Los datos indicados hacen referencia a ciclos completados sin la intervención de diapausa, ya que las especies de este género pasan el invierno como larva L-3.

$\begin{array}{lccccc}\text { ESPECIE } & \text { H } & \text { L-1 } & \text { L-2 } & \text { L-3 } & \text { P } \\ \text { P. ventralis } & 6 & 6 & 8 & 11-10 & 15 \\ \text { P. prasinus } & 5 & 4-5 & 5-6 & 9-11 & 10-12 \\ \text { P. genei } & 6 & 5 & 5-6 & 10-12 & 15-16 \\ \text { P. venosus } & 5 & 5-7 & 7-8 & 8-9 & 19-22 \\ \text { P. clathratus } & 5 & 8-9 & 8-10 & 12 & 17-20 \\ \text { P. flaviforns } & 7 & 8 & 8-12 & 8-9 & 12-14 \\ \text { P. granadensis } & 5 & 4-5 & 7-8 & 8 & 18-20 \\ \text { P. picteti } & 5-6 & 6 & 7-8 & 10-11 & 19-21 \\ \text { P. subcubitalis } & 5 & 8 & 7 & 9-12 & 15-18 \\ \text { P. ibericus } & 6 & 5 & 7-8 & 10 & 18-20\end{array}$

Las condiciones de cultivo y los áfidos empleados en la dieta se anotan en la tabla de la página siguiente:

\begin{tabular}{|c|c|c|c|c|}
\hline ESPECIE & $\mathrm{T}^{\mathrm{a}}$ & FOT. & H.R. & $\begin{array}{c}\text { ÁFIDOS } \\
\text { EMPLEADOS }\end{array}$ \\
\hline P. ventralis & $22^{\circ} \mathrm{C}$ & $14: 10$ & $80 \%$ & Aphis hederae \\
\hline P. prasinus & $25^{\circ} \mathrm{C}$ & $14: 10$ & $80 \%$ & $\begin{array}{c}\text { Aphis craccivora } \\
\text { Aphis pomi }\end{array}$ \\
\hline P. genei & $27^{\circ} \mathrm{C}$ & $16: 8$ & $60 \%$ & $\begin{array}{c}\text { Chaitophorus leucomelas } \\
\text { Aphis fabae }\end{array}$ \\
\hline P. venosus & $27^{\circ} \mathrm{C}$ & $16: 8$ & $60 \%$ & $\begin{array}{c}\text { Chaitophorusleucomelas } \\
\text { Aphis nerii }\end{array}$ \\
\hline P. clathratus & $22^{\circ} \mathrm{C}$ & $14: 8$ & $80 \%$ & $\begin{array}{c}\text { Macrosiphum rosae } \\
\text { Aphis craccivora }\end{array}$ \\
\hline P. flavifrons & $25^{\circ} \mathrm{C}$ & $16: 8$ & $80 \%$ & $\begin{array}{l}\text { Aphis craccivora } \\
\text { Aphis fabae }\end{array}$ \\
\hline P. granadensis & $25^{\circ} \mathrm{C}$ & $14: 10$ & $80 \%$ & Aphis fabae \\
\hline P. picteti & $25^{\circ} \mathrm{C}$ & $14: 10$ & $80 \%$ & $\begin{array}{c}\text { Macrosiphum rosae } \\
\text { Aphis hederae }\end{array}$ \\
\hline P. subc & $7^{\circ}$ & 16: & $60 \%$ & Hyalopterus pruni \\
\hline P. ibericus & $22^{\circ} \mathrm{C}$ & $14: 8$ & $80 \%$ & Aphis craccivora \\
\hline
\end{tabular}

Biología (CONT.), DistRibuCión GEOGRÁFiCA Y ALTITUDINAL, FENOLOGÍA. Los imagos de algunas especies de este género no parecen presentar la más mínima exigencia en el tipo de plantas sobre las que han sido recolectadas en la Península Ibérica (especialmente $P$. prasinus y $P$. flavifrons), presentando una extensa dispersión geográfica peninsular y un amplio rango altitudinal y fenológico. Otras, como mucho, y dentro de una amplia variedad de sustratos, tienden a sesgarse a sustratos de especies vegetales, bien de medios húmedos y eurosiberianos, o los 

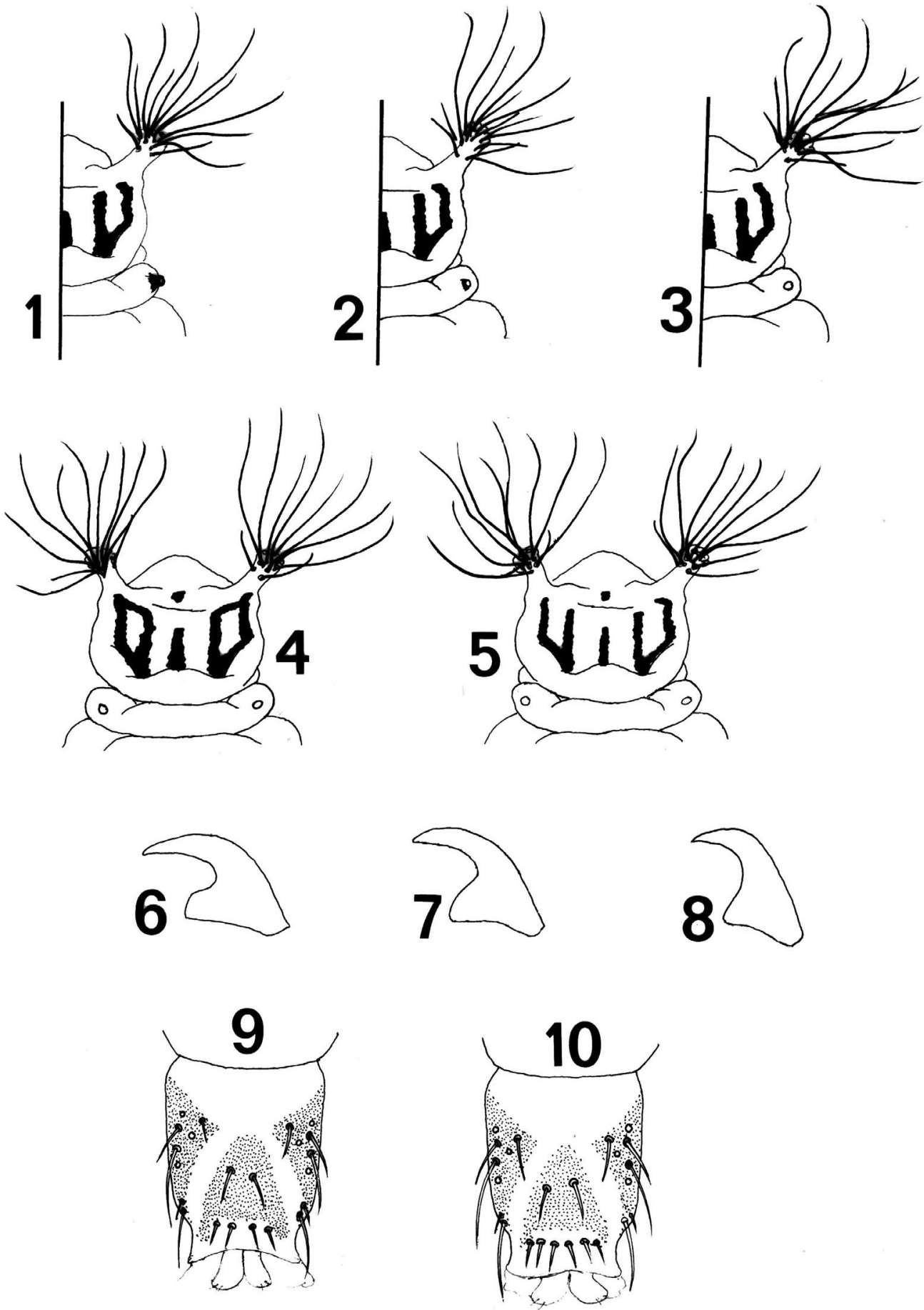

Fig. 34.- Género Pseudomallada (L-3). 1-3: Espiráculo mesotorácico. 1, Troncocónico prominente. 2, Troncocónico no prominente. 3, Circular. 4-5: Esclerito laterodorsal protorácico. 4, De tipo cerrado. 5, De tipo abierto. 6-8: Uña. 6, Base cuadrangular. 7, Triangular dilatada en su base. 8, Triangular no dilatada en su base. 9-10: Segmento abdominal X (VV).

Fig. 34.- Genus Pseudomallada (L-3) (third instar larva). 1-3: Mesothoracic spiracle. 1, Conical trunk shaped prominent. 2, Conical trunk shaped not prominent. 3, Circular. 4-5: Laterodorsal prothoracic sclerite. 4, Closed type. 5, Open type. 68: Claw. 6, Quadrangular base. 7, Triangular dilated base. 8, Triangular not dilated base. 9-10: Abdominal segment X (VV). 
enclaves más húmedos de la región mediterránea $(P$. ventralis, $P$. inornatus), bien más térmicos o mediterráneos (P. picteti, P. granadensis, $P$. clathratus), a veces con preferencia por coníferas (P. ibericus), o bien marcadamente térmicos y xéricos $(P$. genei, $P$. venosus), dentro de un amplio margen altitudinal y fenológico. De P. zelleri existen muy antiguas citas (por confirmar) en Granada, y sólo conocemos dos ejemplares recolectados sobre Quercus sp., en Navarra (Monserrat, 2008). Especial interés tiene $P$. subcubitalis con marcada preferencia por Tamarix spp., y P. alarconi por enebros y sabinas, hechos que delimitan su distribución, rango altitudinal y fenológico, que suele ser, en todo caso, amplio (de 320$1376 \mathrm{~m}$ y entre mayo-septiembre para P. alarconi, y de 10-1480 m y entre abril-octubre para $P$. subcubitalis). Monserrat \& Marín (1994) dan sobrada información sobre el sustrato vegetal preferido por las diferentes especies ibéricas de este género, y más información sobre la biología de las especies aquí estudiadas puede recabarse en Canard et al. (1984); McEwen et.al. (2001); Monserrat \& Díaz-Aranda (1989); Monserrat (2008); Monserrat \& Rodrigo (1992).

\section{Género Nineta}

El género Nineta Navás, 1912, incluye 14 especies, 11 de ellas de distribución paleártica, paleártica occidental, o paleártica oriental, 1 del SE de la India y 2 del E de EE.UU. (Brooks \& Barnard, 1990). Siete especies son conocidas de Europa, de las que tres, N. flava (Scopoli, 1763), N. pallida (Schneider, 1845) y N. guadarramensis (Pictet, 1865), representan a este género en la Península Ibérica. Las citas de $N$. vittata (Wesmael, 1841), que desde Pictet (1865) han venido dándose en Málaga y Lérida y que se reiteran hasta la actualidad (Aspöck et al., 2001), no han sido confirmadas ni, que sepamos, se han recolectado nuevos ejemplares que pudieran corroborar la veracidad de alguna de estas citas (Hölzel \& Ohm, 1972), por lo que, de momento, no ha sido considerada en este estudio.

La morfología de los estadios preimaginales de las especies de este género es conocida en 6 de ellas, todas pertenecientes a la fauna paleártica occidental, y más concretamente a la centroeuropea (Gepp, 1983, 1984b, 1999). Los estadios preimaginales de dos de las tres especies aquí estudiadas han sido descritos o fotografiados por diversos autores, no obstante estas descripciones son, en su mayoría, muy someras o están basadas casi con exclusividad en caracteres de coloración tegumentaria (Gepp, 1983, 1999), y la descripción de la larva de N. guadarramensis debe hoy día asignarse a $N$. principiae Monserrat, 1980. Dado que la coloración tegumentaria se pierde en los ejemplares conservados en alcohol, creemos necesario realizar una descripción más detallada de sus estadios preimaginales con el fin de encontrar caracteres morfológicos externos menos lábiles, que permitan una correcta asignación de los estadios larvarios, sobre todo los pertenecientes a $N$. guadarramensis, especie sobre la que, por lo anteriormente anotado, no existe información.

Material utilizado. Por cuestiones prácticas en este apartado alteramos la ordenación cronológica de las especies, describiendo en primer lugar los estadios preimaginales de Nineta guadarramensis, especie de la que no existe información sobre su morfología larvaria, limitándonos después a señalar únicamente las diferencias existentes entre ésta y las dos especies restantes.

\section{ESTADIOS LARVARIOS}

Características generales: (L-1: Figs. 35.1-11, L-3: Figs. 36.1-10, 37.1-9).

Larvas desnudas, nunca portadoras de capa de camuflaje (Figs. 37.1, 3, 7).

Larvas de tamaño grande $(12-14 \mathrm{~mm})$, cuerpo alargado, fusiforme, aplanado dorsoventralmente. Tubérculos laterales del tórax muy poco desarrollados, prácticamente ausentes (Figs. 37.1, 3, 7).

Patas relativamente largas.

Setas cortas, siempre filiformes (Figs. 35.1, 37.1, 3, 7).

Tubérculos laterodorsales del abdomen muy poco desarrollados (Fig. 35.1, 37.1, 3, 7).

Subsegmento anterior del metatórax bien marcado (Fig. 35.1, 37.1, 3, 7).

De la larva neonata (Figs. 35.1-11).

Tubérculos laterales del tórax portadores de 2 cortas setas en los tres segmentos (Fig. 35.1).

Segmento abdominal I con una seta lateral (Fig. 35.1).

Segmentos abdominales II-VII con tubérculos laterales y 2 pequeños tubérculos laterodorsales portadores, en ambos casos, de 2 cortas setas (Fig. 35.1).

De la larva madura (Figs. 36.1-10, 37.1-9).

Tubérculos laterales del tórax poco desarrollados, casi ausentes en el protórax (Figs. 37.1, 3, 7).

Segmento abdominal I con tubérculos laterales, aunque poco desarrollados, portadores de varias setas (Figs. 37.1, 3, 7). 
ESTADIOS LARVARIOS DE NINETA GUADARRAMENSIS

Material utilizado. Hembras grávidas: España, Madrid, Alcalá de Henares, 15. VII.1988, a la luz.

Larvas: España, Guadalajara, Cantalojas, 2.X.1988, sobre Quercus pirenaica, La Huerce, 9.X.1984, sobre Q. pyrenaica, Mirabueno, 12.IX.1984, sobre Quercus faginea. Madrid, La Hiruela, 25.IX.1984, sobre Q. pyrenaica, Montejo de la Sierra, 20.VIII.1988, sobre Fagus sylvatica.

\section{Descripción de los estadios preimaginales}

Huevo. Huevos elipsoides, de color verde pálido con pedúnculo hialino. Longitud oval: $1 \mathrm{~mm}$; longitud del pedúnculo: 9-10 $\mathrm{mm}$.

Larva neonata. Aspecto general según Fig. 35.1. Color crema amarillento con escleritos laterodorsales pardos. Cabeza de color crema amarillento con manchas cefálicas de color pardo oscuro. Mancha frontoclipeal ausente (Fig. 35.4). Manchas epicraneales formando dos bandas longitudinales, una a cada lado de la sutura coronal, que se extienden desde el margen posterior de la cápsula cefálica hasta las fosetas pretentoriales (Fig. 35.4). Manchas genales (Fig. 35.3, 4) no extendidas a la cara ventral. Cardo y estipe apenas esclerotizados (Fig. 35.3). Quetotaxia dorsal y ventral de la cápsula cefálica según Fig. 35.3, 4, respectivamente. Seta S-12 presente. Maxilas (Fig. 35.5) de color ámbar. Mandíbulas (Fig. 35.6) con una mancha de color pardo oscuro en el borde externo de su parte basal. Antenas (Fig. 35.7) y palpos labiales (Fig. 35.8) de color crema pálido. Ojos negros, formados por 6 estemmata dispuestos según Fig. 35.2, 3.

Tórax de color crema amarillento con escleritos laterodorsales pardos muy patentes, alargados en el pronoto y circulares en meso- y metanoto (Fig. 35.1). Tubérculos laterales muy poco desarrollados, portadores de 2 cortas setas en el protórax y de 3 en meso- y metatórax (Fig. 35.1). Número y disposición de las setas dorsales del tórax según Fig. 35.1. Patas de color crema pálido, pigmentadas de pardo oscuro en el extremo distal del fémur, en el tercio proximal de la tibia y en el pretarso. Uñas (Fig. 35.9) de color ámbar. Empodio pardo-oscuro.

Abdomen de color crema amarillento, con escleritos laterodorsales pardo oscuros (Fig. 35.1). Segmento abdominal I con una seta lateral. Segmentos II-VII con tubérculos laterales portadores de 2 setas. Segmentos I-VII con tubérculos laterodorsales portadores de 2 setas, con tubérculos submediales portadores de 1 seta, con una hilera transversal anterior de 4 cortas y finas setas, y con una seta anterior a cada espiráculo (Fig. 35.1).
Quetotaxia y pigmentación de los segmentos abdominales IX-X según Fig. 35.10, 11.

Larva madura. Aspecto general según Fig. 37.1. Coloración amarillenta con manchas dorsales rojizas formando dos bandas laterodorsales, una a cada lado de la línea media, limitando entre ambas un área mediodorsal de color amarillo grisáceo. Línea mediodorsal pigmentada de pardo o pardo rojizo.

Cabeza de color pardo amarillento con manchas cefálicas pardas. Manchas frontoclipeal ausente (Fig. 36.4). Manchas epicraneales formando dos bandas longitudinales, una a cada lado de la sutura coronal, que se extienden desde el esclerito occipital hasta las fosetas pretentoriales, sobrepasando éstas en algunos ejemplares (Fig. 36.4). Manchas genales no extendidas a la cara ventral. Cardo y estipe ligeramente esclerotizados (Fig. 36.3). Quetotaxia dorsal y ventral de la cápsula cefálica según Fig. 36.3. Seta cefálica S-12 presente, aunque de corta longitud. Maxilas (Fig. 36.5) y mandíbulas (Fig. 36.6) de color ámbar. Palpos labiales (Fig. 36.7) y antenas (Fig. 36.8) de color crema amarillento en toda su longitud, ligeramente más oscuros en el extremo distal. Ojos negros, formados por 6 estemmata dispuestos según Fig. 36.3, 4.

Tórax de color amarillo con manchas dorsales rojizas cubriendo los dos tercios posteriores del pronoto y formando dos bandas laterodorsales que se extienden lateralmente al nivel de los tubérculos laterales del metanoto (Fig. 37.3). Escleritos laterodorsales alargados, más o menos elipsoides, en el pronoto, y circulares y más pequeños en meso- y metanoto (Fig. 37.3). Tubérculos laterales muy poco desarrollados, casi ausentes en el protórax, portadores en los tres casos de numerosas setas, rectas y cortas (Fig. 37.3). Espiráculo mesotorácico circular, no prominente. Patas de color crema pálido con una pequeña mancha parda en el extremo distal del fémur. Uñas ámbar, cuadrangularmente dilatadas en su base (Fig. 37.4).

Abdomen amarillento, con dos bandas laterodorsales continuación de las citadas del tórax (Fig. 37.3). Segmento abdominal I con tubérculos laterales muy poco desarrollados, portadores de escasas setas. Segmentos II-VII con tubérculos laterales bien desarrollados, portadores de varias setas. Segmentos I-VII con tubérculos laterodorsales, muy poco desarrollados, portadores de 2 setas y tres hileras transversales de cortas y finas setas (Fig. 37.3). 
Quetotaxia y pigmentación dorsal y ventral del segmento abdominal X según Fig. 37.5 y 37.6 respectivamente. Margen posteroventral de dicho segmento con numerosas setas, sin formar una hilera transversal bien definida (Fig. 37.6). Todas las setas, tanto torácicas como abdominales, son hialinas.

\section{ESTADIOS LARVARIOS DE NINETA FLAVA}

Información sobre la morfología de los estadios preimaginales de esta especie puede ser recabada en Alderson (1911), Withycombe (1923), Killington (1937) y Gepp (1983, 1989).

Material utilizado. Hembras grávidas: España, Lérida, Mirador la Traba, 14.VIII.1991, sobre Quercus faginea.

Larvas: España, Asturias, Covadonga, 1.VII.1989, sobre Corylus avellana. Huesca, Valle de Pineta, 1.VIII.1982, sobre C. avellana. Navarra, Eugi, 3.VIII.1989, sobre Fagus sylvatica. Orense, Lebozan, 19.VIII.1977, sobre Quercus robur. Santander, Cosgaya, 2.VIII.1989, sobre C. avellana.

Como ya se indicó, nos limitamos a señalar únicamente las diferencias existentes entre los estadios preimaginales de esta especie y los de N. guadarramensis, anteriormente descritos.

Huevo. Huevos elipsoides, de $1 \mathrm{~mm}$ de longitud con pedúnculo muy largo $(8-9 \mathrm{~mm})$. Coloración verde pálido, con micropilo blanco.

Larva neonata. Igual a la descrita para N. guadarramensis exceptuando:

Cápsula cefálica con manchas epicraneales menos marcadas, difusas o interrumpidas en su mitad anterior (Fig. 35.12). Escleritos laterodorsales del pronoto alargados y estrechos.

Patas con fémur de color crema en toda su longitud, sin mancha parda en su extremo distal.

Larva madura. Aspecto general según Fig. 37.1. Larvas de color amarillo con manchas dorsales rojizas formando dos bandas laterodorsales, una a cada lado de la línea mediodorsal, que abarcan el tórax y abdomen en toda su longitud. Línea mediodorsal pigmentada de rojo en toda su longitud.

Cabeza con manchas epicraneales interrumpidas en la mitad de su longitud. Su mitad anterior es mucho menos patente y difusa, donde las manchas se hacen divergentes, estando en ocasiones bifurcadas (Fig. 36.2). Mancha frontoclipeal apenas visible (Fig. 36.2.).

Tórax con las bandas laterodorsales rojizas ensanchadas lateralmente tanto en meso- como en metanoto (Fig. 37.2). Escleritos laterodorsales del pronoto alargados y estrechos (Fig. 37.3). Fémur de color crema en su totalidad.

\section{ESTADIOS LARVARIOS DE NINETA PALLIDA}

La morfología de la larva neonata y larva madura de esta especie fue descrita por Brauer (1867) y Gepp (1983) respectivamente.

Material utilizado. Los ejemplares larvarios (L-3) sobre los que basar las descripciones de esta especie han sido cedidos por el Dr. Michel Canard, y al igual que en el caso anterior, se señalan únicamente las diferencias existentes entre esta especie y $N$. guadarramensis.

Descripción de la larva madura. Aspecto general según Fig. 37.7. Larvas color pardo en su superficie laterodorsal y de color amarillo verdoso en su superficie mediodorsal, separadas ambas por dos estrechas bandas laterodorsales de color pardo oscuro que recorren tórax y abdomen en toda su longitud.

Al margen de las acusadas diferencias de coloración existentes entre las larvas de esta especie y las de las otras dos especies ibéricas, la morfología externa de la larva de esta especie es similar a la de la larva de $N$. guadarramensis exceptuando:

El diseño de las manchas cefálicas (Fig. 36.10). Mancha frontoclipeal presente y muy patente. Cada una de las manchas epicraneles está dividida transversalmente en dos manchas (Fig. 36.10), una anterior, oblicua, que se extiende hasta la base de las prominencias donde quedan insertadas las antenas (Fig. 36.10) y otra posterior, ancha, extendida lateroanteriormente hacia los ojos (Fig. 36.10). La quetotaxia cefálica (Fig. 36.9) está formada por setas sensiblemente más largas que en las otras dos especies ibéricas, y la base de la mayoría de las setas cefálicas está fuertemente esclerotizada (Fig. 36.10). Mandíbulas y maxilas de color pardo muy oscuro (Fig. 37.7).

Tórax con escleritos laterodorsales del pronoto en forma de media luna (Fig. 37.7). Setas dorsales y setas de los tubérculos laterales de color negro (Fig. 37.7). Uñas triangularmente dilatadas en su base (Fig. 37.8).

Segmento abdominal I con tubérculo lateral desarrollado, portador de numerosas setas, y segmento X con una hilera transversal de 4 setas en su margen posteroventral (Fig. 37.7, 9).

Todas las setas, tanto torácicas como abdominales, son negras y sensiblemente más largas que en las otras dos especies ibéricas.

Discusión. Las larvas descritas de las especies del género Nineta presentan acusadas diferencias en su coloración tegumentaria, resultando por ello fácilmente distinguibles, a simple vista (Gepp, 


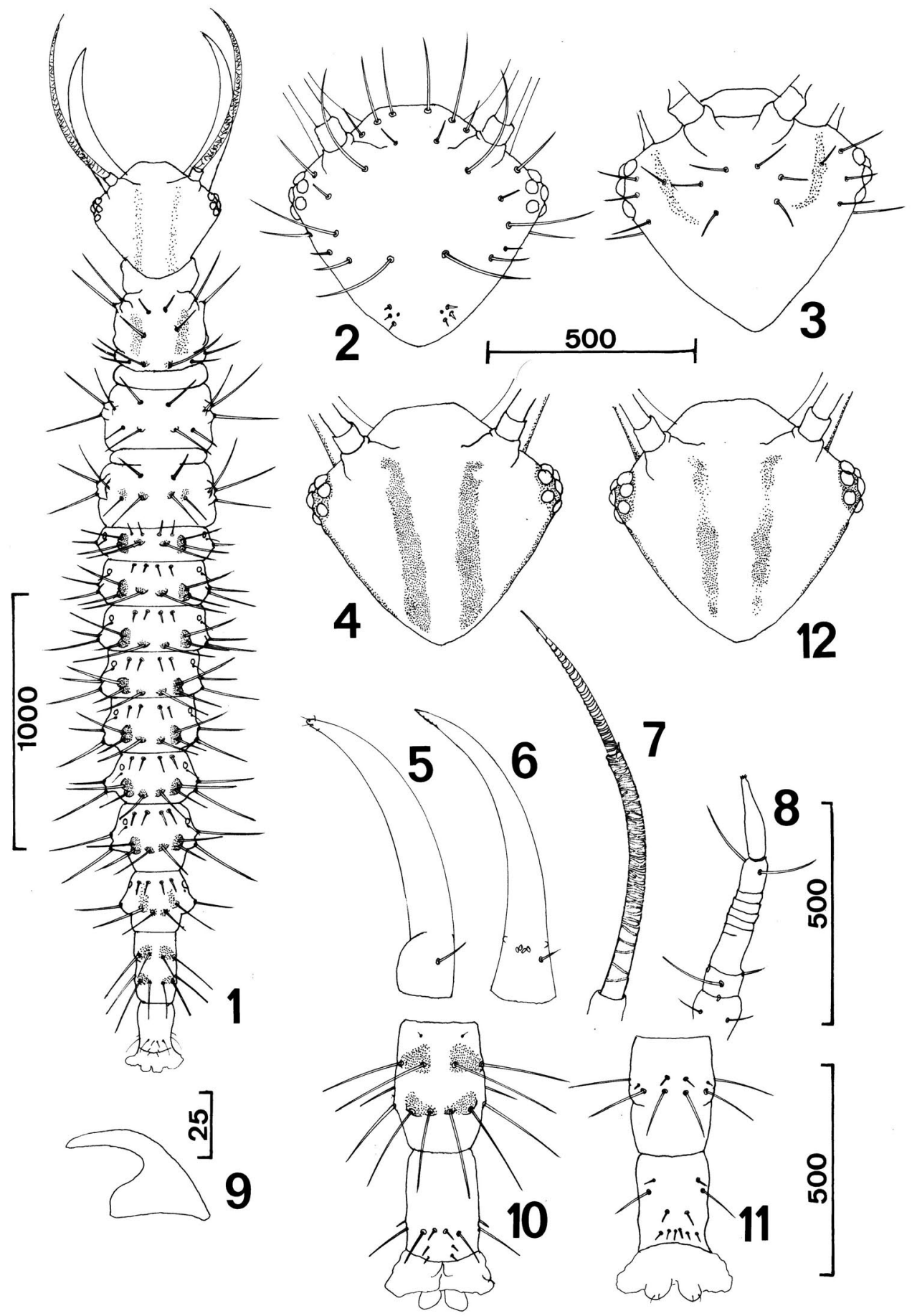

Fig. 35.- Género Nineta (L-1). 1-11: N. guadarramensis. 1, Aspecto general. 2, Quetotaxia cefálica (VD). 3, Idem (VV). 4, Pigmentación cefálica (VV). 5, Maxila. 6, Mandíbula. 7, Antena. 8, Palpo labial. 9, Uña. 10, Segmentos abdominales IX-X (VD). 11, Ídem (VV). 12: N. flava, Pigmentación cefálica (VD). Escalas en $\mu \mathrm{m}$.

Fig. 35.- Genus Nineta (L-1) (first instar larva). 1-11: N. guadarramensis. 1, Habitus. 2, Cephalic chaetotaxy (DV). 3, Ditto (VV). 4, Cephalic pigmentation (VV). 5, Maxilla. 6, Mandible. 7, Antenna. 8, Labial palp. 9, Claw. 10, Abdominal segments IX-X (DV). 11, Ditto (VV). 12: N. flava, Cephalic pigmentation (DV). Scales in $\mu \mathrm{m}$. 
1983, 1999), cuando están vivas. Como ya se comentó con anterioridad, dicha coloración se pierde en los ejemplares conservados en alcohol, haciéndose necesario un análisis más detallado que nos permita encontrar diferencias de pigmentación cefálica y quetotaxia que, junto con las diferencias de coloración tegumentaria de tórax y abdomen, aseguren una correcta asignación de las larvas.

En las larvas neonatas, donde la homogeneidad es mucho más acusada, los caracteres encontrados para diferenciar las larvas L-1 de $N$. guadarramensis aquí descritas y la de $N$. pallida, descrita por Brauer (1867), son la pigmentación cefálica y de las patas y la morfología de las uñas.

Con respecto a la pigmentación cefálica, $N$. pallida es fácilmente diferenciable por la presencia de una mancha frontoclipeal muy patente (ver Brauer, 1867), ausente en las dos especies restantes (Figs. 35.4, 12). En estas dos especies las manchas epicraneales forman dos bandas longitudinales, una a cada lado de la sutura coronal, que son muy patentes y de contorno regular en $N$. guadarramensis (Fig. 35.4) y poco marcadas y difusas, sobre todo en su mitad anterior, en $N$. flava.

En cuanto al segundo carácter, las patas de $N$. guadarramensis son de color crema con una mancha parda o pardo oscura en la parte distal del fémur y tercio proximal de la tibia, sin embargo, en $N$. flava la mancha del fémur no aparece. Brauer (1867) no anota nada a este respecto para $N$. pallida.

El tercer y último carácter, morfología de la uña, permite diferenciar a $N$. pallida de las otras dos especies ibéricas, por presentar la primera las uñas triangularmente dilatadas en su base (ver Brauer, 1867) mientras que las dos especies restantes poseen uñas cuadrangularmente dilatadas en su base (Fig. 35.9).

Con relación a las larvas maduras, los caracteres utilizados en la diferenciación de las tres especies aquí estudiadas son la coloración tegumentaria de tórax y abdomen, la pigmentación cefálica y la morfología de la uña.

Como ya se comentó anteriormente, las larvas de las especies del género que nos ocupan presentan, en general, acusadas diferencias en su coloración tegumentaria. Sin embargo, en dos de las especies ibéricas, $N$. guadarramensis y $N$. flava, la coloración resulta muy similar, ya que ambas poseen coloración amarilla con manchas rojizas formando dos bandas longitudinales laterodorsales que recorren tórax y abdomen en toda su longitud. A pesar de ello, las larvas de estas especies pueden diferenciarse en base a que dichas bandas se extiendan lateralmente hacia el tubérculo lateral del mesotórax y metatórax, como en el caso de $N$. flava (Fig. 37.1) o que lo hagan únicamente en el metatórax, como en $N$. guadarramensis (Fig. 37.3). Las larvas de $N$. pallida son fácilmente diferenciables de las anteriores, ya que presentan coloración parda con una amplia banda mediodorsal de color verde amarillento limitada por dos estrechas bandas laterodorsales de color pardo oscuro (Fig. 37.7).

El segundo carácter citado hace referencia al distinto diseño de las manchas cefálicas. Así, $N$. pallida posee mancha frontoclipeal muy marcada, ausente o muy poco patente en las otras dos especies, y manchas epicraneales dispuestas según Fig. 36.10 , nunca formando dos bandas longitudinales. Sin embargo, en las dos especies restantes las manchas epicraneales forman dos bandas longitudinales, una a cada lado de la sutura coronal, que el caso de $N$. guadarramensis (Fig. 36.4) se extienden desde el esclerito occipital hasta las fosetas pretentoriales, rebasándolas en algunos casos, y en $N$. flava (Fig. 36.2) se hacen muy poco patentes o visibles, en su mitad anterior.

Para el tercer y último carácter mencionado, morfología de las uñas (Figs. 37.2, 4, 8), caben las mismas consideraciones que lo expuesto anteriormente para las larvas neonatas.

Otros caracteres que pueden contribuir en la distinción de las larvas son las diferencias existentes en las setas torácicas y abdominales. Por un lado, en $N$. pallida todas las setas del tórax y abdomen son de color negro y sensiblemente más largas y numerosas que en las dos especies restantes, que poseen setas hialinas. Por otro lado, el margen posteroventral del segmento abdominal X de N. palli$d a$ presenta 4 setas formando una hilera transversal bien definida (Fig. 37.9), mientras que en las otras dos especies existen numerosas setas, irregularmente situadas, no formando una hilera transversal (Fig. 37.6). En base a todo esto aportamos una clave para diferenciar las 3 especies.

\section{Clave para larvas L-1}

1 Mancha frontoclipeal presente. Uñas triangularmente dilatadas en su base ......................................... . pallida

- Mancha frontoclipeal ausente. Uñas cuadrangularmente dilatadas en su base ........................................................ 2

2 Manchas epicraneales formando dos bandas longitudinales bien definidas en toda su longitud (Fig. 35.4). Fémur con una mancha parda en su extremo distal ...... N. guadarramensis 

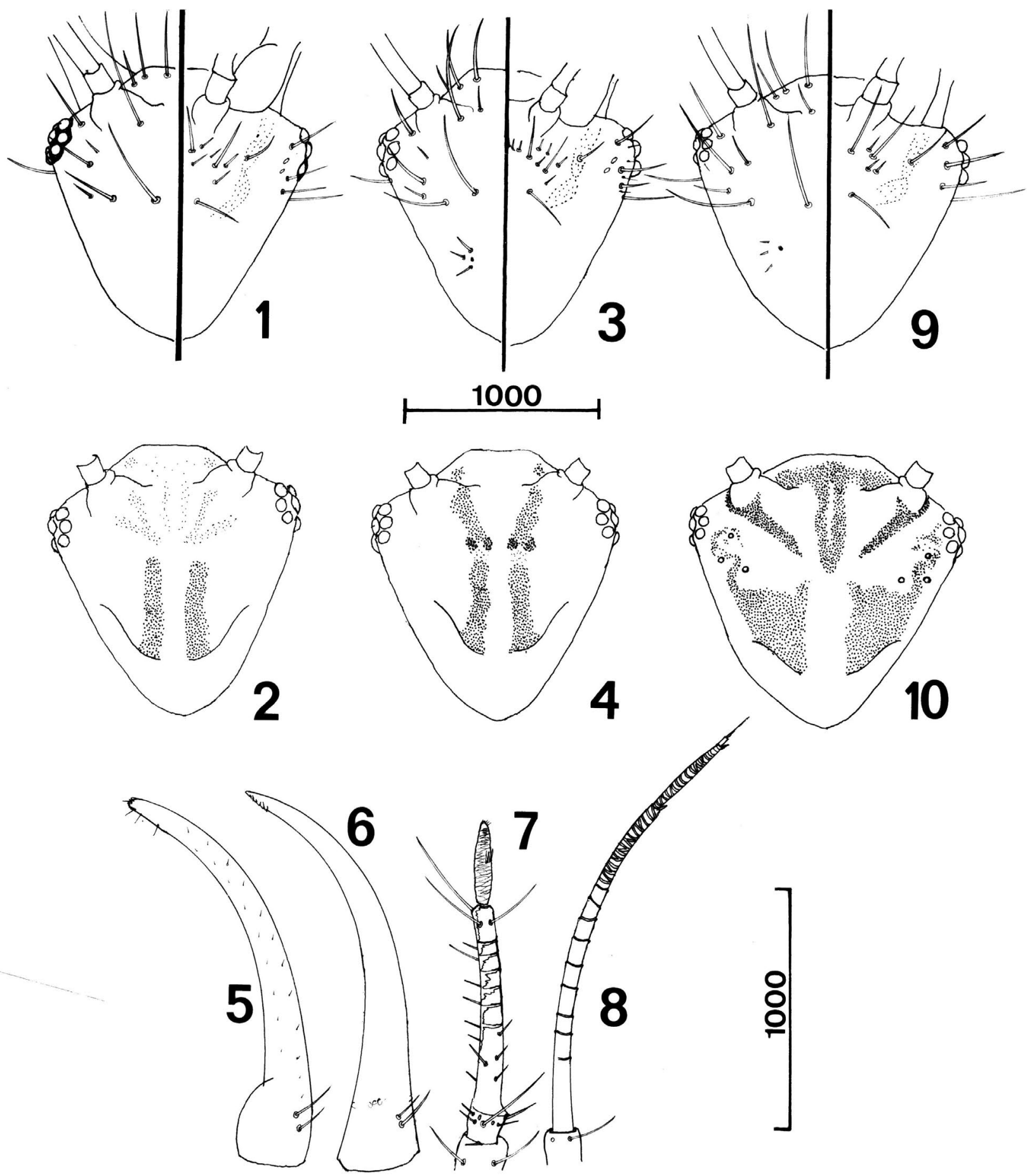

Fig. 36.- Género Nineta (L-3). 1-2: N. flava. 3-8: N. guadarramensis. 9-10: N. pallida. 1, 3 y 9, Quetotaxia cefálica (izda.:VD/ dcha.:VV). 2, 4 y 10, Pigmentación cefálica (VD). 5, Maxila. 6, Mandíbula. 7, Palpo labial. 8, Antena. Escalas en $\mu$ m.

Fig. 36.- Genus Nineta (L-3) (third instar larva). 1-2: N. flava. 3-8: N. guadarramensis. 9-10: N. pallida. 1, 3 and 9, Cephalic chaetotaxy (left: DV / right: VV). 2, 4 and 10, Cephalic pigmentation (DV). 5, Maxilla. 6, Mandible. 7, Labial palp. 8, Antenna. Scales in $\mu \mathrm{m}$. 
- Manchas epicraneales formando dos bandas longitudinales que se hacen difusas y poco visibles en su mitad anterior (Fig. 35.12). Fémur sin una mancha parda en su extremo distal

N. flava

\section{Clave para larvas L-3}

1 Larvas de color pardo laterodorsalmente y verde amarillento mediodorsalmente. Mancha frontoclipeal muy patente y manchas epicraneales formadas por varias manchas (Fig. 33.10). Mandíbulas y maxilas de color pardo muy oscuro. Uñas triangularmente dilatadas en su base (Fig. 37.8) N. pallida

- Larvas amarillas con dos bandas laterodorsales rojizas. Mancha frontoclipeal ausente o apenas marcada y manchas epicraneales formando dos bandas longitudinales (Figs. 36.2, 4). Mandíbulas y maxilas de color ámbar. Uñas cuadrangularmente dilatadas en su base (Figs. 37.2, 4)

2 Bandas laterodorsales ensanchadas únicamente a nivel de los tubérculos laterales del metatórax (Fig. 37.3). Manchas epicraneales bien definidas en toda su longitud y sólo ligeramente interrumpidas en su mitad anterior (Fig. 36.4)

N. guadarramensis

- Bandas laterodorsales ensanchadas a nivel de los tubérculos laterales del meso- y metatórax (Fig. 37.1). Manchas epicraneales muy difusas y poco patentes en su mitad anterior (Fig. 36.2)

N. flava

Biología Y COMPORTAMiENTO. Las hembras de las tres especies depositan los huevos en racimos, con los pedúnculos enrollados (Fig. 1.7). Las larvas nunca cubren su dorso con capa de camuflaje, y son tremendamente activas y voraces durante todo su desarrollo, mostrando un comportamiento ofensivo-defensivo cuando son molestadas. La duración de cada uno de los estadios preimaginales, las condiciones de cultivo y los áfidos empleadas en la dieta, se indican en la siguiente tabla para las especies criadas por nosotros.

\begin{tabular}{|c|c|c|}
\hline \multicolumn{3}{|c|}{ CONDICIONES DE CULTIVO } \\
\hline N. guadarramensis & $25^{\circ} \mathrm{C}$ & $16 \mathrm{~L}: 8 \mathrm{D}$ \\
\hline N. flava & $21^{\circ} \mathrm{C}$ & $16 \mathrm{~L}: 8 \mathrm{D}$ \\
\hline
\end{tabular}

DURACIÓN DE LOS ESTADIOS PREIMAGINALES (días)

$\begin{array}{lccccc} & \mathrm{H} & \mathrm{L}-1 & \mathrm{~L}-2 & \mathrm{~L}-3 & \mathrm{P} \\ N \text {. guadarramensis } & 5 & 4 & 3-4 & 5-6 & (*)\end{array}$

N. flava

$5-6 \quad 4 \quad 4 \quad 5$

\section{N. guadarramensis Aphis fabae N. flava Myzus persicae}

(*) Hiberna como prepupa en el interior del capullo.

Respecto al sustrato vegetal en el que se han hallado las tres especies en la Península Ibérica, $N$. guadarramensis ha sido citada, tanto larvas como imagos, sobre Fagus sylvatica y Castanea sativa, pero especialmente sobre robles: Quercus canariensis, $Q$. robur, Q. faginea y sobre todo Q. pyrenaica. N. palli$d a$ está puntualmente citada sobre Corylus avellana, Fagus sylvatica, Ilex aquifolium, Buxus sempervirens o Crataegus monogyna, pero parece estar fuertemente asociada a coníferas (especialmente Abies alba y Pinus sylvestris), y $N$. flava está puntualmente citada sobre Pinus sylvestris y Q. rotundifolia, pero mayoritariamente, tanto larvas como imagos, sobre planifolios característicos de zonas eurosiberianas (Corylus avellana, Fagus sylvatica, Quercus petrea, Q. faginea, $Q$. robur y $Q$. pyrenaica) (Monserrat \& DíazAranda, 1989; Monserrat \& Rodrigo, 1992; Monserrat \& Marín, 1994; Monserrat, 2008, 2010, y nuevo material estudiado).

DisTRIBUCIÓN GEOGRÁFICA Y ALTITUDINAL, FENOLOGÍA. Su carácter mayoritariamente monovoltino limita la presencia de sus imagos a unos pocos meses. En cuanto a la distribución geográfica de las tres especies en la Península Ibérica, $N$. guadarramensis es la más extendida de todas, encontrándose con frecuencia en las zonas más húmedas de la región mediterránea asociada a robledales. Está citada de las provincias de Barcelona, Cádiz, Cantabria, Granada, Guadalajara, León, Madrid, Segovia, Ávila, Salamanca, Soria, Teruel, Toledo, Cuenca, Huesca, Gerona, Lérida, Lugo, Guipuzcoa, Orense, Pontevedra, Zamora y Zaragoza. Su rango altitudinal 100-1689 m, y sus larvas han sido hallados entre los meses de septiembre y octubre, e imagos entre mayo y octubre. $N$. pallida ha sido citada únicamente en Pirineo (provincias de Huesca y Lérida), su rango altitudinal entre 850-1750 m, y han sido hallados imagos entre los meses de julio a agosto, y sus larvas han sido recolectadas en los meses de otoño e invierno. $N$. flava está mayoritariamente distribuida por toda la zona de influencia eurosiberiana de la península (Asturias, Cantabria, Burgos, Navarra, Huesca, Lérida, Orense, Lugo, Salamanca, Zaragoza y Madrid en España, y Beira Alta en Portugal), su rango altitudinal oscila entre 400-1700 m, y sus larvas han sido halladas entre los meses de julio y agosto, mientras que los imagos entre junio-agosto (Monserrat \& Díaz-Aranda, 1989; Monserrat \& Rodrigo, 1992; Monserrat \& Marín, 1994; Monserrat, 2008, 2010).

\section{Género Peyerimhoffina}

El género Peyerimhoffina Lacroix, 1920 está constituido por una especie: $P$. gracilis (Schneider, 1851), conocida de Europa, norte de África, Anatolia 

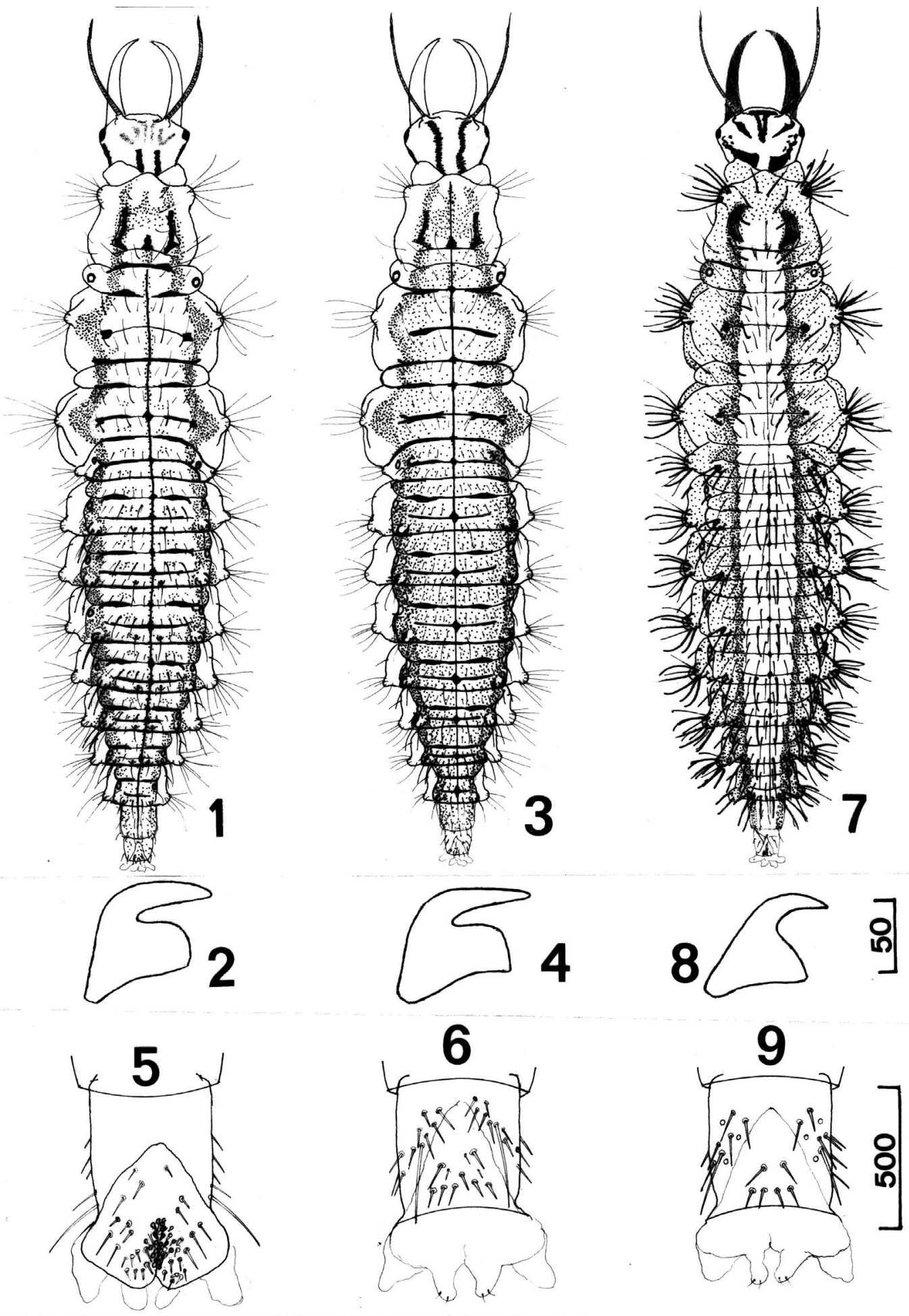

Fig. 37.- Género Nineta (L-3). 1-2: N. flava. 3-6: N. guadarramensis. 7-9: N. pallida. 1, 3 y 7, Aspecto general (VD). 2, 4 y 8, Uña. 5, 6 y 9, Quetotaxia del segmento abdominal X (VV).

Fig. 37.- Genus Nineta (L-3) (third instar larva). 1-2: N. flava. 3-6: N. guadarramensis. 7-9: N. pallida. 1, 3 y 7, Habitus (DV). 2, 4 and 8, Claw. 5, 6 and 9, Chaetotaxy of abdominal segment X (VV). 
y Cáucaso, y dos especies recientemente descritas de China (Brooks \& Barnard,1990, Aspöck et al., 2001), estando representado en la Península Ibérica por la primera de ellas.

Con respecto a sus estadios preimaginales, únicamente la larva adulta de $P$. gracilis ha sido descrita (Gepp, 1983), sin embargo, esta descripción está basada casi exclusivamente en la coloración de la larva y no aporta dato alguno sobre su quetotaxia, por ello consideramos necesario realizar una nueva y más completa descripción de sus estadios preimaginales.

Material utilizado. El material sobre el que hemos basado las descripciones de las larvas neonata y madura de esta especie ha sido cedido por el Dr. R. Cloupeau (Francia, Rochecorbon (F37), Bel-Air, 21.VIII.1988, Cloupeau leg., sobre Pinus sylvestris) y otras recolectadas por nosotros (España, Huesca, Selva de Oza, 3.VIII.1989, sobre Fagus sylvatica).

Estadios LARVARIOS (L-1: Figs. 38.1-10, L-3: Figs. 39.1-11).

Características generales.

Larvas desnudas, no portadoras de capa de camuflaje.

Cuerpo fusiforme, alargado y aplanado dorsoventralmente (Figs. 38.1, 39.1).

Mancha frontoclipeal ausente y manchas epicraneales formando dos bandas longitudinales (Figs. $38.2,39.2)$.

Seta cefálica S-12 presente (Figs. 38.2, 39.2).

Setas torácicas y abdominales muy cortas (Figs. $38.1,39.1,9)$.

De la larva L-1 (Figs. 38.1-10).

Setas muy cortas y filiformes (Fig. 38.1).

Tubérculos laterales del pro- meso- y metatórax poco desarrollados, portadores de 2,3 y 3 setas respectivamente (Fig. 38.1).

Tubérculos laterales de los segmentos abdominales II-VII portadores de 2 setas (Fig. 38.1).

Segmentos abdominales I-VII con tubérculos laterodorsales fuertemente esclerotizados, portadores de 2 setas (Fig. 38.1).

De la larva L-3 (Figs. 39.1-11).

Tubérculos laterales del pro- meso- y metatórax portadores de 4, 7 y 7 setas filiformes (Fig. 39.1).

Tubérculos laterales de los segmentos abdominales II-VII portadores de 7-9 setas filiformes (Fig. 39.1).

Segmentos abdominales I-V con hileras dorsotransversales de setas espatuladas, fuertemente abatidas sobre el dorso y orientadas hacia la línea media (Fig. 39.1, 9).
Segmentos VI-VII sin setas espatuladas, con 2 pequeños tubérculos laterodorsales portadores de 2 setas filiformes (Fig. 39.1).

\section{ESTADIOS LARVARIOS}

Larva L-1. Aspecto general según Fig. 38.1. Cabeza de color amarillo pálido con manchas cefálicas de color pardo oscuro. Mancha frontoclipeal ausente. Manchas epicraneales formando dos bandas longitudinales que se extienden desde el esclerito occipital hasta la región anterior de la cápsula cefálica, rebasando la base de las antenas (Fig. 38.2). Manchas genales (Figs. 38.2, 3) no extendidas a la cara ventral de la cápsula cefálica. Manchas ventrales poco patentes (Fig. 38.3). Quetotaxia dorsal y ventral de la cápsula cefálica según Figs. 38.2 y 38.3, respectivamente. Seta S-12 presente. Maxilas (Fig. 38.4) y mandíbulas (Fig. 38.5) de color pardo oscuro. Palpos labiales (Fig. 38.6) pardo pálido con el último artejo de color pardo oscuro. Antenas (Fig. 38.7) de color pardo pálido. Ojos negros, formados por 6 estemmata dispuestos según Figs. 38.2, 3.

Tórax (Fig. 38.1) con tubérculos laterales muy poco desarrollados, portadores de setas muy cortas y filiformes, en número de 2 en el protórax y de 3 en meso- y metatórax. Setas dorsales del tórax en número y disposición según lo ilustrado en la Fig. 38.1. Escleritos laterodorsales de color pardo oscuro, alargados en el pronoto, circulares y más pequeños en mesonoto y apenas visibles en el metanoto (Fig. 38.1). Patas de color pardo amarillento con coxa, extremo distal del fémur, mitad proximal de la tibia y pretarso de color pardo oscuro. Uñas de color ámbar, con base triangular (Fig. 38.8).

Abdomen aplanado dorsoventralmente. Segmentos II-VII con tubérculos laterales portadores de 2 setas cortas y filiformes. Segmentos I-VII con tubérculos laterodorsales fuertemente esclerotizados (Fig. 38.1), portadores de 2 cortas setas filiformes. Setas dorsales del abdomen muy cortas y filiformes, en número y disposición según lo ilustrado en la Fig. 38.1. Quetotaxia y pigmentación dorsal y ventral de los segmentos VIII-X según Figs. 38.9 y 38.10 respectivamente.

Larva L-3. Aspecto general según Fig. 39.1. Larva de color pardo amarillento con 2 difusas bandas longitudinales laterodorsales, una a cada lado de la línea media, de color pardo rojizo que limitan una banda central de color verde grisáceo (Gepp, 1983).

Cabeza de color pardo amarillento con manchas cefálicas pardo oscuras. Mancha frontoclipeal ausen- 
te. Manchas epicraneales formando dos bandas laterodorsales que se extienden longitudinalmente desde el esclerito occipital hasta el margen anterior de la cápsula cefálica, rebasando las base de las antenas (Fig. 39.2). Manchas genales patentes, no extendidas a la cara ventral de la cápsula cefálica (Figs. 39.2, 3). Cardo y estipe ligeramente esclerotizados (Fig. 39.3). Quetotaxia dorsal y ventral según Figs. 39.2, 3 respectivamente. Seta S-12 presente. Maxilas (Fig. 39.4) y mandíbulas (Fig. 39.5) de color pardo oscuro. Palpos labiales (Fig. 39.6) de color pardo pálido, con último artejo de color pardo muy oscuro. Antenas (Fig. 39.7) de color pardo pálido. Ojos negros, formados por 6 estemmata dispuestos según Figs. 39.2, 3.

Tórax con escleritos laterodorsales de color pardo oscuro, alargados y muy patentes en el pronoto, circulares y más pequeños en el mesonoto, y apenas visibles en el metanoto (Fig. 39.1). Tubérculos laterales de pro- meso y metatórax muy poco desarrollados, portadores de 4, 7 y 7 setas muy cortas y filiformes. Setas dorsales del tórax muy cortas y filiformes, en número y disposición según Fig. 39.1. Uñas de color ámbar, triangulares en su base (Fig. 39.8).

Segmentos abdominales II-VII con tubérculos laterales semiesféricos, muy poco desarrollados, portadores de 7-9 setas muy cortas y filiformes (Fig. 39.1). Segmentos I-V con hileras transversales de setas espatuladas (Fig. 39.9), abatidas sobre el dorso y orientadas hacia la línea media (Fig. 39.1). Cada uno de estos segmentos posee además 2 setas laterodorsales filiformes, más largas y gruesas que las espatuladas (Fig. 39.1). Segmentos VIVII sin setas espatuladas, con dos pequeños tubérculos laterodorsales portadores de 2 setas filiformes (Fig. 39.1). Quetotaxia y pigmentación dorsal y ventral de los segmentos IX-X según Figs. 39.10 y 39.11 respectivamente.

DisCUSIÓn. La larva de $P$. gracilis resulta, a simple vista, muy similar en su morfología externa a las larvas de las especies del género Chrysoperla Steinmann, 1964, presentando una coloración tegumentaria y un diseño de manchas cefálicas muy parecido. No obstante, existen una serie de caracteres de quetotaxia que separan claramente las larvas de ambos géneros. Entre ellos cabe resaltar el tipo de seta de los terguitos abdominales, ya que las larvas del género Chrysoperla poseen exclusivamente setas filiformes, mientras que en la larva aquí estudiada el tipo de seta es espatulado (Fig. 39.9). Además, la disposición de las setas dorsales varía mucho de un género a otro, ya que las larvas de las especies del género Chrysoperla poseen tubérculos laterodorsales portadores de 2 largas setas en los segmentos abdominales I-VII y el resto de las setas, más cortas, se disponen formando 2 pequeñas series transversales anteriores (Fig. 18.1), mientras que en las larvas de $P$. gracilis, las setas dorsales del abdomen son mucho más numerosas, y se disponen formando varias hileras transversales en cada segmento (Fig. 39.1).

Con respecto a este carácter, resulta curioso que larvas desnudas, como es el caso de la larva de $P$. gracilis, posean en los terguitos abdominales hileras transversales de setas de este tipo, características de aquellas larvas que son portadoras de capa de camuflaje. Sin embargo, en las larvas portadoras de esta capa, las setas dorsales del abdomen se disponen perperdiculares al dorso del mismo, ayudando así en la retención de la capa de camuflaje (Fig. 43.2a), mientras que en la especie ahora estudiada las setas quedan abatidas sobre la superficie dorsal del abdomen y orientadas hacia la línea media. Dado que los datos sobre biología y comportamiento de la larva de esta especie son muy escasos, se hace necesario un estudio detallado de la misma en la naturaleza con el fin de poder establecer relaciones entre los hábitos de las larvas y la posesión de setas espatuladas dispuestas de forma tan particular sobre el abdomen.

Biología y comportamiento. Como ya hemos indicado, el material sobre el que hemos basado la descripción de la larva de esta especie fue cedido por el Dr. Cloupeau, motivo por el cual no podemos aportar datos sobre el ciclo de desarrollo de la misma. Información sobre el tema puede ser recabada en Canard \& Grimal (1990), Grimal (1988) y Gepp (1989).

Sobre la biología del imago en la Península Ibérica, Q. gracilis, y a pesar de ser muy local y poco frecuente, parece estar fuertemente asociada a coníferas, especialmente Abies alba, y en menor grado se ha citado sobre Pinus sylvestris o Ilex aquifolium (Monserrat \& Rodrigo, 1992; Monserrat \& Marín, 1994; Monserrat, 2008), sustratos vegetales donde se han colectado imagos de esta especie en este área, pero no así sus larvas, a pesar de haber vareado intensamente estas especies vegetales. Anteriormente hemos citado larvas recolectadas por nosotros sobre Fagus sylvatica.

DISTRIBUCIÓN GEOGRÁFICA Y ALTITUDINAL, FENOLOGÍA. La especie parece poseer una distribución geográfica asociada a la zona eurosiberiana pire- 


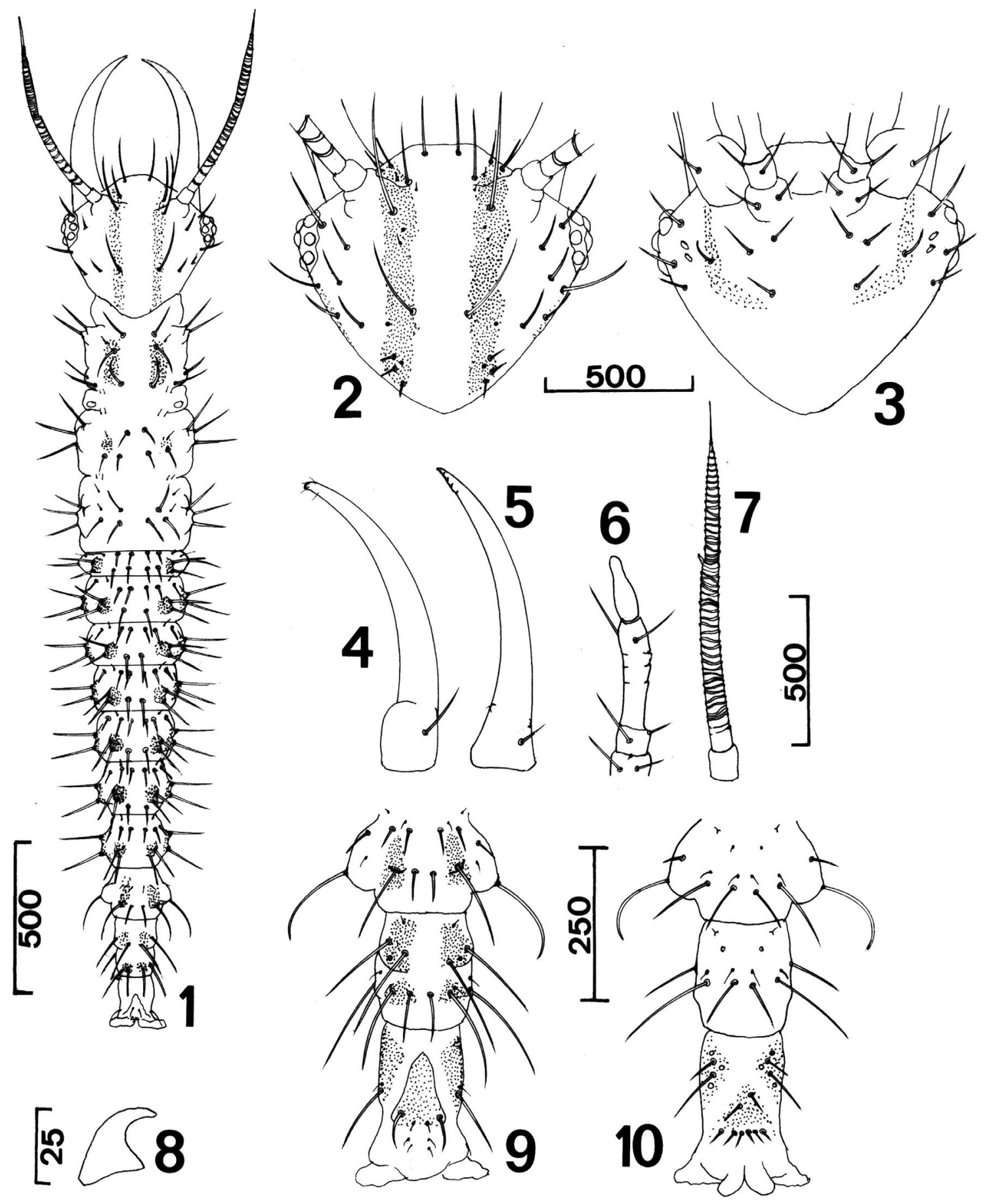

Fig. 38.- Peyerimhoffina gracilis (L-1). 1, Aspecto general (VD), 2, Cápsula cefálica (VD). 3, Ídem (VV). 4, Maxila. 5, Mandibula. 6, Palpo labial. 7, Antena. 8, Uña. 9, Segmentos abdominales VIII-X (VD). 10, Ídem (VV). Escalas en $\mu$ m.

Fig. 38.- Peyerimhoffina gracilis (L-1) (first instar larva). 1, Habitus (DV). 2, Cephalic chaetotaxy (DV). 3, Ditto (VV). 4, Maxilla. 5, Mandible. 6, Labial palp. 7, Antenna. 8, Claw. 9, Abdominal segments VIII-X (DV). 10, Ditto (VV). Scales in $\mu \mathrm{m}$. 

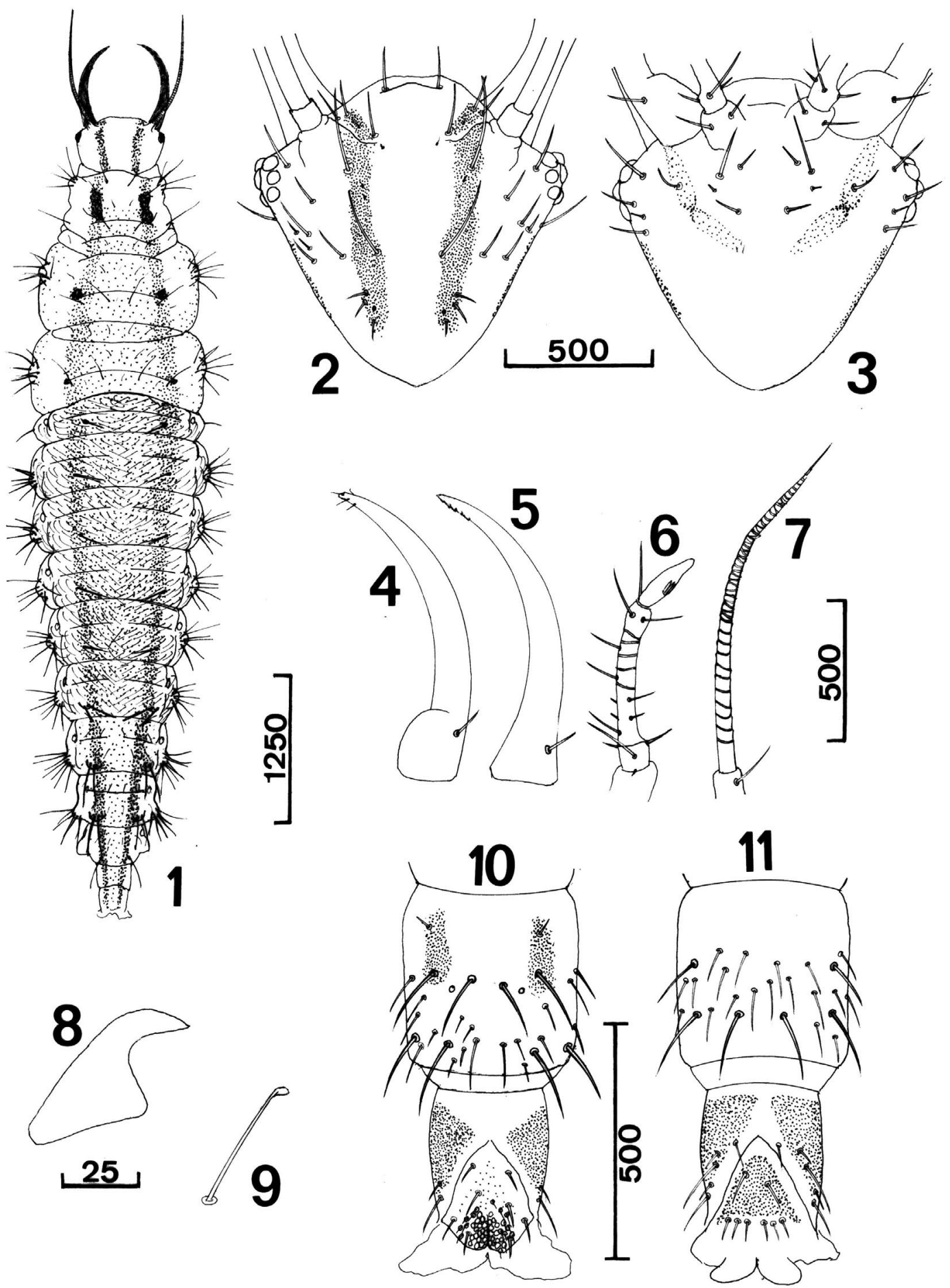

Fig. 39.- Peyerimhoffina gracilis (L-3). 1, Aspecto general (VD), 2, Cápsula cefálica (VD). 3, Ídem (VV). 4, Maxila. 5, Mandíbula. 6, Palpo labial. 7, Antena. 8, Uña. 9, detalle de una seta espatulada del dorso del abdomen. 10, Segmentos abdominales IX-X (VD). 11, Ídem (VV). Escalas en $\mu \mathrm{m}$.

Fig. 39.- Peyerimhoffina gracilis (L-3) (third instar larva). 1, Habitus (DV), 2, Cephalic capsule (DV). 3, Ditto (VV). 4, Maxilla. 5, Mandible. 6, Labial palp. 7, Antenna. 8, Claw. 9, Spatulate seta the abdomen dorsum. 10, Abdominal segments IX-X (DV). 11 , Ditto (VV). Scales in $\mu \mathrm{m}$. 
naica, con poblaciones en zonas montanas más meridionales. Los imagos de esta especie son conocida en la Península Ibérica únicamente de las provincias de Huesca, Lérida y Jaén. Su rango altitudinal oscila entre $1200-1340 \mathrm{~m}$, y ha sido hallada entre los meses de junio-septiembre.

\section{Género Rexa}

El género Rexa Navás, 1920, comprende en la actualidad 3 especies, todas de distribución mediterránea: $R$. corsica (Hagen, 1864), R. lordina Navás, 1920 y $R$. raddai (Hölzel, 1966) (Brooks \& Barnard, 1990; Aspöck et al., 1980, 2001; Canard, 1981; Canard \& Labrique, 1989). En la Península Ibérica está representado por $R$. lordina, única especie del género de la que han sido descritos sus estadios preimaginales (Canard \& Labrique, 1989), aunque hemos considerado ahora aportar nuevos datos.

Material utilizado. El material sobre el hemos basado las descripciones ha sido cedido por el Dr. Michel Canard (ver Canard \& Labrique, 1989) y otras larvas recolectadas en España, Granada, El Zahidín, 3.VII.1988, sobre Olea europea, fueron cedidas por la Dra. Mercedes Campos.

\section{ESTADIOS LARVARIOS}

Características generales: (L-1: Figs. 40.1-11, L-3: Figs. 41.1-13).

Larvas portadoras de capa de camuflaje.

Mandíbulas y maxilas de igual o similar longitud que la cápsula cefálica (Figs. 40.2, 41.1).

Manchas cefálicas de grandes dimensiones, ocupando la práctica totalidad de la superficie cefálica dorsal (Figs. 40.2-3, 41.1-2).

Seta cefálica S-12 presente (Figs. 40.2-3, 41.1-2).

Abdomen moderadamente globoso (Figs. 40.2, 41.1).

De la larva neonata (Figs. 40.1-11).

Tubérculos laterales del pro- meso- y metanoto muy desarrollados, portadores respectivamente de 2, 3 y 3 largas setas filiformes (Fig. 40.2).

Metanoto con 4 tubérculos dorsales portadores de 1 larga seta filiforme (Fig. 40.2).

Segmentos abdominales II-VII portadores de 2 setas filiformes (Fig. 40.2).

Segmentos abdominales I-VII con tubérculos dorsales portadores de setas filiformes (Fig. 40.2).

De la larva madura (Figs. 41.1-13).

Larvas de color blanco amarillento, con manchas dorsales pardas formando dos bandas longitudinales laterodorsales en el abdomen (Fig. 41.1).
Escleritos laterodorsales del pronoto muy desarrollados (Fig. 41.1).

Tubérculos laterales del tórax muy desarrollados, de aspecto robusto, portadores de largas setas, ganchudas en su ápice (Fig. 41.1).

Metanoto con una hilera transversal de setas ganchudas en su ápice (Fig. 41.1).

Abdomen globoso (Fig. 41.1).

Terguitos de los segmentos abdominales I-V con 3 hileras transversales de setas: 2 hileras anteriores de setas uncinadas y 1 hilera posterior de setas más gruesas y largas que las uncinadas, ganchudas en su ápice (Fig. 41.1).

Tubérculos laterales de los segmentos II-VII portadores de setas ganchudas en su ápice, fuertemente recurvadas laterodorsalmente (Fig. 41.1).

La inserción de las setas a los tubérculos, tanto en el tórax como en el abdomen, está fuertemente pigmentada (Fig. 41.1).

\section{Descripción de los estadios preimaginales}

Huevo. Son elipsoides, pedunculados, de color verde amarillento con micropilo blanco. Las dimensiones del huevo oscilan entre 0.8-0.9 mm de longitud y las del pedúnculo entre $6-7 \mathrm{~mm}$.

Ovirruptor. Aparece ligeramente esclerotizado y muestra denticulación según Fig. 40.1.

Larva L-1. Aspecto general según Fig. 40.2, coloración rosa pálido. Cabeza de color amarillo pálido con manchas cefálicas dorsales difusas y poco visibles (Fig. 40.3). Manchas genales bien marcadas (Figs. 40.3-4). Cardo y estipe fuertemente esclerotizados (Fig. 40.4). Antena (Fig. 40.5) de color crema pálido. Palpo labial (Fig. 40.6) crema pálido, con último segmento pardo oscuro. Maxilas (Fig. 40.7) y mandíbulas (Fig. 40.8) de color crema, de igual longitud que la cápsula cefálica. Quetotaxia dorsal y ventral de la cápsula cefálica según Figs. 40.3 y 40.4 respectivamente. Seta S-12 presente. Ojos negros, formados por 6 estemmata dispuestos según Figs. 40.3-4.

Tórax de color blanquecino o crema pálido. Tubérculos laterales del pro- meso- y metatórax portadores de 2, 3 y 3 largas setas filiformes respectivamente. Setas dorsales filiformes, en número y disposición según Fig. 40.2. Metanoto con 4 largas setas. Patas de color prado pálido en su totalidad. Uñas de color ámbar, con morfología según Fig. 40.9.

Abdomen ligeramente globoso. Segmentos IIVII con tubérculos laterales portadores de 2 largas 
setas filiformes (Fig. 40.2). Segmentos I-V con 4 pequeños tubérculos dorsales portadores de largas setas filiformes, recurvadas pero no uncinadas en su ápice (Fig. 40.2). Segmentos VI-VII con dos tubérculos laterodorsales portadores de 2 largas setas filiformes orientadas hacia la región caudal y 2 cortas setas submediales. Quetotaxia dorsal y ventral de los segmentos abdominales VIII-X según Fig. 40.10, 11 respectivamente.

Larva L-3. Aspecto general según Fig. 41.1. Cabeza amarillenta con manchas cefálicas pardas. Mancha frontoclipeal dividida longitudinalmente y cerrada en su margen anterior (Fig. 41.2). Manchas epicraneales de grandes dimensiones, extendidas lateralmente hacia las zonas oculares (Fig. 41.2) y ligeramente unidas a un par de manchas triangulares posteroantenales (Fig. 41.2). Manchas genales muy marcadas, no extendidas a la región ventral (Figs. 41.2-3). Cardo y estipe fuertemente esclerotizados (Fig. 2.3). Quetotaxia dorsal y ventral de la cápsula cefálica según Fig. 41.2 y 41.3 respectivamente. Seta S-12 presente. Antena (Fig. 41.4) y palpo labial (Fig. 41.5) de color pardo basalmente y pardo oscuro distalmente. Maxilas (Fig. 41.6) y mandíbulas (Fig. 41.7) de color ámbar, de longitud similar a la de la cápsula cefálica. Ojos negros, formados por 6 estemmata dispuestos según Fig. 41.2 y 41.3 , rodeados de tegumento fuertemente esclerotizado.

Tórax de color blanco grisáceo o blanco amarillento, con manchas dorsales pardas sobre el mesoy metanoto, dispuestas según Fig. 41.1. Escleritos laterodorsales del pronoto muy desarrollados, de color pardo oscuro y aspecto trapecial (Fig. 41.1). Tubérculos laterales muy robustos, poco alargados (Fig. 41.1), portadores de numerosas setas uncinadas en su ápice (Fig. 41.11), fuertemente esclerotizadas en su inserción al tubérculo (Fig. 41.1). Setas dorsales en número y disposición según Fig. 41.1. Metanoto con una hilera transversal de largas setas, uncinadas en su ápice (Fig. 41.11). Patas de color pardo oscuro salvo los dos tercios distales de las coxas, pretarso y empodio que son negros. Uñas de color ámbar, con base triangular (Fig. 41.8).

Abdomen ligeramente abombado, de color blanco grisáceo o amarillento con manchas laterodorsales pardo rojizas en los segmentos II-VIII, formando en su conjunto dos bandas longitudinales, interrumpidas transversalmente en la parte posterior de cada segmento (Fig. 41.1) mientras recorren el abdomen. Lateralmente existe otra banda pardo rojiza más tenue e irregular. Segmentos II-VII con tubérculos laterales semiesféricos, muy robustos, portadores de numerosas setas recurvadas laterodorsalmente (Fig. 41.2), uncinadas en su ápice (Fig. 41.11) y fuertemente esclerotizadas en su inserción al tubérculo. Segmentos I-V con varias hileras transversales de setas: 2-3 hileras anteriores formada por setas uncinadas (Figs. 41.1 y 41.13) y 1 hilera posterior a éstas, formada por setas más largas y gruesas que las anteriores, ganchudas en su ápice (Figs. 41.1, 12). Segmentos VI-VII con 2 largas setas filiformes laterodorsales orientadas hacia la región caudal (Fig. 41.1). Quetotaxia y pigmentación dorsal y ventral de los segmentos IX-X según Figs. 41.11- 12.

Discusión. La larva del género Rexa comparte una serie de características morfológicas con especies de los géneros Pseudomallada, Chrysopidia, Cunctochrysa y Suarius, cuyas larvas también son portadoras de capa de camuflaje. Como ya se mencionó anteriomente, dichas larvas presentan una serie de modificaciones morfológicas que permiten el anclaje y retención de la capa de camuflaje (Fig. 41.1). Éstas, entre otras, son:

- Tubérculos laterales del tórax alargados y finos, ligeramente ensanchados en su ápice (pedunculados), portadores de largas setas (Fig. 41.1).

- Presencia de una hilera transversal de largas setas en el metanoto (Fig. 41.1).

- Abdomen más o menos globoso o abombado (Fig. 41.1).

- Hileras transversales de setas uncinadas presentes, como mínimo, en los terguitos de los 5 primeros segmentos abdominales (Fig. 41.1).

- Segmentos abdominales I-VI con hileras transversales de setas uncinadas (Fig. 41.1).

- Segmentos II-V con tubérculos laterales portadores de setas que, frecuentemente, están recurvadas laterodorsalmente (Fig. 41.1).

- Segmentos VI-VII con tubérculos laterales portadores de setas orientadas hacia la región caudal y con dos pequeños tubérculos laterodorsales, portadores de 1-2 largas setas orientadas hacia la región caudal y recurvadas dorsalmente (Fig. 41.1).

La larva de la especie que ahora nos ocupa presenta la mayoría de las modificaciones mencionadas, pero cabe resaltar una serie de características morfológicas que la diferencia de las otras larvas típicamente portadoras de capa:

Una de las diferencias es la morfología de los tubérculos laterales del tórax, ya que en las larvas 
portadoras de capa dichos tubérculos son alargados y finos, en la mayoría de los casos ensanchados en su ápice. Sin embargo, en la larva de $R$. lordina los tubérculos laterales son muy robustos, de pedúnculo muy grueso (Fig. 41.1). Además, las setas de estos tubérculos suelen poseer una gran longitud, mientras que en este caso las setas son relativamente cortas.

La segunda diferencia está basada en el tipo de setas de las hileras transversales de los terguitos abdominales y de los tubérculos laterales, tanto de tórax como de abdomen. En cuanto a las hileras transversales del abdomen, las larvas de las especies pertenecientes a los géneros antes mencionados poseen numerosas hileras transversales de setas uncinadas, todas de aproximadamente igual longitud y morfología. Sin embargo, en la especie que nos ocupa, aparecen dos tipos de hileras transversales: 2-3 hileras anteriores formadas por setas uncinadas y 1 hilera posterior compuesta por setas más largas y gruesas que las uncinadas y cuyo ápice está recurvado en forma de gancho (Fig. 41.12). Por su parte, los tubérculos laterales de tórax y abdomen de Rexa lordina poseen setas largas y rectas, ganchudas en su ápice, mientras que en especies de otros géneros estudiados, cuyas larvas también cubren su dorso con capa de camuflaje, las setas de los tubérculos laterales son siempre filiformes en el tórax y, sólo en algunos casos, poseen setas uncinadas en el abdomen (Fig. 41.1).

Al margen de las características morfológicas derivadas del hábito de portar capa de camuflaje, otro carácter morfológico digno de resaltar es la longitud de las mandíbulas y maxilas en relación a la longitud de la cápsula cefálica. En las larvas de todos los géneros estudiados, pertenecientes a la tribu Chrysopini, la longitud de maxilas-mandíbulas es mayor que la de la cápsula cefálica, ya sea ligeramente (como es el caso del género Chrysopa) o llegando casi a duplicar la longitud de dicha cápsula (ver géneros Nothochrysa e Hypochrysa). En el caso de la especie ahora estudiada, la longitud de las mandíbulas-maxilas es, como mucho, de igual longitud que la cápsula cefálica (Fig. 41.1).

Biología Y COMPORTAMIENTO. Las hembras de esta especie depositan los huevos de forma aislada (Canard \& Labrique, 1989). Las larvas son portadoras de una capa de camuflaje de pequeñas dimensiones, a veces portando sus propias exuvias, y son poco activas. En caso de agresión ofrecen la parte dorsal del abdomen. La duración de los estadios preimaginales, las condiciones de cultivo y la dieta empleada son indicadas en la siguiente tabla:

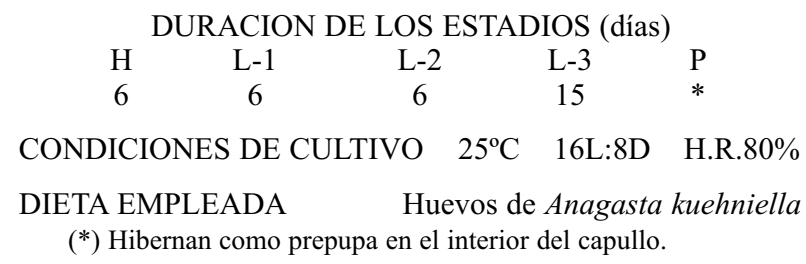

Mayoritariamente citada sobre oleáceas: Olea europea (L.) y Phillyrea angustifolia (L.) Canard \& Labrique (1989); Monserrat \& Díaz-Aranda (1989); Monserrat \& Marín (1994); Monserrat (2008).

DISTRIBUCIÓN GEOGRÁFICA Y ALTITUDINAL, FENOLOGÍA. La distribución geográfica de Rexa lordina en la Península Ibérica es mediterránea litoral. Se trata de una especie poco frecuente y muy local, aunque a veces extremadamente abundante, y fuertemente asociada a acebuches y olivares de las zonas más térmicas y xéricas de dicha región. Ha sido citada de las provincias de Gerona, Huesca, Jaén, Granada, Murcia, Cádiz y Cáceres en España, y Algarve y Tras os Montes en Portugal. Su rango altitudinal entre $200-400 \mathrm{~m}$, y fenología de carácter primaveral, hallada entre los meses de abril-junio, de forma muy específica y limitada.

\section{Género Suarius}

El género Suarius (s.str.) Navás, 1914, posee una distribución paleártica meridional, e incluye en la actualidad 22 especies (Brooks \& Barnard, 1990; Aspöck et al., 2001), de las cuales sólo se conocen los estadios preimaginales de dos especies (DíazAranda \& Monserrat, 1996).

En Europa el género Suarius está representado por cuatro especies: Suarius nanus (McLachlan, 1893), conocida de Mediterráneo oriental hasta Irán y Afganistán, $S$. walsinghami walsinghami Navás, 1914 y Suarius tigridis (Morton, 1921) distribuidas por el norte de Africa, Oriente Medio, Península Arábiga y Península Ibérica, y Suarius iberiensis Hölzel, 1974, únicamente conocida de la Península Ibérica.

De las especies europeas, sólo son conocidas las fases juveniles de Suarius walsinghami walsingha$m i$ y $S$. tigridis que fueron descritas por DíazAranda \& Monserrat (1996), y ahora se describen las de $S$. iberiensis, y se actualizan los registros de las tres especies ibéricas. 


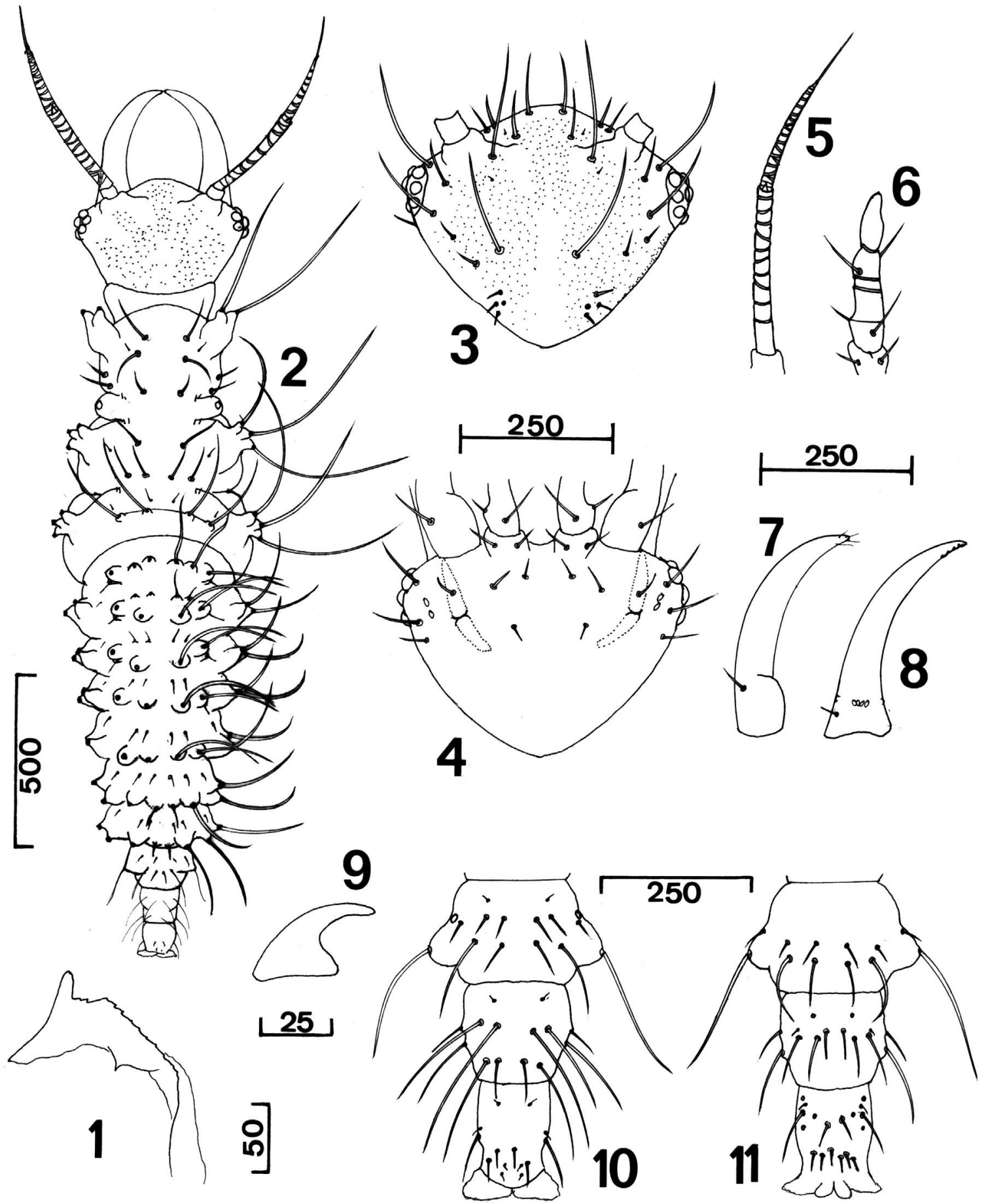

Fig. 40.- Rexa lordina (L-1). 1, Ovirruptor, 2, Aspecto general (VD). 3, Cápsula cefálica (VD). 4, Ídem (VV). 5, Antena. 6, Palpo labial. 7, Maxila. 8, Mandíbula. 9, Uña. 10, Segmentos abdominales VIII-X (VD). 11, Ídem (VV). Escalas en $\mu$ m.

Fig. 40.- Rexa lordina (L-1) (first instar larva). 1, Oviruptor, 2, Habitus (DV). 3, Head capsule (DV). 4, Ditto (VV). 5, Antenna. 6, Labial palp. 7, Maxilla. 8, Mandible. 9, Claw. 10, Abdominal segments VIII-X (DV). 11, Ditto (VV). Scales in $\mu \mathrm{m}$. 
Material utilizado.

\section{Suarius walsinghami}

Hembras grávidas: España, Almería, Rambla de Tabernas, 21.IX.1988, San José, Cerro de Enmedio, 22.VII.1991. En ambos casos las hembras fueron colectadas en trampas de luz.

\section{Suarius tigridis}

Hembras grávidas: España, Almería, Cabo de Gata, Rambla de Morales, 29.VII.1991, Rambla de Tabernas, 28.VII.1991. En ambas localidades las hembras fueron colectadas con trampas de luz.

\section{Suarius iberiensis}

Hembras grávidas: España, Madrid, Rivas Vaciamadrid, Laguna del Campillo, el 25.V.1994 sobre Salsola vermiculata L. y Ammi majus L.

\section{ESTADIOS LARVARIOS}

Características generales: (L-1: Figs. 42.1-11, 44.1-13, L-3: Figs. 42.12-17, 43.1-9, 44.14-23).

Larvas portadoras de abundantes setas uncinadas en el dorso abdominal para anclar la capa de camuflaje (Figs. 42.12, 13, 44.14).

Abdomen extremadamente abombado (Figs. $42.12,13,44.14)$.

Tres tipos morfológicos de setas: Uncinadas, espatuladas y filiformes (Figs. 42.15-17, 44.11-12).

Manchas frontoclipeal y epicraneales bien definidas (Figs. 43.1, 44.15).

Seta cefálica S-12 presente, pero muy corta (Figs. 43.2, 44.15).

Tubérculos laterales del tórax alargados, portadores de setas filiformes muy largas (Figs. 42.12, 14, 44.14).

Tubérculos laterales del abdomen portadores de setas uncinadas (Figs. 42.12, 13, 44.14).

De la larva neonata (Figs. 42.1-11, 44.1-13).

Tórax con tubérculos laterales alargados, portadores de 2 largas setas filiformes en protórax y 3 en meso y metatórax (Figs. 42.2, 44.1).

Segmentos abdominales II-V con tubérculos laterales portadores de 2 setas (Figs. 42.2, 44.1).

Segmentos VI-VII con tubérculos laterales portadores de 2 largas setas y tubérculos laterodorsales portadores de 1 larga seta, espatuladas en el segmento VI y filiformes en el VII (Figs. 42.2, 44.1).

Segmentos abdominales I-V con numerosos tubérculos dorsales portadores de setas uncinadas (Fig. 42.2, 44.1). Dichos tubérculos son considerablemente más numerosos en este género que en otros géneros próximos estudiados (ver Pseudomallada y Cunctochrysa).

De la larva madura (Figs. 42.12-17, 43.1-9, 44.14-23).

Larvas blanquecinas con manchas longitudinales pardas en tórax y abdomen (Figs. 42.12-13, 44.14).
Tubérculos laterales del tórax translúcidos, alargados, con largas setas hialinas (Figs. 42.12, 44.14). Espiráculo torácico troncocónico (Figs. 42.14).

Abdomen extremadamente globoso, con tubérculos laterales portadores de numerosas setas uncinadas y 1-2 setas filiformes más largas (Figs. 42.12-13, 44.14).

Segmentos abdominales con hileras dorsotransversales de setas uncinadas (Figs. 42.12-13, 44.14), en número y longitud mayor a la observada en otros géneros cuyas larvas portan capa de camuflaje (ver Pseudomallada y Cunctochrysa).

ESTADIOS PREIMAGINALES DE SUARIUS IBERIENSIS

Huevo. Huevos elípticos, pedunculados, de color verde muy pálido. Longitud aproximada del huevo: $1 \mathrm{~mm}$; longitud aproximada del pedúnculo: 3-3.5 mm (Fig. 44.13a).

Ovirruptor. El ovirruptor está ligeramente esclerotizado y presenta denticulación según Fig. 44.13b.

Larva neonata (Figs. 44.1-12). Aspecto general según Fig. 44.1. Cabeza crema pálido con manchas cefálicas pardas. Mancha frontoclipeal y epicraneales según Fig. 44.2. Manchas ventrales según Fig. 44.3. Quetotaxia dorsal y ventral de la cápsula cefálica según Figs. 44.2-3, respectivamente. Seta cefálica S-12 presente, pero muy reducida. Maxila (Fig. 44.6) y mandíbula (Fig. 44.7) de color ámbar. Palpo labial (Fig. 44.4) y antenas (Fig. 44.5) enteramente pardas. Ojos negros, con los 6 estemmata pardos oscuros rodeados de tegumento fuertemente esclerotizado.

Tórax de color crema pálido con escleritos laterodorsales pardos (Fig. 44.1). Tubérculos laterales del protórax muy alargados, portadores de 2 largas setas filiformes, y tubérculos laterales del meso- y metatórax ligeramente alargados, portadores de 3 largas setas (Fig. 44.1). Restantes setas filiformes (Fig. 44.1), hialinas, con base oscura. Metanoto con 4 tubérculos dorsales, portadores de 1 larga seta (Fig. 44.1). Quetotaxia dorsal según Fig. 44.1. Patas pardo pálidas, con uñas ámbar, triangularmente dilatadas en su base (Fig. 44.8).

Abdomen muy globoso, color crema pálido. Tubérculos laterales de los segmentos II-V portadores de 2 setas, una filiforme y dirigida hacia la región ventral, y otra uncinada y recurvada dorsalmente (Fig. 44.1). Tubérculos dorsales portadores de setas uncinadas (Fig. 44.1). Segmentos I-V con tubérculos en los espiráculos, portadores de una 

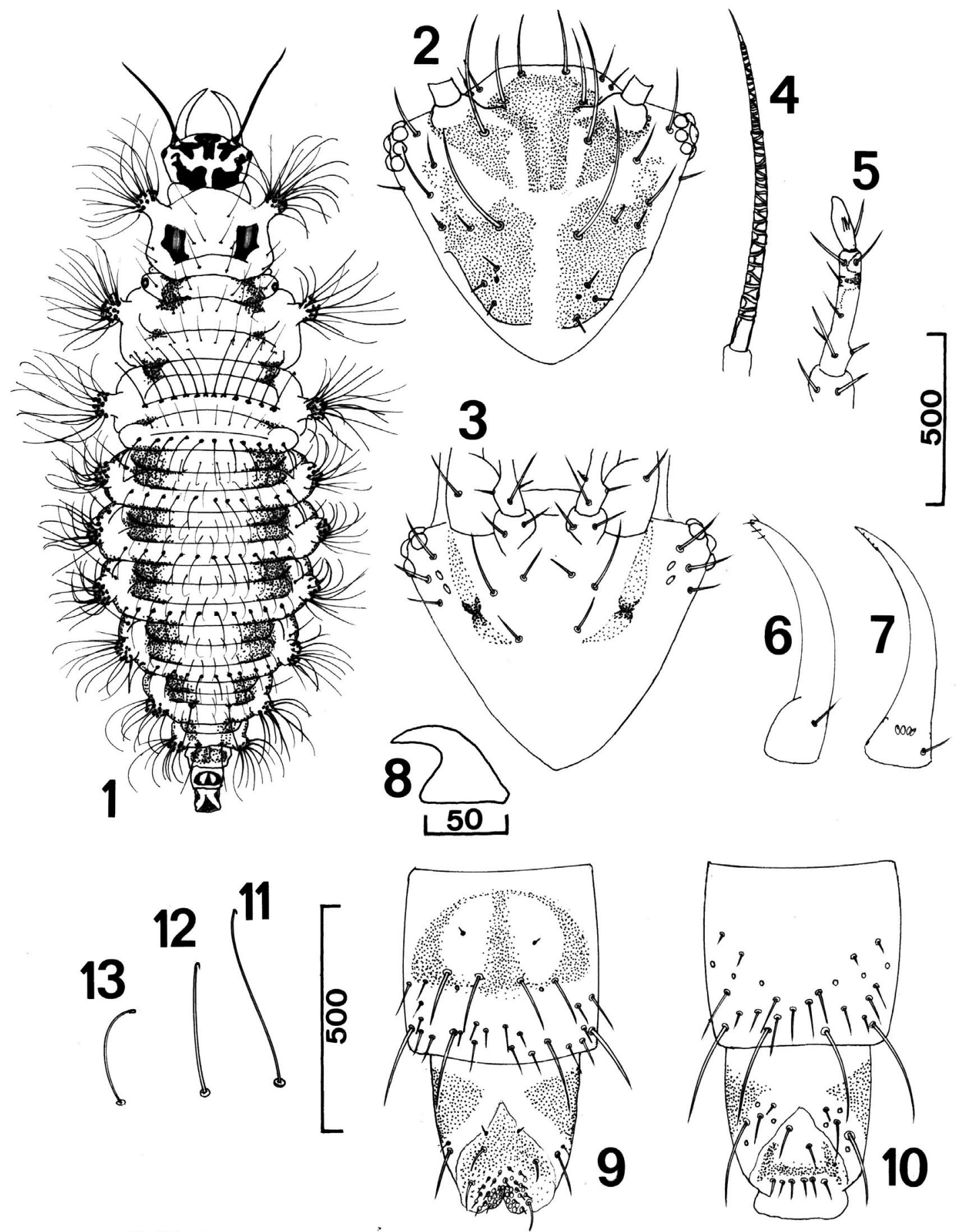

Fig. 41.- Rexa lordina (L-3). 1, Aspecto general (VD). 2, Cápsula cefálica (VD). 3, Ídem (VV). 4, Antena. 5, Palpo labial. 6, Maxila. 7, Mandíbula. 8, Uña. 9, Segmentos abdominales IX-X (VD). 10, Ídem (VV). 11, Seta de los tubérculos laterales. 12, Seta de los segmentos abdominales (hilera posterior). 13, Ídem (hileras anteriores). Escalas en $\mu \mathrm{m}$.

Fig. 41.- Rexa lordina (L-3) (third instar larva). 1, Habitus (DV). 2, Head capsule (DV). 3, Ditto (VV). 4, Antenna. 5, Labial palp. 6, Maxilla. 7, Mandible. 8, Claw. 9, Abdominal segments IX-X (DV). 10, Ditto (VV). 11, Lateral tubercles seta. 12, Abdominal segments seta (posterior row). 13, Ditto (anterior row). Scales in $\mu \mathrm{m}$. 
seta uncinada (Fig. 44.1). Quetotaxia dorsal y ventral de los segmentos IX-X según Figs. 44.9 y 10.

Larva madura (Figs. 44.14-23). Aspecto general según Fig. 44.14. Larvas con coloración blanquecina con manchas pardas y dos sombras longitudinales sobre el dorso recorriendo tórax y abdomen en toda su longitud.

Cabeza crema pálido con manchas frontoclipeal y epicraneal según Fig. 44.15. Manchas genales no alcanzan la cara ventral (Figs. 44.15-16). Maxila (Fig. 44.18) y mandíbula (Fig. 44.17) ámbar. Palpo labial (Fig. 44.19) y antenas (Fig. 44.20) pálidas basalmente y pardas distalmente. Quetotaxia dorsal y ventral de la cápsula cefálica según Figs. 44.1516. Seta cefálica S-12 reducida. Ojos negros, con los 6 estemmata rodeados de tegumento fuertemente esclerotizado.

Tórax blanco con manchas dorsolaterales pardas, escleritos pardos (Fig. 44.14). Tubérculos laterales translúcidos, portadores de setas largas y filiformes (Fig. 44.14). Metanoto con una hilera transversal de 14 setas uncinadas, 7 a cada lado de la línea mediodorsal (Fig. 44.14). Patas de color pardo pálido, con coxa, extremo del tarso y empodio pardo oscuro. Uñas ámbar, triangularmente dilatadas en su base (Fig. 44.23).

Abdomen extremadamente globoso (Fig. 44.14), de color blanco con manchas laterodorsales pardas. Tubérculos laterales de los segmentos II-IV semiesféricos, portadores de numerosas setas filiformes y uncinadas (Fig. 44.14). Terguitos II-VII con numerosas hileras trasversales de setas uncinadas (Fig. 44.14). Segmentos VI-VII con tubérculos laterodorsales portadores de una seta filiforme (Fig. 44.14). Quetotaxia dorsal y ventral de los segmentos IX-X según Fig. 44.21 y 22.

Discusión. Como se ha indicado, las fases juveniles de las otras especies ibéricas: Suarius walsinghami walsinghami y S. tigridis fueron descritas por Díaz-Aranda \& Monserrat (1996), quienes comentan y comparan detalladamente la morfología y la biología de las larvas del género respecto a otros géneros conocidos, por lo que tras lo anotado anteriormente en las características generales, nos limitamos a dar los caracteres diagnósticos para diferenciar las fases larvarias del género Suarius, aportando una clave para la identificación de las larvas de las tres especies ibéricas.

A pesar de la marcada homogeneidad que parecen presentar las larvas estudiadas del género Suarius, un análisis más detallado permite la distin- ción de estas especies en base a la morfología externa de sus estadios larvarios, tanto en L-1 como en L-3. Los caracteres morfológicos externos que diferencian las larvas neonatas son: pigmentación y quetotaxia de la cápsula cefálica (Figs. 42a-b, 44.1), aspecto del esclerito laterodorsal protorácico (Figs. 42.14a-b, 44.1), número de tubérculos (y setas) dorsales del metanoto (Figs. 42.2a-b, 44.1), y número de tubérculos (y setas) dorsales de los segmentos I-V del abdomen (Figs. 42.2a-b, 44.1). Los caracteres que permiten la distinción de las larvas maduras son básicamente los mismos que los utilizados para las larvas neonatas, añadiendo: patrón de coloración torácica y abdominal (Figs. 42.12a-b, 13, 44.14).

\section{Clave para larvas L-1}

1 Metanoto con 4 tubérculos dorsales portadores de largas setas, dos a cada lado de la línea media (Fig. 42.2a). Segmento abdominal VI (Fig. 42.2a) con dos pequeñas sedas mediodorsales entre los tubérculos laterodorsales 2

- Metanoto con 6 tubérculos dorsales portadores de largas setas, tres a cada lado de la línea media (Fig. 42.2b). Segmento abdominal VI (Fig. 42.2b) con dos largas sedas mediodorsales entre los tubérculos laterodorsales S. tigridis

2 Segmentos abdominales II-IV con 24 pequeños tubérculos dorsales (12 a cada lado en tres hileras) (Fig. 44.1). Manchas epicraneales extendidas hacia la base de la antena, conectando con la mancha frontoclipeal (Fig. 44.2)

S. iberiensis

- Segmentos abdominales II-IV con 30 pequeños tubérculos dorsales (15 a cada lado en tres hileras) (Fig. 42a). Manchas epicraneales y la mancha frontoclipeal no unidas en la base de la antena (Fig. 42.4a)

\section{S. walsinghami walsinghami}

\section{Clave para larvas L-3}

1 Longitud de las piezas bucales (mandíbulas-maxilas) superior a la longitud de la cápsula cefálica

S. iberiensis

- Longitud de las piezas bucales (mandíbulas-maxilas) similar al de la cápsula cefálica .................................. 2

2 Manchas epicraneales extendidas hacia la base de las antenas conectando con la mancha frontoclipeal (Fig. 43.1b). Manchas genales extendidas a la cara ventral de la cápsula cefálica, conectando con la mancha ventral (Fig. 43.2b). Escleritos laterodorsales del pronoto trapezoidales con un área pálida central (Fig. 42.14b)

S. tigridis

- Manchas epicraneales no conectadas con la mancha frontoclipeal (Fig. 43.1a). Manchas genales no, o muy ligeramente extendidas a la cara ventral de la cápsula cefálica, no conectadas con la mancha ventral (Fig. 43.2a). Escleritos laterodorsales del pronoto alargados (Fig. 42.14a) S. walsinghami walsinghami 


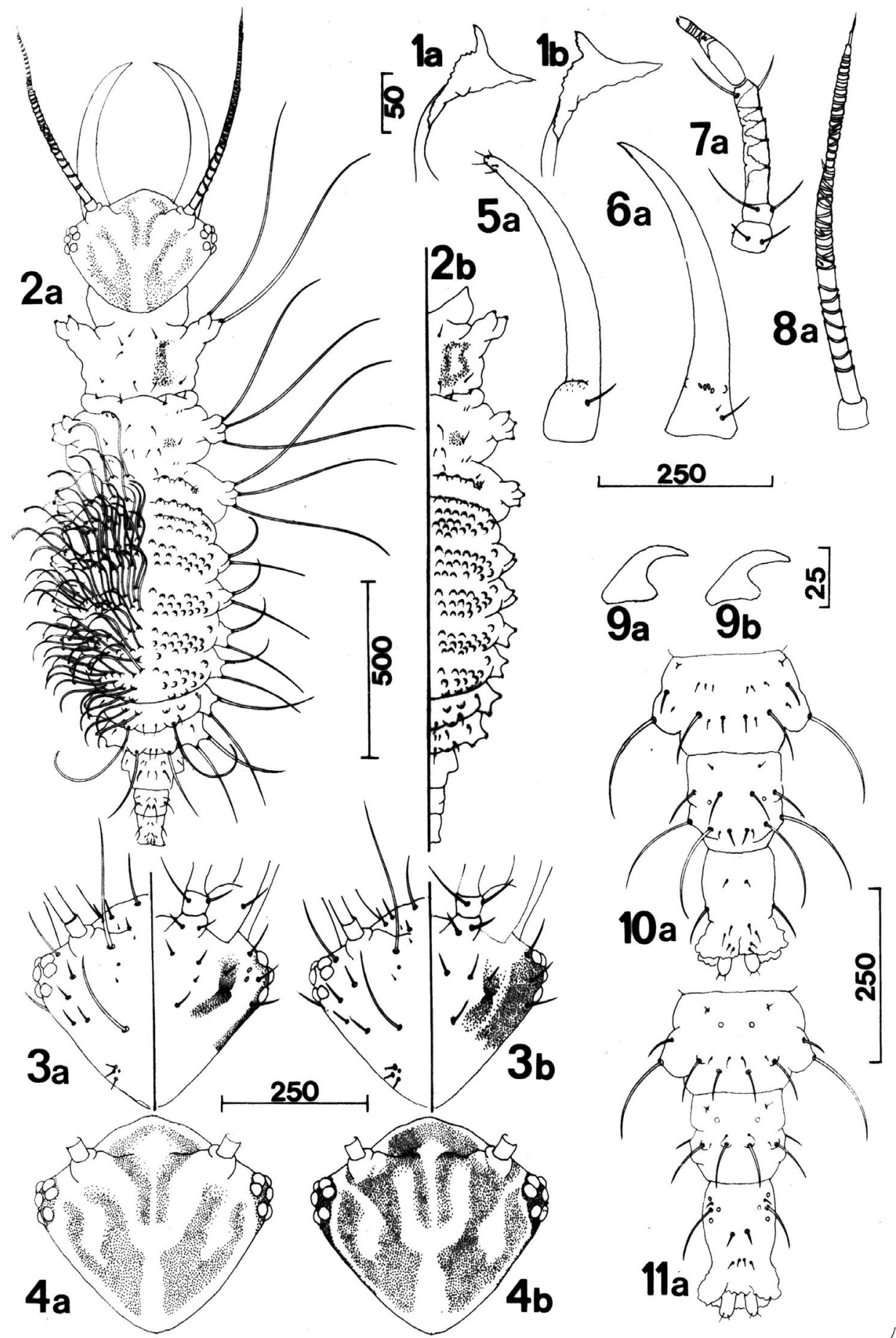

Fig. 42a.- Género Suarius (L-1). a: S. walsinghami. b: S. tigridis. 1, Ovirruptor. 2, Aspecto general (VD). 3, Quetotaxia cefálica (Izda.:VD/ Dcha.:VV). 4, Pigmentación cefálica (VD). 5, Maxila. 6, Mandíbula. 7, Palpo labial. 8, Antena. 9, Uña. 10, Segmentos abdominales VIII-X (VD). 11, Ídem (VV). Escalas en $\mu \mathrm{m}$. Adaptado de Díaz-Aranda \& Monserrat (1996).

Fig. 42a.- Genus Suarius. (L-1). 12-17, a: S. walsinghami. b: S. tigridis. 1, Oviruptor. 2, Habitus (DV). 3, Cephalic chaetotaxy (Left: DV / Right: VV). 4, Cephalic pigmentation (DV). 5, Maxilla. 6, Mandible. 7, Labial palp. 8, Antenna. 9, Claw. 10, Abdominal segments VIII-X (DV). 11, Ditto (VV). Scales in $\mu \mathrm{m}$. Adapted from Díaz-Aranda \& Monserrat (1996). 


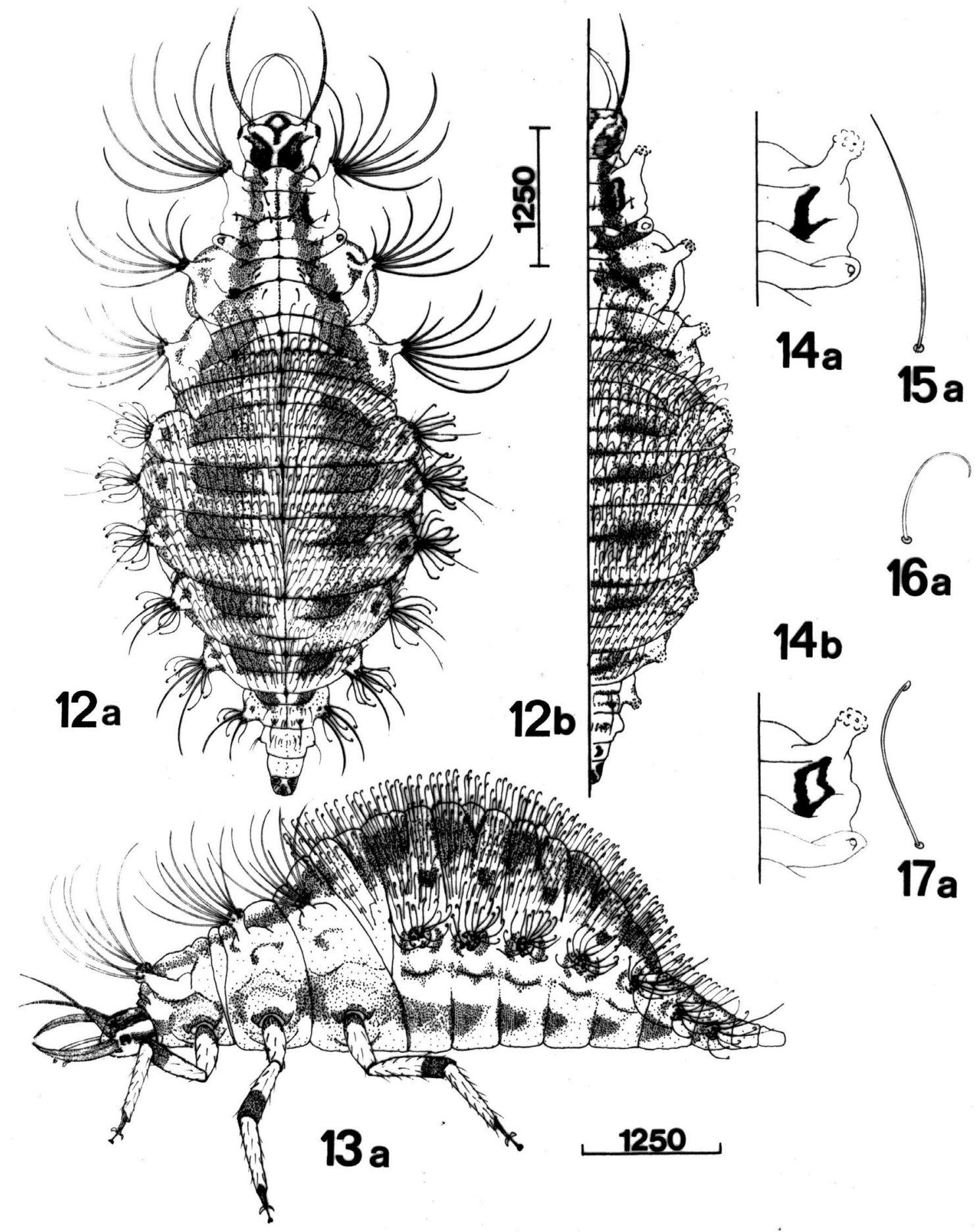

Fig. 42b.- Género Suarius (L-3). a: S. walsinghami. b: S. tigridis. 12, Aspecto general (VD). 13, Ídem (VL). 14, Esclerito latero-dorsal protorácico. 15, Seta filiforme. 16, Seta uncinada. 17, Seta espatulada. Escalas en $\mu$ m. Adaptado de DíazAranda \& Monserrat (1996).

Fig. 42b.- Genus Suarius. (L-3): a: S. walsinghami. b: S. tigridis. 12, Habitus (DV). 13, Ditto (LV). 14, Prothoracic laterodorsal sclerite. 15, Filiform seta. 16, Uncinate seta. 17, Spatulate seta. Scales in $\mu$ m. Adapted from Díaz-Aranda \& Monserrat (1996). 


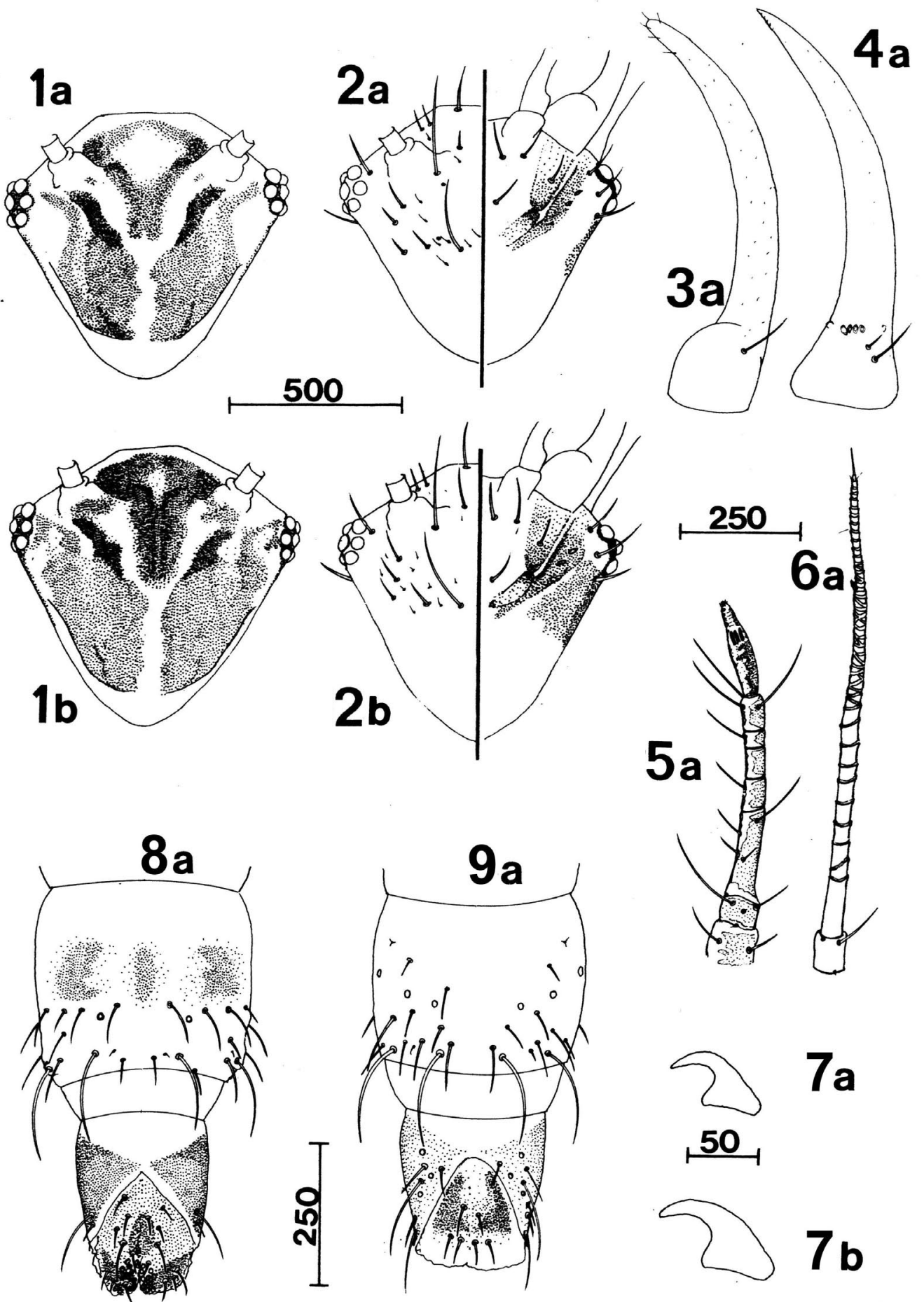

Fig. 43.- Género Suarius (L-3), a: S. walsinghami. b: S. tigridis. 1, Pigmentación cefálica (VD). 2, Quetotaxia cefálica (Izda.: VD/ Dcha.: VV). 3, Maxila. 4, Mandíbula. 5, Palpo labial. 6, Antena. 7, Uña. 8, Segmentos abdominales IX-X (VD), 9, Ídem (VV). Escalas en $\mu \mathrm{m}$. Adaptado de Díaz-Aranda \& Monserrat (1996).

Fig. 43.- Genus Suarius (L-3) (third instar larva), a: S. walsinghami. b: S. tigridis. 1, Cephalic pigmentation (DV). 2, Cephalic chaetotaxy (Left: DV / Right: VV). 3, Maxilla. 4, Mandible. 5, Labial palp. 6, Antenna. 7, Claw. 8, Abdominal segments IX-X (DV), 9, Ditto (VV). Scales in $\mu \mathrm{m}$. Adapted from Díaz-Aranda \& Monserrat (1996). 
BIOLOGÍA Y COMPORTAMIENTO. La biología y comportamiento observados en el desarrollo de $S$. iberiensis es similar al citado para las otras dos especies por Díaz-Aranda \& Monserrat (1996), y anotamos ahora estas similitudes y algunas diferencias. En las tres especies los huevos fueron depositados aisladamente sobre un corto y rígido pedúnculo (Fig. 44.13a). Los lugares elegidos por las hembras para realizar la ovoposición fueron, con frecuencia, el extremo apical de las ramas de Tamarix gallica (Fig. 44.13a), sustrato vegetal añadido a las cajas de cultivo, y en el caso de $S$. iberiensis, no despreciaban la superficie de las tapas de estas cajas y a veces practicaban la puesta de un huevo sobre el pedúnculo de otro previamente depositado (Fig. 44.13a) y su puesta oscilaba entre 20-30 huevos por día.

Todas las larvas presentan una marcada voracidad y actividad durante todo su desarrollo, desplazándose con rápidos movimientos. En sus tres estadios son portadoras de una capa de camuflaje desproporcionadamente grande, que cubre la totalidad del abdomen y la parte posterior del tórax. Dicha capa está fabricada con los restos de las presas succionadas, sus propias exuvias y el tegumento de los áfidos usados en la dieta, con trozos de hojas y con pequeños fragmentos de distintos materiales que encontraban en las cajas de cultivo. Las larvas neonatas de S. iberiensis sometidas a falta de alimento observaron un elevado nivel de canibalismo. En las larvas cultivadas experimentalmente en condiciones ambientales se observó una gran tolerancia a las altas temperaturas $\left(40-42{ }^{\circ} \mathrm{C}\right)$. Este hecho ya fue observado por Canard \& Principi (1984) para S. walsinghami.

La pupa se practica fabricando un capullo esférico que queda recubierto por restos de la capa de camuflaje, y eligen lugares protegidos, como el envés de las hojas o bajo ramitas suministradas.

El tiempo transcurrido en cada uno de los estadios preimaginales, las condiciones de cultivo y las especies de áfidos empleadas en la dieta fueron anotadas para $S$. walsinghami y $S$. tigridis por DíazAranda \& Monserrat (1996), y aquí los anotamos conjuntamente para las tres especies en la siguiente tabla:

CONDICIONES DE CULTIVO $\quad 27^{\circ} \mathrm{C} \quad$ 16L:8D $\quad 60 \%$ H.R.

DURACION DE LOS ESTADIOS PREIMAGINALES (días)

\begin{tabular}{lccccc} 
& $\mathrm{H}$ & L-1 & L-2 & L-3 & P \\
S. walsinghami & 6 & $6-7$ & $7-9$ & $7-10$ & $18-20$ \\
S. tigridis & 6 & $6-7$ & $7-9$ & $7-10$ & $18-20$ \\
S. iberiensis & $6-7$ & $5-6$ & $6-7$ & $7-8$ & $25-30$ \\
ÁFIDOS EMPLEADOS & \multicolumn{5}{c}{ Aphis fabae y Aphis nerii }
\end{tabular}

Ninguna de las tres especies ha sido recolectada sobre cualquiera de las 105 especies vegetales en las que Monserrat \& Marín (1994) basaron su estudio sobre la especificidad de sustrato en los crisópidos ibéricos, lo que demuestra que deben estar vinculadas a otro tipo de vegetación, probablemente baja, leñosa y/o halófila, y poco podemos aportar, ya que sus imagos han sido recolectados siempre en trampas de luz, aunque conocemos ejemplares recolectados con trampas McPhail utilizando como atrayente fosfato amónico 5\% + Bórax sobre Olea europaea, excepcionalmente $S$. tigridis sobre Tamarix africana y $S$. iberiensis sobre Salsola sp., Salsola vermiculata o Ammi majus (Monserrat \& Rodrigo, 1992; Díaz-Aranda \& Monserrat, 1996; Monserrat, 2008, 2010).

DisTRIBUCIÓN GEOGRÁFICA Y ALTITUDINAL, FENOLOGíA. Dos de las tres especies ibéricas del género Suarius habitan en la zona subdesértica del SE peninsular, en zonas costeras y ramblas secas, a veces extendida a zonas aledañas ( $\mathrm{S}^{\mathrm{a}} \mathrm{Nevada}$ ), mientras que $S$. iberiensis se extiende alcanzando zonas gipsícolas, térmicas y xéricas del centro peninsular.

En la Península Ibérica los imagos de $S$. walsinghami son conocidos únicamente de las provincias de Almería y Granada, con rango altitudinal entre 30 y $1750 \mathrm{~m}$, y han sido hallados entre los meses de junio y septiembre. S. tigridis sólo es conocida de Almería con rango altitudinal 10-750 $\mathrm{m}$, y han sido hallados en el mes de julio. Por último $S$. iberiensis es conocida de Murcia, Almería, Toledo y Madrid, con rango altitudinal entre 280$670 \mathrm{~m}$, y han sido hallados entre los meses de mayo-agosto.

Se trata de especies generalmente locales en su distribución, pero a veces poseen poblaciones extremadamente frecuentes, si bien muy temporales. Más información en Monserrat \& Rodrigo (1992); Díaz-Aranda \& Monserrat (1996); Monserrat (2008, 2010).

\section{Género Italochrysa}

El género Italochrysa Principi, 1946, es conocido de las regiones Afrotropical, Oriental, Australiana y sur de la región Paleártica. Incluye hasta el presente unas 75 especies (Brooks \& Barnard, 1990; Aspöck et al., 2001), de las que sólo existe información sobre los estadios preimaginales de I. italica (Rossi, 1790) 

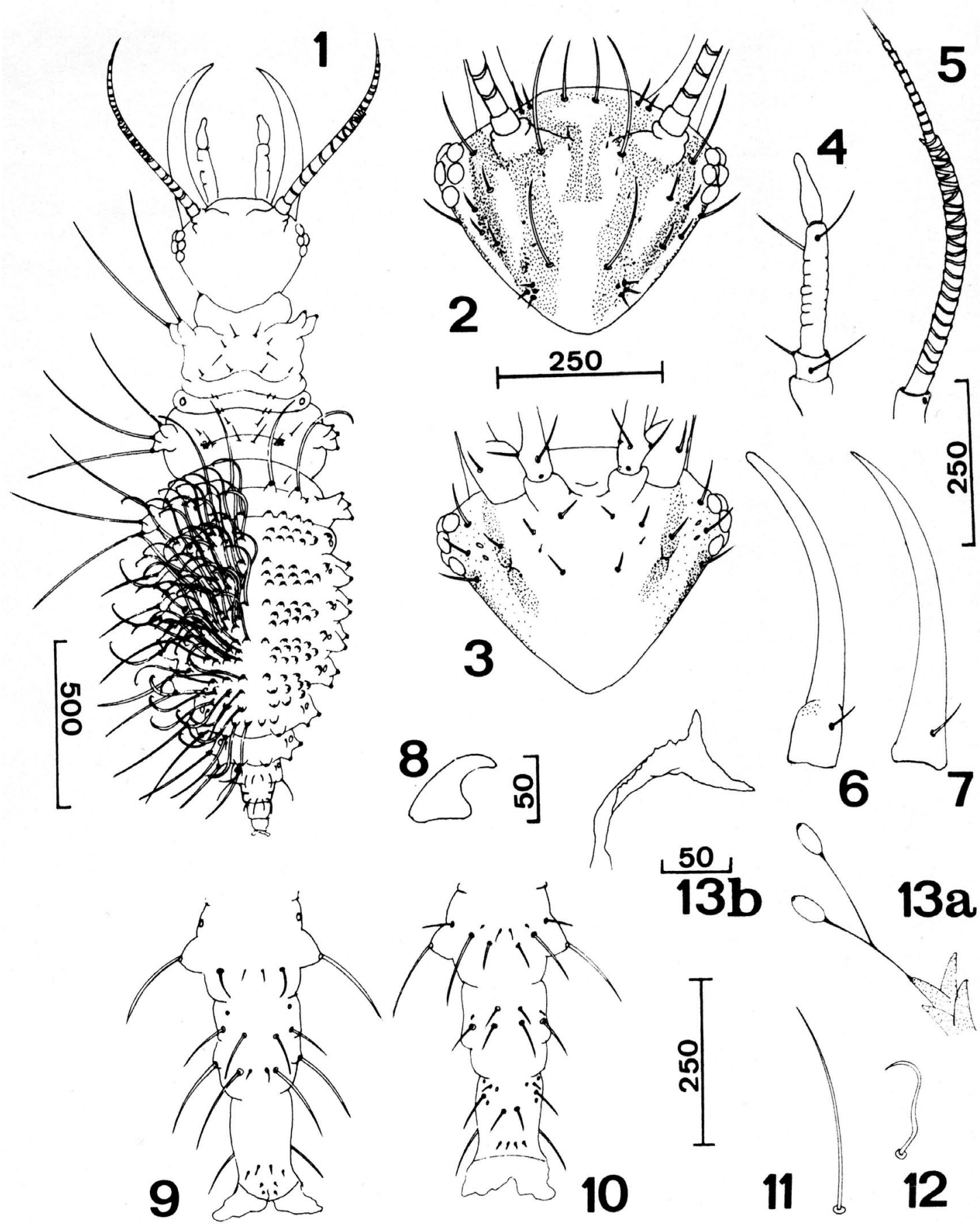

Fig. 44a.- Suarius iberiensis (L-1): 1, Aspecto general (VD). 2, Pigmentación cefálica (VD). 3, Quetotaxia cefálica (VD). 4, Palpo labial. 5, Antena, 6, Maxila. 7, Mandíbula, 8, Uña. 9, Segmentos abdominales VIII-X (VD). 10, Ídem (VV).11, Seta filiforme. 12, Seta uncinada. 13a, Huevos, 13b, Ovirruptor. Escalas en $\mu \mathrm{m}$.

Fig. 44a.- Suarius iberiensis (L-1): 1, Habitus (DV). 2, Cephalic pigmentation (DV). 3, Cephalic chaetotaxy (DV). 4, Labial palp. 5, Antenna, 6, Maxilla. 7, Mandible, 8, Claw. 9, Abdominal segments VIII-X (DV). 10, Ditto (VV). 11, Filiform seta. 12, Uncinate seta. 13a, Eggs, 13b, Oviruptor. Scales in $\mu \mathrm{m}$. 


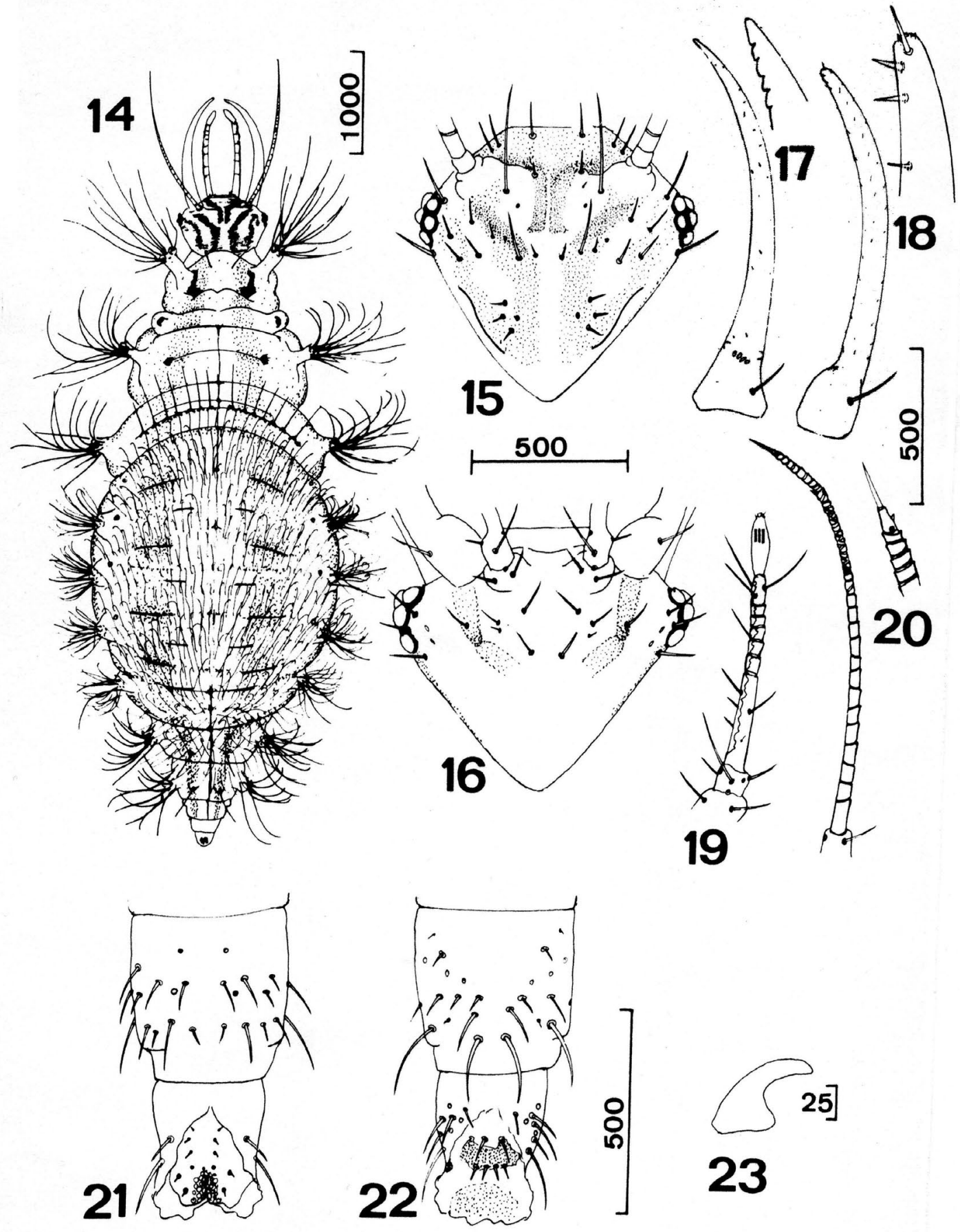

Fig. 44b.- Suarius iberiensis (L-3): 14, Aspecto general (VD). 15, Quetotaxia y pigmentación cefálica (VD). 16, Ídem (VV). 17, Mandíbula. 18, Maxila. 19, Palpo labial. 20, Antena y detalle de su extremo. 21, Segmentos abdominales IX-X (VD), 22, Ídem (VV). 23, Uña. Escalas en $\mu \mathrm{m}$.

Fig. 44b.- Suarius iberiensis (L-3): 14, Habitus (DV). 15, Cephalic chaetotaxy and pigmentation (DV). 16, Ditto (VV). 17, Mandible. 18, Maxilla. 19, Labial palp. 20, Antenna and particular of the tip. 21, Abdominal segments IX-X (DV), 22, ditto (VV). 23, Claw. Scales in $\mu \mathrm{m}$. 
dada por Principi (1946); I. japonica (McLachlan, 1875) por Tsukaguchi (1982), e I. insignis (Walker, 1853) por New (1983), y ahora aportamos los primeros datos del huevo, ovirruptor y larva neonata de I. stigmatica.

En Europa el género está representado por I. italica e I. stigmatica, de marcada distribución mediterránea expansiva hacia Arabia, Irán e Irak, incluyendo la Península Ibérica, donde se conocen ambas especies. Como se ha indicado, de la primera son conocidas sus fases juveniles, biología y comportamiento (Principi, 1946), y ahora aportamos datos sobre la segunda, ampliando con ello la escasa información existente sobre la morfología de los estadios preimaginales en este género, así mismo, actualizamos los registros ibéricos de ambas especies.

\section{Material utilizado.}

\section{Italochrysa stigmatica}

Hembras grávidas: España, Almería, Rambla de Tabernas, 11.VII.1985 a la luz, Ricaveral, 28.VI.1983 sobre Stipa tenacissima. Jaén, Bedmar, 17.VII.1990, recolectada a la luz.

\section{ESTADIOS LARVARIOS}

Características generales: (L-1: Figs. 45.1-13).

Larvas portadoras de capa de camuflaje. 45.2).

Tórax y abdomen fuertemente convexos (Fig.

Mandíbulas-maxilas de longitud notablemente menor que la cápsula cefálica, y bruscamente estrechadas en su ápice (Figs. 45.2, 5, 6).

Setas cefálicas muy gruesas, denticuladas (Figs. $45.3,4,13)$.

Tubérculos laterales del tórax palmeados, y junto a los del abdomen portadores de setas denticuladas (Fig. 45.2).

Meso- y metatórax cubiertos dorsalmente por numerosas hileras transversales de finas setas uncinadas (Fig. 45.2).

Segmentos abdominales I-VI cubiertos dorsalmente por numerosas hileras transversales de finas setas uncinadas (Fig. 45.2).

Antenas muy robustas (Figs. 45.2, 8), con último segmento según Fig. 45.9.

De la larva neonata (Figs. 45.1-13).

Tubérculos laterales del tórax portadores de 8 a 10 setas denticuladas (Fig. 45.2).

Tubérculos laterales del abdomen portadores de 2 setas denticuladas (Fig. 45.2).

De la larva madura (ver Principi, 1946).

Tubérculos laterales del tórax palmeados, portadores de 16 a 18 setas denticuladas.
Tubérculos laterales del abdomen portadores de 10 setas denticuladas.

Como ya se mencionó anteriormente, el huevo y la larva madura de Italochrysa italica (Rossi, 1790) y su sorprendente biología, han sido detalladamente descritos por Principi (1946). En el presente estudio no hemos conseguido que las hembras grávidas recolectadas depositaran huevos a partir de los cuales poder iniciar los cultivos. No así de I. stigmati$c a$, aunque lamentablemente, nos ha sido imposible llevar a término el desarrollo de su larva, motivo por el que sólo procedemos a la descripción del huevo, ovirruptor y larva neonata.

ESTADIOS PREIMAGINALES DE ITALOCHRYSA STIGMATICA

Huevo. Posee los polos afilados, adquiriendo aspecto de uso. Son huevos pedunculados, de color blanco-grisáceo. Las dimensiones del huevo oscilan entre 2 y $2,5 \mathrm{~mm}$ y las del pedúnculo entre 10 y $15 \mathrm{~mm}$ (Fig. 1.2).

Ovirruptor. El ovirruptor, ligeramente esclerotizado, presenta denticulación según Fig. 45.1.

Larva neonata. Aspecto general según Fig. 45.2. Cápsula cefálica (Figs. 45.3,4) sinuosa en su margen posterior. Manchas cefálicas pardo rojizas muy poco marcadas, apenas visibles. Setas cefálicas muy gruesas y denticuladas (Fig. 45.13), dispuestas según Fig. 45.3, 4. Mandíbulas (Fig. 45.5) y maxilas (Fig. 45.6) de longitud notablemente inferior a la de la cápsula cefálica, bruscamente estrechadas en su ápice. Mandíbulas portadoras, en el margen externo de su porción basal, de 2 setas denticuladas (Fig. 45. 5). Labro trilobulado anteriormente (Fig. 45.3). Palpos labiales según Fig. 45.7, con el segundo segmento carente de anulaciones secundarias. Antenas (Fig. 45.8) relativamente cortas y gruesas, con el último segmento según Fig. 45.9. Ojos negros formados por 6 estemmata, dispuestos según Fig. 45.3, 4.

Tórax con tubérculos laterales palmeados, dirigidos hacia la región cefálica y portadores de 8 setas pálidas en el protórax y de 8 a 10 setas en meso- y metatórax (Fig. 45.2), todas ellas denticuladas y romas (Fig. 45.13). Pronoto con escasas y pequeñas setas dorsales. Meso- y metanoto enteramente cubiertos por hileras transversales de numerosas setas pálidas y uncinadas (Fig. 45.2). Patas cubiertas por setas denticuladas. Uñas muy estrechas (Fig. 45. 10).

Abdomen amarillento. Segmentos abdominales II-VII con tubérculos laterales portadores de 2 setas 


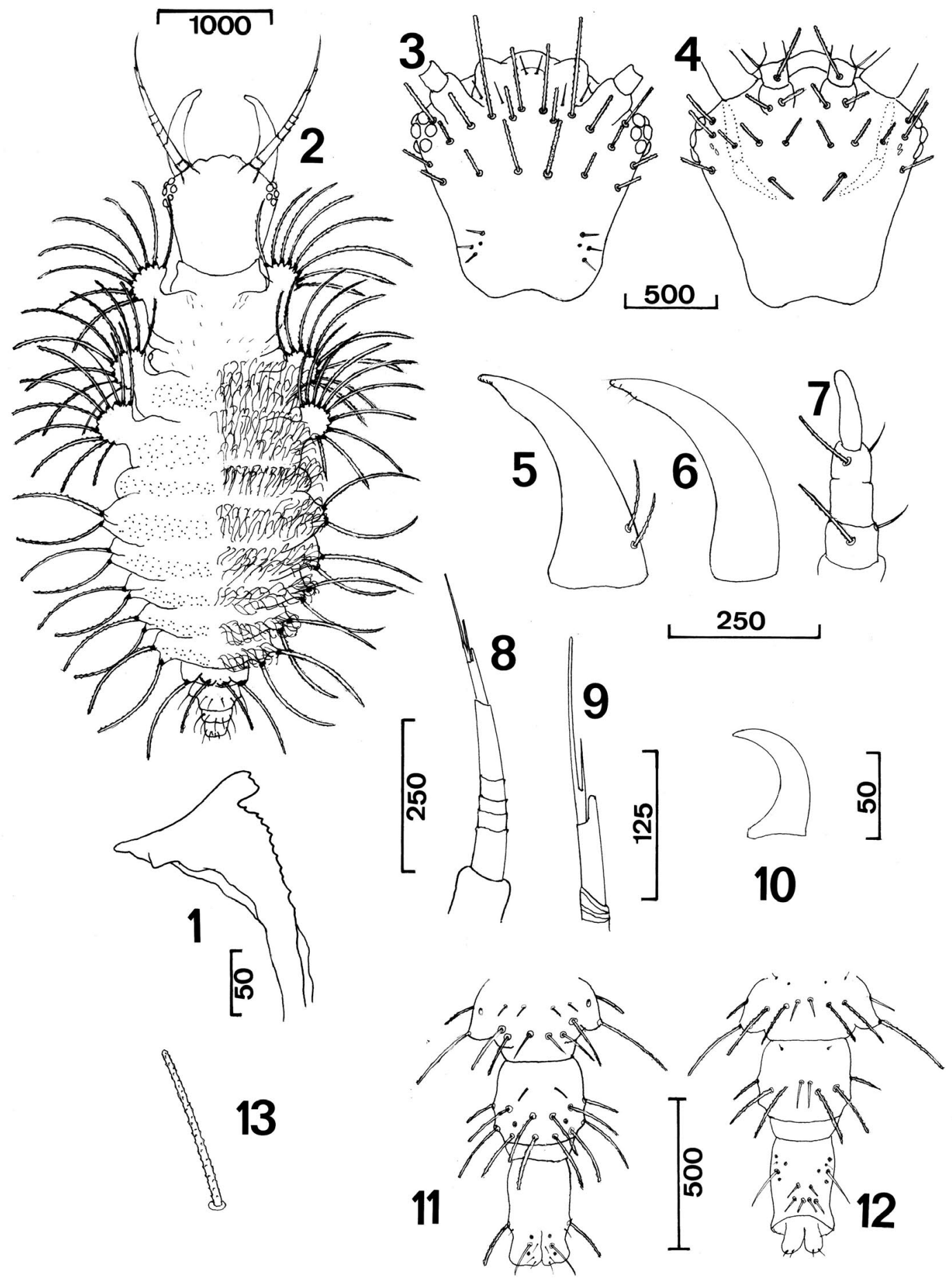

Fig. 45.- Italochrysa stigmatica (L-1). 1, Oviruptor, 2, Habitus (VD). 3, Cápsula cefálica (VD). 4, Ídem (VV). 5, Mandíbula. 6, Maxila. 7, Palpo labial. 8, Antena. 9, Detalle del último segmento antenal. 10, Uña. 11, Segmentos abdominales VIII-X (VD). 12, Ídem (VV). 13, Seta denticulada. Escalas en $\mu$ m.

Fig. 45.- Italochrysa stigmatica (L-1) (first instar larva). 1, Oviruptor, 2, Habitus (DV). 3, Head capsule (DV). 4, Ditto (VV). 5, Mandible. 6, Maxilla. 7, labial palp. 8, Antenna. 9, Detail of the last antennal segment. 10, Claw. 11, Abdominal segments VIII-X (DV). 12, Ditto (VV). 13, Denticulate seta. Scales in $\mu \mathrm{m}$. 
denticuladas (Fig. 45.2). Terguitos de los segmentos I-VI enteramente cubiertos por numerosas setas uncinadas (Fig. 45.2). Quetotaxia dorsal y ventral de los segmentos VIII-X según Fig. 45.11 y 45.12 respectivamente.

Discusión. Los estadios preimaginales (huevo y neonatos) de $I$. stigmatica presentan acusadas semejanzas con los descritos en otras especies de este género.

Entre los caracteres morfológicos analizados, cabe resaltar en primer lugar, la morfología del huevo, descrito en I. italica (Rossi, 1790) por Principi (1946), I. japonica (McLachlan, 1875) por Tsukaguchi (1982) e I. insignis (Walker, 1853) por New (1983), que como lo anotado ahora para $I$. stigmatica, es básicamente la misma, ya que en todos los casos son huevos con los polos afilados, tomando aspecto de uso y con un micropilo muy prominente (Fig. 1.2).

En segundo lugar, la larva neonata es muy similar a la de Italochrysa insignis, descrita por New (1983). Estas especies comparten una serie de caracteres morfológicos que, a su vez, no han sido observados en ninguna de las larvas neonatas, descritas hasta ahora, de esta familia. Tales caracteres son: Tubérculos laterales del tórax palmeados, portadores de 8-10 setas denticuladas (Fig. 45.2), mientras que en las larvas L-1 de las otras especies de Chrysopidae, generalmente los tubérculos laterales del pro- meso- y metatórax son portadores de 2, 3 y 3 setas respectivamente. Meso- y metanoto enteramente cubiertos por numerosas setas uncinadas (Fig. 45.2), mientras que lo general en las larvas L-1, en el meso- y metatórax aparecen, como mucho, una hilera transversal de largas setas, en cualquier caso, nunca uncinadas. Segmentos abdominales I-VI, al igual que en el caso anterior, densamente cubiertos por setas uncinadas (Fig. 45.2). Las larvas L-1 de otras especies portadoras de capa de camuflaje poseen pequeños tubérculos portadores de setas uncinadas, en número muy inferior al que aparecen en esta especie y nunca formando hileras transversales.

Otros muchos caracteres, estudiados en las larvas neonatas, aparecen también en la larva madura de I. italica, descrita por Principi (1946) y que habrá que suponerlos en las fases maduras de $I$. stigmatica. Estos son: mandíbulas y maxilas bruscamente estrechadas en su ápice y de longitud considerablemente menor a la de la cápsula cefálica. Ultimo segmento antenal (Fig. 45.9), portador de una seta de longitud varias veces mayor a la de ese mismo segmento. Quetotaxia cefálica (Figs. 45.3 y 45.4) constituida por setas relativamente largas, gruesas y denticuladas. Tubérculos laterales del tórax y abdomen portadores de setas denticuladas (Fig. 45.2). Meso-, metanoto densamente cubiertos por setas uncinadas (Fig. 45.2). Desconocemos si estas setas, romas y mucho más escasas en neonatas de I. stigmatica y apuntadas y mucho más numerosas en las larvas maduras de I. italica (Principi, 1946) obedece a diferencias entre especies o estadios.

Todos los caracteres hasta ahora mencionados, tanto para el huevo como para las larvas de Italochrysa, aparecen también en Calochrysa extranea (Esben-Petersen, 1917), especie también perteneciente a la tribu Belonopterygini, y de la que New (1986b) describe el huevo, ovirruptor y larva neonata. La marcada uniformidad existente, en los estadios preimaginales de las especies de esta tribu, nos hace pensar que, al menos, algunos de los caracteres mencionados, puedan ser útiles para definir dicha tribu. En todo caso, ello será analizado en la discusión general de este trabajo.

Con los datos ahora aportados, y ya que no conocemos aún las larvas maduras de I. stigmatica, ni hay datos descritos sobre las neonatas de I. itali$c a$, no podemos realizar una clave para las especies, y simplemente hemos anotado algunas diferencias (aspecto y número de las setas de los tubérculos torácicos y abdominales) sin conocer si son diferencias por pertenecer a especies distintas o por tomarse en estadios diferentes.

BIOLOGÍA Y COMPORTAMIENTO. Las puestas observadas estaban formadas por 5-12 huevos (desconocemos si hubo posiciones previas), puestos aislados y espaciados, en dos días consecutivos. Las puestas se practicaron en el envés de las hojas de gramíneas proporcionadas, colgando bajo la tapa de la caja de cultivo o sobre sus paredes laterales. El desarrollo embrionario osciló entre 9-10, según las puestas (Principi, 1946 anota 7-8 días para I. italica). Las larvas neonatas tras la eclosión permanecen un tiempo (1-4 h) sobre el corion con la cabeza hacia el pedúnculo y posteriormente inician una gran actividad, caminan, desprecian potenciales presas y ayudándose con las mandíbulas y arqueando la cabeza, se colocan abundantes restos sobre el dorso, incluso algún corion abandonado separado del pedúnculo. Los movimientos del abdomen hacia los lados y arqueándolo hacia la línea media ventral provoca la 
oscilación de las setas dorsales, favoreciendo el anclaje de las partículas empleadas en su camuflaje (Principi, 1946 anota similar comportamiento para I. italica). Conocemos que las larvas de I. italica están asociadas a hormigueros de Crematogaster scutellaris (Olivier, 1791), presentan capa de camuflaje y el periodo de tiempo empleado para completar su ciclo de desarrollo es de aproximadamente un año (Principi, 1946), que debe suponerse similar en I. stigmatica, aunque se deduce entre ambas especies ciertas diferencias en el sustrato y modo elegido para realizar las puestas o el color de los huevos. Más información sobre la biología de las especies de este género puede ser recabada en Principi (1946), Tsukaguchi (1982) y New (1983).

En cuanto a este citado tipo de asociación, Principi (1946) anota que la larva de I. italica preda exclusivamente sobre larvas y pupas de Crematogaster scutellaris, y New (1983, 1986 b) también anota hábitos mirmecófilos para las larvas por él descritas, indicando, ambos autores, que este tipo de hábitos, posiblemente, sea común en las especies de esta tribu, hecho que parece sugerir los datos existentes sobre dicha tribu, aunque la información en la actualidad sea muy escasa y poco representativa, ya que concierne sólo a tres de los 14 géneros: Calochrysa Banks, 1943 (New, 1986b), Italochrysa Principi, 1946 (Principi, 1946; New, 1983; Tsukaguchi, 1982) y Nacarina Navás, 1915 (Weber, 1942) quien asocia la larva de $N$. valida (Erichson, 1848) con hormigas de Camponotus abdominalis (Fabricius, 1781). Nosotros hemos intentado en alguna ocasión proporcionar a la larva neonata larvas de hormigas por las que no prestaron el más mínimo interés (similar a lo anotado por Principi, 1946).

Como se indicó anteriormente, no hemos podido llevar a término el desarrollo de la larva de esta especie, motivo por el cual no aportamos datos sobre la biología y comportamiento de sus larvas, aunque es de esperar que posea una biología similar (sin competir) a la de otras especies del género.

En la Península Ibérica, ambas especies están asociadas a medios marcadamente mediterráneos, habiéndose citado I. italica sobre Pinus halepensis, $P$. pinaster, Quercus rotundifolia, $Q$. faginea, $Q$. pyrenaica, Ulmus minor, Olea europaea y Eucaliptus globulus, pero sobre todo sobre $Q$. rotundifolia y Ceratonia siliqua, e I. stigmatica mayoritariamente sobre gramíneas, especialmente Stipa tenacissima, también está citada sobre Vicia peregrina y Retama sphaerocarpa (Monserrat \& Díaz-Aranda, 1989; Monserrat \& Rodrigo, 1992; Monserrat \& Marín, 1994; Monserrat, 2008).

DiSTRIBUCIÓN GEOGRÁFICA Y ALTITUDINAL, FENOLOGÍA. En cuanto a la distribución geográfica de las especies del género en la Península Ibérica, I. italica se encuentra ampliamente distribuida en la región de influencia mediterránea y, sin embargo, $I$. stigmatica parece estar más relegada a zonas más litorales, xéricas y térmicas.

Los imagos de I. italica son conocidos en la Península Ibérica de las provincias de Albacete, Alicante, Almería, Barcelona, Cáceres, Cádiz, Castellón, Granada, Córdoba, Cuenca, Guadalajara, Huesca, Jaén, Lérida, Madrid, Tarragoza, Teruel, Toledo, Valencia, y Zaragoza y Baleares (Mallorca) en Estaña, y Beira Alta y Estremadura en Portugal, y los de I. stigmatica de Alicante, Almería, Castellón, Granada, Huesca, Madrid, Murcia, Málaga, Jaén, Tarragona, Valencia y Baleares (Ibiza, Mallorca). Su rango altitudinal oscila entre $10-2000 \mathrm{~m}$ para la primera y de 15-1300 m para la segunda, y han sido hallados entre los meses de junio y septiembre los de I. italica, y de mayo-octubre para I. stigmatica.

\section{Género Nothochrysa}

El género Nothochrysa McLachlan, 1868, incluye en la actualidad 4 especies, dos de las cuales: $N$. capitata (Fabricius, 1793) y N. fulviceps (Stephens, 1836) presentan una distribución paleártica occidental-mediterránea, y otras dos especies son conocidas de Estados Unidos (California) y China (Brooks \& Barnard, 1990; Aspöck et al., 2001). La morfología larvaria del género es conocida en tres especies. Toschi (1965) describe en detalle los estadios preimaginales de N. californica y Withycombe (1923), Killington (1937), Kimmins (1939) y Gepp (1983, 1989) lo hacen, de forma mucho más superficial, para $N$. capitata. Killington $(1935,1937)$ describe la larva neonata de $N$. fulviceps, y Gepp (1983, 1984b, 1989) aporta datos sobre la morfología de la larva madura, basándose casi exclusivamente en la coloración de las mismas, pero Gepp (1983) realiza una asignación errónea de las larvas de las dos especies paleárticas, ya que considera a la larva de $N$. capitata como perteneciente a $N$. fulviceps y viceversa, no coincidiendo con lo aportado en las descripciones de los autores anteriormente mencionados, ni con lo ahora observado por nosotros. 
En Europa, y dentro de ella en la Península Ibérica, este género está representado por las dos primeras especies citadas, de las que realizamos la descripción de sus larvas maduras, aportando datos nuevos sobre su morfología.

\section{Material utilizado.}

\section{Notochrysa capitata}

Durante los muestreos que hemos realizado hasta ahora no se han capturado hembras grávidas de esta especie, o si lo estaban, no efectuaron puesta, por lo que no podemos realizar la descripción del huevo, ovirruptor y larva L-1, y sólo se realiza la descripción de la larva madura basándonos en las larvas que a continuación se detallan:

España, Barcelona, St. Marçal, 7.VII.1989, sobre Quercus robur, J.A. Barrientos. Huesca, Embalse de Paso Nuevo, 2.VIII.1989, sobre Abies alba, V.J. Monserrat. Italia, Pistoia, El Abetone, 5.IX.1991, sobre Fagus sylvatica, A. Baz leg.

\section{Nothochrysa fulviceps}

Las puestas obtenidas a partir de hembras grávidas no prosperaron en ningún caso, por lo que se describe únicamente el huevo y la larva madura basada en los ejemplares recolectados por nosotros e indicados a continuación:

Hembras grávidas: España, Guadalajara, Orihuela del Tremedal, 1.VIII.1988, sobre Quercus pyrenaica. Lérida, Mirador la Traba, 1.VIII.1991, sobre $Q$. faginea.

Larvas: España, Guadalajara, Orihuela del Tremedal, 30.VIII.1989, sobre $Q$. pyrenaica, La Huerce, 9.X.1984, sobre $Q$. pyrenaica. Lérida, Mirador la Traba, 21.IX.1991, sobre $Q$. faginea. Madrid, La Hiruela, 25.IX.1984, sobre Q. pyrenaica, Montejo de la Sierra, 30.IX.1989, sobre F. sylvatica.

\section{ESTADIOS LARVARIOS}

Características generales: (Figs. 46.1-6, 47.1-12).

Larvas generalmente portadoras de capa de camuflaje, estando formada, en la mayoría de los casos, por grandes partículas y elementos de diversa naturaleza.

Larvas de tamaño grande (10-12 $\mathrm{mm})$ con cuerpo fusiforme y abdomen muy ligeramente globoso (Figs. 46.1, 5).

Manchas cefálicas muy patentes, ocupando prácticamente toda la superficie cefálica dorsal (Figs. 46.1, 5, 47.2, 8).

Antenas con el tercer segmento muy corto (Figs. 46.1, 5, 47.6, 12).

Piezas bucales notablemente más largas que la cápsula cefálica (Figs. 46.1, 5).

Tórax con tubérculos laterales poco desarrollados, portadores de 1-2 o escasas setas (Figs. 46.1, 5).

Metanoto con una hilera transversal de setas (Figs. 46.1, 5).

Patas muy largas en relación al tamaño del cuerpo (Figs. 46.1, 5).

Segmentos abdominales II-VII con tubérculos laterales bien desarrollados, semiesféricos, portadores de setas filiformes y uncinadas (Figs. 46.1, 5).
Segmentos abdominales I-VII con hileras dorsotransversales de setas uncinadas (Figs. 46.1, 5).

Segmentos abdominales V-VII con dos pequeños tubérculos laterodorsales portadores de 1 seta filiforme (Figs. 46.1, 5).

\section{ESTADIOS LARVARIOS DE NOTOCHRYSA CAPITATA}

Descripción de la larva madura (Figs. 46.1, 47.1-6).

Aspecto general según Fig. 46.1. Larvas de color pardo oscuro con los tubérculos laterales del tórax anaranjados.

Cabeza de color pardo con manchas cefálicas pardo oscuras. Mancha frontoclipeal dividida transversalmente a nivel de las fosetas pretentoriales, estando la mancha inferior, a su vez, dividida longitudinalmente (Fig. 47.2). Manchas epicraneales ligeramente bifurcadas en su parte anterior (Fig. 47.2). Existe además una mancha parda rodeando la cara externa de las elevaciones donde quedan insertadas las antenas (Fig. 47.2). Manchas genales fuertemente extendidas a la cara ventral de la cápsula cefálica (Fig. 47.1). Cardo, estipe y labio fuertemente pigmentados (Fig. 47.1). Quetotaxia dorsal y ventral de la cápsula cefálica según Fig. 47.1. Seta S-12 presente. Palpo labial de color pardo pálido, con el último segmento pardo más oscuro, portador de numerosas sensilas en su cara externa (Fig. 47.3). Maxilas (Fig. 47.4) y mandíbulas (Fig. 47.5) de color ámbar, ambas con 2 setas basales. Antenas (Fig. 47.6) pardo amarillento basalmente, y pardo oscuro distalmente, con último segmento muy corto y con numerosas setas en su segmento basal. Ojos negros, formados por 6 estemmata dispuestos según Fig. 47.1.

Tórax de color pardo oscuro con los tubérculos laterales de color naranja o rojizo, y la inserción de las setas dorsales de color crema o pardo pálido. Pronoto con escleritos laterodorsales de aspecto triangular y esclerito submedial más o menos circular, dividido longitudinalmente (Fig. 46.1). Meso- y metanoto con escleritos laterodorsales esféricos (Fig. 46.1). Tubérculos laterales muy poco desarrollados, portadores de 1 seta en el protórax y de 2 setas en meso- y metatórax (Fig. 46.1). Quetotaxia dorsal del tórax según Fig. 46.1. Todas las setas torácicas son filiformes y negras (Fig. 46.1). Patas de color crema con una mancha parda en el extremo distal del fémur y extremo proximal de la tibia. Pretarso y empodio de color pardo oscuro. Uñas de color ámbar, triangularmente dilatadas en su base (Fig. 46.2). 

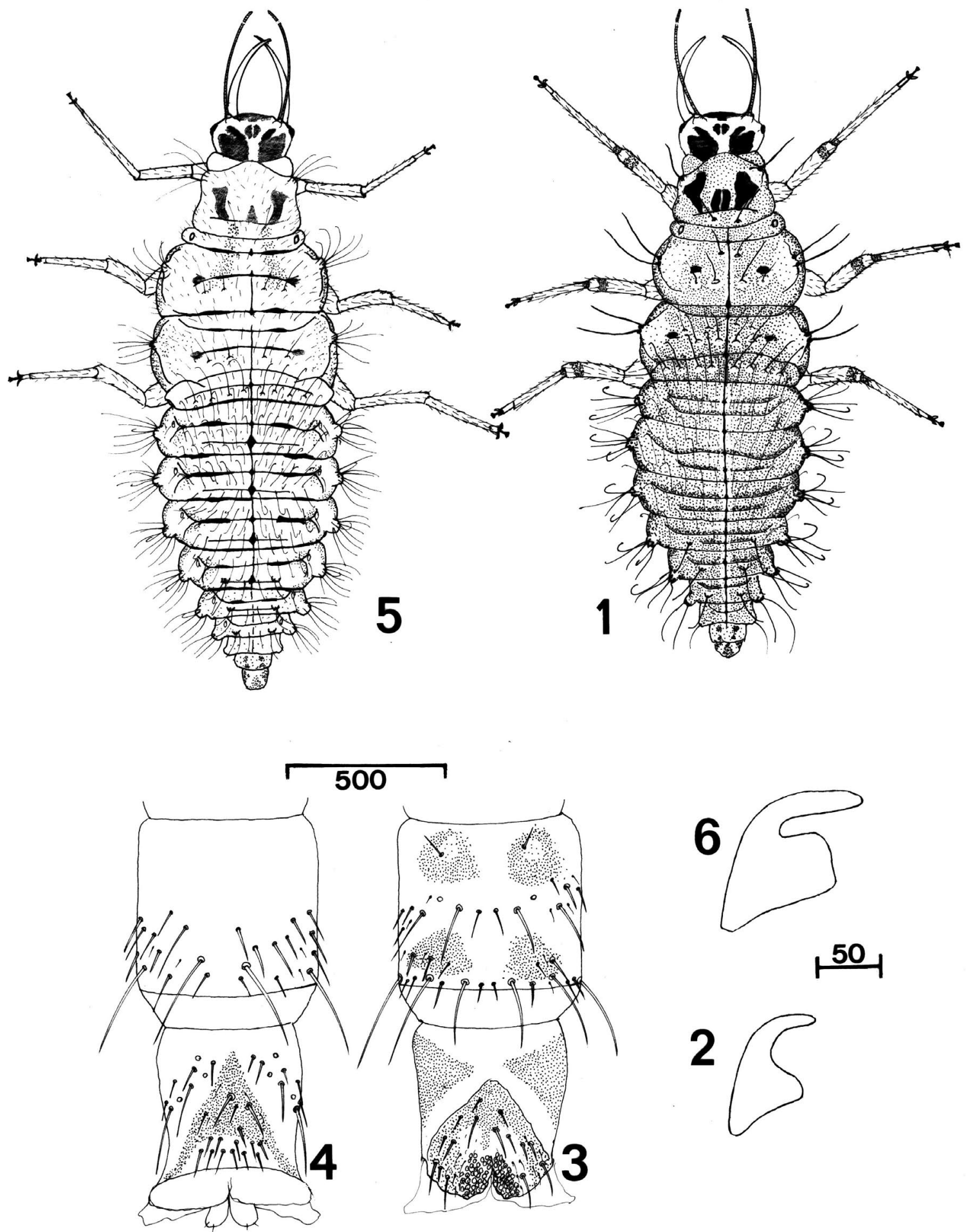

50

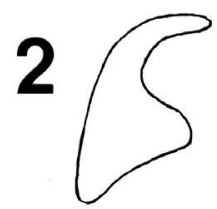

Fig. 46.- Género Nothochrysa (L-3). 1-4: N. capitata, 1, Aspecto general (VD). 2, Uña. 3, Segmentos abdominales IX-X (VD). 4, Ídem (VV). 5-6: N. fulviceps, 5, Aspecto general (VD). 6, Uña. Escalas en $\mu \mathrm{m}$.

Fig. 46.- Género Nothochrysa (L-3) (third instar larva). 1-4: N. capitata, 1, Habitus (DV). 2, Claw. 3, Abdominal segments IX-X (DV). 4, Ditto (VV). 5-6: N. fulviceps, 5, Habitus (DV). 6, Claw. Scales in $\mu \mathrm{m}$. 

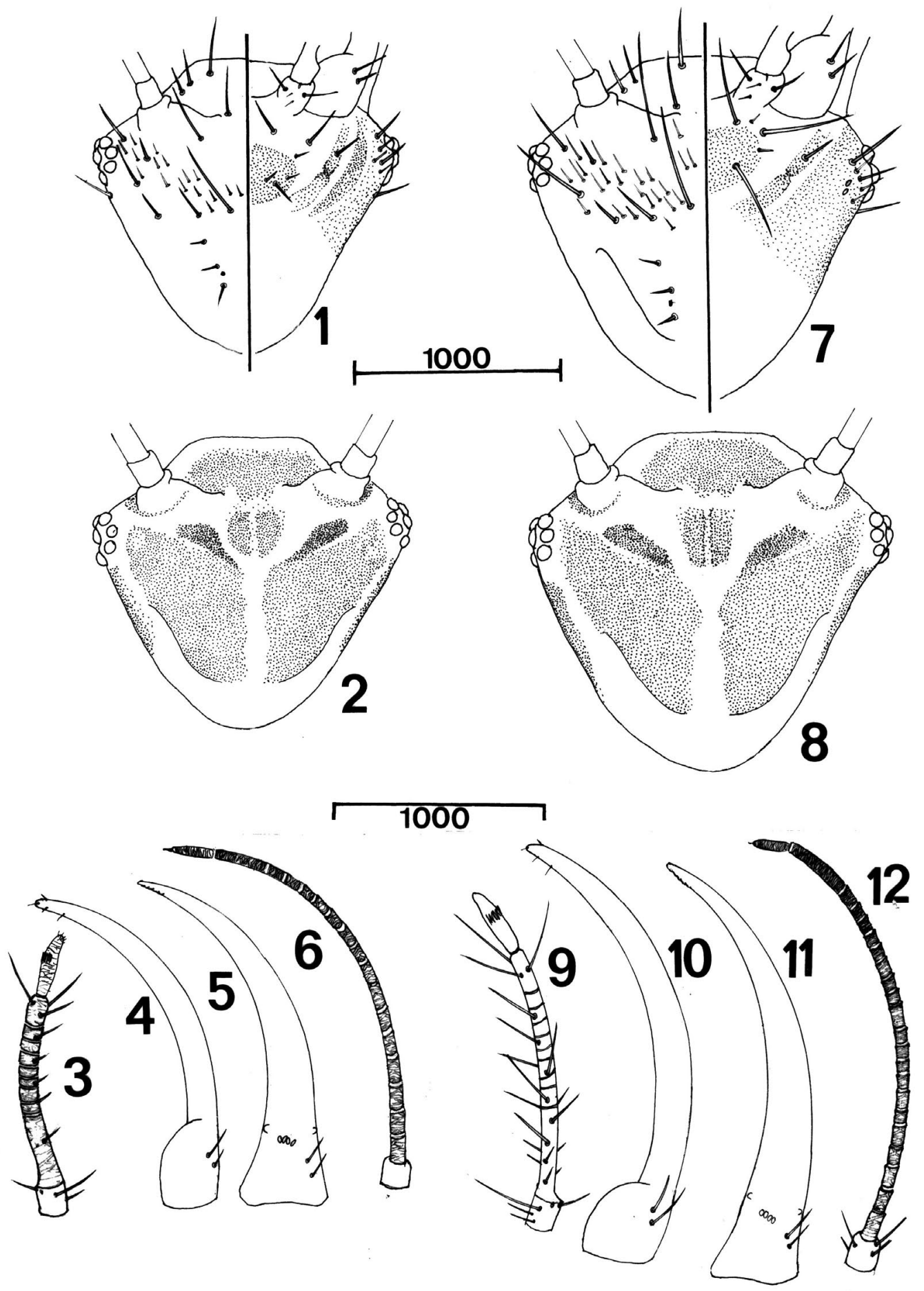

Fig. 47.- Género Nothochrysa (L-3). 1-6: N. capitata. 7-12: N. fulviceps. 1 y 7: Quetotaxia cefálica (Izda.:VD/ Dcha.:VV). 2 y 8: Pigmentación cefálica (VD). 3 y 9: Palpo labial. 4 y 10: Maxila. 5 y 11: Mandibula. 6 y 12: Antena. Escalas en $\mu$ m.

Fig. 47.- Género Nothochrysa (L-3) (third instar larva). 1-6: N. capitata. 7-12: N. fulviceps. 1 and 7: Cephalic chaetotaxy (Left:DV/ Right:VV). 2 and 8: Cephalic pigmentation (DV). 3 and 9: Labial palp. 4 and 10: Maxilla. 5 and 11: Mandible. 6 and 12: Antenna. Scales in $\mu \mathrm{m}$. 
Abdomen muy ligeramente abombado, casi aplanado dorsoventralmente, de color pardo oscuro en su totalidad, exceptuando los lugares de inserción de las setas dorsales, que aparecen de color pardo pálido. Segmentos abdominales II-VII con tubérculos laterales bien desarrollados, portadores de setas filiformes y uncinadas (Fig. 46.1). Segmento I con una hilera transversal de 8 setas filiformes (Fig. 46.1). Segmentos II-VI con hileras transversales de setas uncinadas (Fig. 46.1). Segmentos V-VII con dos pequeños tubérculos laterodorsales portadores de 1 seta filiforme (Fig. 46.1). Quetotaxia y pigmentación dorsal y ventral de los segmentos abdominales IX-X según Fig. 46.3 y 46.4 respectivamente.

\section{ESTADIOS PREIMAGINALES DE NOTHOCHRYSA FULVICEPS}

Huevo. Huevos elipoides, de gran tamaño (2 $\mathrm{mm}$ de longitud y $1 \mathrm{~mm}$ de diámetro), con pedúnculo hialino de $15 \mathrm{~mm}$ de longitud. Son de color verde manzana con micropilo blanco.

Larva madura (Figs. 46.5-6, 47.7-12). Igual a lo indicado para $N$. capitata exceptuando:

Coloración tegumentaria amarilla anaranjada con dos bandas laterales, pardas o rojizas, que recorren tórax y abdomen en toda su longitud, y dispersas y tenues manchas del mismo color en el dorso del tórax y abdomen.

Cápsula cefálica (Fig. 47.8). Piezas bucales (Figs. 47.9-11) y antenas (Fig. 47.12) de mayor tamaño que en la especie anterior.

Tórax con tubérculos laterales portadores de varias setas (Fig. 46.5). Escleritos laterodorsales de los tres segmentos torácicos poco patentes. Patas de color crema en toda su longitud, sin manchas pardo oscuras en fémur y tibia. Uñas cuadrangularmente dilatadas en su base (Fig. 46.6).

Abdomen con tubérculos laterales portadores de numerosas setas, filiformes en su mayoría (Fig. 46.5). Todas las setas, tanto torácicas como abdominales, son hialinas.

Discusión. Como se ha indicado, los estadios preimaginales de $N$. capitata fueron descritos por Withycombe (1923), Killington (1937), Kimmins (1939) y Gepp (1983, 1989), aunque la larva de esta especie es considerada como perteneciente a $N$. fulviceps por Gepp (1983). También Killington (1935, 1937) describe la larva neonata de $N$. fulviceps y Gepp (1989) aporta datos sobre la morfología de la larva madura con el citado error en Gepp (1983).

Las larvas maduras de las dos especies ibéricas del género Nothochrysa (Figs. 46.1-6, 47.1-12) son fácilmente diferenciables en base a cuatro caracteres de morfología externa: coloración tegumentaria, número de setas de los tubérculos laterales del tórax, color de las setas y morfología de la uña.

El primer carácter es el más conspicuo en la diferenciación de las larvas vivas de ambas especies, ya que las $N$. capitata son de color pardo oscuro con tubérculos laterales torácicos de color anaranjado, mientras que las pertenecientes a $N$. fulviceps presentan coloración amarillenta o anaranjada con tenues manchas pardas o rojizas en el dorso de tórax y abdomen, pero dado que este carácter desaparece en las larvas conservadas en alcohol, no es recomendable utilizarlo con exclusividad.

El segundo carácter mencionado también permite una cómoda y correcta asignación de las larvas de ambas especies, ya que en $N$. capitata los tubérculos laterales del pro-, meso- y metatórax portan 1, 2 y 2 setas respectivamente (Fig. 46.1), mientras que en $N$. fulviceps los tubérculos laterales de los tres segmentos torácicos son portadores de varias (siempre más de 2) setas (Fig. 46.5).

El tercer carácter hace referencia al color de las setas de los tubérculos laterales y dorsales, tanto en tórax como en abdomen. Así, en N. capitata todas las setas son negras, mientras que en $N$. fulviceps son hialinas.

El último carácter mencionado, morfología de la uña, se mantiene también en los imagos de estas especies. Las larvas de $N$. capitata poseen uñas triangularmente dilatadas en su base (Fig. 46.2) y las de $N$. fulviceps uñas cuadrangularmente dilatadas en su base (Fig. 46.6).

Tras esto proponemos la siguiente clave para las larvas maduras de las especies ibéricas.

\section{Clave para larvas L-3}

1 Larvas de color pardo oscuro con tubérculos laterales torácicos anaranjados. Tubérculos laterales del promeso- y metatórax portadores de 1, 2 y 2 setas respectivamente (Fig. 46.1). Setas negras. Uñas triangularmente dilatadas en su base (Fig. 46.2) ................. N. capitata

- Larvas de color amarillento o anaranjado con tenues y dispersas manchas pardas o rojizas en tórax y abdomen. Tubérculos laterales de los 3 segmentos torácicos portadores de varias setas (siempre más de 2) (Fig. 46.5). Setas hialinas. Uñas cuadrangularmente dilatadas en su base (Fig. 46.6) N. fulviceps

Biología y COMPORTAMiento. En la Península Ibérica, y en relación a las fases juveniles, sólo podemos aportar lo anotado en el material estudiado (larvas de N. fulviceps halladas sobre Quercus 
pyrenaica, $Q$. faginea y Fagus sylvatica, y larvas de $N$. capitata halladas sobre $Q$. robur y Abies alba). Los imagos de $N$. fulviceps se han hallado asociados frecuentemente a Quercus pyrenaica, y en menor medida a $Q$. faginea, $Q$. robur, Betula pendula y F. sylvatica (Monserrat \& Marín, 1994) y como los imagos en $N$. capitata.

DISTRIBUCIÓN GEOGRÁFICA Y ALTITUDINAL, FENOLoGíA. N. fulviceps es conocida en la Península Ibérica de las provincias de Barcelona, Cantabria, Salamanca, Lérida, Gerona, Orense, Teruel, Zamora, Zaragoza, Guadalajara y Madrid. Su rango altitudinal entre $400-1620 \mathrm{~m}$, y han sido halladas larvas entre agosto y octubre, e imagos entre los meses de junio - agosto. Por el contrario N. capitata es mucho menos conocida en la Península Ibérica, donde parece ser algo más frecuente en las zonas montanas de la cordillera pirenaica y estribaciones, y se conoce de las provincias de Gerona, Barcelona, Huesca y Baleares (Mallorca). Su rango altitudinal oscila entre los 600 y los $850 \mathrm{~m}$, y sus larvas han sido halladas en julio y agosto y sus imagos entre los meses de mayo y octubre.

\section{Género Hypochrysa}

El género Hypochrysa Hagen, 1866, comprende 2 especies: H. elegans (Burmeister, 1839), conocida de Europa y extendida hacia Anatolia e Irán, e $H$. viridula Adams, 1978, conocida de Argentina (Brooks \& Barnard, 1990). En la Península Ibérica hallamos a $H$. elegans.

Respecto a la morfología larvaria de estas especies, sólo los estadios preimaginales de $H$. elegans han sido descritos. Información sobre la morfología del huevo y larva madura de esta especie puede ser recabada en Brauer (1867), Principi (1956b), Grimal (1986) y Gepp (1983, 1989, 1999), no obstante, estas descripciones nos resultan poco detalladas e incompletas, ya que en ninguna de ellas se describe la larva neonata y los datos aportados sobre la morfología y quetotaxia de la larva madura resultan muy superficiales o testimoniales. Por ello realizamos la descripción de su larva neonata, hasta ahora desconocida, y de la larva madura con mayor detalle, y por tratarse de un género con una única especie representante en la fauna europea, nos permite compararla mejor con las larvas conocidas de otras especies pertenecientes a la subfamilia Nothochrysinae.
Material utilizado. El material sobre el que hemos basado las descripciones de las larvas L-1 y L-3 ha sido cedido por el Dr. Michel Canard. Dos ejemplares en estado de larva L-3 fueron capturados en España, Santander, Salceda, 1.VIII.1988 y Valdeprado, 26.VIII.1988, ambos sobre Fagus sylvatica.

ESTADIOS LARVARIOS

Características generales: (L-1: Figs. 48.1-12, L-3: Figs. 49.1-12).

Cuerpo fusiforme, muy alargado y aplanado dorsoventralmente (Figs. 48.1, 49.1).

Larvas desnudas, no portadoras de capa de camuflaje (Figs. 48.1, 49.1).

Larvas maduras con cabeza amarilla y tórax y abdomen de color verde en su totalidad.

Antenas ligeramente más largas que las piezas bucales, con último segmento muy corto y de morfología similar al último segmento del palpo labial (Figs. 48.1, 4, 5, 49.1, 6, 7).

Ultimo segmento del palpo labial con 4 sensilas (Fig. 49.6).

Mandíbulas y maxilas considerablemente más largas que la cápsula cefálica (Figs. 48.1, 49.1).

Tubérculos laterales de tórax y abdomen muy poco desarrollados o ausentes (Figs. 48.1, 49.1).

Setas muy cortas, baciliformes y/o claviformes las situadas en el dorso del cuerpo (Figs. 48.11-12, 49.12) y filiformes las ventrales (Fig. 48.18, 49.11).

De la larva neonata (Figs. 48.1-12).

Tal cual se ha citado anteriormente.

De la larva madura (Figs. 49.1-12).

Tal cual se ha citado anteriormente, salvo mayor intensidad en la pigmentación estructural y con dos bandas longitudinales de color pardo oscuro o negro sobre los segmentos VI-IX (Fig. 49.1).

\section{Descripción de los estadios preimaginales}

Huevo. Pedunculado, de color verde con micropilo blanco (Principi, 1956b). La ornamentación del corion fue estudiada por Grimal (1983).

Larva L-1 (Fig. 48.1-12). Aspecto general según Fig. 48.1. Cabeza amarilla con manchas cefálicas de color pardo oscuro dispuestas según Fig. 48.2. Manchas genales ausentes y manchas ventrales muy poco marcadas (Fig. 48.3). Quetotaxia cefálica dorsal y ventral según Figs. 48.2 y 48.3 respectivamente. Setas cefálicas dorsales claviformes (Fig. 48.2) y ventrales filiformes (Fig. 48.3). Antenas (Fig. 48.4) de color pardo pálido con el último segmento y porción distal del segundo de color pardo oscuro, segundo segmento antenal portador de una gruesa y corta seta apical externa (Fig. 48.4), tercer y último segmento muy corto, con aspecto similar al último 


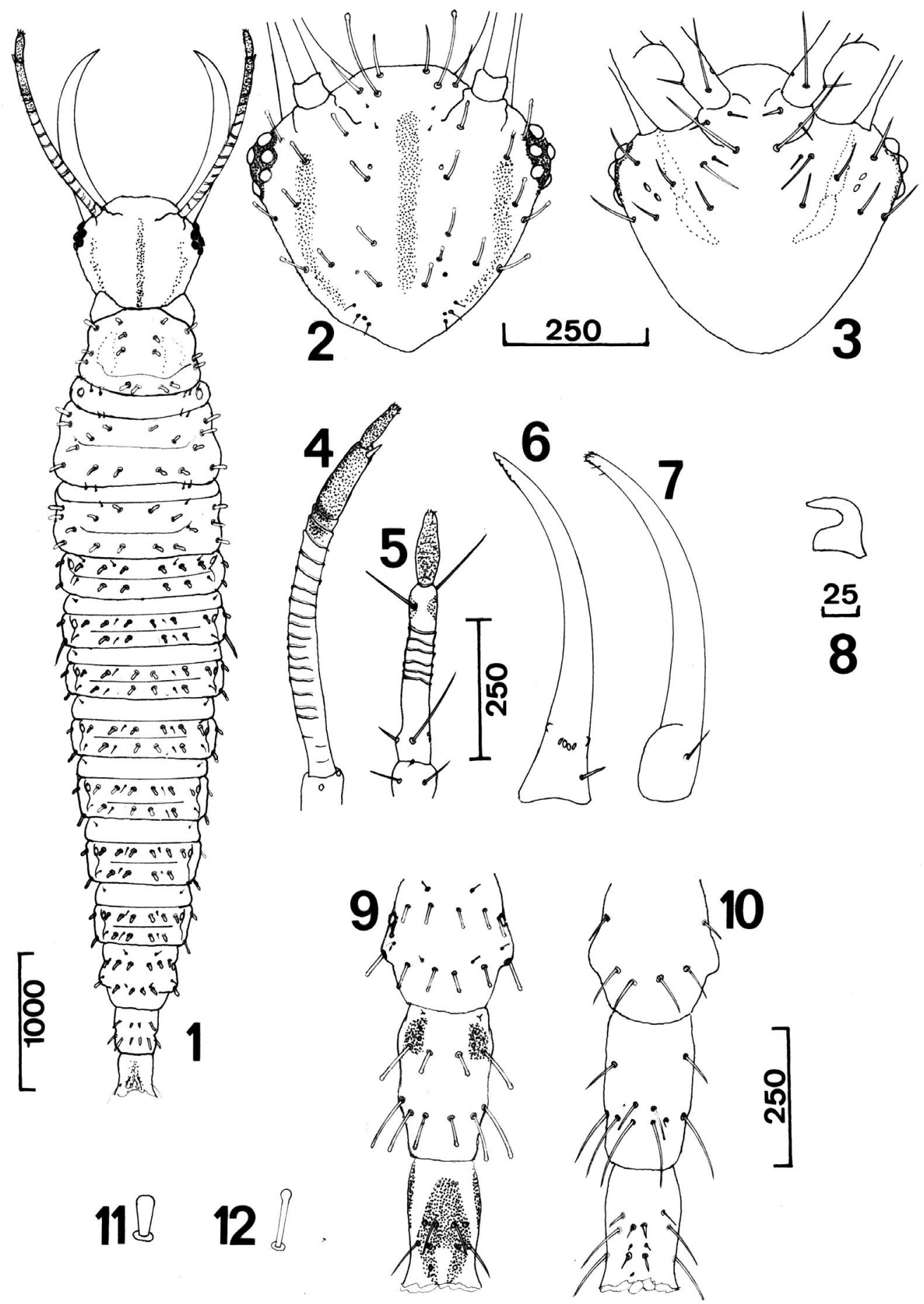

Fig. 48.- Hypochrysa elegans (L-1). 1, Aspecto general (VD). 2, Cápsula cefálica (VD). 3, Ídem (VV). 4, Antena. 5, Palpo labial. 6, Mandibula. 7, Maxila. 8, Uña. 9, Segmentos abdominales VIII-X (VD). 10, İdem (VV). 11, Seta baciliforme. 12, Seta claviforme. Escalas en $\mu \mathrm{m}$.

Fig. 48.- Hypochrysa elegans (L-1) (first instar larva). 1, Habitus (DV). 2, Head capsule (DV). 3, Ditto (VV). 4, Antenna. 5, Labial palp. 6, Mandible. 7, Maxilla. 8, Claw. 9, Abdominal segments VIII-X (DV). 10, Ditto (VV). 11, Bacilliform seta. 12, Clavate seta. Scales in $\mu \mathrm{m}$. 


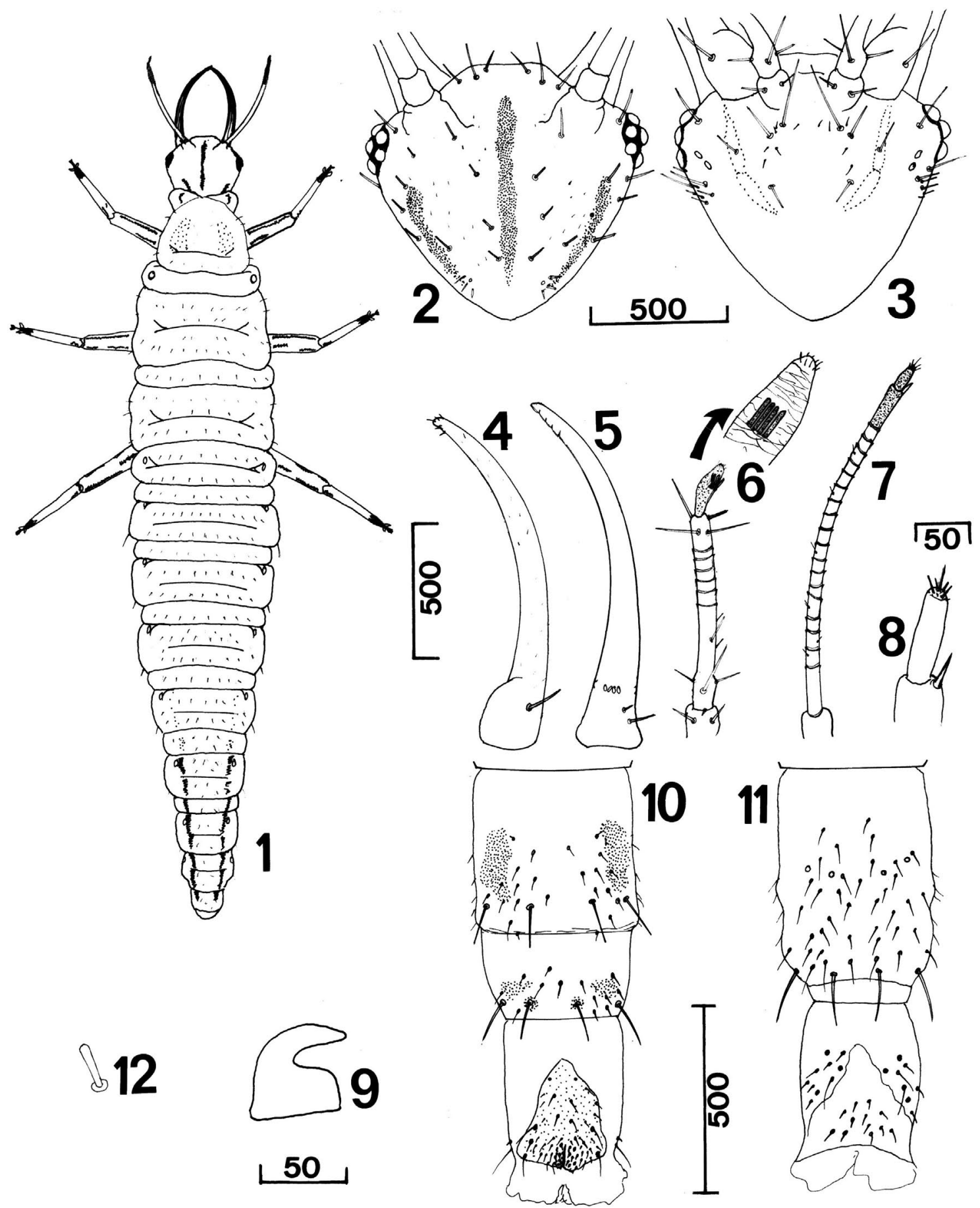

Fig. 49.- Hypochrysa elegans (L-3). 1, Aspecto general (VD). 2, Cápsula cefálica (VD). 3, Ídem (VV). 4, Maxila. 5, Mandíbula. 6, Palpo labial y detalle del último segmento. 7, Antena. 8, Detalle del último segmento antenal. 9, Uña. 10, Segmentos abdominales IX-X (VD). 11, Ídem (VV). 12, Seta baciliforme. Escalas en $\mu \mathrm{m}$.

Fig. 49.- Hypochrysa elegans (L-3) (third instar larva). 1, Habitus (DV). 2, Head capsule (DV). 3, Ditto (VV). 4, Maxilla. 5, Mandible. 6, Labial palp and detail of last segment. 7, Antenna. 8, Particular of the last antennal segment. 9, Claw. 10, Abdominal segments IX-X (DV). 11, Ditto (VV). 12, Bacilliform seta. Scales in $\mu \mathrm{m}$. 
segmento del palpo labial, con una corta y fina seta apical y varias sensilas periféricas a ésta (Fig. 48.4). Palpo labial (Fig. 48.5) de color pardo pálido con el último segmento pardo oscuro. Mandíbulas (Fig. 48.6) y maxilas (Fig. 48.7) de color pardo. Ojos formados por 6 estemmata negros, rodeados de tegumento fuertemente esclerotizado (Fig. 48.2, 3).

Tórax (Fig. 48.1) con tubérculos laterales muy poco desarrollados o ausentes. Quetotaxia dorsal compuesta por setas muy cortas (Fig. 48.1), baciliformes (Fig. 48.11). Quetotaxia ventral con setas filiformes. Escleritos laterodorsales del pronoto poco patentes, en forma de media luna (Fig. 48.1). Escleritos laterodorsales de meso- y metanoto ausentes. Espiráculo mesotorácico circular, no prominente (Fig. 48.1). Patas de color pardo pálido con tibias y tarsos pardo oscuros, superficie dorsal de las patas con setas claviformes (Fig. 48.11) y superficie ventral con setas filiformes, uñas de color ámbar, con base rectangular (Fig. 48.8).

Abdomen con tubérculos laterales no desarrollados (Fig. 48.1). Segmentos I-VII con setas dorsales baciliformes (Fig. 48.11) dispuestas según Fig. 48.1 y setas ventrales filiformes. Segmentos I-VII con dos setas laterales, una anterior y otra posterior, todas ellas mazudas, exceptuando la seta posterior del segmento II que es filiforme (Fig. 48.1). Segmentos VIII-X con quetotaxia y pigmentación dorsal y ventral según Fig. 48.9 y 48.10 respectivamente. Segmentos VIII-X con setas dorsales claviformes (Fig. 48.12).

Larva L-3 (Figs. 49.1-12). Aspecto general según Fig. 49.1. Larvas con cabeza amarilla y tórax y abdomen de color verde en su totalidad. Cabeza amarilla con manchas cefálicas de color pardo muy oscuro dispuestas según Fig. 49.2. Manchas genales ausentes y ventrales muy poco patentes (Fig. 49.3). Quetotaxia dorsal formada por setas muy cortas (Fig. 49.2), romas en su ápice, pero no claviformes. Quetotaxia ventral (Fig. 49.3) formada por setas filiformes. Maxilas (Fig. 49.4) y mandíbulas (Fig. 49.5) de color pardo oscuro, considerablemente más largas que la cápsula cefálica (Fig. 49.1). Palpo labial (Fig. 49.6) de color crema pálido, con último segmento pardo oscuro, portador de 4 sensilas en su cara externa. Antenas de color crema pálido con último segmento y tercio final del segundo de color pardo oscuro (Fig. 49.7). Segundo segmento antenal portador de una gruesa seta apical en su cara externa (Fig. 49.8). Tercer segmento antenal portador de una fina seta apical y varias sensilas (Fig. 49.8). Ojos formados por 6 estemmata de color negro, rodeados de tegumento fuertemente esclerotizado (Figs. 49.2-3).

Tórax de color verde, con cortas setas hialinas. Escleritos laterodorsales del pronoto poco patentes. Espiráculo mesotorácico circular, no prominente (Fig. 49.1). Setas dorsales baciliformes (Fig. 49.12) y setas ventrales filiformes. Patas de color crema con 2 bandas longitudinales de color pardo oscuro en la región dorsolateral del fémur y tibia (Fig. 49.1). Tarsos de color pardo oscuro. Uñas de color ámbar, con base rectangular (Fig. 49.9).

Abdomen de color verde con dos bandas longitudinales de color pardo oscuro o negro sobre los segmentos VI-IX (Fig. 49.1). Tubérculos laterales muy poco desarrollados o ausentes. Setas dorsales baciliformes (Fig. 49.12) y setas ventrales filiformes. Segmentos I y III-VII con una seta lateral baciliforme. Segmento II con una seta lateral filiforme, algo más larga que las anteriores (Fig. 49.1). Quetotaxia y pigmentación dorsal y ventral de los segmentos IX-X según Figs. 49.10-11.

Discusión. Circunscribiéndonos a la fauna ibérica, al margen de la característica coloración amarilla y verde de la larva viva de $H$. elegans, hecho que permite reconocerla a simple vista, se han encontrado caracteres de morfología externa y quetotaxia que resultan de gran utilidad para establecer relaciones entre la larva de ésta y otras especies de Chrysopidae de la fauna ibérica. Algunos de estos caracteres son comunes a otras larvas de géneros/ especies pertenecientes a la subfamilia Nothochrysinae a la que pertenece, y otros, en cambio, parecen ser exclusivos del género/ especie aquí estudiada y que permiten diferenciarla inequívocamente.

Entre los caracteres comunes en las especies de Nothochrysinae (Nothochrysa e Hypochrysa) respecto a las otras especies ibéricas de otras subfamilias, dos merecen ser destacados: morfología de la antena (el tercer y último segmento antenal diez veces más corto que el resto de la antena y porta una corta seta apical con pequeñas setas periféricas a ésta, ver Figs. 49.7-8 para Hypochrysa y Figs. 47.6, 12 para Nothochrysa) frente a géneros de otras subfamilias (Chrysopinae) en los que es tres veces más corto que el resto de la antena y termina en una estrecha formación cilíndrica sobre la cual se inserta una larga y fina seta apical. El segundo carácter es el número de sensilas del último segmento del palpo labial, que son tres en las larvas descritas de Chrysopinae y más de tres en Nothochrysinae (4 en 
Hypochrysa y numerosas formando una hilera transversal en Nothochrysa) (Figs. 47.3, 9, 49.6).

Segregadas las características de la subfamilia Nothochrysinae, y dentro de ella, el género Hypochrysa posee setas muy cortas de aspecto baciliforme (Figs. 48.11, 49.12) y claviforme (Fig. 48.12), mientras que son filiformes, bien alargadas o acabadas en anzuelo en Nothochrysa (Figs. 46.1, 5). Otras características generales anteriormente anotadas como la coloración tegumentaria, pigmentación y quetotaxia cefálica y tegumentaria y ser desnudas, sin capa de camuflaje (ver Figs. 46.1, 5, 47.1-2, 47.7-8 y Fig. 49.1, 3) contribuyen a su inequívoca identificación.

Biología y COMPORTAMiENTO. Se trata de una especie de biología prácticamente desconocida en la Península Ibérica. Debido al material sobre el que hemos basado esta descripción (mayoritariamente material conservado en alcohol), no hemos podido aportar, como en otras especies, datos sobre la biología y comportamiento de sus fases juveniles (tamaño y tipo de la puesta, duración del desarrollo embrionario y comportamiento de las larvas, duración de los estadios larvarios o periodo de pupación), salvo que son muy activas y desnudas. Los imagos de esta especie son poco frecuentes y, sin embargo, sus larvas han sido colectadas en varias ocasiones sobre Abies alba y Fagus sylvatica, y sobre esta fagácea también han sido hallados varios imagos y más puntualmente sobre Quercus robur, Crataegus monogyna (Monserrat \& Marín, 1994; Monserrat, 2008). Alguna información complementaria puede obtenerse de la bibliografía anteriormente citada y en Canard et al., 1984; Grimald \& Canard, 1996 y McEwen et al., 2001.

DISTRIBUCIÓN GEOGRÁFICA Y ALTITUDINAL, FENOLOGÍA. Se trata de una especie escasa y muy localizada en la Península Ibérica, donde está distribuida en las zonas de influencia eurosiberiana, habiéndose citado en las provincias de Álava, Cantabria, Guipúzcoa y Huesca. Su rango altitudinal de 350$1400 \mathrm{~m}$, y ha sido hallada entre los meses de mayoagosto.

\section{Conclusiones y discusión general}

En esta contribución se han revisado los estadios preimaginales de las especies de crisopas ibéricas y se describen las fases juveniles de 38 de sus 49 especies $(77,5 \%)$, pertenecientes a todos los géneros ibé- ricos/europeos, tanto en base a la información existente en la bibliografía, como en las descripciones realizadas por los autores tras la recolección de hembras grávidas, obtención de las puestas y cultivo de sus larvas. De ellas se describen por primera vez los estadios preimaginales de Chrysopa dorsalis, Nineta guadarramensis, Suarius iberienis e Italochrysa stigmatica. De las restantes especies ibéricas, o bien no han podido ser recolectadas, o no hemos obtenido puestas (Chrysopa phyllochroma, C. nierembergui, Nineta pallida, Pseudomallada alarconi, P. inornatus, P. clathratus, Chrysoperla mutata, Italochrysa italica), y basamos la información en elementos publicados o en material cedido por otros autores, o bien permanecen desconocidos sus estadios juveniles. En otros casos no se han completado sus ciclos juveniles, o sólo hemos podido describir parte de él (Italochrysa stigmatica, Nothochrysa fulviceps, N. capitata). Por último, otras especies (no recolectadas por nosotros) han sido muy escasamente citadas en la fauna ibérica o/y sus citas han sido descartadas o requieren confirmación (Chrysopa abbreviata, $C$. dubitans, $C$. walkeri, Pseudomallada abdominalis, P. zelleri, Nineta vittata), y otras están a la espera de una satisfactoria diagnosis identificatoria (grupo de Chrysoperla carnea s.l.).

Aún así, consideramos muy satisfactorio el nivel de conocimientos que, sobre este particular, ahora disponemos sobre la rica, abundante y diversa fauna de crisópidos ibéricos, de la que, para la mayoría de sus especies, se ofrece información actualizada sobre su biología, preferencia de sustrato, comportamiento, huevo, aspecto, pigmentación y quetotaxia de la larva neonata y de la larva madura, así como de su distribución geográfica, altitudinal y fenológica en la Península Ibérica.

Tras este estudio hemos comprobado que el empleo de caracteres morfológicos larvarios apoya, de forma general, la actual clasificación basada en los imagos, y de hecho, el estudio de la morfología larvaria de todas estas especies, nos ha permitido detectar una serie de anomalías que podrían cuestionar la validez o la identidad taxonómica de lo que hasta ahora asumíamos sobre los imagos de algunas especies ibéricas (P. prasinus, $C$. nigricostata, C. phyllochroma y C. viridana).

En base a este estudio se propone una serie de caracteres morfológicos especialmente válidos para la diferenciación de las larvas de especies ibéricas a nivel de subfamilia, tribu, género y especie que 
pasamos a discutir, y en base a estos caracteres, se ha ofrecido una clave de subfamilias, géneros (todos los géneros europeos) y de especies ibéricas $(77,5 \%)$ que posibilitan su identificación.

Basándonos en estos datos morfológicos ahora estudiados en las larvas, disponemos de nueva información aplicable a la sistemática general de la familia. La utilidad del empleo de caracteres morfológicos de los estadios inmaduros en los estudios taxonómicos y sistemáticos de Neurópteros no ha sido una práctica extendida, fue indicada por primera vez por Withycombe (1925), quien les asigna un considerable significado filogenético, al menos, a nivel de familia. Posteriormente, y circunscribiéndonos a la familia que tratamos, Tjeder (1966), en su monografía sobre los crisópidos de Sudáfrica, concluye que las larvas de esta familia poseen caracteres útiles en la clasificación a nivel genérico y subgenérico. El número de trabajos posteriores, que abordan el estudio detallado de la morfología larvaria como complemento a los estudios taxonómicos y sistemáticos realizados en los imagos, es proporcionalmente escaso, y los más significativos se han citado anteriormente, y como ya se indicó en la "Introducción General", uno de los problemas con el que nos encontramos en este campo de estudio es, frecuentemente, el desconocimiento general sobre la morfología de los estadios preimaginales en muchos géneros de esta familia (Brooks \& Barnard, 1990), tanto por el escaso número de especies en las que son conocidos, como por el escaso detalle de muchas de las descripciones realizadas.

La insuficiencia de información disponible en este campo nos limita a la hora de poder establecer comparaciones entre la morfología de las larvas de muchas especies, resultando, por ahora, un tanto prematuro proponer una serie de caracteres, basados en la morfología externa de los estadios preimaginales, que sirvan para definir incuestionablemente una subfamilia, tribu o género, hasta que, en un futuro, un mayor y más representativo número de trabajos sobre los estadios preimaginales de otros muchos géneros y especies amplíen el conocimiento general de la familia.

Aún así, y dado que tratamos todos los géneros de crisópidos europeos, en este apartado resaltaremos, de entre todos los caracteres estudiados, aquellos que, desde nuestro punto de vista, nos resultan de mayor valor en la diferenciación a nivel de subfamilias, tribus y géneros presentes en la fauna europea, hecho que no ha sido abordado hasta la fecha. Estos caracteres morfológicos externos pueden, por ahora, ser válidos para definir dichos taxones, pero a medida que vayamos disponiendo de mayor información sobre la morfología de los estadios preimaginales de otras subfamilias, tribus y géneros, deberán ser reconsiderados o, en su caso, confirmados.

\section{CARACTERES VÁlidOS A NIVEL DE SUBFAMILIA}

En primer lugar nos limitaremos a señalar aquellos caracteres que pueden ser utilizados a nivel de subfamilia (excluyendo, por no estar representada en la fauna tratada, la subfamilia Apochrysinae), basándonos tanto en los caracteres estudiados por nosotros, como en los aportados en la bibliografía.

Teniendo en cuenta esto, nos limitamos a la subfamilia Nothochrsinae, considerada como la más primitiva de todas basándose en una serie de caracteres de los imagos, y la subfamilia Chrysopinae, la más evolucionada de ellas (Adams, 1967 y Brooks \& Barnard, 1990), y que en el caso de sus larvas, quedan definidas por los siguientes caracteres morfológicos larvarios:

- Morfología de la antena.

- Número de sensilas del último segmento del palpo labial.

En las larvas de Nothochrysinae estudiadas en este trabajo, Hypochrysa elegans (Burmeister, 1839), Nothochrysa capitata (Fabricius, 1793) y $N$. fulviceps (Stephens, 1836), o en las descritas por otros autores, pertenecientes a las especies $N$. californica (Banks, 1892) (ver Toschi, 1965) o Dictyochrysa fulva Esben-Petersen, 1917 (ver New, 1981), el tercer y último segmento antenal es piriforme y muy corto, unas 10 veces menor que el segundo segmento, y porta una corta seta apical con pequeñas setas periféricas a ésta (Fig. 49.8). Sin embargo, en la subfamilia Chrysopinae, el último segmento antenal es de 2 a 3 veces más corto que el segundo y termina en una estrecha formación cilíndrica sobre la cual se inserta una larga y fina seta apical (Fig. 10.7).

En cuanto al segundo carácter mencionado, el último segmento del palpo labial posee en su cara externa sensilas que aparecen siempre en número de 3 en las larvas descritas de Chrysopinae y en número mayor a 3 en Nothochrysinae. Así, en Hypochrysa elegans existen 4 sensilas (Fig. 49.6) y en las especies de Nothochrysa McLachlan, 1868, existen numerosas sensilas, formando una hilera transversal 
que recorre la cara externa del último segmento del palpo labial (Fig. 47.9). No disponemos de información al respecto sobre el género Dictyochrysa EsbenPetersen, 1917, ya que New (1981) describe únicamente la larva neonata de D. fulva y, en esta fase larvaria, no existen sensilas en la cara externa del último segmento del palpo labial.

Todo lo anteriormente expuesto deja de manifiesto que existe cierta correlación, a nivel de subfamilia, entre la clasificación basada en los imagos y en la propuesta aquí para las larvas.

\section{CARACTERES VÁlidOS A NIVEL DE TRIBU}

A la hora de analizar caracteres preimaginales que pudieran ser utilizados para agrupar un determinado número de géneros en una misma tribu, nos encontramos, una vez más, con la falta de datos a este respecto. En la actualidad, de las cuatro tribus en las que ha sido dividida la subfamilia Chrysopinae, únicamente nos limitamos a lo obtenido sobre los estadios preimaginales en dos de ellas: Belonopterygini Navás, 1913 y Chrysopini Schneider, 1851 (dejamos al margen, por no estar representadas, las dos tribus restantes, Ankylopterygini Navás, 1910 y Leucochrysini Adams, 1978).

Las larvas de las especies europeas de la tribu Belonopterygini (y otras no europeas) están íntimamente asociadas a hormigueros y parece posible que éstas y las restantes especies de la tribu depreden exclusivamente sobre estadios inmaduros de hormigas. El hecho de que todas las larvas descritas de esta subfamilia sean mirmecófilas, sugiere una estrecha relación entre este hábito, con una marcada homogeneidad encontrada en la morfología de las larvas. Las modificaciones morfológicas observadas, tanto en la fase de larva como en el huevo, son, hasta ahora, únicas en las especies de esta tribu y, por ahora, pueden ser considerados como válidos para definirla. Dichos caracteres son:

- Los huevos de todas las especies descritas son afilados en sus polos, sobre todo en el micropilar, adquiriendo aspecto de huso, y poseen un prominente micropilo (Fig. 1.2).

- En las larvas neonatas los tubérculos laterales del tórax son palmeados, portadores de 8-10 setas denticuladas (Fig. 45.2), mucho más abundantes en las larvas maduras.

Los siguientes caracteres afectan tanto a la larva neonata como a la larva madura:
- Meso-, metanoto y segmentos abdominales I-VI cubiertos por numerosas setas uncinadas (Fig. 45.2).

- Mandíbulas y maxilas muy robustas, de longitud considerablemente menor que la de la cápsula cefálica, bruscamente estrechadas hacia su ápice (Figs. 45.5 y 45.6).

- Palpo labial muy corto, con su segundo segmento carente de anulaciones secundarias (Fig. 45.7).

- Antenas cortas y robustas, muy afiladas distalmente, con el último segmento muy breve, portador de una larga seta apical de longitud varias veces superior a la de dicho segmento (Figs. 45.8 y 45.9).

Los restantes 31 géneros de la subfamilia Chrysopinae quedan agrupados, por razones de conveniencia, bajo la cuarta y última tribu, Chrysopini, tribu a la que Brooks \& Barnard (1990) no consideran monofilética y sobre la que anotan la necesidad de un estudio más profundo que dilucide las relaciones filogenéticas en el grupo. A pesar de que es, precisamente en esta tribu, donde existen un mayor número de trabajos acerca de la morfología de sus estadios preimaginales (en 20 de los 31 géneros se conocen los estadios preimaginales), algunos excelentemente descritos, su heterogeneidad, el escaso y poco representativo número de especies en las que han sido descritos los estadios preimaginales de cada género, y la insuficiente minuciosidad en muchas de las descripciones realizadas, hacen prácticamente imposible el análisis y establecimiento de caracteres que puedan servir para definir dicha tribu (ver bibliografía).

\section{CARACTERES VÁLIDOS A NIVEL DE GÉNERO}

Huevo. Salvo el aspecto y forma del huevo en Italochrysa (Fig. 1.2) que se distingue de todos los demás (Figs. 1.1, 1.3-8), será necesario abordar estudios de microscopía de barrido sobre la ornamentación del corion para aplicarlo a los datos que ya conocemos al respecto (Mazzini (1974, 1976); (Hinton, 1981); Gepp (1984b, 1990); Grimal (1986), etc. y ver si existen diferencias de valor taxonómico.

Ovirruptor. Pese a que Toschi (1965) y New (1989) adjudican a la denticulación de esta estructura un posible valor taxonómico, en este estudio hemos encontrado una gran homogeneidad entre los ovirruptores de los distintos géneros, a la vez que una cierta variabilidad intraespecífica de la denticulación del mismo, motivo por el cual no nos parece un carácter con validez taxonómica, al 
menos, a nivel de genérico y subgenérico. New $(1983,1986 b)$ anota que el ovirruptor de Italochrysa insignis y el de Calochrysa extranea, ambas pertenecientes a la tribu Belonopterygini, se diferencian del de las restantes especies de la familia Chrysopidae en el enorme desarrollo del proceso anterior y en la incipiente denticulación. Estas diferencias, a las que dicho autor confiere cierto valor taxonómico, no han sido observadas en el ovirruptor de Italochrysa stigmatica, descrito en este estudio (Fig. 45.1).

Larva. Como ya se indicó anteriormente, nos limitaremos a proponer una serie de caracteres morfológicos válidos para la diferenciación de las larvas europeas/ibéricas a nivel de género. Algunos de estos caracteres son utilizados por primera vez, otros, sin embargo, ya han sido utilizados por otros autores, indicándose las correspondientes referencias en cada caso.

Como primer paso, con el objeto de facilitar el estudio de los géneros aquí analizados, podemos separar las larvas en dos grandes grupos: el primero de ellos incluye los géneros cuyas larvas son portadoras de capa de camuflaje, y el segundo a aquellos otros cuyas larvas son desnudas.

En el primer gran grupo quedan incluidos los géneros Chrysopidia Navás, 1910, Cunctochrysa Hölzel, 1970, Italochrysa Principi, 1946, Pseudomallada Tsukaguchi, 1995, Nothochrysa McLachlan, 1868, Rexa Navás, 1920 y Suarius Navás, 1914. Las larvas de todos ellos presentan en común una serie de modificaciones morfológicas que ayudan en la retención y soporte de la capa de camuflaje. Dichas modificaciones, de forma general, son:

- Tubérculos laterales del tórax cilíndricos o palmeados, más o menos alargados, portadores de setas muy largas.

- Metanoto con una hilera transversal de setas relativamente largas.

- Abdomen globoso.

- Terguitos de los segmentos abdominales I-VI cubiertos por setas uncinadas.

- Tubérculos laterales de los segmentos abdominales II-VII portadores de setas largas, generalmente recurvadas laterodorsalmente.

Estas modificaciones son compartidas por la gran mayoría de las larvas portadoras de capa de camuflaje. Sin embargo, debemos recordar que las especies de los géneros Nothochrysa e Italochrysa presentan grandes variaciones al respecto, variacio- nes que ya fueron comentadas en la discusión del capítulo dedicado a cada uno de estos géneros.

El segundo grupo incluye larvas desnudas (géneros Brinckochrysa Tjeder, 1966, Chrysopa Leach, 1815, Chrysoperla Steinmann, 1964, Hypochrysa Hagen, 1866, Nineta Navás, 1912 y Peyerimhoffina Lacroix, 1920), todos ellos están caracterizados por presentar:

- Cuerpo fusiforme, más o menos alargado.

- Abdomen subcónico, aplanado dorsoventralmente.

- Tubérculos laterales del tórax ausentes o semiesféricos, portadores, generalmente, de setas cortas.

- Segmentos abdominales con setas, generalmente, muy cortas y filiformes, no uncinadas.

- Tubérculos laterales de los segmentos abdominales II-VII portadores de setas generalmente cortas y rectas, no recurvadas laterodorsalmente.

Al igual que en el caso anterior, las características morfológicas indicadas son generales para las mayoría de las larvas desnudas, exceptuando la larva de Peyerimhoffina gracilis, por ser la única larva desnuda en la que, hasta el momento, se han descrito hileras transversales de setas espatuladas sobre los terguitos abdominales, tipo de seta característico de larvas portadoras de capa (ver discusión del capítulo correspondiente).

Una vez separados los géneros en dos grupos distintos, procederemos a indicar los caracteres morfológicos que, a nuestro parecer, resultan útiles en la definición de géneros europeos/ibéricos, tanto para las larvas neonatas como para las larvas maduras.

Los caracteres morfológicos de interés taxonómico encontrados en los géneros cuyas larvas son portadoras de capa de camuflaje son los siguientes:

\section{Para larvas L-1:}

NÚMERO Y DISPOSICIÓN DE LOS TUBÉRCULOS DORSALES DE, AL MENOS, LOS SEGMENTOS ABDOMINALES II-V:

Este carácter atañe exclusivamente a las larvas neonatas, en las que dichos tubérculos son portadores, cada uno de ellos, de una seta uncinada:

- 12 tubérculos (8 dispuestos en semicírculo, 2 centrales a éstos y 2 laterodorsales próximos a los espiráculos): Pseudomallada, Cunctochrysa y Chrysopidia (Figs. 25.2, 22.4 y 20.2 respectivamente).

- Más de 12 tubérculos, irregularmente dispuestos: Suarius (Fig. 42.2).

- 4 grandes tubérculos en posición centrodorsal, portadores de setas filiformes: Rexa (Fig. 40.2). 
- Sin tubérculos bien definidos, con hileras transversales de numerosas setas uncinadas: Italochrysa (Fig. 45.2).

\section{Para larvas L-3:}

GRADO DE DESARROLLO DE LOS TUBÉRCULOS LATERALES DEL TÓRAX:

- No desarrollados: Nothochrysa (Figs. 46.1, 5).

- Muy alargados y muy finos, no ensanchados en su ápice: Chrysopidia (Fig. 21.1).

- Alargados, con pedúnculo fino y ensanchados en su ápice: Pseudomallada y Suarius (Figs. 26.1 y 43.1 respectivamente).

- Poco alargados, con pedúnculo fino y ensanchados en su ápice: Cunctochrysa (Fig. 24.1).

- Ligeramente alargados y muy robustos: Rexa (Fig. 41.1).

- De aspecto palmeado: Italochrysa (ver Principi, 1946).

\section{Para larvas L-1 y L-3:}

PRESENCIA DE UNA HILERA TRANSVERSAL DE SETAS EN MESONOTO Y/O METANOTO:

- En mesonoto y metanoto: Cunctochrysa y Chysopidia (Figs. 24.1 y 21.1 respectivamente).

- Sólo en metanoto: Pseudomallada, Suarius, Rexa y Nothochrysa (Figs. 26.1, 43.1, 41.1 y 46.1 respectivamente).

Esta diferencia ha sido también observada, por ejemplo, por Tauber (1975) y Brooks \& Barnard (1990).

PRESENCIA DE TUbÉRCUlos LATERODORSALES, PORTADORES DE 1-2 SETAS, EN LOS SEGMENTOS ABDOMINALES V-VII O EN LOS SEGMENTOS VI-VII:

- En los segmentos V, VI y VII: Pseudomallada (Fig. 30.1).

- En los segmentos VI y VII: restantes géneros del grupo.

Este carácter ha sido utilizado, por ejemplo, por Boros (1984) en la diferenciación entre larvas del género Pseudomallada y Plesiochrysa Adams, 1982.

Por otro lado, los caracteres encontrados en la diferenciación de los géneros incluidos en el grupo de larvas desnudas son:

\section{Para larvas L-1 y L-3:}

GRADO DE DESARROLLO DE LOS TUBÉRCULOS LATERALES DEL TÓRAX:

- No desarrollados: Brinckochrysa e Hypochrysa (Figs. 8.1 y 49.1 respectivamente).
- Poco desarrollados: Nineta y Peyerimhoffina (Figs. 37.1 y 39.1 respectivamente).

- Bien desarrollados: Chrysopa y Chrysoperla (Figs. 10.1 y 18.1 respectivamente).

LONGITUD DE LAS SETAS DE LOS TUBÉRCULOS LATERALES DE TÓRAX Y ABDOMEN:

- Setas largas: Chrysopa (Fig. 10.1).

- Setas cortas: Nineta, Chrysoperla y Peyerimhoffina (Figs. 37.1, 18.1 y 39.1 respectivamente).

- Setas muy cortas: Brinckochrysa e Hypochrysa (Figs. 8.1 y 49.1 respectivamente).

\section{Para larvas L-3:}

AUSENCIA O PRESENCIA DE TUBÉRCULOS LATERODORSALES EN EL TÓRAX Y/O ABDOMEN:

- Sin tubérculos laterodorsales: Hypochrysa y Brinckochrysa (Figs. 49.1 y 8.1 respectivamente).

- Tubérculos laterodorsales en segmentos abdominales I-VII: Chrysopa, Chrysoperla y Nineta (Figs. 10.1, 18.1 y 37.1 respectivamente).

- Tubérculos laterodorsales sólo en segmentos abdominales VI-VII: Peyerimhoffina (Fig. 39.1).

NÚMERO DE SETAS DE LOS TUBÉRCULOS LATERODORSALES ABDOMINALES:

- Unicamente 2 setas: Nineta y Chrysoperla (Figs. 37.1 y 18.1 respectivamente).

- Más de 2 setas: Chrysopa (Fig. 10.1).

Este carácter ha sido utilizado por Pantaleoni (1983) en la diferenciación de las larvas entre el género Chrysopa y Chrysoperla.

Por último, otros caracteres que resultan válidos para la definición de géneros, independientemente de que las larvas sean o no portadoras de capa de camuflage, son:

TIPO DE SETAS PREDOMINANTES:

- Únicamente setas filiformes: Chrysopa, Chrysoperla y Nineta (Fig. 6.7).

- Setas espatuladas: Peyerimhoffina (Fig. 6.8).

- Setas truncadas en estrella: Brinckochrysa (Fig. $6.10)$.

- Setas baciliformes y/o claviformes: Hypochrysa (Fig. 6.11).

- Setas denticuladas: Italochrysa (Fig. 6.12).

- Setas uncinadas y espatuladas: Pseudomallada, Rexa, Chrysopidia, Suarius y Nothochrysa (Figs. 6.8-9).

Exceptuando la diferenciación entre setas serradas, rectas y uncinadas, este carácter no ha sido uti- 
lizado hasta el momento en la diferenciación de géneros, sin embargo, distintos autores describen o ilustran un tipo de seta característico para determinadas especies de un mismo género. Así por ejemplo, al margen de los tipos de setas descritos en este estudio, han sido anotadas "setas romas" para especies del género Anomalochrysa McLachlan, 1883 (ver New, 1986 y Tauber et al., 1992); "setas truncadas" para especies de Brinckochrysa (ver Tsukaguchi, 1979); "setas serradas" para especies del subgénero Prochrysopa (Tauber, 1975); "setas denticuladas" para especies de Italochrysa (ver Principi, 1946, New, 1983); "setas plumosas" para especies del género Ankylopteryx Brauer, 1864 (Brooks \& Barnard, 1990); etc.

\section{QueTOTAXIA CEFÁLICA}

- Longitud de las setas S-1 y S-11 en relación a las restantes setas cefálicas:

- S-1 y S-11 de longitud similar a la de las restantes setas cefálicas: Hypochrysa y Brinckochrysa (Figs. 49.2 y 8.3 respectivamente).

- S-1 y S-11 notablemente más largas que las restantes setas cefálicas: el resto de los géneros europeos/ibéricos.

- Ausencia o presencia de la seta S-12:

- S-12 ausente: Chrysopa y Pseudomallada (Fig. $4.3)$.

- S-12 presente: restantes géneros europeos/ibéri$\cos$ (Fig. 4.1).

CARACTERES LARVARIOS DE INTERÉS PRA LA SISTEMÁTICA DE LA FAMILIA

Aunque en este trabajo no pretendemos establecer relaciones filogenéticas entre géneros, queremos resaltar que es necesario conocer los hábitos y el ambiente donde viven las larvas, ya que en muchas ocasiones, éstos pueden afectar a su morfología y, por ello, las larvas de muchos géneros, no necesariamente relacionados filogenéticamente, presentan una morfología externa muy similar. Sin embargo, en relación a ello, las larvas neonatas ofrecen caracteres de gran utilidad, ya que las similitudes morfológicas entre larvas L-1 de distintos géneros sugieren una mayor relación entre los mismos que los caracteres encontrados en las larvas maduras. Por ello, en este apartado, indicaremos la mayor o menor relación encontrada entre los diversos géneros europeos/ibéricos, en función, principalmente, de los novedosos caracteres estudiados en las larvas neonatas. Los géneros Nothochrysa e
Hypochrysa por un lado, y el género Italochrysa por otro, quedan excluidos por haber sido separados anteriormente basándonos en los caracteres válidos para subfamilia y tribu respectivamente, ciñéndonos ahora a los géneros incluidos en la tribu Chrysopini.

Dentro del grupo de las larvas portadoras de capa de camuflaje, existe un grupo homogéneo formado por los géneros Chrysopidia, Cunctochrysa y Pseudomallada, caracterizados por el número y disposición de los tubérculos dorsales del tórax. Dentro de este grupo, el género Pseudomallada queda ligeramente separado de Cunctochrysa y Chrysopidia, ya que las larvas de estos dos últimos poseen seta cefálica S-12 y tubérculos dorsales portadores de largas setas en el mesonoto, caracteres ausentes en las larvas de Pseudomallada. De los otros dos géneros restantes, las larvas de Suarius presentan una serie de caracteres morfológicos que le aproximan con los géneros antes mencionados; éstos son la posesión de setas uncinadas sobre los terguitos abdominales y la morfología de los tubérculos laterales, alargados, finos, ensanchados en su ápice y portadores de setas muy largas. Las larvas del último género de este grupo, Rexa, presentan algunas características morfológicas que lo sitúan entre las larvas portadoras de capa de camuflaje y las larvas desnudas. Este género queda separado de los anteriores por el escaso número de tubérculos dorsales en el abdomen, portadores, además, de setas filiformes, y por la morfología de los tubérculos laterales del tórax, que son ligeramente alargados, muy robustos y portadores de setas relativamente cortas.

Con relación a ello, Brooks \& Barnard (1990), basándose en caracteres estudiados en los adultos, sugieren una marcada relación entre el género Cunctochrysa y los géneros Pseudomallada y Atlantochrysa Hölzel, 1970. Sin embargo, la larva de Atlantochrysa atlantica (MacLachlan, 1882), difieren considerablemente de las larvas de los otros dos géneros mencionados, asemejándose más a las larvas de tipo desnudo (Monserrat, 1978). De Suarius y Chrysopidia, estos autores no establecen relaciones con otros géneros de la tribu y, por último, con respecto a Rexa, anotan una posible proximidad al género Himalochrysa Hölzel, 1973, género del que aún desconocemos sus estadios larvarios.

En el grupo de larvas desnudas, las semejanzas entre las neonatas de los distintos géneros es aún 
más acusada, y sólo las larvas del género Brinckochrysa presentan marcadas diferencias con las de los restantes géneros del grupo. Sus tubérculos laterales del tórax portadores de una seta, el escaso desarrollo de los tubérculos laterales y laterodorsales, la posesión de setas muy cortas y truncadas, la particular quetotaxia cefálica $\mathrm{y}$, por último, la menor longitud de las antenas respecto a las piezas bucales, sugieren que este género no sea próximo a los demás géneros del grupo. En contra de ello, Brooks \& Barnard (1990) anotan una posible relación entre éste y los géneros Chrysoperla y Peyerimhoffina.

De los cuatro géneros restantes, únicamente las larvas neonatas de Chrysopa presentan diferencias con las pertenecientes a los otros tres géneros y pueden ser diferenciadas por la ausencia de la seta cefálica S-12 y por el mayor grado de desarrollo de los tubérculos laterales, portadores de setas largas.

Por último, las larvas neonatas de Chrysoperla, Nineta y Peyerimhoffina son extremadamente parecidas, y únicamente presentan diferencias en el grado de desarrollo de los tubérculos laterales y laterodorsales, y en la longitud de las setas insertadas en estos tubérculos.

Brooks \& Barnard (1990) anotan una estrecha relación entre los géneros Chrysoperla y Peyerimhoffina, relación que queda secundada con los caracteres morfológicos de las larvas neonatas aquí estudiadas.

En cuanto al género Chrysopa, estos mismos autores señalan una marcada relación entre éste y los géneros Ceratochrysa Tjeder, 1966 y Plesiochrysa Adams, 1982 y, menos acusada, con los géneros Nineta y Tumeochrysa Needham, 1909. Las larvas de Ceratochrysa antica (Walker, 1853), descrita por Barnard \& Brooks (1984) y de Plesiochrysa ramburi (Sneider, 1851), descrita por Adams (1959) y Boros (1984) son portadoras de capa de camuflaje y se caracterizan por un abdomen moderadamente abombado e hileras transversales de cortas setas unicinadas en los terguitos abdominales I-V, caracteres que las separa marcadamente de las larvas conocidas de Chrysopa. En cuanto a su relación con los otros dos géneros mencionados, los estadios preimaginales de Tumeochrysa son todavía desconocidos y los caracteres larvarios compartidos con el género Nineta, a nuestro parecer, indican una mayor relación de Chrysopa con Nineta que la anotada por Brooks \& Barnard (1990) con Ceratochrysa y Plesiochrysa.
Para el género Nineta caben las mismas consideraciones que lo expuesto para Chrysopa, ya que estos mismos autores indican una estrecha relación entre éste y Tumeochrysa y una relación, menos marcada, con Ceratochrysa y Chrysopa.

A pesar de que Brooks \& Barnard (1990) no establecen relación alguna entre los géneros Chrysopa y Nineta con los géneros Chrysoperla y Peyerimhoffina, las caracteres morfológicos de las larvas neonatas y maduras muestran que Nineta presenta un mayor grado de relación con Chrysoperla y Peyerimhoffina que con Chrysopa, basada en la presencia de la seta cefálica S-12; el menor desarrollo de los tubérculos laterales, portadores de setas rígidas y cortas $\mathrm{y}$, finalmente, en el número de setas insertadas en los tubérculos laterodorsales del abdomen, que es siempre de 2 en estos géneros y mayor de 2 (generalmente 5) en el género Chrysopa.

Todo lo anteriormente expuesto deja de manifiesto la necesidad de un estudio en profundidad sobre un mayor número taxa y de caracteres morfológicos, moleculares/ genéticos y biológicos/ comportamentales, tanto en los imagos como en los estadios larvarios de esta familia, que aclararen en un futuro y aún más, las posibles relaciones filogenéticas del grupo.

Aún así, y a nivel global, el desconocimiento general sobre la morfología larvaria de muchos géneros de esta familia limita, por ahora, la utilización de caracteres morfológicos larvarios en estudios taxonómicos y sistemáticos, haciéndose necesaria la realización de descripciones más detalladas y completas en un mayor número de especies de un mayor número de géneros/tribus/subfamilias a nivel mundial.

\section{Agradecimientos}

Agradecemos al Dr. R. Cloupeau, al Dr. Michel Canard, y a la Dra. Mercedes Campos el envío de material, y al Dr. M. Stelzl, que nos ha proporcionado valiosa información. También a Eduardo Ruiz por su ayuda en el tratamiento de las imágenes, al Dr. Juan M. Nieto-Nafría por la identificación de los áfidos, y a Víctor Triviño por su colaboración en la realización de nuestro banco de datos, del que hemos tomado abundante información sobre la biología y distribución de las especies tratadas.

\section{Referencias}

Adams, P. A., 1959. Insects of Micronesia. Neuroptera: Myrmeleontidae and Chrysopidae. Insects of Micronesia, 8(2): 13-33. 
Adams, P. A., 1967. A review of the Mesochrysinae and Nothochrysinae (Neuroptera: Chrysopidae). Bulletin of the Museum of Comparative Zoology 135: 215238.

Adams, P. A., 1987. Studies in Neotropical Chrysopidae (Neuroptera) III. Notes on Nodita amazonica Navás and N. oenops, n.sp. Neuroptera International, 4(4): 287-294.

Agekjan, N. G., 1973. Neuroptera feeding on bamboo aphids in Adzharia and their parasites. Revue d'Entomologie de l'URRS, 52(3): 549-563.

Alderson, E. M., 1911. Notes on the life-history of Chrysopa flava, Scopoli. The Entomologist 4: 126130.

Arzet, H. R., 1973. Suchverhalten der larven von Chrysopa carnea Steph. (Neuroptera, Chrysopidae). Zeitschrift für Angewandte Entomologie, 74: 64-79.

Aspöck, H., 1992. The Neuropteroidea of Europe: a review of present knowledge (Insecta). In: M. Canard, H. Aspöck \& M. W. Mansell (eds.). Current Research in Neuropterology. Proceedings of the Fourth International Symposium on Neuropterology. Bagnères-de-Luchon. Toulouse: 43-56.

Aspöck, H. \& Aspöck, U., 2007. Illustrations of Chrysopidae in the early entomological literature. Annali del Museo Civico di Storia Naturalle di Ferrara, 8: 27-44.

Aspöck, H., Aspöck, U. \& Hölzel, H., 1980. Die Neuropteren Europas. 2 Vols. Goecke \& Evers. Krefeld. 495 pp. y 355 pp.

Aspöck, H., Hölzel, H. \& Aspöck, U., 2001. Kommentierter Katalog der Neuropterida (Insecta: Raphidioptera, Megaloptera, Neuroptera) der Westpaläarktis. Denisia, 2: 3-606.

Aspöck, U., 1992. Crucial points in the phylogeny of the Neuroptera (Insecta). In: M. Canard, H. Aspöck, H. \& M. W. Mansell (eds.). Current Research in Neuropterology. Proceedings of the Fourth International Symposium on Neuropterology. Bagnères-deLuchon. Toulouse: 63-73.

Aspöck, U., 2002. Kamelhälse, Schlammfliegen, Netzflügler zur Phylogenie der Neuropterida (Insecta: Holometabola). Verhandlungen der Westdeutscher Entomologentag 14:7-9.

Aspöck, U. \& Aspöck, H., 2010. Landmarks toward a phylogeny-based classification of the Neuropterida (Insecta: Endopterigota). In: D. Devetak, S. Lipovsck \& A. E. Arnett (eds.). Proceedings of the Tenth International Symposium on Neuropterology, Maribor: 67-74.

Aspöck, U., Plant, J. D. \& Nemeschkal, H. L., 2001. Cladistic analisys on Neuroptera and their systematic position within the Neuropterida (Insecta: Holometabola: Neuropterida: Neuroptera). Systematic Entomology, 26: 73-86.
Bansch, R., 1966: On prey-seeking behaviour of aphidophagous insects. En: Ecology of Aphidophagous Insects. Czechoslovak Academy of Sciences. Prague: 123-128.

Barnard, P. C., 1984. Adult morphology related to classification. In: M. Canard, Y. Séméria \& T. R. New (eds.). Biology of Chrysopidae. Dr W. Junk. The Hague: 19-29.

Barnard, P. C. \& Brooks, S. J., 1984. The African lacewing genus Ceratochrysa (Neuroptera: Chrysopidae): a predator on the cassava mealybug, Phenacoccus manihoti (Hemiptera: Pseudococcidae). Systematic Entomology, 9: 359-3771.

Bigler, F., 1984. Biological control by chrysopids: integration with pesticides. In: M. Canard, Y. Séméria \& T. R. New (eds.). Biology of Chrysopidae. Dr W. Junk. The Hague: 233-245.

Bock, E., 1939. Bildung und Differenzierung der Kleimblätter bei Chrysopa perla (L.). Zeitschrift für Morphologie und Ökologie der Tiere, 35: 615-702.

Bond, A. B., 1980. Optimal foraging in a uniform habitat: the search mechanism of the green lacewing. Animal Behaviour, 28: 10-19.

Boros, C. B., 1984. Descriptions of the larvae of six Australian species of Chrysopa Leach, s.l. (Neuroptera: Chrysopidae). Australian Journal of Zoology, 32: 833-849.

Brauer, F., 1850. Beschreibung und Beobachtung der Österreichischen Arten der Gattung Chrysopa. Naturwissenschaftliche Abhandlungen Wien, 4(4): 114.

Brauer, F., 1867. Larve von Hypochrysa nobilis Heyd. Verhandlungen der Zoologisch-Botanischen Gesellschaft in Wien 17: 27-30.

Bristow, C.M., 1978. What makes a predator specialize? Tree, 3(2): 1-2.

Brooks, S. J., 1994. A taxonomic review of the common green lacewing genus Chrysoperla (Neuroptera: Chrysopidae). Bulletin of the British Museum, Natural History. Entomology, 63(2): 137-210.

Brooks, S. J. \& Barnard, P. C., 1990. The green lacewings of the world: a generic review (Neuroptera: Chrysopidae). Bulletin of the British Museum, Natural History. Entomology, 59(2): 117-286.

Bruch, C., 1917. Desarrollo de Chrysopa lanata Banks (Neuroptera). Physis, 3: 361-369.

Bullini, L. \& Cianchi, R., 1984. Electrophoretic studies of gene-enzyme systems in chrysopid lacewings. En: M. Canard, Y. Séméria, Y. \& T. R. New (eds.). Biology of Chrysopidae. Dr W. Junk. The Hague: 48-56.

Bullini, L., Principi, M. M. \& Cianchi, R., 1980. Ricerche eletroforetiche su specie italiane del genere Chrysopa s.l. (Neuroptera, Chrysopidae). Atti del Congresso Nazionale Italiano di Entomologia, 12(2): 235-237. 
Bullini, L., Principi, M. M., Cianchi, R. \& Pantaleoni, R., 1983. Nuovi dati sulla tassonomia biochimica delle crisope italiane (Neuroptera, Chrysopidae). Atti del Congresso Nazionale Italiano di Entomologia, 13: 479-483.

Burke, H. R. \& Martin, D. F., 1956. The biology of three chrysopid predators of the cotton. Journal of Economic Entomology, 49(5): 698-700.

Canard, M., 1981. Chrysopes (Neuroptera) peu connues ou nouvelles pour la France. Neuroptera International, 1: 99-109.

Canard, M., 1986. Is the iberian lacewing Chrysopa regalis a semivoltine species? Ecological Entomology 11: 27-30.

Canard, M. \& Duelli, P., 1984. Predatory behavior of larvae and cannibalis. In: M. Canard, Y. Séméria, \& T. R. New (eds.). Biology of Chrysopidae. Dr W. Junk. The Hague: 92-100.

Canard, M. \& Grimal, A., 1990. The role of photoperiod in the regulation of the annual cycle in two montane conifer-inhabiting green lacewings in southwestern Europe (Insecta: Neuroptera: Chrysopidae). In: M. W. Mansell \& H. Aspöck (eds.). Advances in Neuropterology. Pretoria: 39-46.

Canard, M. \& Labrique, H., 1989. Bioécologie de la chrysope méditerranéenne Rexa lordina Navás (Neuroptera: Chrysopidae) et description de ses stades larvaires. Neuroptera International, 5(3): 151158.

Canard, M. \& Principi, M. M., 1984. Development of Chrysopidae. In: M. Canard, Y. Séméria \& T. R. New (eds.). Biology of Chrysopidae. Dr W. Junk. The Hague: 76-92.

Canard, M., Séméria, Y. \& New, T.R., 1984. Biology of Chrysopidae. Series Entomologica 27. Dr W. Junk. The Hague. 294 pp.

Canard, M. \& Thierry, D., 2007. A historical perspective on nomenclature within the genus Chrysoperla Steinmann, 1964 in Europe: the carnea-complex (Neuroptera Chrysopidae). Annali del Museo Civico di Storia Naturale di Ferrara, [2005], 8: 173-179.

Canard, M. \& Vannier, G., 1992. Adaptations of preimaginal stages of Nineta pallida (Schneider) to frost and heat (Insecta: Neuroptera; Chrysopidae). In: M. Canard, A. Aspöck \& M. W. Mansell (eds.). Current Research in Neuropterology. Proceedings of the Fourth International Symposium on Neuropterology. Bagnères-de-Luchon. Toulouse: 75-85.

Chen, S. H. \& Young, B., 1941. On the protective value of the egg-pedicel of Chrysopidae. Sinensia, Shanghai, 12: 211-215.

Cianchi, R. \& Bullini, L., 1992. New data on sibling species in chrysopid lacewings: The Chrysoperla carnea (Stephens) and Mallada prasinus (Burmeister) complexes (Insecta: Neuroptera: Chrysopidae). In: M. Canard, H. Aspöck \& M. W.
Mansell (Eds.). Current Research in Neuropterology. Proceedings of the Fourth International Symposium on Neuropterology. Bagnères-de-Luchon. Toulouse: 99-104.

Clancy, D. W., 1946. The insect parasites of the Chrysopidae (Neuroptera). University of California Publications in Entomology, 7: 403-496.

Crouzel, I. S. \& Saini, E., 1979: Llave dilemática para el reconocimiento de los 3 Estadios larvales de Chrysopa lanata lanata (Banks) (Neuroptera: Chrysopidae). Acta zoologica Lilloana, 35: 417-425.

Díaz-Aranda, L. M. \& Monserrat, V. J., 1988a. Estadios larvarios de los Neurópteros ibéricos. IV: Mallada granadensis (Pictet, 1865) (Planipennia: Chrysopidae). Neuroptera International, 5(2): 111-119.

Díaz-Aranda, L. M. \& Monserrat, V. J., 1988b. Contribución al conocimiento de los Neurópteros de Granada (Insecta, Neuropteroiea). Actas III Congreso Ibérico de Entomología, Granada: 211-227.

Díaz-Aranda, L. M. \& Monserrat, V. J., 1990a. Estadios larvarios de los Neurópteros ibéricos.VI: Chrysoperla carnea (Stephens, 1836), Chrysoperla mediterranea (Hölzel, 1972) y Chrysoperla ankylopteryformis Monserrat y Díaz-Aranda, 1989. (Insecta, Neuroptera: Chrysopidae). Boletín de Sanidad Vegetal, Plagas, 16: 675-689.

Díaz-Aranda, L. M. \& Monserrat, V. J., 1990b. Estadios larvarios de los Neurópteros ibéricos. VIII: Mallada venosus (Rambur, 1842) (Planipennia: Chrysopidae). Neuroptera International, 6(2): 95-105.

Díaz-Aranda, L. M. \& Monserrat, V. J., 1991. Estadios larvarios de los Neurópteros ibéricos (VII). Mallada picteti (McLachlan, 1880) (Planipennia: Chrysopidae). Neuroptera International, 6(3): 141-147.

Díaz-Aranda, L. M. \& Monserrat, V. J., 1992. Descripción de los estadios larvarios de Brinckochrysa nachoi Monserrat, 1977 (Neuroptera: Chrysopidae). Nouvelle revue d'Entomologie (N.S.), 9(3): 207-214.

Díaz-Aranda, L. M. \& Monserrat, V. J., 1994. The larval stages of genus Cunctochrysa Hölzel, 1970 in Europe (Neuroptera, Chrysopidae). Deutsche Entomologische Zeitschrift, N.F., 41(1): 163-171.

Díaz-Aranda, L. M. \& Monserrat, V. J., 1995. Aphidophagous predator diagnosis: Key to genera of European chrysopid larvae (Neur.: Chrysopidae). Entomophaga, 40(2): 169-181.

Díaz-Aranda, L. M. \& Monserrat, V. J., 1996. On the larval stages of genus Suarius Navás, 1914 in Europe (Neuroptera, Chrysopidae). Deutsche Entomologische Zeitschrift, N.F., 43(1): 89-97.

Díaz-Aranda, L. M. \& Monserrat, V. J. \& Tauber, C. A., 2001. Recognition of early stages of Chrysopidae, In: P. K. McEwen, T. R. New \& A. E. Whittington (eds.). Lacewings in the Crop Environment. Cambridge University Press. Cambridge: 60-81. 
Duelli, P., 1981. Is larval cannibalism in lacewings adaptative? Researches on Population Ecology, 23: 193209.

Duelli, P., 1984. Oviposition. In: M. Canard, Y. Séméria, Y. \& T. R. New (eds.). Biology of Chrysopidae. Dr W. Junk. The Hague: 129-133.

Duelli, P., 1986. A "missing link" in the evolution on the egg pedicel in Lacewings. Experientia, 42: 624

Duelli, P., 1987. Eine isolierte Reliktpopulation von Chrysoperla mediterranea (Planipennia: Chrysopidae) in der Schweiz. Bulletin de la Société entomologique Suisse, 60: 301-306.

Duelli, P., 1989. Zwei für die Scheweiz neue Flortliegenarten aus dem Wallis (Planipennia: Chrysopidae). Bulletin de la Société entomologique Suisse, 62: 345347.

Duelli, P., 1999. Honigtau und stumme Gesänge: Habitatund Partnersuche bei Florfliegen (Neuroptera, Chrysopidae). Stapfia, 138: 35-48

Duelli, P. \& Johnson, J. B., 1992. Adaptative significance of the egg pedicel in green lacewings (Insecta: Neuroptera: Chrysopidae). En: M. Canard, H. Aspöck y M. W. Mansell (eds.). Current Research in Neuropterology. Proceedings of the Fourth International Symposium on Neuropterology. Bagnères-deLuchon. Toulouse: 125-134.

Egger, A., 1974. Zur Biologie und Wirtschaftlichen Bedeutung von Chrysopa carnea Steph. (Neuropt., Planip., Chrysopidae). Anzeiger für Schädlingskunde, Pflanzenschutz, Umweltschutz, 47(12): 189-191.

Eisner, T., Attygalle, A. B., Conner, W. E., Eisner, M., MacLeod, E. \& Meinwald, J., 1996. Chemical egg defense in a green lacewing (Ceraeochrysa smithi). Proceedings of the National Academy of Sciences of USA, 93: 3280-3283.

Eisner, T., Hiks, K., Eisner, M. \& Robson, D. S., 1978. "Wolf-in-sheep's-clothing" strategy of a predaceous insect larva. Science, 199: 790-794.

Fleschner, C. A., 1950. Studies on searching capacity of the larvae of three predators of the citrus red mite. Hilgardia, 20: 233-265.

Frankenberg, G. von, 1936. Das Puppenstadium der Florfliege (Chrysopa vulgaris Sch). Biologisches Zentralblatt, 56: 94-100.

Freitas, S. de, 2007. Ocorrência de Ungla Navás (Neuroptera, Chrysopidae) no Brasil e descripção de nova espécie. Revista Brasileira de Entomologia, 51(4): 413-415.

Gaumont, J., 1976. L'appareil digestif des larves de planipennes. Annales des Sciences naturelles, Zoologie et Biologie animale, 18: 145-249.

Gepp, J., 1983. Schlüssel zur Freilanddiagnose mitteleuropäisches Chrysopidenlarven (Neuroptera: Chrysopidae). Mitteilungen des Naturwissenschaftlichen Vereines für Steiermark, 113: 101-132.
Gepp, J., 1984a. Erforschunsstand der NeuropterenLarven der Erde. In: J. Gepp, H. Aspöck \& H. Hölzel (eds.). Progress in World's Neuropterology. Graz: 183-239.

Gepp, J., 1984b. Morphology and anatomy of the preimaginal stages of Chrysopidae: a short survey. In: M. Canard, M., Séméria, Y. y New, T.R. (Eds.) Biology of Chrysopidae. W.Junk. The Hague: 9-19.

Gepp, J., 1986. Biology and larval diagnosis of Central European Neuroptera (A Review of Present Knowledge). In: J. Gepp, H. Aspöck \& H. Hölzel (eds.). Progress in World's Neuropterology. Graz: 137-144.

Gepp, J., 1989. Zur ökologischen Differenzierung der präimaginaln Stadien baumbewohnender Chrysopiden im Alperaum (Planipennia: Chrysopidae). Sitzungsberichte - Österreichische Akademie der Wissenschaften. Mathematisch-naturwissenschaftliche Klasse. Abteilung I, Biologie, Mineralogie, Erkunde und Verwandte Wissenschaften, 197(1-4): 1-73.

Gepp, J., 1990. An illustrated review of egg morphology in the families of Neuroptera (Insecta: Neuropteroidea). In: M. W. Mansell \& H. Aspöck. (eds.). Advances in Neuropterology. Pretoria: 131129.

Gepp, J., 1999. Neuropteren als Indicatoren der Naturraumbewertung. Stapfia, 138: 167-208

Grimal, A., 1983. Iconographia Neuropterorum Mundi (II): Structure Chorionique externe chez Hypochrysodes elegans (Burmeister) (Neuroptera: Chrysopidae). Neuroptera International, 4(2): 122-124.

Grimal, A., 1988. Exigences photopériodiques du cycle de développement de la chrysope Tjederina gracilis. Entomologia Experimentalis et Applicata, 47: 189194.

Grimal, A. \& Canard, M., 1996. Preliminary observations on the effect of photoperiod on the life cycle of the green lacewing Hypochrysa elegans (Burmeister) (Insecta: Neuroptera: Chrysopidae: Nothochrysynae). In: M. Canard, H. Aspöck \& M. W. Mansell (eds.). Pure and Applied Research in Neuropterology. Proceedings of the Fifth International Symposium on Neuropterology, Toulouse, Francia: 119 - 127.

Hagen, H. A., 1859. Ausschlüpfen von Chrysopa larven. Stettiner entomologische Zeitung, 20: 333.

Henry, C. S., 1984. The sexual behavior of green lacewings. En: M. Canard, Y. Séméria \& T. R. New (eds.). Biology of Chrysopidae. Dr W. Junk. The Hague: 101-110.

Henry, C. S., 1985. Sibling species, call differences, and speciation in green lacewings (Neuroptera: Chrysopidae: Chrysoperla). Evolution, 39: 965-984.

Henry, C. S., Brooks, S. J., Thierry, D., Duelli, P. \& Johnson, J. B., 2001. The common green lacewing (Chrysoperla carnea s.lat.) and the sibling species 
problem. En: P. K. McEwen, T. R. New \& A. E. Whittington (eds.). Lacewings in the Crop Environment. Cambridge University Press. Cambridge: 29-42.

Hinton, H. E., 1981. Biology of the insect Eggs. 3 vols. Pergamon Press. Oxford. 1125 pp.

Hirai, H., 1957. A cytotaxonomic study of the Chrysopidae (Neuroptera). Journal of the Faculty of Science Hokkaido University, Serie 6 Zoology, 13: 220-223.

Hoffmann, J., 1962. Faune des Névroptèroïdes du Grand-Duché de Luxembourg. Archives - Institut grand-ducal de Luxembourg, Section des sciences naturelles, physiques et mathématiques, 28: 249-332.

Hölzel, H., 1974. Zwei neue Chrysopiden-Arten aus Südwesteuropa (Planipennia, Chrysopidae). Entomologische Zeitschrift, 84: 257-260.

Hölzel, H., 1987. Descriptions of two new Brinckochrysa species from South Africa, with taxonomic notes on other African species of the genus (Neuropteroidea: Planipennia: Chrysopidae). Journal of the Entomological Society of Southern Africa, 50(2): 261-268.

Hölzel, H. \& Duelli, P., 1990. Remarks on the chrysopidae of Madagascar (Insecta: Neuroptera). In: M. W. Mansell \& H. Aspöck, H. (eds.) Advances in Neuropterology. Pretoria: 271-275.

Hölzel, H. \& Monserrat, V. J., 1992. Chrysopidae from Equatorial Guinea (Neuroptera, Chrysopidae). Entomofauna, 13(28): 465-476.

Hölzel, H. \& Ohm, P., 1972. Die Chrysopiden der Iberischen Halbinsel (Planipennia, Chrysopidae). Faunistisch-ökologische Mitteilungen, 4: 127-145.

Kennett, C. E., 1948. Defense mechanism exhibited by larvae of Chysopa californica Coq. (Neuroptera, Chrysopidae). Pan-Pacific Entomologist, 24: 209-211.

Killington, F. J., 1928. Notes on the Neuroptera and Mecoptera of Hampshire, 1928. Transactions of the Hampshire Entomological Society, 4: 49-52.

Killington, F. J., 1935. Notes on the habitat and life-history of Nathanica (Nothochrysa) fulviceps (Steph.) (Neuroptera). Journal of the Society for British Entomology, 1(4): 110-113.

Killington, F. J., 1936. A Monograph of the British Neuroptera. I. Ray Society 122. London. 269 pp.

Killington, F. J., 1937. A Monograph of the British Neuroptera II. Ray Society 123. London. 306 pp.

Kimmins, D. E., 1939. The first instar larva of Nathanica capitata (Fabr.). Journal of the Society for British Entomology, 1: 240-241.

Kirby, M., 1984. The structure of the pretarsus in the third instar larvae of the Chrysopidae. In: J. Gepp, H. Aspöck \& H. Hölzel (eds.). Progress in World's Neuropterology. Graz: 261-265.

Labrique, H., 1990. Description de la larve de la chrysope méditerranéene Mallada picteti (McLachlan, 1880) (Neuroptera: Chrysopidae). Nouvelle Revue d'Entomologie (N.S.), 7(4): 427-434.
Labrique, H. \& Canard, M., 1989. Description de la larve de Mallada ibericus (Navás) (Neur. Chrysopidae). Bulletin de la Société entomologique Française, 94(1-2): 59-68.

Lacroix, J. L., 1921. Études sur les Chrysopides. Premier mémoire. Annales de la Société Linnéenne de Lyon, 68: 51-104.

Lacroix, J. L., 1922. Études sur les Chrysopides. Deuxième Mémoire. Chrysopes du groupe prasinus Burm. Annales de la Société Linnéenne de Lyon, 69: 119-144.

Lacroix, J. L., 1925. Études sur les Chrysopides. Époque du coconnage chez larves du groupe Chrysopa prasinus Burm. Bulletin de la Société d'Étude des Sciences Naturelles d'Elbeuf, 43: 87-91.

Lacroix, J. L., 1929. Quelques most sur les Chrysopides. Revue de Zoologie Agricole et Appliquée, 29: 129141.

LaMunyon, C. W. \& Adams, P. A., 1987. Use and effect of an anal defensive secretion in larval Chrysopidae (Neuroptera). Annals of the Entomological Society of America, 80(6): 804-808.

Lucas, F., Shaw, J. T. B. \& Smith, S. G., 1957. Aminoacid Composition of the Silk of Chrysopa Eggstalks. Nature, London, 179: 906-907.

Manson, R. T., Fales, H. M., Eisner, M. \& Eisner, T., 1991. Wax of a whitefly and its utilization by a chrysopid larva. Naturwissenschaften, 78: 28-30.

Mantoanelli, E., Tauber, C. A., Albuquerque, G. S. \& Tauber, M. J., 2011. Larvae of four Leucochrysa (Nodita) species (Neuroptera: Chrysopidae: Leucochrysini) from Brazil's Atlantic Coast. Annals of the Entomological Society of America, 104(6): 12331259.

Marín, F. \& Monserrat, V. J., 1991.Contribución al conocimiento de los neurópteros de Albacete (Insecta, Planipennia). Jornadas sobre el Medio Natural Albacetense, Albacete 1990: 179-184.

Mazzini, M., 1974. Sulla fine struttura del micropilo negli insetti. Redia, 55: 343-372.

Mazzini, M., 1976. Fine structure of the insect micropyle.III. Ultrastructure of the egg of Chrysopa carnea Steph. (Neuroptera: Chrysopidae). International Journal of Insect Morphology and Embryology, 5(4/5): 273-278.

McEwen, P. K., New, T. R. \& Whittington, A. E., 2001. Lacewings in the Crop Environment. Cambridge University Press. Cambridge. 546 pp.

Monserrat, V. J., 1977. Brinckochrysa nachoi n.sp., nuevo crisópido en la fauna europea (Insecta, Neuroptera: Chrysopidae). Vie et Milieu, 27(c): 267-277.

Monserrat, V. J., 1978. Sobre los Neurópteros de las Islas Canarias I: Anisochrysa (Atlantochrysa) atlantica (McLachlan, 1882) (Plan., Chrysopidae). Boletín de la Asociación española de Entomología, 1: 151-159. 
Monserrat, V. J., 1979. Segunda contribución al conocimiento de los Neurópteros de Cádiz (Insecta, Planipennia). Boletín de la Real Sociedad Española de Historia Natural (Sección Biológica), 77: 409-417.

Monserrat, V. J., 1982a. Sobre los Neurópteros de las Islas Canarias III: Chrysopa flaviceps (Brullé, 1838) (Neur., Plan., Chrysopidae). Boletín de la Asociación española de Entomología, 6: 113-119.

Monserrat, V. J., 1982b. Contribución al conocimiento de los Neurópteros de Cáceres (Neuroptera, Planipennia). Graellsia, 38: 67-84.

Monserrat, V. J., 1984 a. Estadios larvarios de los Neurópteros ibéricos. III: Anisochrysa genei. (Neur., Plan., Chrysopidae). Neuroptera International, 3(1): 13-21.

Monserrat, V. J., 1984 b. Contribución al conocimiento de los neurópteros de Alicante (Neur., Planipennia). Mediterranea, Serie de Estudios Biológicos, 7: 91116.

Monserrat, V. J., 1985. Contribución al conocimiento de los Neurópteros (Neuroptera:Planipennia) de Murcia. Anales de Biología. Sección Biología Animal, 1:81-94.

Monserrat, V. J., 1987. Contribución al conocimiento de los Neurópteros de Almería (Neuroptera, Planipennia). Graellsia, 42: 131-147.

Monserrat, V. J., 1989. Estadios larvarios de los Neurópteros ibéricos. II: Mallada subcubitalis (Planipennia: Chysopidae). Neuroptera International, 5(3): 125132.

Monserrat, V. J., 2008. Nuevos datos sobre algunas especies de crisópidos (Insecta: Neuroptera, Chrysopidae). Heteropterus Revista de Entomología, 8(1): 171-196.

Monserrat, V. J., 2010. Nuevas o interesantes citas de neurópteros en la Península Ibérica (Insecta: Neuroptera). Heteropterus Revista de Entomología, 10(1): 19-34.

Monserrat, V. J. \& Díaz-Aranda, L. M., 1989a. Nuevos datos sobre los crisópidos ibéricos (Neuroptera, Planipennia: Chrysopidae). Boletín de la Asociación española de Entomología, 13: 251-267.

Monserrat, V. J. \& Díaz-Aranda, L. M., 1989 b. Suarius walsinghami Navás, 1914, nuevo crisópido para la fauna europea (Neuroptera: Chrysopidae). Nouvelle Revue d'Entomologie (N.S.), 6(4): 407-411.

Monserrat, V. J. \& Freitas, S. de, 2005. Contribución al conocimiento de los crisópidos de Coquimbo, Patagonia y Tierra del Fuego (Argentina, Chile) (Insecta, Neuroptera, Chrysopidae). Graellsia, 61(2): 163-179.

Monserrat, V. J. \& Marín, F., 1994. Plant substrate specificity of Iberian Chrysopidae (Insecta: Neuroptera). Acta Oecologica, 15(2): 119-131.

Monserrat, V. J. \& Marín, F., 2001. Comparative plant substrate specificity of Iberian Hemerobiidae, Coniopterygidae and Chrysopidae. In: P. McEwen, T.
R. New \& A. E. Whittington (eds.). Lacewings in the Crop Envirionment. Cambridge University Press. Cambridge: 424-434.

Monserrat, V. J., Oswald, J. D., Tauber, C. A. \& DíazAranda, L. M., 2001. Recognition of larval Neuroptera. In: P. McEwen, T. R. New \& A. E. Whittington (eds.). Lacewings in the Crop Envirionment. Cambridge University Press. Cambridge: 43-81.

Monserrat, V. J. \& Rodrigo, F., 1992. Nuevas citas sobre los crisópidos ibéricos (Insecta, Neuroptera: Chrysopidae). Zoologica Baetica, 3: 123-138.

Muma, M. H., 1959. Chrysopidae associated with Citrus in Florida. The Florida Entomologist, 42(1): 21-29.

Navás, L., 1901. Notas neuropterológicas III. El género Chrysopa en España. Butlletí de la Institució Catalana d'Història Natural, 1: 23-28.

Navás, L., 1903. Algunos Neurópteros de España nuevos. Boletín de la Sociedad aragonesa de Ciencias Naturales, 2: 99-109.

Navás, L., 1915. Crisòpids d'Europa (Ins. Neur.). Arxius de l'Institut de Ciències, 3(2): 1-99.

Navás, L., 1924. Fauna de Catalunya. Entomologia de Catalunya. Neuròpters. Fascicle I. Neuròpters Propis. Publicacions de l'Institut d'Estudis Catalans, seccio de Ciències. Barcelona. 270 pp.

Navás, L., 1925. Sinópsis de los Neurópteros (Ins.) de la Península Ibérica. Memorias de la Sociedad Ibérica de Ciencias Naturales, 4: 5-149.

Naumark, S., 1952. Chrysopa carnea St. and its enemies in Israel. Ilanoth, Forest Research Station, 1: 1-127.

New, T. R., 1969. Notes on the debris-carrying habit in larvae of British Chrysopidae (Neuroptera). Entomologist's Gazette, 20: 119-124.

New, T. R., 1981. Some early stages of Dictyochrysa Esben-Petersen (Neuroptera: Chrysopidae). Neuroptera International, 1(3): 136-140.

New, T. R., 1983. The egg and first instar larva of Italochrysa insignis (Neuroptera, Chrysopidae). Australian Entomological Magazine, 10(2-3): 29-32.

New, T. R., 1984. The need for taxonomic revision in Chrysopidae. In: M. Canard, Y. Séméria \& T. R. New (eds.). Biology of Chrysopidae. Dr W. Junk. The Hague: 37-42.

New, T. R., 1986a. Notes on the larva of Anomalochrysa Mclachlan (Neuroptera, Chrysopidae). Neuroptera International, 4(1): 31-34.

New, T. R., 1986b. Some early stages of Calochrysa Banks (Neuroptera, Chrysopidae). Australian Entomological Magazine, 13(1-2): 11-14.

New, T. R., 1989. Planipennia Lacewings. Walter de Gruyter. New York. 129 pp.

New, T. R., 1999. Neuroptera and Biological Control (Neuropteridae). Stapfia, 60: 147-166. 
New, T. R., 2001a. Introduction to the Neuroptera: what are they and how do they operate? In: P. K. McEwen, T. R. New \& A. E. Whittington (eds.). Lacewings in the Crop Environment. Cambridge University Press. Cambridge: $3-5$.

New, T. R., 2001b. Introduction to the systematic and distribution of Coniopterygidae, Hemerobiidae, and Chrysopidae used in pest management. In: P. K. McEwen, T. R. New \& A. E. Whittington (eds.). Lacewings in the Crop Environment. Cambridge University Press. Cambridge: 6-28.

Pantaleoni, R. A., 1983. Riconoscimento in campo delle larve di crisopidi. Informatore Fitopatologico, 7/8: 31-36.

Pariser, K., 1917. Beiträge zur Biologie und Morphologie der einheimischen Chrysopiden. Archiv für Naturgeschichte, 83A(11): 1-57.

Parker, K. D. \& Rudall, K. M., 1957. The silk of the eggstalk of the green lace-wing fly. Nature, London, 179: 905-906.

Penny, N. D., Tauber, C. A. \& De León, T., 2000. A new species of Chrysopa from Western North America with a key to North American species (Neuroptera: Chrysopidae). Annals of the Entomological Society of America, 93: 776-784.

Paterson, A., 1964. Entomological techniques. How to work with insects. Edwards Brothers. Ann Arbor. Los Angeles. 435 pp.

Pictet, A. E., 1865. Synopsis des Névroptères d'Espagne. H. Georg, Genèva and J. B. Baillière \& F. Savy, Paris. 123 pp. 14 pl.

Principi, M. M., 1940. Contributi allo studio dei neurotteri italiani. 1. Chrysopa septempunctata Wesm. e Chrysopa flaviforns Brauer. Bollettino dell'Instituto di Entomologia della Università di Bologna, 12: 63144.

Principi, M. M., 1946. Contributi allo studio dei "neurotteri" italiani. IV. Nothochrysa italica Rossi. Bollettino dell'Instituto di Entomologia della Università di Bologna, 15: 85-102.

Principi, M. M., 1947. Contributi allo studio dei neurotteri italiani. 5. Ricerche su Chrysopa formosa Brauer e su acuni suoi parassiti. Bollettino dell'Instituto di Entomologia della Università di Bologna, 16: 134175.

Principi, M. M., 1954. Contributi allo studio dei neurotteri italiani. 11. Chrysopa viridana Schn. Bollettino dell'Instituto di Entomologia della Università di Bologna, 20: 359-376.

Principi, M. M., 1956a. Contributi allo studio dei neurotteri italiani. 13. Studio morfologico, etologico e sistematico di un gruppo omogeneo di specie del gen. Chrysopa Leach (C. flavifrons Brauer, prasinus Burm. e clathratus Schn.). Bollettino dell'Instituto di Entomologia della Università di Bologna, 21: 319410.
Principi, M. M., 1956b. Reperti etologici su di un raro neurottero crisopide. L'Hypochrysa nobilis Schneider. Atti della Accademia delle Scienze dell'Istituto di Bologna, 3: 152-154.

Principi, M. M., 1984. I Neurotteri Crisopidi e le possibilità della loro utilizzazione in lotta biologica e in lotta integrata. Bollettino dell'Instituto di Entomologia della Università di Bologna, 33: 231-261.

Principi, M. M. \& Canard, M., 1974. Les Nèvroptères. En: Les organismes auxiliaires en verger de pommiers. OILB/SRO. Wageningen: 151-162.

Putman, W.L., 1937. Biological notes on the Chrysopidae. Canadian Journal of Research, Section D, Zoological Sciences, 15: 29-37.

Rosenhauer, W. G., 1856. Die Thiere Andalusiens nach dem Resultate einer Reise. Erlangen. 429 pp.

Rousset, A., 1966. Morphologie céphalique des larves de planipennes (Insectes, Névroptéroïdes). Mémoires $d u$ Muséum Nationale d'Histoire Naturelle. Série A, Zoologie, 42: 1-199.

Rousset, A., 1969. Morphologie thoracique des larves de Planipennes (Insectes, Névroptérö̈des). I. Squelette et musculature des régions antérieures du thorax chez les larves de Chrysopa et de Conioptérygides. Annales des Sciences Naturelles. Zoologie et Biologie Animale, 12(11): 97-138.

Rousset, A., 1984. Reproductive physiology and fecundity. En: M. Canard, Y. Séméria \& R. T. New (eds.). Biology of Chrysopidae. Dr W. Junk. The Hague: 116-129.

Ru, N., Withcomb, W. H., Murphey, M. \& Carlysle, T. C., 1975. Biology of Chrysopa lanata (Neuroptera, Chrysopidae). Annals of the Entomological Society of America, 68: 187-190.

Rudall, K. M. \& Kenchington, W., 1971. Arthropod silks: the problem of fibrous proteins in animal tissues. Annual Review of Entomology, 16: 73-96.

Schlüter, T. H., 1984. Paleontology and evolutionary relationships. In: M. Canard, Y. Séméria \& T. R. New (eds.). Biology of Chrysopidae. Dr W. Junk. The Hague: 1-8.

Schneider, W. G., 1851. Symbolae and monographiam generis Chrysopae, Leach. Vratislaviae. 178 pp.

Smirnoff, W., 1953: Chrysopa vulgaris Schneider prédateur important de Parlatoria blanchardi Targ. dans les palmeraies de l'Afrique du Nord (Planip. Chrysopidae). Bulletin de la Société entomologique de France, 59: 146-152.

Smith, R. C., 1921. A Study of the Biology of the Chrysopidae. Annals of the Entomological Society of America, 14: 27-35.

Smith, R. C., 1922. The biology of the Chrysopidae. Memoirs of the Cornell university Agricultural Experimental Station, 58: 1287-1372.

Smith, R. C., 1926. The trash-carrying habit of certain lacewing larvae. The Scientific Monthly, 23: 265-267. 
Smith, R. C., 1931. The Neuroptera of Haiti, West indies. Annals of the Entomological Society of America, 24: 798-823.

Spiegler, P. E., 1962. The origin and nature of the adhesive substance in larvae of the genus Chrysopa (Neuroptera, Chrysopidae). Annals of the Entomological Society of America, 55: 69-77.

Stehr, F. W., 1990. Immature insects, vol. 1. Kendall/Hunt. Dubuque. $230 \mathrm{pp}$.

Steinke, G., 1922. Beobachtungen an der Larve von Chrysopa vulgaris. Zeitschrift für Wissenschaftliche Insektenbiologie, 17: 22-25.

Stitz, H., 1931. Planipennia. En: Biologie der Tiere Deutschlands. fasc. 33(35). Berlin: 34-304

Tauber, C. A., 1969. Taxonomy and biology of the Lacewing genus Meleoma (Neuroptera, Chrysopidae). University of California publications in entomology, 58: 1-94.

Tauber, C. A., 1974. Systematics of North American chrysopid larvae: Chrysopa carnea group (Neuroptera). Canadian Entomologist, 106: 1133-1153.

Tauber, C. A., 1975. Larval characteristics and taxonomic position of the lacewings genus Suarius. Annals of the Entomological Society of America, 68(4): 695-700.

Tauber, C. A., 2003. Generic characteristics of Chrysopodes (Neuroptera: Chrysopidae) with new larval descriptions and a review of species from the United States and Canada. Annals of the Entomological Society of America, 96(4): 472-490.

Tauber, C. A., 2004. A systematic review of the genus Leucochrysa (Neuroptera: Chrysopidae) in the United States. Annals of the Entomological Society of America, 97(6): 1129-1158.

Tauber, C. A., 2010. Revision of Neosuarius, a subgenus of Chrysopodes (Neuroptera, Chrysopidae). ZooKeys, 44: 1-104.

Tauber, C. A., Albuquerque, G. S. \& Tauber, M. J., 2008. Gonzaga nigripes (McLachlan) (Neuroptera: Chrysopidae): diagnosis of larvae and adults, biological notes, and generic affiliation. Proceedings of the Entomological Society of Washington, 110(2): 417-438.

Tauber, C. A., Johnson, J. B. \& Tauber, M. J., 1992. Larval and devlopmental characteristics of the endemic Hawaiian lacewing, Anomalochrysa frater (Neuroptera: Chrysopidae). Annals of the Entomological Society of America, 85(2): 200-206.

Tauber, C. A. \& León, T. de, 2001. Systematics of green lacewings (Neuroptera: Chrysopidae): larvae of Ceraeochrysa from Mexico. Annals of the Entomological Society of America, 94(2): 197-209.

Tauber, C. A., León, T. de, López Arroyo, J. I. \& Tauber, M. J., 1998. Ceraeochrysa placita (Neuroptera: Chrysopidae): Generic characteristics of larvae, larval descriptions, and life cycle. Annals of the Entomological Society of America, 91(5): 608-618.
Tauber, C. A., León, T. de, Penny, N. \& Tauber, M. J., 2000. The genus Ceraeochrysa (Neuroptera: Chrysopidae) of America north of Mexico: Larvae, adults, and comparative biology. Annals of the Entomological Society of America, 93(6): 1195-1221.

Tauber, C. A., Ruberson, J. R. \& Tauber, M. J., 1995. Size and morphological differences among the larvae of two predacious species and their hybrids (Neuroptera: Chrysopidae). Annals of the Entomological Society of America, 88(4): 502-511.

Tauber, C. A. \& Tauber, M. J., 1973. Diversification and secondary intergradation of two Chrysopa carnea strains (Neuroptera: Chrysopidae). Canadian Entomologist, 105(9): 1153-1167.

Tauber, C. A. \& Tauber, M. J., 1977. A genetic model for sympatric speciation through habitat diversification and seasonal isolation. Nature, 268: 702-705.

Tauber, C. A. \& Tauber, M. J., 1987. Food specificity in predacious insects: a comparative ecophysiological and genetic study. Evolutionary Ecology, 1: 175-186.

Tauber, C. A., Tauber, M. J. \& Albuquerque, G. S., 2001. Plesiochrysa brasiliensis (Neuroptera: Chrysopidae): Larval stages, biology, and taxonomic relationships. Annals of the Entomological Society of America, 94(6): 858-865.

Tauber, C. A., Tauber, M. J. \& Albuquerque, G. S., 2006. Berchmansus elegans (Neuroptera: Chrysopidae): Larval and adult characteristics and new tribal affiliation. European Journal of Entomology, 103: 221231.

Tauber, C. A., Tauber, M. J. \& Albuquerque, G. S., 2008. A new genus and species of green lacewings from Brazil (Neuroptera: Chrysopidae: Leucochrysini). Annals of the Entomological Society of America, 101(2): 314-326.

Tauber, M. J. \& Tauber, C. A., 1972. Larval diapause in Chrysopa nigricornis: sensitive stages, critical photoperiod and termination (Neuroptera: Chrysopidae). Entomologia Experimentalis et Applicata, 15: 105111.

Tauber, M. J., Tauber, C. A. \& Hilton, T. W., 2006. Life history and reproductive behavior of the endemic Hawaiian Anomalochrysa hepatica (Neuroptera: Chrysopidae): A comparative approach. European Journal of Entomology, 103: 327-336.

Thierry, D., Cloupeau, R. \& Jarry, M., 1996. Distribution of the sibling species of the common green lacewing Chrysoperla carnea (Stephens) in Europe (Insecta: Neuroptera: Chrysopidae). In: M. Canard, H. Aspöck \& M. W. Mansell (eds.). Pure and Applied Research in Neuropterology. Proceedings of the Fifth International Symposium on Neuropterology. Toulouse: 233-240.

Thierry, D., Cloupeau, R. \& Jarry, M., 1992. La chrysope comunne Chrysoperla carnea (Stephens) sensu lato dans la centre de la France: mise en évidence d'un 
complexe d'especes. Insecta: Neuroptera; Chrysopidae). In: M. Canard, A. Aspöck \& M. W. Mansell (eds). Current Research in Neuropterology. Proceedings of the Fourth International Symposium on Neuropterology. Bagnères-de-Luchon. Toulouse: 379-392.

Tjeder, B., 1966. Neuroptera, Planipennia. The Lacewings of Southern Africa. 5. The family Chrysopidae. South African animal Life, 12: 228-534.

Toschi, C. A., 1965. The taxonomy, life histories, and mating behaviour of the green lacewings of Strawberry Canyon (Neuroptera: Chrysopidae). Hilgardia, 36(11): 391-433.

Tsukaguchi, S., 1977. Biology and rearing of green lacewings. Insectarium, 14: 180-184.

Tsukaguchi, S., 1978. Descriptions of the larvae of Chrysopa Leach (Neuroptera: Chrysopidae) of Japan. Kontyû, 46: 99-122.

Tsukaguchi, S., 1979. Taxonomic notes on Brinckochrysa kintoki (Okamoto) (Neuroptera, Chrysopidae). Kontyû, 46: 99-122.

Tsukaguchi, S., 1982. [Chrysopa septempunctata.] The Insectarium, 19: 16 (en japonés).

Tulisalo, U., 1984. Mass rearing techniques. En: M. Canard, Y. Séméria \& T. R. New (eds.). Biology of Chrysopidae. Dr W. Junk. The Hague: 213-220.

Vidal y López, M., 1943. Catálogo provisional de los Neurópteros de la región levantina. Graellsia, 1(6): 13-24.

Weber, N. A., 1942. A Neuropterous Myrmecophile Nadiva valida Erichs. Psyche, 49(1, 2): 1-3.
Whittington, A. E., 2002. Resources in Scottish Neuropterology. Acta Zoologica Accademiae Scientiarum Hungaricae, 48(2): 371-387.

Withycombe, C. L., 1923. Notes on the biology of some British Neuroptera. Transactions of the Royal entomological Society of London, 1922: 501-594.

Withycombe, C. L., 1925. Some aspects of the biology and morphology of the Neuroptera. With special reference to the immature stages and their possible phylogenetic significance. Transactions of the Royal entomological Society of London, 1924: 303-411.
Recibido / Received, 26-11-2011 Aceptado / Accepted, 21-05-2012 Publicado impreso / Published in print, 30-06-2012 